\title{
Organic aerosol and global climate modelling: a review
}

\author{
M. Kanakidou ${ }^{1}$, J. H. Seinfeld ${ }^{2}$, S. N. Pandis ${ }^{3}$, I. Barnes ${ }^{4}$, F. J. Dentener ${ }^{5}$, M. C. Facchini ${ }^{6}$, R. Van Dingenen ${ }^{5}$, \\ B. Ervens ${ }^{7}$, A. Nenes ${ }^{8}$, C. J. Nielsen 9 , E. Swietlicki ${ }^{10}$, J. P. Putaud ${ }^{5}$, Y. Balkanski ${ }^{11}$, S. Fuzzi ${ }^{6}$, J. Horth ${ }^{5}$, \\ G. K. Moortgat ${ }^{12}$, R. Winterhalter ${ }^{12}$, C. E. L. Myhre ${ }^{9}$, K. Tsigaridis ${ }^{1}$, E. Vignati ${ }^{5}$, E. G. Stephanou ${ }^{1}$, and J. Wilson ${ }^{5}$ \\ ${ }^{1}$ Environmental Chemical Processes Laboratory, Dept. of Chemistry, University of Crete, 71409 Heraklion, Greece \\ ${ }^{2}$ California Institute of Technology, 210-41, 1200 E. California Blvd., Pasadena, CA 91125, USA \\ ${ }^{3}$ Dept. of Chemical Engineering, University of Patras, Patras, Greece \\ ${ }^{4}$ Bergische University Wuppertal, Physical Chemistry FB C, Gauss Str. 20, 42119 Wuppertal, Germany \\ ${ }^{5}$ Climate Change Unit, Institute for Environment and Sustainability, JRC, Ispra, Italy \\ ${ }^{6}$ Istituto di Scienze dell'Atmosfera e del Clima - CNR, Italy \\ ${ }^{7}$ Cooperative Institute for Research in the Atmosphere, Colorado State University, Fort Collins, Colorado 80523, USA \\ ${ }^{8}$ Schools of Earth and Atmospheric Sciences and Chemical and Biomolecular Engineering, Georgia Institute of Technology, \\ Atlanta, Georgia, 30332-0340 Atlanta, USA \\ ${ }^{9}$ Dept. of Chemistry, University of Oslo, Oslo, Norway \\ ${ }^{10}$ Div. of Nuclear Physics, Dept. of Physics, Lund University, Lund, Sweden \\ ${ }^{11}$ LSCE, CNRS/CEA, Orme des Merisiers, 91198 Gif-sur-Yvette, France \\ ${ }^{12}$ Max Planck Institute for Chemistry, Atmospheric Chemistry Division, Mainz, Germany
}

Received: 3 August 2004 - Published in Atmos. Chem. Phys. Discuss.: 28 September 2004

Revised: 1 March 2005 - Accepted: 12 March 2005 - Published: 30 March 2005

\begin{abstract}
The present paper reviews existing knowledge with regard to Organic Aerosol (OA) of importance for global climate modelling and defines critical gaps needed to reduce the involved uncertainties. All pieces required for the representation of OA in a global climate model are sketched out with special attention to Secondary Organic Aerosol (SOA): The emission estimates of primary carbonaceous particles and SOA precursor gases are summarized. The up-to-date understanding of the chemical formation and transformation of condensable organic material is outlined. Knowledge on the hygroscopicity of OA and measurements of optical properties of the organic aerosol constituents are summarized. The mechanisms of interactions of OA with clouds and dry and wet removal processes parameterisations in global models are outlined. This information is synthesized to provide a continuous analysis of the flow from the emitted material to the atmosphere up to the point of the climate impact of the produced organic aerosol. The sources of uncertainties at each step of this process are highlighted as areas that require further studies.
\end{abstract}

Correspondence to: M. Kanakidou

(mariak@chemistry.uoc.gr)

\section{Introduction}

Atmospheric aerosols can scatter or absorb solar radiation, which modifies therefore the radiative balance of the atmosphere (IPCC, 2001). Black carbon heats the atmosphere by absorption of solar radiation, whereas most organic aerosol components cool the Earth's atmosphere. Fine aerosols have sizes close to wavelengths in the visible and are thus expected to have a stronger climatic impact than larger particles. In addition fine aerosols are transported far from their source regions and their climatic and environmental impact is, therefore, delocalized compared to the emission areas. Hydrophilic aerosols can act as cloud condensation nuclei (CCN), and thus have an indirect climatic effect through modification of cloud properties (Novakov and Penner, 1993; Novakov and Corrigan, 1996; IPCC, 2001). A number of studies have indicated that organic aerosol plays an important role in both the direct as well as the indirect aerosol forcing (Liousse et al., 1996; Cooke et al., 1999; Hansen et al., 1998; Penner et al., 1998; Lohmann et al., 2000; Jacobson, 2001; Chung and Seinfeld, 2002). However, there is an uncertainty of at least of a factor of 3 related to this forcing (IPCC, 2001) that deserves further study.

Organic material significantly contributes $\sim 20-50 \%$ to the total fine aerosol mass at continental mid-latitudes (Saxena and Hildemann, 1996; Putaud et al., 2004) and as high as

(C) 2005 Author(s). This work is licensed under a Creative Commons License. 

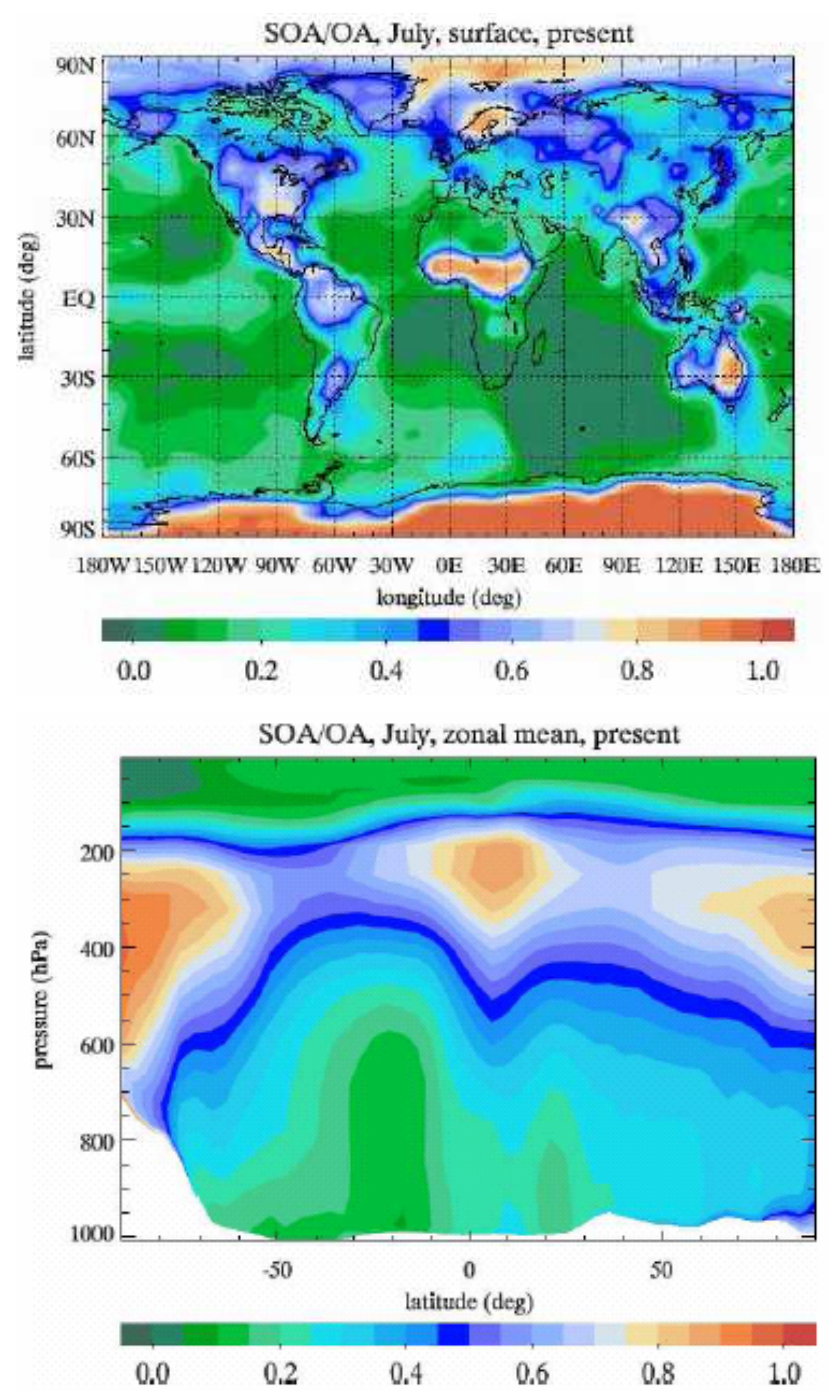

Fig. 1. Ratio of concentrations of the secondary organic aerosol (SOA) to the total organic aerosol (OA) as computed by a 3-D global chemistry transport model for surface (upper panel) and zonal mean distribution (lower panel) for the month of July (Tsigaridis, 2003; Tsigaridis and Kanakidou, 2003).

90\% in tropical forested areas (Andreae and Crutzen, 1997; Talbot et al., 1988, 1990; Artaxo et al., 1988, 1990; Roberts et al., 2001). Significant amounts of carbonaceous aerosols are also observed in the middle troposphere (Huebert et al., 2004). A substantial fraction of the organic component of atmospheric particles consists of water-soluble, possibly multifunctional compounds (Saxena and Hildemann, 1996; Kavouras et al., 1998; Facchini et al., 1999a). Carbonaceous species that exist in the aerosol phase tend to be identified according to the manner in which they entered the particulate phase. Organic compounds that are emitted directly in particulate form are referred to as Primary Organic Aerosol (POA). Note that the particulate matter in which these organic com- pounds reside may contain non-organic compounds as well. Many gas-phase organic compounds undergo oxidation in the gas phase to yield products, generally oxygenated, that have sufficiently low vapor pressures that they will partition themselves between the gas and aerosol phases. Such compounds are often referred to as semi- or non- volatile, and when residing in the aerosol phase, as Secondary Organic Aerosol (SOA). Thus, in its common usage, SOA refers to that organic component of particulate matter that transfers to the aerosol phase from the gas phase as products of gas-phase oxidation of parent organic species. Other classes of aerosol organic compounds exist that do not fit neatly into these two categories. One class is organic compounds emitted into the atmosphere in vapor form, which subsequently condense into the aerosol phase without undergoing gas-phase chemistry. Since these compounds can be identified with a particular source, it seems most appropriate that they fall into the POA category. Another class of compounds are gasphase organic species that are absorbed into cloud droplets and subsequently end up in the aerosol phase when the cloud droplets evaporate and leave residual aerosol. Again, the distinction can be drawn as to whether the compound was emitted directly by a source or resulted from chemical processing in the atmosphere, in terms of its categorization as POA or SOA, respectively. Model studies (e.g. Pun et al., 2003; Kanakidou et al., 2000; Tsigaridis and Kanakidou, 2003) indicate that under certain circumstances the main fraction of organic aerosol can be of secondary origin, i.e. it is chemically formed in the atmosphere (Fig. 1).

This applies also to the free troposphere where low temperatures favour condensation of semi-volatile compounds that have been chemically produced locally or elsewhere. This highlights the importance of secondary organic aerosol (SOA) for direct and indirect forcing. In addition, inclusion of SOA in climate models is needed since verification of aerosol calculations with remote sensed techniques (e.g. satellite/sun photometers) requires a full description of all aerosol components. In-situ measurements are often not able to discriminate between primary organic aerosol (POA) and SOA.

The processes that have to be considered in climate models to account for the organic aerosol (OA) and its climatic impact comprise chemistry, physics and biology. Chemical processes include chemical formation and transformation of the OA by homogeneous reactions followed by condensation or/and by heterogeneous reactions on particle surfaces or/and in clouds. Physical processes that determine OA mass and size distributions are emissions of primary OA and SOA precursors, followed by transport by advection, convection and diffusion, mixing with other particles by coagulation, evaporation and condensation of organic vapours as well as dry and wet removal (in cloud and below cloud scavenging). Emissions of primary organic particles and also SOA precursors can occur by various sources in the boundary layer and to a lesser extent in the free troposphere. The dry and wet 
removal processes of OA depend on the water solubility and size of the particles containing these compounds. Finally, the simulation of the climatic impact of these aerosols will additionally require the description i) of the water uptake by the particles, which depends on their hygroscopic properties, and ii) of the optical properties of the OA that also depend on the state of mixing of OA components with other aerosol components and are needed for the computation of the extinction of solar radiation.

Therefore, the following questions need to be addressed with regard to the OA and particularly of the SOA in the atmosphere:

- What are the SOA precursor gases? How important are their emissions into the atmosphere? How important are the emissions of the primary OA?

- What are the main mechanisms of SOA formation? And how much SOA is formed in the atmosphere?

- How important is organic nucleation on a global scale?

- How can we simulate the partitioning of semivolatile OA species between the gas and particulate phases? Can we assume thermodynamic equilibrium between the two phases?

- What are the hygroscopic properties of OA? How is OA involved in the $\mathrm{CCN}$ formation?

- What are the optical properties of OA? And how are they altered during ageing of the aerosols?

- How are aerosols mixed in the atmosphere? And how does this mixing alter their chemical, physical and optical properties?

- What are the responses of the climate system to changes in organic aerosol?

During the last decade important advances were made in understanding OA and its behaviour in the atmosphere. Different studies have shown in the past years that biogenic hydrocarbons play a significant role in the formation of tropospheric ozone and that even in urban areas with high anthropogenic emissions they still need to be considered in order to develop reliable strategies for the reduction of tropospheric ozone (Chameides et al., 1988; Roselle, 1994; Vogel et al., 1995; Atkinson and Arey, 1998). It has also been known for quite some time that the oxidation of monoterpenes in the troposphere plays a potentially important role in the generation of secondary organic particulate matter (Went, 1960; Rasmussen, 1972; Trainer et al., 1987; Jacob and Wofsy, 1988; Andreae and Crutzen, 1997). Many biogenic hydrocarbons show much higher reactivity towards the important atmospheric oxidants $\mathrm{OH}, \mathrm{NO}_{3}$ and ozone than the anthropogenically emitted VOCs, which adds further to the significance of VOCs emitted from biogenic sources (BVOCs) as a major potential contributor to global organic particulate mater (PM) formation (Atkinson, 2000).

In recent years BVOCs have been positively identified as precursor substances to the formation of SOA in the atmosphere (Kavouras et al., 1999; Pandis et al., 1992; Yu et al., 1999a, b). That BVOCs contribute to aerosol formation has now been amply demonstrated in different laboratory and outdoor chamber experiments (e.g., Palen et al., 1992; Zhang et al., 1992; Hoffmann et al., 1997; Griffin et al., 1999a; Barnes, 2004; Hoffmann, 2001; Jaoui and Kamens, 2003a and references therein). In spite of this there is still a paucity of, data on and understanding of, the composition and the properties of the aerosol formed from the gas phase photooxidation of biogenic hydrocarbons (Christoffersen et al., 1998; Kavouras et al., 1998).

A number of review papers exist that are used as a starting point for the present review: In 1996, Saxena and Hildemann (1996) identified and estimated the solubilities of an extensive set of water soluble organic compounds that could be present in atmospheric particles. Atkinson et al. (1997) have reviewed VOC gas phase chemical mechanisms, including those leading to aerosol formation. Seinfeld and Pankow (2003) summarized kinetic knowledge on SOA formation and appropriate parameterisations. Kulmala (2003) described the procedure of formation and growth of particles in the atmosphere. Jacobson et al. (2000) focused on an extensive presentation and discussion of OA measurement techniques.

The present paper aims to build upon these earlier reviews especially by including recently acquired knowledge in the area of Secondary Organic Aerosol. It also intends to examine the OA problem from the point of view of climate modelling and define critical areas where additional knowledge is needed to reduce the involved uncertainties. In the next sections, the state-of-the-art of all the components needed for the representation of OA in a climate model is outlined: The emission estimates of primary carbonaceous particles and SOA precursor gases are summarized. The up-to-date understanding of the chemical formation and transformation of condensable organic material is outlined together with an overview of the SOA formation representation in global climate models. Measurements of physical and optical properties of the organic aerosol are summarized and needs for modelling studies are highlighted. The mechanisms of interactions of SOA with clouds are discussed. Dry and wet removal parameterisations in global models are outlined. Effort is put into synthesizing this information to provide a continuous flow from the emitted material to the climatic impact of the organic aerosol. The sources of uncertainties at each individual step of the overall process are highlighted as areas that require further studies. 


\section{Emissions of primary carbonaceous aerosols and of SOA precursors}

This section evaluates the current knowledge and uncertainties of emissions of primary carbonaceous aerosol and of the volatile organic compounds (VOC) that can contribute to the chemical formation of organic particulate matter in the atmosphere.

2.1 Primary carbonaceous emissions: global and regional emission estimates

Sources of primary carbonaceous particles include fossil fuel burning (especially transportation and energy production), domestic burning (cooking and heating), and uncontained burning of vegetation (savannah and deforestation fires) and agricultural waste. There are a number of other types of primary carbonaceous material in the atmosphere such as viruses, bacteria, fungal spores and plant debris (Bauer et al., 2002) that may be relevant because they are effective ice nuclei (see compilation of laboratory data by Diehl and Wurzler, 2004). Their contribution to aerosol mass may be substantial (Wiedinmyer, 2004, and references therein), but due to their residence in the coarse aerosol fraction, their climate relevance is generally considered to be relatively low. Recently a significant marine POA source acting during the period of high biological activity has been identified in North Atlantic (O'Dowd et al., 2004). During phytoplankton blooms, progressing from spring through autumn, bubble bursting produces submicrometre particles enriched in insoluble and high molecular mass organic matter. Unfortunately there are no quantitative estimates of their global and regional emissions, and to our knowledge there are no studies on their potential role as condensation sites for SOA. It is currently believed that fine organic particles offer surface and mass, on which SOA precursor gases may preferentially condense.

Note that black carbon (BC) is an operationally defined quantity and the use of $\mathrm{BC}$ should be accompanied by the method used for its measurement. In the present paper we will use the term $\mathrm{BC}$ since it is more relevant to climate change. Therefore, the compiled inventories are based on emission measurements with all types of sampling and analysis methods introducing thus significant inconsistencies between the emission inventories and the observations. At present most measurement techniques can not discriminate between the organic aerosol formed from biogenic and anthropogenic precursor gases and the primary carbonaceous particles emitted from, mainly, pyrogenic processes.

A recent and extensive analysis of regional black carbon (BC) and organic particulate carbon (OC) emissions is provided by Bond et al. (2004), using energy statistics for the year 1996. Global emissions of BC are estimated to be 1.6, 3.3 and 3.0 Tg C $\mathrm{y}^{-1}$ for biofuel, vegetation fires, and fossil fuel burning, respectively. For Primary Organic Aerosol these numbers are 9.1, 34.6, and 3.2 Tg POA $\mathrm{y}^{-1}$. Main uncertainties are connected to the choice of emission factors that depend on the fuel burnt and the type of combustion. Biofuel consumption for domestic use is the source category associated with the highest uncertainty due to the difficulty in getting reliable statistics. A recent study by Schaap et al. (2004) suggests that, at least in Europe, the BC emissions of this inventory may be underestimated by a factor of two. Novakov et al. (2003) estimated historical trends in fossil fuel BC emissions since 1875 . These trends show rapid increase in the latter part of the 1800s, levelling off in the first part of 1900s and the re-acceleration in the past 50 years as China and India have been developing. These changes that have caused regionally large temporal modifications in aerosol absorption might be accompanied by similar trends in OA emissions. These possible emission changes and their climate impact need to be evaluated.

\subsection{SOA precursor emissions}

\subsubsection{Mechanism and composition of natural SOA precur- sor emissions}

VOCs are emitted into the atmosphere from natural sources in marine and terrestrial environments, as well as from anthropogenic sources. A key study on global natural emissions was published by Guenther et al. (1995); hereafter called G1995, which is still the basis for later estimates of natural VOC emissions. On a global basis the emissions of biogenic volatile organic compounds (BVOCs), which are emitted mainly by vegetation, are estimated to exceed those from anthropogenic emissions (G1995: Guenther et al., 1999, 2000). Recently, Wiedinmeyer et al. (2004), hereafter W2004, provided an excellent review paper of emissions of organics from vegetation. Here we focus on those emissions and their uncertainties relevant for SOA formation.

Isoprene accounts for about half of all natural VOC emissions and is, on a mass basis, the dominant emitted biogenic VOC component. Estimated global emissions range between 250 and $750 \mathrm{Tg} \mathrm{C}^{-1}$ (W2004). However, isoprene is generally not considered as a major producer of SOA. Very recent studies, however, detected the presence of humic like substances, glycol aldehyde and hydroxy aceton as well as methyltetrols indicating involvement of isoprene as source for SOA (Jang et al., 2003a; Claeys et al., 2004a, b; Limbeck et al., 2003; Matsunaga et al., 2003). Claeys et al. (2004a) proposed that a small $(0.2 \%)$ fraction of all isoprene may be converted into SOA, corresponding to $2 \mathrm{Tg}^{-1}$ emissions. This number deserves revision since fastly after Claeys et al. (2004b) suggested that aqueous phase oxidation of isoprene products is a more important source of SOA. Thus far more than 5000 terpenes have been identified (Geron et al., 2000), such as monoterpenes $\left(C_{10}\right)$, sesquiterpenes $\left(\mathrm{C}_{15}\right)$, diterpenes $\left(\mathrm{C}_{20}\right)$ and higher molecular weight compounds. Most important components in the group 'terpenes', 
Table 1. Mass percentage of monoterpene, and reactive ORVOC emission as given by Seinfeld and Pankow (2003; SP2003 based on Guenther et al., 1995, and Griffin et al., 1999b), Owen et al. (2001) and Geron et al. (2000).

\begin{tabular}{llccc}
\hline Species & Mass \% Contribution & & \\
\hline & Class & $\begin{array}{c}\text { SP2003 } \\
\text { global }\end{array}$ & $\begin{array}{c}\text { Owen } \\
\text { S. Europe and } \\
\text { Mediterranean }\end{array}$ & $\begin{array}{c}\text { Geron } \\
\text { N. America }\end{array}$ \\
& & & & \\
\hline$\alpha$-pinene & M & 24.8 & $30-58$ & $12-53$ \\
$\beta$-pinene & M & 16.4 & $8-33$ & $10-31$ \\
Sabinene+terpenoid Ketones & M/ORVOC & 10.0 & $2.5-14$ & $2-5$ \\
$\Delta^{3}$-carene & M & 3.0 & 0 & $4-9$ \\
Limonene & M & 16.4 & $0-5$ & $6-10$ \\
$\alpha-\gamma$ terpinene & M & 0.6 & $2-5$ & $0-6$ \\
Terpinolene & M & 1.4 & n.d. & $0-2$ \\
Myrcene & M & 3.5 & $0-4$ & $2-7$ \\
Terpenoid alcohols & ORVOC & 14.9 & $0-20$ & n.d. \\
Ocimene & M & 1.5 & $0-1$ & $0-1$ \\
Sesquiterpenes & ORVOC & 7.4 & n.d. & n.d. \\
\hline
\end{tabular}

${ }^{1} \mathrm{M}$ : Monoterpenes; ${ }^{2}$ ORVOC: Other reactive VOCs; ${ }^{3}$ n.d.: not determined

after isoprene that is a hemi-terpene, are the mono-terpenes $\left(\mathrm{C}_{10} \mathrm{H}_{16}\right) \alpha$-pinene, $\beta$-pinene, sabinene, and limonene (Table 1 ), accounting for $40-80 \%$ of the overall terpene emission on a global scale when isoprene is excluded. Field measurements have shown that the mono-terpenes represent a significant fraction of the BVOCs emitted from vegetation to the atmosphere with contributions ranging from 10 to $50 \%$ dependent on the type of vegetation prevailing in the area (G1995; Guenther, 1995; Guenther et al., 2000).

Excluding isoprene and methane, VOCs from biogenic sources are often divided (G1995) into the lumped categories i) terpenes, ii) other reactive VOC (ORVOC) and iii) other VOCs (OVOCs). In the widely used GEIA dataset (URL http://geiacenter.org/), the latter two are lumped together. ORVOC represent reactive VOCs, with lifetimes $<1$ day, such as terpenoid alcohols, n-carbonyls, aromatics, sesquiterpenes $\left(\mathrm{C}_{15} \mathrm{H}_{24}\right)$, terpenoid ketones and higher olefins. OVOCs are the less reactive VOCs, with lifetimes longer than 1 day, typically methanol, various aldehydes and ketones. The latter are believed to have little aerosol formation potential, and are not further considered in this section. Note however that recent studies report that $>\mathrm{C} 7$ carbonyls may be important contributors to SOA (Matsunaga et al., 2003). Current analytical methods may need to be improved before we can accurately quantify these compounds. According to Griffin et al. (1999b), only about $30 \%$ of the lumped ORVOC and OVOCs have the potential to form SOA. In contrast, the mono-terpenes, and especially the sesquiterpenes $(100 \%)$, have large potential for SOA formation. Note also that lumping of various chemical compounds in the emissions inventories like for instance ORVOC puts together compounds that form aerosols with compounds that are not precursors of SOA. This introduces further uncertainties in the SOA modelling.

Woods, crops and shrubs contribute by 55\%, $15 \%$, and $14 \%$, respectively, to the non-isoprene biogenic emissions (G1995), whereas oceans emit $<1 \%$. Emission amounts and composition are species and thus ecosystem dependent; the main external factors influencing emissions are i) temperature ii) light (for some species) and iii) water stress. G1995 describe an algorithm that uses ecosystem input data, emission factors, light and temperature dependent functions and a canopy radiative transfer model. The most recent updates of the algorithms are provided by the MEGAN activity (http://cdp.ucar.edu).

Seinfeld and Pankow (2003) combined the Griffin et al. (1999b) ORVOC breakdown in smaller chemical categories and classify the SOA forming compounds in a total of 11 categories, which encompass on a global scale most of the observed terpenes and ORVOCs emissions, with the Guenther et al. (1995) mass emissions. For comparison we also give the fractions obtained in N. America (Geron et al., 2000) and Southern Europe Mediterranean (Owen et al., 2001). As becomes apparent in Table 2, the species contributions to the emissions adopted in global models is rather similar to those obtained by regional estimates. However, care should be taken in extrapolating regional results to the global scale, since precursors like sesquiterpenes that have the largest potential in forming SOA (e.g. Vizuete et al., 2004) have also highly uncertain emissions.

\subsubsection{Anthropogenic SOA precursor emissions}

Aromatic components have also the potential to form SOA (Odum et al., 1997). Tsigaridis and Kanakidou (2003) 
Table 2. Regional breakdown of Anthropogenic Primary Organic Aerosol, Black Carbon, terpenes (excluding isoprene), other reactive VOC (ORVOC) terpenes [ $\left.\mathrm{Tg}^{-1}\right]$. Table adopted from Bond (2004).

\begin{tabular}{lcccc}
\hline Region & POA & BC & terpenes & ORVOC \\
\hline OPEN OCEAN & 0.1 & 0.03 & 0.2 & 2.8 \\
CANADA & 1.0 & 0.1 & 4.8 & 4.1 \\
USA & 1.9 & 0.4 & 8.3 & 13.6 \\
LATIN AMERICA & 10.5 & 1.3 & 48.5 & 104.4 \\
AFRICA & 16.8 & 2.0 & 28.2 & 57.0 \\
OECD EUROPE & 1.3 & 0.4 & 2.3 & 3.9 \\
E. EUROPE & 0.4 & 0.1 & 0.5 & 1.2 \\
CIS (FORMER) & 2.0 & 0.3 & 6.6 & 7.7 \\
MIDDLE EAST & 0.5 & 0.2 & 0.9 & 1.7 \\
INDIA REGION & 3.7 & 0.8 & 6.0 & 16.4 \\
CHINA REGION & 4.7 & 1.7 & 6.5 & 14.1 \\
EAST ASIA & 2.2 & 0.5 & 8.7 & 25.5 \\
OCEANIA & 1.6 & 0.2 & 5.7 & 7.8 \\
JAPAN & 0.1 & 0.2 & 0.4 & 0.6 \\
WORLD & $\mathbf{4 6 . 9}$ & $\mathbf{8 . 0}$ & $\mathbf{1 2 7 . 4}$ & $\mathbf{2 6 0 . 7}$ \\
\hline
\end{tabular}

adopted the EDGAR2.0 database (Olivier et al., 1996, 1999a) for the anthropogenic emissions of SOA precursor gases. This database is giving global emissions of $6.7 \mathrm{Tg} \mathrm{y}^{-1}$ toluene, $4.5 \mathrm{Tg} \mathrm{y}^{-1}$ xylene, $0.8 \mathrm{Tg} \mathrm{y}^{-1}$ trimethylbenzene and $3.8 \mathrm{Tg}^{-1}$ of other aromatics. These emissions add up to about $10-15 \%$ of all anthropogenic NMVOC emissions.

These values were determined for the year 1990; emission factors are highly uncertain, and moreover subject to strong temporal changes. e.g. in Europe and USA decreasing trends of hydrocarbon emissions have been reported in the last 23 decades. In the USA, reported NMVOC emissions have been decreasing from $35 \mathrm{kT} \mathrm{y}^{-1}$ in 1970 to $20 \mathrm{kT} \mathrm{y}^{-1}$ in 2001 (http://www.epa.gov/ttn/chief/trends/index.html). From sector analysis it follows that traffic, industrial processes and solvent use were responsible for that large decrease. In Europe, reported emissions decreased in the EU from $16 \mathrm{kT} \mathrm{y}^{-1}$ in 1989 to $12 \mathrm{kT} \mathrm{y}^{-1}$ in 2000 (EMEP, 2003). Latter trends are confirmed by a limited number of measurements (Monks et al., 2003). Reductions have been reported for acetylene, ethane, benzene and toluene (Roemer, 2001). In contrast, in the period 1970-2000, in South and East Asia and China anthropogenic NMVOC emissions may have increased by 50 $\%$ (IIASA, M. Amann, personal communication, 2004) from 41 to $63 \mathrm{Tg}^{-1}$.

\subsubsection{Global and regional estimates}

A gridded compilation of the global emissions, divided into two categories, terpenes and the lumped ORVOC and OVOC, has been made by G1995. Table 2 gives the regional breakdown of the primary anthropogenic organic aerosol (POA) flux estimates by Bond (2004) and terpene and ORVOC emissions. Note that the importance of oceans (O'Dowd et al., 2004) and of vegetation as natural sources of POA remains to be determined. As a rough estimate, assuming that a constant fraction of 0.15 of the terpene emissions reacts on a very short timescale to form SOA then $19.1 \mathrm{Tg} \mathrm{y}^{-1}$ of SOA are calculated to be globally produced by terpenes. This crude assumption provides an order-of-magnitude comparison of the relative importance of SOA versus primary organic aerosol emissions on regional and global scales. This estimate shows that the SOA contribution to OA is likely to be highly variable ranging from 10-70\%, in Eastern Europe, and Canada, respectively. Obviously this approach should be viewed with caution, since as discussed below, SOA formation is a complex and not yet sufficiently understood process. In addition, Tsigaridis and Kanakidou (2003) have shown that a significant proportion of the SOA formation occurs in the free troposphere due to enhanced condensation favoured by low temperatures. This is crucial for SOA fate since the lifetime of aerosol is larger in the free troposphere than in the boundary layer as discussed in Sect. 4.3.

We can make a similar, but even more speculative, analysis of the importance of ORVOC as precursor for SOA. If $30 \%$ of the ORVOC emissions can form SOA (of which 5\% consist of sesquiterpenes), assuming a $100 \%$ aerosol yield for the sesquiterpenes (higher than reported by Griffin et al., 1999b), and $15 \%$ for the other components, an additional amount of $15 \mathrm{Tg}$ SOA $\mathrm{y}^{-1}$ could be formed, with regional contributions varying between 10 and 50\%. Following the hypothesis by Claeys et al. (2004a) that a small but significant fraction of isoprene oxidation products may lead to SOA, an additional amount of $2 \mathrm{Tg} \mathrm{SOA}^{-1}$, may be formed, $65 \%$ of which can be attributed to Africa and S. America. In addition, anthropogenic organic compounds like aromatics are also forming SOA (see Sect. 3) although their contribution based on actual understanding of their chemistry has been evaluated to be a small fraction (about 10\%) of the global SOA formation in the troposphere (Tsigaridis and Kanakidou, 2003), although locally might be much more important. This contribution is of the same order of magnitude with the naturally driven variation of the SOA chemical production (Tsigaridis et al., 2005).

According to these rough estimates, the chemical formation of SOA may be significant when compared to the primary carbonaceous emissions (about $60 \%$ on a global scale and even more regionally).

\subsubsection{Uncertainties of estimates}

There are large uncertainties associated with both anthropogenic and natural emission inventories on regional and global scales. For instance, using detailed land cover and tree species information Guenther et al. (2000) estimated for North America monoterpene emissions of 17.9 and ORVOC emissions of $31.8 \mathrm{Tg} \mathrm{y}^{-1}$. These can be compared with 13.1 
and $17.7 \mathrm{Tg}^{-1}$ presented in Table 2 (for USA and Canada). A difference of 30 to $80 \%$ between these two inventories is deduced. This can not be generalised since other inventories might compare better. This is the case for the estimate of $6.1 \mathrm{Tg} \mathrm{y}^{-1}$ terpene and OVOC emissions by Simpson et al. (1999) for OECD Europe that is comparable to the $6.2 \mathrm{Tg} \mathrm{y}^{-1}$ given in Table 2. However, when comparing Simpson et al. (1999) in more detail with country specific data compiled by Lenz (2001) differences of a factor of 2 show up over Europe as can be seen from Table 3 where both emission estimates for Italy and for France are compared.

These regional differences and uncertainties propagate to the global scale inventories. As described before, forests have the largest potential to form SOA. Global emissions estimates of isoprene have an overall uncertainty of a factor of 3 (250-750 $\mathrm{TgC}^{-1}$, W2004) whereas those of the other terpenes and sesquiterpenes that are the main known SOA precursors are subject to a factor of 5 uncertainty (W2004). In addition, branch enclosure measurements by Goldstein et al. (2004) confirm more than 100 BVOCs are emitted but not typically observed over the forest; these unmeasured BVOC emissions are approximately 10 times the measured monoterpene fluxes. An extensive overview of the uncertainties in these emissions and the global uncertainty range is given by W2004. The main uncertainties are associated with (W2004):

1. tree specific emissions factors and functions

2. the use of geographical data-bases of land-cover, ecosystems and tree abundances

3. foliar density and phenology of these trees

4. environmental conditions.

Most emission rates adopted for the construction of the inventories of biogenic emissions and in particular those of monoterpenes and sesquiterpenes have not been evaluated based on measured ambient concentrations. There is a clear need for more data on emissions chemical speciation since aerosol formation potential largely depends on the chemical structure of the precursor molecules. This applies particularly to sesquiterpenes that are known to have the largest potential to form SOA and their emission factors have been poorly studied.

Anthropogenic VOC emissions are 5-10 times lower than biogenic VOC emissions (excluding $\mathrm{CH}_{4}$ ). When considering the known SOA precursor emissions alone, this ratio increases above 10. Large uncertainties exist also in the anthropogenic emission factors for SOA precursors like aromatics and some oxygenated solvents. Global inventories of NMVOC anthropogenic emissions are generally calculated in two steps. First, using an emission factor approach, total NMVOC emissions are calculated on the basis of (inter)national activity statistics (e.g. fuel consumption, solvent use) and emission factors that take into account
Table 3. Comparison of BVOC emissions - Lenz (2001) and Simpson et al. (1999) - for forest tree species in Italy and France (in $\left.\mathrm{Gg}^{-1}\right)$.

\begin{tabular}{lcc}
\hline Reference, Area & Monoterpenes & OVOCs \\
\hline Lenz (2001), Italy & 115 & 63 \\
Simpson et al. (1999), Italy & 32 & 46 \\
Lenz (2001), France & 276 & 130 \\
Simpson et al. (1999), France & 111 & 110 \\
\hline
\end{tabular}

abatement technologies. According to Olivier et al. (1999b), the uncertainty in total NMVOC emissions has been estimated to be $\sim 50 \%$ for fossil fuel related emissions and $\sim 100 \%$ for non fossil fuel emissions. Second, the total NMVOC emissions are generally subdivided in specific NMVOC species clusters. Toluene, xylene and trimethylbenzene are three different NMVOC groups for which an emission profile has been defined in the EDGAR database (Oliver et al., 1996). For each NMVOC profile an activity specific profile has been defined, which assigns the fraction of each of the NMVOC group to the total NMVOC emissions. In general global uniform NMVOC profiles are based on data from USA and EU countries (e.g. http:// www.epa.gov/ttn/chief/software/speciate/index.html or http: //reports.eea.eu.int/EMEPCORINAIR3/en). Application of these global aggregated NMVOC profiles leads to another considerable uncertainty. Specific quantitative uncertainty estimates on toluene, xylene and trimethylbenzene are - to our best knowledge - not available at the moment.

2.2.5 Change of Natural Emissions due to land-use and climate change

Global use of land has been changing in the last 2 centuries, and is expected to be further modified in the future. The largest recent changes of land-use are in the tropics, mainly due to conversion of tropical forests into crop-lands. For instance from 1970-2000 forest areas in Asia, Latin America and Africa have decreased by 26, 12 and 13\%, respectively (source: IMAGE2.2; http://arch.rivm.nl/image/). Global forests decreased by $2 \%$ in this period. According to the FAO 2003 State of the World Forest Report (http: //www.fao.org/DOCREP/005/Y7581E/Y7581E00.HTM) the decadal deforestation rates for the above mentioned areas were 1,4 , and $8 \%$ in the period $1990-2000$.

Naik et al. (2004) using a dynamic global ecosystem model calculated that the combined fluctuations in climate and atmospheric $\mathrm{CO}_{2}$ during 1971-1990 caused significant seasonal (17-25\%) and interannual (2-4\%) variability in the simulated global isoprenoid fluxes with an increasing trend during this time period. 
The quantification of the impact of climate change on future biogenic VOC emissions remains complex. The most important effect might be an increase in emission rates as a direct result of higher temperatures; however changes in cloudiness, precipitation, and land use may influence emissions as well. Little is known about the final combined effect of land-use change and climate change on VOC emissions. An exemplary model study by Sanderson et al. (2002) combining climate change and land-use changes suggests that global isoprene emissions may increase by $27 \%$.

\subsection{Uncertainties and Research Needs}

- The overall knowledge of emissions both of primary carbonaceous particles and of gaseous precursors of SOA is far from being satisfactory. The overall uncertainties range between a factor of 2 and 5 .

- Significant effort needs to be put in improving the $\mathrm{BC}$ and $\mathrm{OC}$ inventories however progress can be only achieved via standardizing the $\mathrm{BC}$ measurements.

- POA appears to be quite an important part of the carbonaceous aerosol. However accurate emission estimates received relatively little attention. Further studies based on coherent observations are required to construct reliable POA emission inventories not only from the anthropogenic sources that are the most commonly considered in modelling studies but also from the biogenic sources, the importance of which remains to be determined. In particular the potential important POA marine source from the ocean currently omitted from climate modelling prediction should be evaluated (O'Dowd et al., 2004).

- Although sesquiterpenes are known to be the most efficient natural SOA precursors (see further discussion) their emission rates from vegetation have been poorly studied due to their high reactivity and require more attention in the future with targeted experimental and modelling studies.

- Future studies to improve our knowledge on primary emissions invoke integration of various approaches to address these questions such as:

- enclosure measurements

- above-canopy and deposition flux measurements of gases and aerosols

- ambient concentrations measurements

- both forward and inverse modelling to link emissions with observed concentrations

- use of satellite observations in models to evaluate/improve emission inventories or derive them, see for instance examples by Abbot et al. (2003) and Martin et al. (2003).
- The consistency of emission inventories with the ambient observed concentrations can be evaluated by applying chemistry/transport models to simulate the observed concentrations based on these emission inventories.

\section{Representation of Secondary Organic Aerosol forma- tion in atmospheric models}

The processes leading to SOA formation can be viewed as occurring sequentially:

Emissions of gases $\rightarrow$ Gas-phase chemistry $\leftrightarrow$ Nucleation/Gas-particle partitioning $\leftrightarrow$ Aerosolphase/aqueous phase chemistry/cloud processing

To represent SOA formation quantitatively requires each of these steps to be modelled. At present, although the potential importance of aerosol-phase chemistry has been recently established through the identification of oligomeric species (see Sect. 3.1); these reactions are not yet represented in models.

In this section we first summarize actual knowledge on the chemical reactions responsible for SOA formation (Sect. 3.1) and on the involvement of SOA constituents in nucleation (Sect. 3.2). Then, the aerosol dynamics are summarised (Sect. 3.3) and the gas-to-particle partitioning parameterisations used in atmospheric models (Sect. 3.4) are outlined and finally in Sect. 3.5 the actual representation of SOA formation in current global models is summarized.

\subsection{Chemistry of Secondary Organic Aerosol formation}

Since monoterpenes would appear to be the major precursors of secondary organic particulate matter (SOA) from BVOCs, much work has gone into investigating the reactions of monoterpenes, particularly over the past decade. Summaries, up to 2000, of the gas-phase kinetics of the monoterpene reactions with $\mathrm{OH}$ and $\mathrm{NO}_{3}$ radicals and ozone, products of these reactions and the pathways leading to their formation can be found in several review articles/books (e.g., Atkinson, 1997; Atkinson and Arey, 1998; Calogirou et al., 1999; Calvert et al., 2000). Seinfeld and Pankow (2003) have summarized laboratory studies of SOA formation performed over the last decade. The studies have been categorized according to the experimental conditions employed such as $\mathrm{NO}_{\mathrm{x}}$ photooxidation, $\mathrm{O}_{3}$ reaction or $\mathrm{OH}$ reaction.

As a result of ever increasing information on the nature of the gas-phase products and the composition of the resulting aerosol from the oxidation of monoterpenes much effort is now being spent in developing combined gas-phase kinetics and aerosol partitioning models to represent secondary organic aerosol formation in ambient models. (e.g., Kamens et al., 1999; Kamens and Jaoui, 2001; Pankow et al., 2001; Seinfeld et al., 2001; Griffin et al., 2002a, b, 2003; Pun et al., 2002). 
Most of the experiments on the atmospheric chemistry of monoterpenes, i.e. gas-phase kinetic rate coefficients, gasphase product identification and quantification, quantification of SOA yields and its molecular composition, have been performed in smog chambers using either natural or artificial sunlight. Seinfeld and Pankow (2003) have discussed the pros and cons of the size of the chamber, indoor and outdoor chambers with artificial and natural light sources, etc and the arguments will not be pursued further here. However, irrespective of the type of chamber, chamber experiments have inherent difficulties associated with the chemistry of SOA formation when extrapolating the results to atmospheric conditions.

- Carefully designed chamber experiments using modern analytical techniques to allow accurate quantitative detection of organics at low concentrations, are needed to investigate SOA formation under atmospheric conditions.

In the case of the $\mathrm{NO}_{\mathrm{x}}$ photooxidation systems oxidation by the $\mathrm{OH}$ radical will initially dominate, however, as the reaction proceeds, $\mathrm{O}_{3}$ and under some circumstances also $\mathrm{NO}_{3}$ radicals will be formed in high enough concentration to compete with the $\mathrm{OH}$ radical oxidation. This makes assignment of the relative importance of the oxidants $\mathrm{OH}, \mathrm{NO}_{3}$ and $\mathrm{O}_{3}$ in the SOA formation problematic. In the ozonolysis reactions peroxy radicals will be formed which under most normal atmospheric conditions would react with NO to form alkoxy radicals. Ozonolysis experiments can not be performed in the laboratory in the presence of $\mathrm{NO}_{\mathrm{x}}$ since the $\mathrm{NO}_{\mathrm{x}}$ reacts rapidly with $\mathrm{O}_{3}$.

- It is, therefore still an open question as to whether the aerosol yields observed in laboratory ozonolysis experiments are transferable to atmospheric conditions; in reality the yields could be higher or lower.

Recently, Docherty and Ziemann (2003), Ziemann (2003) and Keywood et al. (2004) have shown that the presence of $\mathrm{OH}$ scavenger in ozonolysis experiments has significant impact on SOA yields. Keywood et al. (2004) explained this behaviour by the involvement of acylperoxyradicals formed via isomerisation of alkoxy radical which in turn are produced from Crieege Intermediates during ozonolysis of endocyclic alkenes. Winterhalter et al. (2000), Koch et al. (2000) and Jenkin et al. (2000) showed that acylperoxy radicals from both endo- and exocyclic monoterpenes are involved in the formation of dicarboxylic acids via permutation reactions with $\mathrm{HO}_{2}$ or $\mathrm{RO}_{2}$ radicals. These radical reactions are initiated by the decomposition of the excited Criegee Intermediates via the hydroperoxy channel or the ester channel (Calvert et al., 2000). Bonn et al. (2002) have recently shown that the addition of $\mathrm{H}_{2} \mathrm{O}$ and carbonyl compounds affects the yield of SOA. This observation was explained by the involvement of stabilized Criegee Intermediates in the SOA formation processes.
The translation of these results to the real atmosphere requires thorough interpretation and further understanding of the corresponding chemical mechanisms. For the reaction of $\mathrm{NO}_{3}$ with monoterpenes this may also be an issue but because the reactions occur mainly during the night time when $\mathrm{NO}$ is low the effect (if any) will not be so far reaching.

- In $\mathrm{NO}_{3}$ radical chamber chemistry systems, however, reactions of the high levels of $\mathrm{NO}_{\mathrm{x}}$ often employed can block many reaction pathways, which would otherwise be important under atmospheric conditions.

\subsubsection{Gas phase reactions leading to semivolatile products}

Because of the potential importance of monoterpenes to SOA formation much of the research related to elucidating the oxidation mechanisms and products of monoterpenes known to be emitted into the troposphere in substantial quantities (Atkinson and Arey, 1998; Calogirou et al., 1999) has been focussed primarily on $\alpha$ - and $\beta$-pinene. Measurements of monoterpenes speciation suggest that these make a particularly significant contribution to global monoterpenes emissions (Guenther et al., 1994; Geron et al., 2000 and references therein). These monoterpenes are also representative of classes of monoterpenes having either an endocyclic double bond (in the case of $\alpha$-pinene) or an exocyclic double bond (in the case of $\beta$-pinene), therefore, the discussion on monoterpenes chemistry leading to SOA will focus on these two compounds and, in particular, on $\alpha$-pinene.

In the case of $\alpha$-pinene considerable progress has been made in determining the kinetics and elucidating the mechanisms of the early stages of its gas-phase degradation chemistry initiated by reaction with $\mathrm{OH}$ radicals (e.g., Arey et al., 1990; Hakola et al., 1994; Hallquist et al., 1997; Vinckier et al., 1997; Aschmann et al., 1998; Noziere et al., 1999a; Orlando et al., 2000; Jaoui and Kamens, 2001; Larsen et al., 2001; Wisthaler et al., 2001; Winterhalter et al., 2003), $\mathrm{NO}_{3}$ radicals (e.g., Wangberg et al., 1997; Berndt and Böge, 1997; Hallquist et al., 1997; Jang and Kamens, 1999) and ozone (e.g., Hakola et al., 1994; Alvarado et al., 1998a; Kamens et al., 1999; Yu et al., 1999a; Koch et al., 2000; Orlando et al., 2000; Winterhalter et al., 2003). The further oxidation of the major first generation product, pinonaldehyde, has also been studied quite extensively (e.g., Glasius et al., 1997; Hallquist et al., 1997; Alvarado et al., 1998b; Noziere et al., 1999a, b; Jaoui and Kamens, 2003a). There have also been some theoretical studies of the oxidation mechanisms (Peeters et al., 2001; Vereecken and Peeters, 2000).

The reactions with $\mathrm{OH}, \mathrm{NO}_{3}$ and $\mathrm{O}_{3}$ lead to a large suite of oxygenated reaction products which include aldehydes, oxy-aldehydes, carboxylic acids, oxy-carboxylic acids, hydroxy-carboxylic acids, dicarboxylic acids, organic nitrates etc. In addition, several peaks with $\mathrm{m} / \mathrm{z}$ $187[\mathrm{M}+\mathrm{H}]+$ observed in the LC-MS analysis of filter samples from the oxidation of $\alpha$-pinene (Hoffmann, 
Table 4. Structures and IUPAC names of a selection of products typically observed in the oxidation of $\alpha$-pinene (source: Winterhalter et al., 2003).

\begin{tabular}{|c|c|c|c|c|}
\hline 1 & 2 & & 4 & 5 \\
\hline 2-hydroxy-3-pinanone & $\begin{array}{l}\text { 8-hydroxy-menthen-6- } \\
\text { one }\end{array}$ & pinonaldehyde & pinalic acid & pinalic acid \\
\hline $\begin{array}{l}\text { 2-Hydroxy-2,6,6-trimethyl- } \\
\text { bicyclo[3.1.1]heptan-3-one }\end{array}$ & $\begin{array}{l}\text { 5-(1-Hydroxy-1-methyl- } \\
\text { ethyl)-2-methyl-cyclohex-2- } \\
\text { enone }\end{array}$ & $\begin{array}{l}\text { (3-Acetyl-2,2-dimethyl- } \\
\text { cyclobutyl)-acetaldehyde }\end{array}$ & $\begin{array}{c}\text { 2,2-Dimethyl-3-(2-oxo- } \\
\text { ethyl)-cyclobutane-carboxylic } \\
\text { acid }\end{array}$ & $\begin{array}{l}\text { (3-Formyl-2,2-dimethyl- } \\
\text { cyclobutyl)-acetic acid }\end{array}$ \\
\hline 6 & 7 & 8 & 9 & 10 \\
\hline $\begin{array}{c}\text { norpinonic acid } \\
\text { 3-Acetyl-2,2-dimethyl- } \\
\text { cyclobutanecarboxylic acid }\end{array}$ & $\begin{array}{c}\mathbf{M}_{\mathbf{w}} \mathbf{1 7 2} \text { "pinolic acid" } \\
\text { 3-(2-Hydroxy-ethyl)-2,2- } \\
\text { dimethyl-cyclobutane- } \\
\text { carboxylic acid }\end{array}$ & $\begin{array}{c}\text { norpinic acid } \\
\text { 2,2-Dimethyl-cyclobutane- } \\
\text { 1,3-dicarboxylic acid }\end{array}$ & $\begin{array}{c}\text { 10-keto-pinonaldehyde } \\
\text { (3-Acetyl-3-oxo-2,2- } \\
\text { dimethyl-cyclobutyl)- } \\
\text { acetaldehyde }\end{array}$ & $\begin{array}{l}\text { 4-keto-pinonaldehyde } \\
\text { (3-Acetyl-2,2-dimethyl- } \\
\text { cyclobutyl)-2-oxo- } \\
\text { acetaldehyde } \\
\end{array}$ \\
\hline 11 & 12 & 13 & 14 & 15 \\
\hline 10-OH-pinonaldehyde & 1-OH-pinonaldehyde & 4-OH-pinonaldehyde & & pinalic acid methyl ester \\
\hline $\begin{array}{c}\text { [3-(2-Hydroxy-ethanoyl)-2,2- } \\
\text { dimethyl-cyclobutyl]- } \\
\text { acetaldehyde }\end{array}$ & $\begin{array}{c}\text { (3-Acetyl-3-hydroxy-2,2- } \\
\text { dimethyl-cyclobutyl)- } \\
\text { acetaldehyde }\end{array}$ & $\begin{array}{c}\text { (3-Acetyl-2,2-dimethyl- } \\
\text { cyclobutyl)-2-hydroxy- } \\
\text { acetaldehyde }\end{array}$ & 3-Acetyl-5,6-dioxo-heptanal & $\begin{array}{c}\text { 2,2-Dimethyl-3-(2-oxo- } \\
\text { ethyl)-cyclobutanecarboxylic } \\
\text { acid methyl ester }\end{array}$ \\
\hline 16 & 17 & 18 & 19 & 0 \\
\hline $\begin{array}{l}\text { Acetic acid 2,2-dimethyl-3- } \\
\text { (2-oxo-ethyl)-cyclobutyl ester }\end{array}$ & $\begin{array}{l}\text { Formic acid 3-acetyl-2,2- } \\
\text { dimethyl-cyclobutyl ester }\end{array}$ & $\begin{array}{c}\text { pinonic acid } \\
\text { (3-Acetyl-2,2-dimethyl- } \\
\text { cyclobutyl)-acetic acid }\end{array}$ & $\begin{array}{c}\boldsymbol{\beta} \text {-hydroxy- } \\
\text { hydroperoxide } \\
\text { 2-Hydroperoxy-2,6,6- } \\
\text { trimethyl- } \\
\text { bicyclo[3.1.1]heptan-3-ol } \\
\end{array}$ & $\begin{array}{c}\boldsymbol{\beta} \text {-hydroxy- } \\
\text { hydroperoxide } \\
\text { 3-Hydroperoxy-2,6,6- } \\
\text { trimethyl- } \\
\text { bicyclo[3.1.1]heptan-2-ol } \\
\end{array}$ \\
\hline 21 & 22 & 23 & 24 & 25 \\
\hline $\begin{array}{c}\text { pinic acid } \\
\text { 3-Carboxymethyl-2,2- } \\
\text { dimethyl-cyclobutane- } \\
\text { carboxylic acid } \\
\end{array}$ & $\begin{array}{l}\text { pinalic-peroxo acid } \\
\text { 2,2-Dimethyl-3-(2-oxo- } \\
\text { ethyl)-cyclobutane- } \\
\text { carboperoxoic acid }\end{array}$ & $\begin{array}{l}\text { 7-keto-pinonic acid } \\
\text { [2,2-Dimethyl-3-(2-oxo- } \\
\text { ethanoyl)-cyclobutyl]-acetic } \\
\text { acid }\end{array}$ & $\begin{array}{l}\text { 4-keto-pinonic acid } \\
\text { (3-Acetyl-2,2-dimethyl- } \\
\text { cyclobutyl)-2-oxo-acetic acid }\end{array}$ & $\begin{array}{l}\text { 3-(1-Hydroxy-1-methyl- } \\
\text { ethyl)-5,6-dioxo-heptanal }\end{array}$ \\
\hline 26 & 27 & 28 & 29 & 30 \\
\hline $\begin{array}{c}\text { 10-OH-pinonic acid } \\
\begin{array}{c}\text { [3-(2-Hydroxy-ethanoyl)-2,2-2- } \\
\text { dimethyl-cyclobutyl]-acetic } \\
\text { acid }\end{array} \\
\end{array}$ & $\begin{array}{c}\text { 1-OH-pinonic acid } \\
\text { (3-Acetyl-3-hydroxy-2,2- } \\
\text { dimethyl-cyclobutyl)-acetic } \\
\text { acid }\end{array}$ & $\begin{array}{c}\text { 4-OH-pinonic acid } \\
\begin{array}{c}\text { (3-Acetyl-2,2-dimethyl- } \\
\text { cyclobutyl)-2-2ydroxy-acetic } \\
\text { acid }\end{array} \\
\end{array}$ & $\begin{array}{c}\text { 4-hydroperoxy- } \\
\text { pinonaldehyde } \\
\text { (3-Acetyl-2,2-dimethyl- } \\
\text { cyclobutyl)-2-hydroper-oxy- } \\
\text { acetaldehyde } \\
\end{array}$ & $\begin{array}{c}\text { peroxo-pinic acid } \\
\text { 3-Hydroperoxycarbonyl- } \\
\text { methyl-2,2-dimethyl-cyc- } \\
\text { lobutane-carboxylic acid }\end{array}$ \\
\hline
\end{tabular}

2001; Winterhalter et al., 2003) have been tentatively assigned to hydroperoxides; 2-hydroperoxy-3-hydroxypinane (2-hydroperoxy-2,6,6-trimethyl-bicyclo [3.1.1] heptan-3-ol) and 3-hydroperoxy-2-hydroxypinane (3-hydroperoxy-2,6,6trimethyl-bicyclo [3.1.1] heptan-2-ol). Two isomers exist of each compound, so in principle four products may be present. Peroxo-pinalic acid (2,2-dimethyl-3-(2-oxooxoethyl)-cyclobutane-carboperoxoic acid) is also a possible product candidate. Table 4 gives the structures and IUPAC names of 30 of the products observed in the oxidation of apinene. 
- There is mounting evidence from laboratory studies of monoterpenes oxidation by $\mathrm{O}_{3}, \mathrm{OH}$ - and $\mathrm{NO}_{3}$-radicals that the most important process with regard to aerosol formation is the reaction with ozone (Hoffmann et al., 1997; OSOA project: Hoffmann, 2001).

- There is very little and fragmentary information available about the SOA yields from sesquiterpenes. These yields are much higher than those of the monoterpenes (17-67\% on a mass basis reported by Griffin et al., $1999 \mathrm{~b}$ ) and based on these yields the contribution of sesquiterpenes to SOA global formation may be up to 9\% (Griffin et al., 1999a).

Oxidation products of pinenes others than those detected during ozonolysis chamber experiments have been observed in the ambient SOA suggesting that other oxidants and secondary reactions may be involved in oxidized SOA formation (Claeys et al., 2004b; Edney et al., 2003; Kubátová et al., 2002).

The contributions of the three major oxidation processes of monoterpenes $\left(\mathrm{OH}, \mathrm{NO}_{3}\right.$ and ozone) to new aerosol formation and aerosol yield have been found in laboratory studies to be very different for the three possible reactions.

- Ozone was found by far to have the highest potential to form new particles at similar reactant consumption rates of $\alpha$-pinene as well as for $\beta$-pinene (Bonn and Moortgat, 2002).

- Reactions of the monoterpenes with either $\mathrm{OH}$ or $\mathrm{NO}_{3}$ result in remarkably less nucleation but with minor differences in the new-formed aerosol volume compared to the ozone reaction. This suggests that products with higher volatility than in the ozone experiments may have been formed in $\mathrm{OH}$ and $\mathrm{NO}_{3}$ reactions (Hoffmann, 2001).

For new particle formation to occur by homomolecular nucleation, an oxygenated product must be generated in the gas phase at a concentration in substantial excess of its saturation vapour concentration with respect to the condensed phase. Oxygenated products capable of generating new particles in the atmosphere must of necessity be particularly nonvolatile. Inclusion of polar functional groups with retention of carbon number will reduce product volatility quite considerably in comparison with that of the parent hydrocarbon. Experimental evidence indicates that high molecular weight compounds containing the $-\mathrm{OH},-\mathrm{C}=\mathrm{O}$ and, in particular, the carboxylic acid $-\mathrm{C}(=\mathrm{O}) \mathrm{OH}$ functionality are particularly important in this respect (e.g., Tao and McMurry, 1989; Yu et al., 1998 and references therein). The ability of most SOA compounds to nucleate in the atmosphere is not well understood and is the topic of current research. One needs to understand not only the volatility of these compounds but also their surface energy because of the importance of the Kelvin effect for nucleation. Note, that the increase in molecular weight leads to greater Kelvin effect (Seinfeld and Pandis, 1998) that hinders the homogeneous nucleation. Therefore, for an organic species to homogeneously nucleate, the lowering of vapour pressure when increasing functionality with increased molecular weight should overcome the counteracting Kelvin effect.

Until recently, dicarboxylic acids were the lowest volatile compounds positively identified in terpenes generated aerosol. cis-Pinic acid (a $\mathrm{C}_{9}$ dicarboxylic acid) has been identified as a condensed product of the ozonolysis of both $\alpha$ - and $\beta$-pinene (e.g., Christoffersen et al., 1998; Hoffmann et al., 1998; Glasius et al., 2000; Kamens et al., 1999; Jaoui and Kamens, 2003b, c).

It has been suggested (Koch et al., 2000; Winterhalter et al., 2000; Jenkin et al., 2000) that cis-pinic acid is the most likely photooxidation product of both $\alpha$ - and $\beta$-pinene that will result in prompt formation of new aerosols by nucleation. Pathways leading to cis-pinic acid have been suggested from the secondary reactions of the first-generation gas-phase products generated in monoterpenes photooxidation (Jenkin et al., 1997) or from their auto-oxidation in the condensed phase (Jang and Kamens, 1999). However, as remarked by Jenkin et al. (2000) the observed timescale of aerosol formation (Koch et al., 1999) appears to require that cis-pinic acid is itself a "1st-generation product". Winterhalter et al. (2000), Koch et al. (2000) and Jenkin et al. (2000) have suggested a possible mechanism for the formation of cis-pinic acid from the ozonolysis of both $\alpha$ - and $\beta$-pinene. These mechanisms have been discussed by Jenkin (2004). The key intermediate is an acyl radical (see circled intermediate in Fig. 2, adopted from Winterhalter et al., 2000), which is formed from exo- and endocyclic alkenes, like $\alpha$ - and $\beta$ pinene. Two pathways are proposed for this acyl radical. Either isomerisation of the complex $\mathrm{C}_{9}$-acyloxy radical by an 1,7 $\mathrm{H}$ atom shift (see Fig. 2, Pathway A: Jenkin et al., 2000) or reaction with $\mathrm{HO}_{2}$, yielding pinalic peroxo acid, which finally isomerizes to $c i s$-pinic acid (Fig. 2: Pathway B: Winterhalter et al., 2000).

- There is, however, evidence that compounds less volatile than dicarboxylic acids are present in the aerosol.

Edney et al. (2003) and Kubátová et al. (2002) have detected a $\mathrm{C}_{8}$ tricarboxylic acid, an $\alpha$-pinene oxidation product, in semi-rural and urban aerosols. Ziemann (2002) has presented evidence for the possible formation of diacyl peroxides in the ozonolysis of cyclohexene and homologous compounds and has suggested that these compounds may be the major nucleating agent in these systems and are also responsible for a significant fraction of the aerosol mass.

Mechanisms have been developed to describe the reaction pathways leading to these products. For example, explicit or lumped degradation schemes can be found for the chemistry of both $\alpha$-and $\beta$-pinene either in the new version of the 


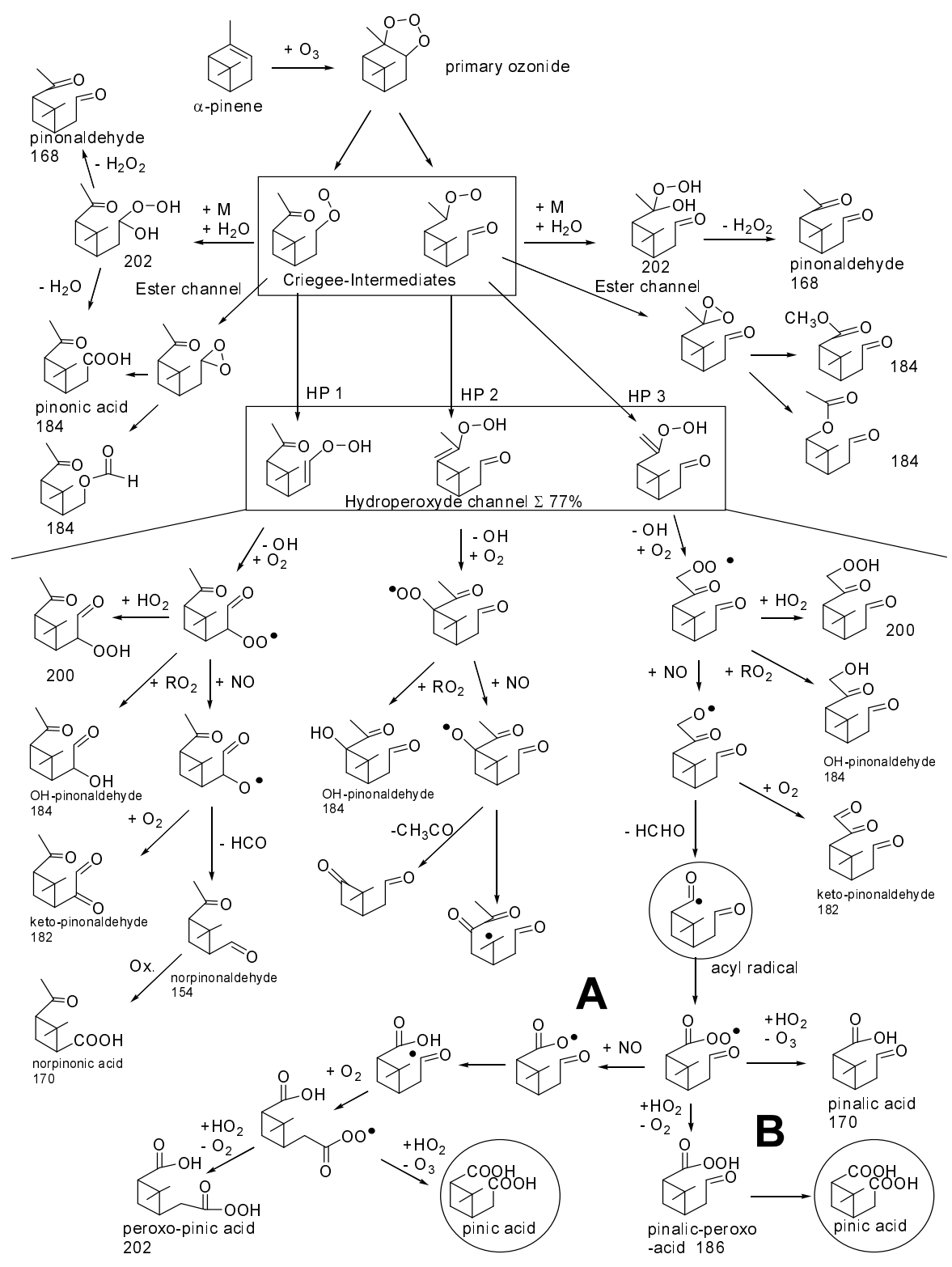

Fig. 2. Reaction mechanism for the ozonolysis of $\alpha$-pinene (adopted from Winterhalter et al., 2003). The two Criegee Intermediates and the main decomposition channel (Hydroperoxyde channel) are highlighted with square boxes. One channel leads to the formation of an acyl-type radical (circle), which can also be formed in case of $\beta$-pinene. Consecutive reactions of this acyl radical then lead to $c i s$-pinic acid (also highlighted by circles) via two possible pathways (A: Jenkin et al., 2000, B: Winterhalter et al., 2000).

Master Chemical Mechanism (MCM version 3: Saunders et al., 2003; http://www.chem.leeds.ac.uk/Atmospheric/MCM/ mcmproj.html) or SAPRC-97 and SAPRC-99 (Carter, 1997, 1999). Figure 2 shows a schematic overview of the possible pathways in the ozonolysis of $\alpha$-pinene leading to products which have been observed experimentally (Winterhalter et al., 2003) indicating also the formation of hydroxyperoxides. Recent effort by Jenkin (2004) to model the formation and composition of SOA produced during the ozonolysis of pinene using the MCM mechanism (v3) is also pointing to the key role of multifunctional products of VOC oxidation in SOA formation which contain, for example, the hydroperoxide functionality. Bonn et al. (2004) have also pointed out the importance of hydroperoxides in global SOA formation.

\subsubsection{Organic polymerisation in the aerosol phase}

A long-standing puzzle associated with the analysis of molecular speciation of SOA has been the presence in the aerosol of species whose vapour pressures are far too high to support significant partitioning into the aerosol phase 

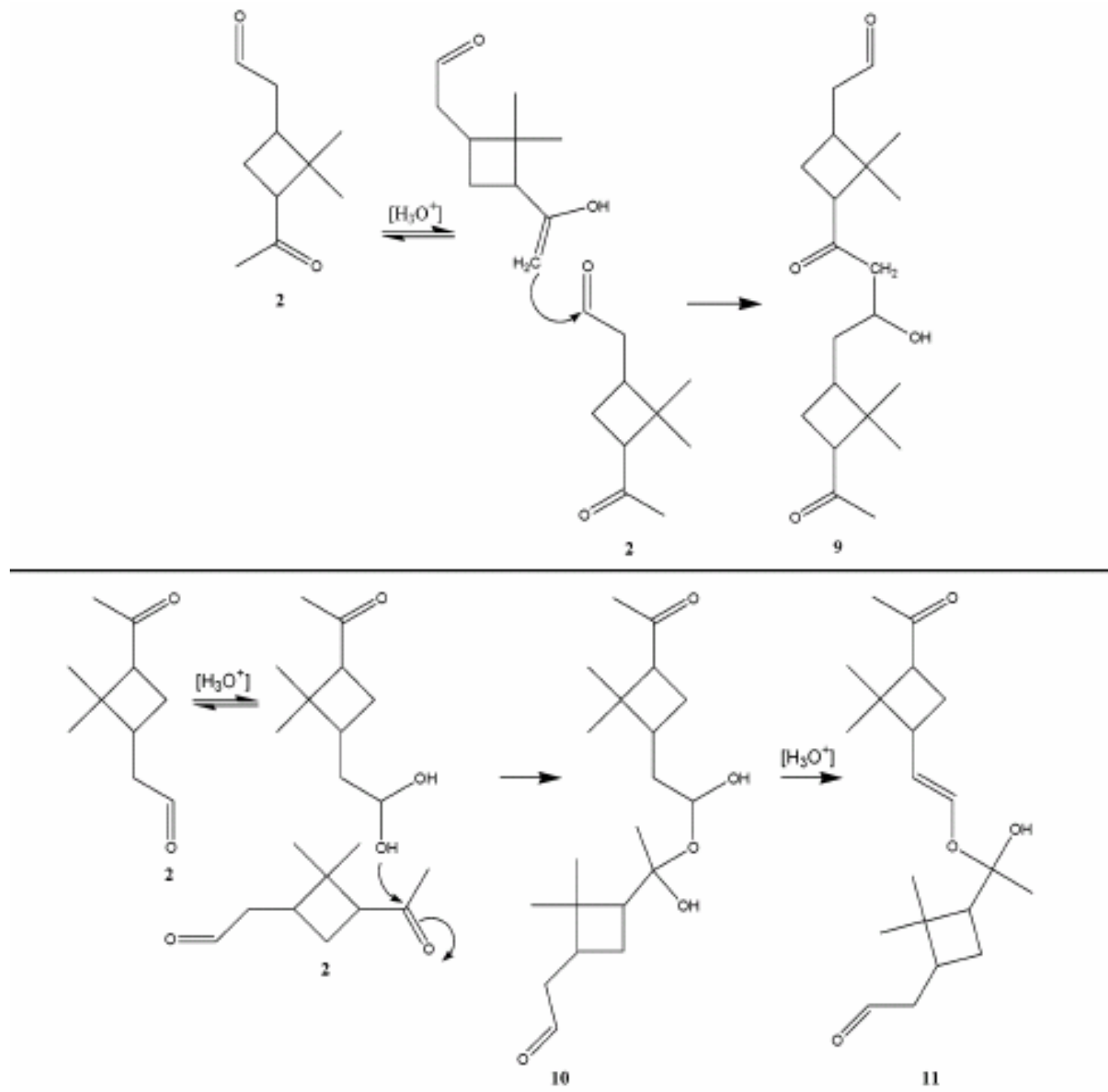

Fig. 3. Dimerisation of pinonaldehyde via aldol condensation (upper panel) and by gem-diol formation with subsequent dehydration (lower panel) (Tolocka et al., 2004).

(Forstner et al., 1997ab; Yu et al., 1998, 1999a, b). It was speculated that these relatively small and volatile species might actually be decomposition products of larger, less volatile molecules that were broken apart by the relatively harsh environment of the mass spectrometric methods traditionally used for analysis. Very recently, high molecular weight (and therefore low vapour pressure) products have been identified in the aerosol phase using analytical techniques that do not tend to break the molecules apart (Kalberer et al., 2004; Tolocka et al., 2004; Gao et al., 2004). Experimental results are just now emerging, but the existence of heterogeneous reactions between semi-volatile condensed SOA products to yield compounds of much lower volatility could play an important role in causing SOA yields to exceed those calculated solely on gas-particle partitioning of the gaseous semi-volatile oxidation products.
Oligomer and/or polymer formation following both biogenic and anthropogenic VOC degradation has been proven and may be considered as responsible for an important fraction of the SOA chemical build up in the troposphere (Tolocka et al., 2004; Kalberer et al., 2004; Gao et al., 2004). Limbeck et al. (2003) have shown that SOA formation of atmospheric polymers - humic like substances - occurs by heterogeneous reaction of isoprenoid and terpenoid emission in the presence of a sulphuric acid aerosol catalyst. Jang et al. $(2002,2003)$ presented chemical mechanisms leading to the formation of low volatility organic products from oxidation of aldehydes by acid-catalysed heterogeneous reactions. Iinuma et al. (2004) and Gao et al. (2004) found that acid catalysis can increase by about $40 \%$ the particle phase organics produced during ozonolysis experiments and suggest that condensation of smaller molecules takes place by polymerization or aldol condensation following the for- 
mation of aldehydes from terpenes ozonolysis. Tolocka et al. (2004) and Gao et al. (2004) have identified oligomers as large as tetramers in chamber experiments during $\alpha$-pinene ozonolysis using acidic inorganic seed aerosol. They conclude that $\alpha$-pinene ozonolysis in the presence of an acid catalyst is strongly influenced by oligomerisation reactions of primary ozonolysis products, most likely by aldol condensation and/or gem-diol formation (Fig. 3). An ion consistent with the dimer of pinonaldehyde has been also detected on ambient aerosols (Tolocka et al., 2004). These recent discoveries provide a new point of view for SOA formation experimental studies and modelling. The exact mechanisms of the oligomer and/or polymer formation and their significance for the chemical formation and properties of the secondary organic aerosol remain to be determined.

\subsubsection{Multiphase oxidation of hydrated gases}

Claeys et al. (2004a) have analysed aerosols from the Amazonian rain forest and identified in the fine size fraction considerable quantities of a mixture of two diastereoisomeric 2-methyltetrols, 2-methylthreitol and 2-methylerythritol, which they proposed could be explained by isoprene oxidation. Note that, until recently, isoprene was not considered a significant contributor to SOA.

The first paper was followed very quickly by a second, Claeys et al. (2004b), in which they revise the mechanism postulated in Claeys et al. (2004a) by which 2-methyltetrols are generated from isoprene. In their latest study they propose the multiphase acid-catalysed oxidation of isoprene, methacrolein and methacrylic acid with hydrogen peroxide as a new route to SOA formation. They mention that partitioning of isoprene into the aqueous phase is expected to be enhanced under acidic conditions since isoprene is hydrated in aqueous solutions of sulphuric acid (Ryabova et al., 1992). Based on preliminary kinetic studies, Claeys et al. (2004b) suggest that these SOA forming reactions are more likely to occur in hydrated aerosols or haze droplets rather than in short-lived cloud droplets. Finally, they suggest that monoterpenes and their gas phase oxidation products might undergo similar multiphase reactions leading to SOA formation.

This proposed multiphase mechanism, reaction with hydrogen peroxide under acidic conditions is an analogue to atmospheric sulphate formation and is different from all previously mentioned mechanisms. The importance of this new route in the global SOA formation requires investigation; however, this will only be possible when an improved understanding of the actual mechanism and the associated kinetic data become available.

\subsubsection{Concluding remarks}

Over the past decade significant progress has been made in our understanding of the gas-phase oxidation mechanisms of biogenic hydrocarbons. However, our knowledge is far from being complete and many gaps exist in the determination

- of all potential gaseous anthropogenic and biogenic precursor molecules of SOA,

- of the secondary photooxidation processes in the gas phase leading to low volatility compounds and thus to SOA formation,

- of the impact of $\mathrm{NO}_{\mathrm{x}}$ levels on the final products of the SOA formation chemistry

- of the heterogeneous reactions between particle associated substances and gaseous compounds able to modify the composition and the mass of aerosol,

- of the aerosol chemistry responsible for the recently reported oligomer formation which increases the aerosol mass,

- of the aqueous phase chemistry, which might produce semi-volatile compounds that build up aerosol mass,

- of the complete molecular composition of the aerosol produced from the above mentioned processes.

A full appreciation of all the processes involved will probably have to await the evolution of new more powerful analytical probing techniques that are starting to emerge. Further experimental work is also needed in order to translate laboratory results obtained in high concentrations of organic precursors and oxidants to atmospheric conditions with often much lower concentrations.

\subsection{Nucleation}

The ability of SOA compounds to form new particles in the atmosphere is a rather controversial issue. In the laboratory, formation of new particles is routinely observed during oxidation of SOA precursors (Stern et al., 1987; Hatakeyama et al., 1989; Pandis et al., 1991; Wang et al., 1992; Hoffmann et al., 1998; Koch et al., 2000; Hoppel et al., 2001; Bonn et al., 2002). However, these experiments often use moderate to high concentrations of VOCs and no pre-existing aerosol. For example, reaction of $20 \mathrm{ppb}$ of $\alpha$-pinene with $120 \mathrm{ppb}$ of ozone and no pre-existing particles can create $50000 \mathrm{~cm}^{-3}$ (Hoppel et al., 2001). Nucleation in these systems (even at high concentrations) can be relatively easily suppressed if a moderate concentration of seed aerosol is present (Cocker et al., 2001a, b). In this case the SOA compounds condense on the pre-existing aerosols and nucleation does not take place at the same time. Many studies have reported rather frequent nucleation events in the boundary layer and free troposphere in a variety of environments (see Kulmala et al., 2004a for a review of field observations). It has been suggested that 
some of these observed new particle formation events in remote areas may be due to nucleation of biogenic SOA compounds (Marti et al., 1997; O'Dowd et al., 2002; Kavouras and Stephanou, 2002).

The potential for the formation of new particles during various reactions of $\alpha$ - and $\beta$-pinene was investigated by Bonn and Moortgat (2002). Their experiments indicated that the ozonolysis dominates the new particle formation compared to the reactions with $\mathrm{OH}$ and $\mathrm{NO}_{3}$. The authors argued that ozonolysis is probably the only atmospherically relevant organic source for new particle formation from biogenic precursors, because of the low atmospheric concentrations of these biogenic compounds. The formation of new particles during the monoterpenes ozonolysis is negatively affected by water vapour (Bonn et al., 2002). Bonn and Moortgat (2002) suggested the involvement of stabilized Criegee Intermediates and the formation of secondary ozonides as nucleating species. Bonn and Moortgat (2003) argued that the atmospheric new particle formation observed in remote areas and generally attributed to low-volatility oxidation products of monoterpenes may be actually initiated by products of sesquiterpenes reactions with ozone. The cyclic alkene ozonolysis experiments of Ziemann (2002) suggested that diacyl peroxides and not dicarboxylic acids might be the nucleating agents in SOA systems. Hoppel et al. (2001) concluded that the nucleating species during $\alpha$-pinene ozonolysis must have a saturation mixing ratio lower than $10 \mathrm{ppt}$ at $25^{\circ} \mathrm{C}$ and that classical nucleation theory is not able to explain their observations. For the anthropogenic emissions the processes leading to nucleation and SOA will probably be much more varied than for the biogenics because of the greater diversity in the chemical structures of the compounds emitted. There are experiments (Johnson et al., 2004b) which support that ozone is not a major player in the aromatic systems and that nitroaromatic compounds may be playing a dominate role. For anthropogenic species containing double bonds, however, the evidence here again (Tobias et al., 2000; Kalberer et al., 2000) supports that ozone reactions are probably the most important for SOA formation.

The analysis of all the measurements in a boreal forest site in Southern Finland indicated that the most probable new particle formation mechanism in the area is ternary nucleation of water-sulphuric acid-ammonia (Kulmala et al., 2001; Janson et al., 2001). After nucleation the major part of the growth is probably due to condensation of organic vapours. However, there is lack of direct proof of this phenomenon because the composition of $1-5 \mathrm{~nm}$ size particles is extremely difficult to determine using the present state-of-art instrumentation. Similar conclusions have been reached by Marti et al. (1997) about new particle formation in Colorado and by Gaydos et al. (2005) about the nucleation events in the NE US. Gao et al. (2001) also concluded based on their smog chamber studies that sulphuric acid is a superb nucleating species, while secondary organic compounds probably play a role more confined to growing newly formed particles. The dominance of sulphuric acid as a nucleating agent over atmospheric organics was also suggested by the work of Tobias et al. (2001). The authors investigated the formation of new particles in the exhaust of a diesel engine and concluded that the results were consistent with a mechanism of nanoparticle formation involving nucleation of sulphuric acid and water, followed by particle growth by condensation of organic species.

Kulmala et al. (2004a) in their review of the available field observations of nucleation concluded that organic vapours could, in principle, participate in nucleation, but nucleation mechanisms that involve organics have not yet been identified. It appears very likely, however, that organics contribute to the growth of nucleated particles and indirectly affect the formation rate of new particles of detectable sizes (Zhang and Wexler, 2002; Anttila and Kerminen, 2003; Kulmala et al., 2004b). Boy et al. (2003) estimated that condensation of monoterpenes oxidation products is able to explain $10-50 \%$ of the observed growth rates of fresh particles in Southern Finland.

Garman et al. (2004) investigated theoretically the binary homogeneous nucleation of water-succinic acid and water-glutaric acid based on the classical nucleation theory. They concluded that under atmospheric conditions these binary systems would not form new particles. Kavouras and Stephanou (2002) measured, by using a minimizing artifact sampling device, biogenic primary organic polar compounds and monoterpene carbonyl and acidic photooxidation products in both gas and particles over a Mediterranean conifer forest. On the basis of these field measurements they calculated saturation concentrations of the acidic and carbonyl photooxidation products for non-ideal conditions using a previously developed absorptive model (Pankow, 1994). The results of this study suggested that the formation of SOA goes on through a heterogeneous heteromolecular nucleation mechanism, where the effects of both pre-existing organic aerosol (mostly primary) and ambient temperature are crucial.

The absence of nucleation events in the Amazon (Andreae, Swietlicki personal communication), an environment with very low sulphur concentrations but very high biogenic VOC concentrations, strongly suggests that nucleation of purely SOA compounds in the atmosphere may not be that frequent. A potential explanation for this could be that most low-vapour-pressure organics have high molecular weight, but high-MW species have a strong Kelvin effect at nucleation sizes as discussed in Sect. 3.1.1.

Zhang et al. (2004) based on laboratory experiments of mixtures of aromatic acid vapours (benzoic and p- and $\mathrm{m}$ toluic acids) with sulphuric acid $\left(\mathrm{H}_{2} \mathrm{SO}_{4}\right)$ have shown that the presence of these organic acids enhance sulphuric acid nucleation. Based on bonding energies theoretical calculations, they explain these finding by the formation of aromatic acid- sulphuric acid complexes via two hydrogen bonds. The organic acid molecule acts as both a hydrogen bond donor 
and acceptor (see supporting material in Zhang et al., 2004). These new findings on a heteromolecular nucleation mechanism in which both sulphuric acid and organic acids are involved could be of crucial importance to understand formation of new particles of a few (3-4) nm size in polluted areas where both sulphuric and organic acids exist at significant levels. Kulmala et al. (2004b) further presented a new theory that explains new particle formation via activation of stable inorganic clusters by organic vapors.

- Therefore, based on current knowledge there is no proof that homogeneous nucleation of organics occurs and is of any significance for global scale modelling.

- Organics also contribute to the growth of nucleated particles and indirectly affect the formation rate of new particles of detectable sizes.

- There is emerging evidence that heteromolecular nucleation involving organics might be crucial for understanding new particle formation in polluted areas of the globe.

- Characterisation of the chemical composition of the aerosol at the very early stage of its formation is critical for identifying the nucleating agents.

\subsection{Aerosol dynamics}

The ageing and removal of particles from the atmosphere as well as their climatic impact depends among other parameters on their size distribution that is determined by aerosol dynamics (the description of the aerosol using size distributions, condensation/evaporation of material, and coagulation). There are few studies evaluating these aspects of OA. Therefore there is a high degree of uncertainty in the evaluation of the aerosol dynamics of OA.

\subsubsection{Size distribution}

Various approaches have been developed to represent the size distribution of aerosols in models:

- the bulk mass approach,

- the sectional approach (e.g. Zhang et al., 2004a; Gelbard and Seinfeld, 1980) where the aerosol are usually assumed internally mixed and properties of the particles, such as mass and chemical composition, are assumed uniform within each size bin (Griffin et al., 2002),

- the modal approach where the size distribution is described by several modes, and usually a log-normal distribution is used to represent the size distribution in each mode (e.g. Schell et al., 2001; Whitby and McMurry, 1997).
Most of the modelling applications to urban and regional air quality have focused on aerosol mass distributions whereas aerosol number distributions have received a minor attention due to major availability of aerosol mass measurements compared to number concentrations. In most cases the only available measurements are the total mass of particles smaller than a certain size $\left(\mathrm{PM}_{2.5}\right.$ and $\left.\mathrm{PM}_{10}\right)$. Furthermore number size distributions are more sensitive to dynamic processes such as coagulation than mass distributions. Based on actual knowledge, in most global models organic aerosol mass is assumed to be distributed mainly in the accumulation mode.

\subsubsection{Condensation/nucleation}

The mass transfer flux $(J)$ of an organic species from the gas phase to the aerosol phase is proportional to the difference between its gas-phase concentration, $c_{\infty}$, and equilibrium concentration at the particle surface, $c_{e q}$, (Seinfeld and Pandis, 1998):

$J=4 \pi R_{p} D_{i} f(K n, a)\left(c_{\infty}-c_{e q}\right)$

where $R_{p}$ is the particle radius, $D_{i}$ is the gas-phase diffusivity. $f(K n, a)$ is the correction to the mass transfer flux due to noncontinuum effects and imperfect accommodation, $K n$ is the Knudsen number and $a$ is the accommodation coefficient.

The organic vapour condenses onto the particle phase when $c_{\infty}>c_{e q}$. The equilibrium concentration depends not only on the properties of the organic species but also on its ability to form solutions with compounds already present in the aerosol phase (see next section). Equilibrium tends to be achieved more quickly for small particles than large ones (see, for example, Meng and Seinfeld, 1996) and growth of aerosols occurs on a time scale of minutes to hours.

Koo et al. (2003b) using a one-dimensional Lagrangian trajectory model have explored whether gas-particle equilibrium may be assumed to hold instantaneously or whether gas-particle mass transfer needs to be treated kinetically. They found that the equilibrium assumption is valid for the conditions examined. For global climate applications, because of the considerably large time steps used, the dynamic treatment of condensation/evaporation may be avoided and equilibrium assumed. However, recent studies show that other processes, e.g. polymerization (Kalberer et al., 2004; Tolocka et al., 2004), have a significant effect on the composition and volatility of SOA, which may be more important than classical microphysical processes and requires investigation.

\subsubsection{Coagulation}

Coagulation is a function of both the particle number concentration and particle size (Seinfeld and Pandis, 1998). The rate of change of the number concentration of a polydisperse 
aerosol due to (Brownian) coagulation depends on the coagulation coefficient $\mathrm{k}_{1,2}$ that can be expressed by

$k_{1,2}=4 \pi\left(r_{1}+r_{2}\right)\left(D_{1}+D_{2}\right) \beta$

where $D_{1}$ and $D_{2}$ are the particle diffusion coefficients, $r_{1}$ and $\mathrm{r}_{2}$ the radius of the particles and $\beta$ is the Fuchs correction factor (Fuchs, 1964). Coagulation may have an important impact on particle number concentration when the concentrations are high, i.e. close to emission sources, or may affect particle mass and chemical composition by internally mixing particles.

In most urban and regional modelling applications that focus on aerosol mass distributions, coagulation can be ignored (Wexler et al., 1994). However, for studies that focus on aerosol number, and that consider fine mode aerosol distribution, coagulation is one of the most important processes that reduce aerosol number. So far no study has been done specifically on the importance of coagulation on secondary organic aerosol properties. The importance of coagulation in transforming insoluble particles into soluble is discussed in Sect. 5.2.

\subsection{Gas-particle partitioning}

Semi-volatile VOC oxidation products tend to partition between the gas and particulate phases. The ambient atmospheric particulate phase will consist, in general, of a mixture of organic and inorganic components, as well as water, and itself may consist of one or more phases. Organics can be either in liquid or solid or mixed phase or they may be dissolved in aqueous solutions. If the aerosol is composed by more than one phase, it has generally been presumed that one of the phases is primarily an organic phase and the other is predominantly an aqueous phase. The basic theory of equilibrium gas-particle partitioning of a condensable organic species into an aerosol phase consisting, in general, of an organic sub-phase and an aqueous sub-phase can be described as follows (Griffin et al., 2003).

Let the organic aerosol-phase concentrations of each of the partitioning secondary organic species be denoted as $O_{i}$ ( $\mu \mathrm{g} \mathrm{m}^{-3}$ air), $i=1,2 \ldots, n$, where $n$ is the number of partitioning species. The equilibrium organic aerosol-phase partitioning coefficient, $K_{\text {om }, i}$, describes the distribution of each product between the gas phase and an absorbing organic aerosol phase. If $G_{i}$ denotes the gas-phase concentration of species $i\left(\mu \mathrm{g} \mathrm{m}^{-3}\right.$ air $)$ and $M_{o}$ the total mass concentration ( $\mu \mathrm{g} \mathrm{m}^{-3}$ air) of organic aerosol available to act as an organic medium into which the $n$ species may partition, then

$K_{o m, i}=\frac{O_{i}}{M_{o} G_{i}}$

where $M_{o}$ is the sum of all $O_{i}$ and the mass concentrations of each primary organic aerosol species present. $G_{i}$ for each species is computed from Eq. (3) once the set of $K_{o m, i}\left(\mathrm{~m}^{3}\right.$ air $\mu \mathrm{g}^{-1}$ ) values is calculated according to (Pankow, 1994):

$K_{o m, i}=\frac{R T}{10^{6} M W_{o m} \gamma_{i} p_{L, i}^{o}}$

where $R$ is the ideal gas constant $\left(8.2 \times 10^{-5} \mathrm{~m}^{3}\right.$ atm $\left.\mathrm{mol}^{-1} \mathrm{~K}^{-1}\right), \quad T$ is temperature $(\mathrm{K})$, $M W_{\text {om }}$ is the average molecular weight $\left(\mathrm{g} \mathrm{mol}^{-1}\right)$ of the absorbing organics (including both primary organic compounds and secondary products), $p_{L, i}^{o}$ is the pure component vapour pressure (atm) of species $i$, and $\gamma_{i}$ is the activity coefficient of species $i$ in the organic phase. The activity coefficient $\gamma_{i}$ describes the nonideal interaction between dissolved species $i$ and the other components of the solution. A value of $\gamma$ above 1 , for example, means that the compound in question is not easily miscible with the absorbing aerosol, and the nonideal interactions favour its remaining in the gas phase. The factor $10^{6}$ converts $\mathrm{g}$ to $\mu \mathrm{g}$. The molecular identities of the condensing and primary non-volatile species must be known in order to calculate the parameters in Eq. (4). These include species-specific molecular weights and vapour pressures as a function of temperature.

Few experimental values of the vapour pressures of secondary organic aerosol components exist. The vapour pressure of five mono-carboxylic acids $\left(\mathrm{C}_{14}-\mathrm{C}_{18}\right)$ and two di-carboxylic acids (glutaric and adipic acid) were measured by Tao and McMurry (1989) over the temperature range $283-323 \mathrm{~K}$ using a Tandem Differential Mobility Analyzer (TDMA) system. Vapour pressures of the monocarboxylic acids were in the range $3 \times 10^{-7}$ to $10^{-4} \mathrm{~Pa}$ at $296 \mathrm{~K}$ and vapour pressures of the di-carboxylic acids were $8 \times 10^{-4}$ and $10^{-5} \mathrm{~Pa}$ for glutaric and adipic acid at $296 \mathrm{~K}$. Heats of formation were in the range $163-191 \mathrm{~kJ} \mathrm{~mol}^{-1}$ for the mono-carboxylic acids and 102 and $117 \mathrm{~kJ} \mathrm{~mol}^{-1}$, for glutaric and adipic acid, respectively. Additional measurements of the vapour pressures of $\mathrm{C}_{3}-\mathrm{C}_{9}$ dicarboxylic acids were reported by Bilde et al. (2003). Hallquist et al. (1997) using a Knudsen effusion apparatus, measured the vapour pressures of two oxidation products of $\alpha$-pinene and $\Delta^{3}$-carene, namely pinonaldehyde and 2,2-dimethyl-3-(2oxypropyl)-cyclopropaneacetaldehyde (in the paper referred to as caronaldehyde), respectively. Vapour pressures were measured over the temperature range $255-276 \mathrm{~K}$ and the values at $296 \mathrm{~K}$ were $4.2 \mathrm{~Pa}$ for pinonaldehyde and $2.3 \mathrm{~Pa} 2,2$ dimethyl-3-(2-oxypropyl)cyclopropane-acetaldehyde. Using the Tandem Differential Mobility Analysis (TDMA) technique Bilde and Pandis (2001) measured the vapour pressures of glutaric acid, trans-norpinic acid and pinic acid particles. Additional measurements of the volatility of the various SOA components are needed for a comprehensive description of SOA formation in atmospheric chemical transport models.

The gas-particle partitioning coefficient $K_{o m, i}$ is inversely proportional to the pure component vapour pressure of 
species $i$. Thus, uncertainties in the value of vapour pressure translate directly into uncertainties in the predicted gasparticle partitioning.

Species $i$ may also partition to an aqueous particulate phase. If $A_{i}$ represents the aqueous-phase concentration of species $i\left(\mu \mathrm{g} \mathrm{m}^{-3}\right.$ air) and $H_{i}$ the Henry's law coefficient of species $i\left(\left(\mu \mathrm{g} \mu \mathrm{g}^{-1} \mathrm{H}_{2} \mathrm{O}\right) / \mu \mathrm{g} \mathrm{m}^{-3}\right.$ air $\left.)\right)$ :

$A_{i}=\frac{G_{i}(\mathrm{LWC}) H_{i}}{\gamma_{a q, i}}$,

where LWC has units of $\mu \mathrm{g} \mathrm{H}_{2} \mathrm{O} \mathrm{m}^{-3}$ air, and $\gamma_{a q, i}$ is the activity coefficient of organic species $i$ in the aqueous phase (normalized by that at infinite dilution).

The aqueous-phase equilibrium is also subject to constraints imposed by dissociation of the dissolved organic species. The degree of dissociation of the organics that one encounters in the aerosol phase is variable. The dissociation of most dicarboxylic acids (with the exception of oxalic acid) and of most large acids can be neglected. For the few small acids like formic and acetic acid this has to be taken into consideration. Note the general lack of experimental data on combinatory reactions between organic anions and inorganic electrolytes in the aqueous phase for the compounds of interest as SOA.

Both the organic and aqueous phase equilibrium relations require activity coefficients, $\gamma_{i}$ and $\gamma_{a q, i}$ (see paramaterisation proposed by Bowman and Karamalegos, 2002). An iterative solution to determine the organic- and aqueous-phase equilibrium concentrations is necessary because activity coefficients are themselves a function of composition. This solution must also satisfy mass conservation: the sum of the values for $O_{i}, G_{i}, A_{i}, A M_{i}$, and $A D_{i}$ must equal the total amount of $i$ available, where $A M_{i}$ and $A D_{i}$ are the concentration of singly and of the doubly (when applicable) charged ion from species $i$, respectively (details are given in Griffin et al., 2003).

\subsection{Representation of SOA formation in Atmospheric Chemistry Transport Models}

The representation of gas-phase VOC oxidation chemistry that leads to SOA formation in current Atmospheric Chemistry Transport Models generally falls into one of three categories:

1. Use of empirical data fits derived from laboratory chamber data;

2. Use of completely explicit gas-phase oxidation for the VOCs in question to predict the spectrum of condensing products;

3. Use of lumped gas-phase oxidation mechanisms derived from simplification of fully explicit mechanisms.
The purpose of the mechanisms in points (2) and (3) above is to predict condensable products from gas-phase oxidation of the parent VOC.

The formation of SOA from a particular VOC is often described in terms of the fractional mass yield, $Y$, which relates how much particulate matter is produced when a certain amount of parent gaseous VOC is oxidized:

$Y=\frac{M_{o}}{\triangle V O C}$

where $M_{o}\left(\mu \mathrm{g} \mathrm{m}^{-3}\right)$ is the mass concentration of SOA produced from the reaction of $\Delta \operatorname{VOC}\left(\mu \mathrm{g} \mathrm{m}^{-3}\right)$.

Two product yield method. Odum et al. (1996) utilized the concepts of multicomponent gas-particle partitioning to develop a framework for parameterising the trend of increasing $Y$ values with increasing $M_{o}$ for chamber experiments involving water-dry aerosols. Assuming that the photooxidation of a parent VOC can be represented as leading to just two overall semi-volatile products $\mathrm{P}_{1}$ and $\mathrm{P}_{2}$, then

$V O C+$ oxidants $\rightarrow p_{1} P_{1}+p_{2} P_{2}+$ volatile products

where $p_{1}$ and $p_{2}$ are molar stoichiometric coefficients. Reaction (7) does not represent a fundamental reaction but rather a convenient way to represent observed data. Then $\alpha_{1}=p_{1} \times \mathrm{MW}_{\mathrm{P}_{1}} / \mathrm{MW}_{\mathrm{VOC}}$ and $\alpha_{2}=p_{2} \times \mathrm{MW}_{\mathrm{P}_{2}} / \mathrm{MW}_{\mathrm{VOC}}$ are the mass stoichiometric factors for the production of $\mathrm{P}_{1}$ and $\mathrm{P}_{2}$ from the parent hydrocarbon (VOC) with $\mathrm{MW}_{P 1}, \mathrm{MW}_{P 2}$ and $\mathrm{MW}_{V O C}$ the molecular weights of $\mathrm{P}_{1}, \mathrm{P}_{2}$ and VOC, respectively (Seinfeld and Pankow, 2003).

Using the mass-based stoichiometric coefficients, $\alpha_{i}$, the result for the overall yield $Y$ is:

$Y=\sum_{i} Y_{i}=\sum_{i} \alpha_{i}\left(\frac{K_{\text {om }, i} M_{o}}{1+K_{\text {om }, i} M_{o}}\right)$

where $Y_{i}$ is the individual contribution to the yield from compound $i$.

The above framework has been used extensively in analysing yield data for laboratory smog chamber experiments conducted in the absence of water, for a wide range of parent VOC compounds. Each of those experiments has been described by fitting the $Y$ versus $M_{O}$ data by assuming that two hypothetical average product compounds, $\mathrm{P}_{1}$ and $\mathrm{P}_{2}$, were formed. Yield data are not generally fit well by assuming a single product, and the assumption of three products does not improve the fits significantly. In a two-product fit $(i=2)$, there are four fitting parameters: two $\alpha_{i}$ values and two $K_{o m, i}$ values and are used to fit a monotonically increasing curve that goes through zero. This method provides a good fit under the studied experimental conditions however its applicability to different conditions requires to be carefully checked.

The empirical two-product representation of SOA formation has been highly successful in fitting laboratory SOA yield data at the California Institute of Technology for over 
50 parent VOCs (Odum et al., 1997; Griffin et al. 1999a). Even though its simplicity and its basis in actual laboratory data are strong points, the approach suffers disadvantages for use in atmospheric models. It is well established that, even for a single VOC, many more than two products are involved in SOA formation and, as conditions such as temperature and oxidant level change, a different distribution of products might be condensing than those on which the original correlation was based. Laboratory experiments have generally been carried out in a modest temperature range around $298 \mathrm{~K}$. At temperatures of the upper troposphere, oxidation products that might otherwise remain largely or wholly in the gas phase around $298 \mathrm{~K}$ may shift to the SOA phase. Such behaviour cannot be captured by a two-component model derived on the basis of higher temperature chamber data.

Detailed chemical mechanisms. The approach to the gasphase modelling step of SOA formation that is at least in principle most chemically rigorous is to represent the gasphase chemistry with a fully explicit mechanism. An example of such a mechanism is the University of Leeds Master Chemical Mechanism version 3.0 (MCM v3) (http://www. chem.leeds.uk/Atmospheric/MCM/mcmproj.html). The use of a chemically explicit mechanism could impart a degree of confidence when all conceivable important chemical paths have supposedly been accounted for and have been carefully evaluated against measurements. Unfortunately this is not the case of SOA forming chemical mechanisms since the rate constants of many among the involved reactions have not been determined in the laboratoty. While such a detailed mechanism is important for evaluating the extent of agreement of predictions of a chemically explicit mechanism with chamber data, the computations associated with using such a mechanism in a regional or global atmospheric model render it completely impractical.

Recently, Jenkin (2004) has summarized actual knowledge on the $\alpha$ - and $\beta$ - pinene ozonolysis in the MCM v3 mechanism. He considered equilibrium absorptive partitioning of a total of about 200 semivolatile products and has been able to reasonably describe the SOA accumulation when substantial SOA mass was already present and the partitioning coefficients of the semivolatiles have been increased by 2 orders of magnitude compared with those based on estimated vapour pressures. The consideration of the gas phase production and subsequent transfer to the aerosol phase of involatile dimers of $22 \mathrm{bi}$ - and multifunctional carboxylic acids in the MCM v3 allowed the description of the early stages SOA formation i.e. at low mass concentrations. This mechanism has been evaluated against some chamber experiments with regard to the SOA mass accumulation. The computed SOA mass consists in majority from multifunctional acid products and increasing contributions from more volatile products, like pinonaldehyde and nopinone, with increasing aerosol mass.

Regional or tropospheric-scale ozone chemistry is typically represented by lumped mechanisms, those in which reactions of similar type are grouped together or in which the chemistry of certain species is used to represent that of a wide spectrum of related species. The mechanisms have been tested to insure they exhibit the proper response of calculated $\mathrm{O}_{3}$ concentrations to changes in key variables, such as $\mathrm{NO}_{\mathrm{x}}$ level. Significant deviations between gas phase chemical mechanisms in the calculated $\mathrm{NO}_{2}$ and organic peroxy radicals concentrations are encountered when comparing them under high $\mathrm{NO}_{\mathrm{x}}$ conditions due to the different simplification of the organic peroxy radical chemistry (Gross and Stockwell, 2003; Pöschl et al., 2000). In addition, such evaluations are limited by the experimental data on which the chemical mechanisms rely. As discussed in Sect. 3.1 ozonolysis experiments might be biased by $\mathrm{OH}$ formation in the chamber and have been performed in the absence of NO, thus neglecting reaction of products with $\mathrm{NO}$ that can be of atmospheric relevance. Similarly, $\mathrm{NO}_{3}$ chamber experiments are performed under very high $\mathrm{NO}_{\mathrm{x}}$ levels that block 'clean' chemistry pathways (like permutation reactions and hydrogenperoxide formation paths).

Although significant advances have been made in understanding the SOA formation, targeted chamber and field experiments are needed to allow evaluation and provide confidence to chemical mechanisms used in regional and global models that treat both gas phase chemistry and SOA formation. Approaches based on lumped mechanisms are just starting to emerge in regional/global modelling of SOA (see, for example, Griffin et al., 2002a), and it is this direction that offers the most promise for development of chemically realistic models of SOA formation in the next ten years or so. The gas-phase chemical mechanism predicts the amounts of oxidation products; the next step is to partition those products between the gas and aerosol phases. First, it is generally established that such products will tend to partition themselves between the gas and particulate phases in accord with the equilibrium relations discussed in Section 3.4. But several questions arise:

1. What is the nature of the particles to which the condensable species are partitioning? Does primary organic aerosol also act as an absorbing medium in addition to the already-condensed SOA? Is liquid water in the particles present as a separate aqueous phase into which gaseous oxidation products may also dissolve? To what extent does the presence of the condensed SOA induce the further condensation of water?

2. Is gas-aerosol equilibrium for the condensing organic species established rapidly or are the kinetics of condensation/evaporation important?

3. Are aerosol-phase reactions occurring involving the condensing SOA products?

SOA in global models. Consideration of the OA in regional modelling has started in the 80 s with pioneering work by Pilinis et al. (1987). Since then a lot of progress has been made 
in regional/urban modelling of SOA whereas only recently a few global modelling efforts have emerged. Generally, because of computational considerations, the urban/regional models include a more detailed representation of SOA formation than do the global models. This is reflected both in the size of the gas-phase VOC oxidation mechanism and in the level of detail in the gas-particle partitioning calculation. In global models, because of the considerably larger time steps, the equilibrium assumption appears to be valid (Koo et al., 2003b). This outcome is fortuitous because it is unlikely that global models could accommodate the significant computational burden associated with a kinetic calculation of gas-particle partitioning of SOA components.

There exist two sensitivity studies of SOA modelling, one on regional scale (Pun et al., 2003) and the second on global scale (Tsigaridis and Kanakidou, 2003), both of which illustrate the wide degree of variation in predicted SOA depending on the actual model used or on assumptions made about the gas-particle partitioning process. Pun et al. (2003) investigated differences among three SOA modules caused by the representation of terpenes, the mechanistic versus empirical representation of SOA-forming reactions, the identities of SOA, and the parameters used in the gas/particle partitioning calculations. Tsigaridis and Kanakidou (2003) investigated differences caused by the assumptions in the parameters used for the gas/particle partitioning calculations, in the primary emissions of POA and in the hydrophobic to hydrophilic conversion.

Table 5 presents a summary of the recent global modelling studies that include SOA and their main assumptions. The models in this table follow rather different approaches; they assume different substrates for the condensation of SOA as well as the surrogate VOC compounds considered to form SOA precursors and have different treatment of the evaporation. They also differ in the consideration or not of primary carbonaceous aerosol and in the amount of it that is being emitted into the atmosphere. To these conceptual particularities of the models, more generally applied technical differences are added. For instance, models differ in the spatial and temporal resolutions, the parameterisations and input data used to represent transport and wet deposition processes. Therefore, global SOA formation estimates vary by almost a factor of 6 between about 12 and $70 \mathrm{Tg}-\mathrm{SOA} \mathrm{y}^{-1}$. This reflects the uncertainty in our current understanding of the SOA occurrence in the global troposphere.

One draws the following conclusions concerning the treatment of SOA in global models:

- Use of detailed gas-phase VOC oxidation mechanisms is not currently feasible in global atmospheric models. At the other extreme, however, laboratory chamber studies have not been carried out over a sufficient parameter range to provide entirely empirically-based representations of SOA formation. A need exists to de- velop robust, lumped mechanisms capable of representing the generation of condensable products.

- The gas-particle partitioning is among the key processes. It cannot simply be assumed that all semivolatile products condense entirely or that they always condense in the same proportion regardless of conditions. Therefore, it is necessary to represent the details of gas-particle partitioning in global models. Condensable SOA products will dissolve in both organic and aqueous aerosol phases, and the organic phase can consist of primary organic aerosol as well as condensed SOA itself. Since the nature of the aerosol phase is important in this partitioning, it will be necessary to account for the presence of primary organics as well as inorganics that govern the amount of condensed water in the global model.

- The extent to which heterogeneous aerosol chemistry is important in SOA formation is currently unknown. The effect of heterogeneous reactions is to form larger molecules through addition reactions; such molecules have significantly lower vapour pressures than the addition partners, essentially freezing these molecules in the aerosol phase (i.e. increasing $K_{\text {om }}$ ). At present, not enough is known about such chemistry to include it explicitly in global SOA models; based on recent chamber results it may be possible to estimate its importance through sensitivity studies.

\section{Removal of organic aerosols}

\subsection{Dry deposition of aerosols in climate models}

Dry deposition of aerosols is a significant removal process close to the ground. Models calculate the dry deposition flux $F$ by assuming that it is directly proportional to the concentration $C$ of the deposited species:

$F=-u_{d} C$

The dry deposition velocity $u_{d}$, is calculated based on the electrical resistance analogy. According to this, the deposited species has to overcome three resistances connected in series prior to deposition: the aerodynamic resistance $r_{a}$, the quasi-laminar layer resistance $r_{b}$ and the canopy resistance $r_{c}$. The aerodynamic resistance is controlled by the turbulent transport of the species from the atmosphere close to the surface, while the quasi-laminar resistance depends on the molecular properties of the deposited species and the surface characteristics. The canopy resistance is controlled greatly by the surface characteristics, since the species are assumed deposited only if they cannot escape back to the atmosphere after the direct contact with the surface. For aerosol species, the canopy resistance is equal to zero, since it is generally assumed that whenever a particle reaches the surface it has 
Table 5. Representation of Secondary Organic Aerosol Formation in Global Atmospheric Models. (POA: primary organic aerosol); *Volatile Organic Species (VOC) used in the model to represent all VOC compounds forming SOA during their oxidation.

\begin{tabular}{|c|c|c|c|}
\hline VOC considered* & Gas-phase mechanism. & Gas-particle partitioning. & Reference \\
\hline 14 Terpenes & $\begin{array}{l}\text { None. } \mathrm{OH}, \mathrm{O}_{3}, \mathrm{NO}_{3} \\
\text { from global CTM. }\end{array}$ & $\begin{array}{l}\text { Two-product fits of chamber } \\
\text { data, imposed T dependence. } \\
\text { Absorption into POA + SOA } \\
\text { aerosol. }\end{array}$ & Chung and Seinfeld (2002) \\
\hline$\alpha$-pinene & $\begin{array}{l}\text { STOCHEM + } 20 \text { species/ } \\
48 \text { reactions. }\end{array}$ & $\begin{array}{l}\text { 1st order scavenging of } \\
\text { condensable oxidation products. }\end{array}$ & Derwent et al. (2003) \\
\hline$\alpha-\& \beta$-pinene & $\begin{array}{l}\mathrm{C}_{1}-\mathrm{C}_{5} \text { chemistry and } \\
\text { highly simplified pinene chemistry }\end{array}$ & $\begin{array}{l}\text { Two-product model. Absorption } \\
\text { into POA + SOA aerosols }\end{array}$ & Kanakidou et al. (2000) \\
\hline $\begin{array}{l}\alpha \text { - \& } \beta \text {-pinenes } \\
\text { toluene } \& \text { xylene }\end{array}$ & $\begin{array}{l}\text { Modified CB } 4+12 \text { species/ } \\
12 \text { total reactions }\end{array}$ & $\begin{array}{l}\text { Two-product model, imposed } \mathrm{T} \\
\text { dependence. Absorption possible } \\
\text { into all aerosols }\end{array}$ & Tsigaridis and Kanakidou (2003) \\
\hline $\begin{array}{l}\text { Biogenic } \mathrm{C}_{10} \mathrm{H}_{16} \\
\text { Anthropogenic } \mathrm{C}_{4} \mathrm{H}_{10}\end{array}$ & $\mathrm{C}_{1}-\mathrm{C}_{5}$ and $\mathrm{C}_{10} \mathrm{H}_{16}$ chemistry & $\begin{array}{l}\text { 1. Bulk yield method } \\
\text { 2. two product model }\end{array}$ & Lack et al. (2004) \\
\hline$\alpha$-pinene & $\mathrm{C}_{1}-\mathrm{C}_{5}$ and $\alpha$-pinene chemistry & $\begin{array}{l}\text { when saturation vapour pressure } \\
\text { of species is exceeded, aerosol } \\
\text { is formed }\end{array}$ & Bonn et al. (2004) \\
\hline
\end{tabular}

been deposited. More details of the resistance model can be found elsewhere (e.g. Seinfeld and Pandis, 1998; Wesely and Hicks, 2000).

The most critical factor controlling the dry deposition velocity of aerosols is the particle size, aerosol mass density being the second factor affecting sedimentation of the larger particles. Very small particles behave much like gases, making turbulent transport and Brownian diffusion the most efficient removal pathways from the atmosphere, while large particles, due to their weight, the settle to the surface due to gravity, with a gravitational settling velocity $u_{g}$. Mediumsized particles do not have a very efficient removal pathway, and have the longest lifetimes concerning dry deposition. The deposition velocity of particles is calculated based on the following equation:

$u_{d}=\left(r_{a}+r_{b}+r_{a} r_{b} u_{g}\right)^{-1}+u_{g}$

In order to calculate the dry deposition velocity of organic aerosols in climate models, the aerodynamic and the quasilaminar layer resistances need to be calculated directly from the climate routines of the models. The aerodynamic resistance is calculated by integrating the micrometeorological conditions of the lower model layer, such as the momentum, the eddy diffusivity and the friction velocity. The model layer thickness is also taken into account. The aerosol quasilaminar layer resistance calculation is based on the Brownian diffusion, while the gravitational settling velocity is calculated using Stokes Law. More details on these calculations can be found in Seinfeld and Pandis (1998).
The evaluation of dry deposition removal of aerosols in the models remains quite uncertain since it would require eddycorrelation measurements of carbonaceous aerosols which to our knowledge do not exist at present.

As explained above dry deposition gains importance as a loss process for aerosol with increasing particle size since gravitational sedimentation is applicable to coarse particles. In the accumulation range (particles smaller than $2.5 \mu \mathrm{m}$ ) where most OA components seem to be present, it is mainly the wet removal that determines the removal of OA from the atmosphere.

\subsection{Wet scavenging of organic aerosols}

Aerosol is scavenged both in-cloud and below-cloud. The wet scavenging of all aerosols depends on large-scale features such as cloud formation, the conversion of cloud droplets into rain drops, sedimentation and evaporation of rain. Globally, $50-60 \%$ of the earth is covered by clouds, but only $10 \%$ of the clouds are rain clouds. Roelofs et al. (2001) showed that the treatment of wet scavenging was the largest source of uncertainty in global models of the sulphur cycle. Likewise it is expected that wet scavenging of organic aerosol is highly important. In addition to large scale cloud and rain processes, the wet-scavenging also depends on microphysical properties of the aerosol, determining its ability to get included in cloud and rain droplets.

The most important process by which organic aerosol mass is scavenged is formation and removal of cloud condensation nuclei. The Köhler equation describes the aerosol 
nucleation process (Köhler, 1936; Shulman et al., 1996; Seinfeld and Pandis, 1998). Other processes include diffusion scavenging by activated raindrops and impaction by hydrometeors either in the solid phase (ice and snow) or liquid phase. In addition, cloud droplets can be intercepted by larger falling raindrops. All the scavenging processes mentioned above will reduce aerosol number concentrations. This decrease in aerosol numbers is particularly efficient for the accumulation mode.

The entrainment of air in clouds occurs very differently depending on the cloud type: large scale or convective. In the case of convective clouds, air is either entrained at the basis of cloud either between the base and the top through multiple entrainment-detrainment entry points along the tower of the updraft. Whether the aerosol is scavenged by aerosol nucleation or by impaction below cloud from the falling hydrometeors, it is relevant to measure whether the aerosol is in the liquid phase in clouds or in the interstitial air. The partitioning of organics compounds between cloud water and interstitial air in cloud was investigated among others by Facchini et al. (1999a) who concluded that polar soluble compounds were most likely found in fog droplets whereas insoluble compounds remained in interstitial air.

Puxbaum and Limbeck (2000) have measured the scavenging efficiency of different organic compounds at Mt Sonnblick, Austria. Their measurements stress the important role of the polarity in determining the efficiency with which organic compounds are uptaken in cloud droplets (see also Facchini et al., 1999b). Dicarboxylic acids are the most efficient class of organics to be scavenged, with efficiency comparable to that of sulphate. The ratio of the concentration in cloud droplets to the sum of the concentrations in droplets and in interstitial air was measured as 0.8 . For aromatic compounds the same ratio was 0.6 , intermediate between nonpolar alcohols and slightly polar monocarboxylic acids for which about $40 \%$ of the molecules were measured in cloud water.

Hallberg et al. (1992) studied the unscavenged fraction of aerosol in fog droplets. The fraction of elemental carbon was found to be significantly more abundant than for sulfate. The study could not determine whether chemical composition or size distribution was the decisive factor in controlling this difference. A further study (Hallberg et al., 1994a) compared, respectively, soluble, insoluble and soluble with insoluble inclusions aerosol of the same size. Amongst the particles that formed cloud droplets most of them were shown to be soluble. When the partitioning of aerosol particles between cloud droplets and interstitial air was compared during 2 periods of a field experiment, the scavenging efficiency decreased with increasing aerosol loads in the accumulation mode, (Hallberg et al., 1994b). Two processes could explain the size partitionning of aerosols between cloud droplets and interstitial air: the speed of the cloud updaft and/or the difference in particle chemical composition.
The efficiency of aerosol scavenged by snow or ice is particularly uncertain. The interception of aerosols by snow flakes is linked to their shape (see Slinn, 1984 and Hegg et al., 1989). Dendritic shapes and riming snow flakes will efficiently collect aerosols. Capture of aerosols by snow and ice is still poorly described in general circulation models. It follows that the column loads and aerosol vertical distributions at high latitudes are poorly represented in these models. Only a model that predicts the shape of the snow flakes can account for the widely varying efficiency of collection of the aerosol by snow flakes (Jacobson, 2003). Hegg (2001) discusses the efficient scavenging of aerosols in mixed phase clouds. Since hydrophobic aerosols are efficient ice nuclei their scavenging by mixed phase clouds is favoured.

In summary, the high uncertainty in the wet-scavenging of organic aerosol in climate models is related

- to uncertainties in the description of large scale cloud and rain formation processes, and

- to intrinsic uncertainties in the detailed description of the role of organic aerosol in micro-physical cloud and rain processes.

\subsection{Lifetime of carbonaceous aerosols}

The lifetime of carbonaceous aerosols driven by wet and dry deposition depends on the affinity for water of the aerosols (whether they are hydrophobic or hydrophilic, see discussion in Sect. 5). The main sink process for these aerosols is wet deposition which represents 70 to $85 \%$ of the total sink for these species; the other remaining sink is dry deposition.

The AEROCOM intercomparison (http://nansen.ipsl. jussieu.fr/AEROCOM/ global aerosol model intercomparison) that includes the results of 16 global models which represent the main aerosol components showed a range of lifetimes of organic aerosol from 4.3 to 11.1 days with 13 out of these 16 models lying between 5.4 and 8.1 days. The main cause for the variations of aerosol lifetime is the spatial (latitude and altitude) and temporal variation of the precipitation and the vicinity of surfaces for dry deposition. Integrated monthly, the latitudinal variations in lifetime can be as large as a factor of 4 (Balkanski et al., 1993). The variations with altitude are of similar importance since for an aerosol produced in the first kilometer of the troposphere the globally mean lifetime is of approximately 4 days whereas when the aerosol is formed at $10 \mathrm{~km}$ its lifetime increases to 12 days (Balkanski, 1991).

\section{Conversion of hydrophobic to hydrophilic aerosol}

Both chemical and physical ageing processes can lead to an increase in hygroscopicity. Chemical ageing is the chemical modification of the aerosol components due to heterogeneous and liquid phase reactions which may change chain length, 
functional groups, thereby modifying the hygroscopicity of the particles. Physical ageing is due to mixing processes such as coagulation and condensation adding more soluble material and thereby increasing the over-all solubility and hygroscopicity of the particles. The aerosol ageing that converts the hydrophobic to hydrophilic particles is a key process determining the wet removal (see Sect. 4) and hence the residence time and atmospheric burden of carbonaceous particles in the atmosphere.

There is evidence, from in-situ measurements (e.g. Ogren et al. 1984) that anthropogenic carbonaceous aerosol components typically have a longer residence time in the atmosphere than water-soluble aerosol components such as sulphate. Additionally, black carbon which is a component of anthropogenic carbonaceous aerosol is insoluble and inert, yet it is known to be wet deposited. Finally, wet deposition is the dominant process for removing water-soluble aerosols from the entire tropospheric column. Consequently, several models of the black carbon aerosol cycle (e.g. Cooke and Wilson, 1996; Cooke et al., 1999; Myhre et al., 1998; Wilson et al., 2001) have proposed that some or all of the primary emissions of black carbon with associated organic compounds to be hydrophobic and thus not wet deposited, but converting to a hydrophilic, wet depositing form with time. This approach was found to improve the agreement between modelled and observed black carbon concentrations at remote surface stations.

In this section we discuss first the major mixing processes and their respective timescales by which non-hygroscopic particles are converted into hygroscopic ones and then outline actual knowledge on chemical processes that modify the hygroscopic properties of the aerosols.

The following questions need to be addressed:

- What have we learned from measurements of the hygroscopicity of freshly emitted/formed carbonaceous particles (engine combustion, biomass burning, secondary organic aerosol from anthropogenic/biogenic precursors) and aged (accumulation mode) particles?

- For modelling purposes, can we define a "reference hygroscopicity" which defines the transition between hydrophobic and hygroscopic particles, the latter being affected by wet deposition processes and leading to cloud formation?

- What are the processes and time scales converting hydrophobic to hydrophilic particles?

\subsection{Effect of ageing on hygroscopicity}

Fossil fuel as well as biomass burning carbonaceous aerosol immediately after emission is more hydrophobic, becoming more hygroscopic with time. The picture emerging from the 'real-world' data is that in traffic-dominated conditions (street canyon and urban background), a significant fraction
Table 6. Ageing rates applied in global models for BC aerosol from fossil fuel (ff) and biomass burning (bb).

\begin{tabular}{lccc}
\hline & $\begin{array}{c}\text { Ageing rate } \\
\text { constant }\left(\mathrm{s}^{-1}\right)\end{array}$ & $\begin{array}{c}\text { Turn-over } \\
\text { time }^{\$}(\mathrm{~h})\end{array}$ & $\begin{array}{c}\text { \% emissions } \\
\text { hydrophobic }\end{array}$ \\
\hline ff : Cooke and Wilson (1996) & $7.1 \times 10^{-6}$ & 39 & $100 \%$ \\
bb: Cooke and Wilson (1996) & $7.1 \times 10^{-6}$ & 39 & $100 \%$ \\
ff : Cooke et al. (1999) & $7.1 \times 10^{-6}$ & 39 & $80 \%$ \\
ff : Wilson et al. (2001)* & $8.7 \times 10^{-6}$ & 32 & $100 \%$ \\
bb: Wilson et al. (2001) & $7.1 \times 10^{-6}$ & 39 & $50 \%$ \\
\hline
\end{tabular}

* Annual average. Used a size resolving aerosol model and a varying ageing rate dependent upon the $\mathrm{SO}_{4}$ condensation rate onto the hydrophobic $\mathrm{BC}$, monthly average ageing rates varied between $7.7 \times 10^{-6}$ and $1.1 \times 10^{-5}$. Myhre et al. (1998) used the Cooke and Wilson (1996) scheme; Lohmann et al. (1999) used the Cooke et al. (1999) scheme. ${ }^{\$}$ The turn-over time is calculated as the inverse of the ageing rate constant and corresponds to the time needed to convert $63 \%$ of the fresh-hydrophobic aerosol hygroscopic.

of less hydroscopic particles is quasi permanently observed. This fraction decreases with increasing particle size for a given urban site. The fraction of occurrence of these less hygroscopic particles decreases when moving from the urban background (0.35-1) to continental sites $(0.01-0.35)$ of time), down to 0 in remote marine locations. Simultaneously, a population of more hygroscopic particles is always present. (Weingartner et al., 1997; Pagels et al., 2003; Marelli et al., 2003). The concept of a single turnover time from hydrophobic to hydrophilic, can thus describe scale changes from urban to background, or from street canyon to urban, while not necessarily being applicable to the entire spatial scale.

A key issue is nevertheless to evaluate the turn-over time converting particles into hygroscopic ones. Presently, most models are applying first order conversion kinetics of hydrophobic to hygroscopic $\mathrm{BC}$ and $\mathrm{OC}$ with turn over time equal to $0.7-1.2$ days (see Table 6), but are also varying the fraction of primary emissions that are assumed to be hydrophobic in order to arrive at realistic BC and OC burdens.

An important question to address is: which soluble fraction in a mixed particle is needed in order to make a "hydrophobic" particle "hygroscopic"? Applying the Köhler equations (see Appendix A), Pruppacher and Klett (1980) obtained a relation between particle radius, critical supersaturation and soluble fraction for mixed particles consisting of an insoluble core and given fraction of a soluble salt. The equation below is the version of the Köhler equation as given by Weingartner et al. (1997):

$S=\exp \left[\frac{\alpha}{d}\right] \exp \left[-\frac{\beta N_{1}}{\left(d^{3}-d_{0}^{3}\right)}\right]$

where

$S=\mathrm{RH} / 100 \%$

$\alpha=2.155 \mathrm{~nm}$

$\beta=5.712 \times 10^{-2} \mathrm{~nm}^{3}$ 
$N_{1}=$ number of molecules dissociated in the water in the droplet (dimensionless)

$d=$ wet particle diameter $(\mathrm{nm})$

$d_{0}=$ dry (soluble + insoluble) particle diameter $(\mathrm{nm})$

This equation has been used hereafter to derive the amount of soluble mass that has to be "acquired" by an insoluble particle in order to become a cloud condensation nucleus at $0.2 \%$ and $0.3 \%$ supersaturation, respectively. The thus calculated soluble fraction (soluble/(soluble + insoluble)) required for an initially insoluble particle to become a $\mathrm{CCN}$ at 0.2 and $0.3 \%$ supersaturation respectively is depicted in Fig. 4. Due to the competing Kelvin and Raoult terms in the Köhler equation, small particles have to acquire more soluble material relative to their mass than larger ones. However, the required soluble mass per particle is relatively insensitive to the diameter of the initial insoluble particle.

The occurrence of distinct hygroscopicity modes has been investigated and explained by Kerminen (1997), who proposes cloud-processing as the major process adding soluble material to cloud-activated particles and creating a 'more hygroscopic' particle after as few as 2 cloud cycles. A particle can be considered as 'more hygroscopic' and subject to efficient wet deposition once it has become a CCN. Kerminen (1997) argued that coagulation and condensation can not explain the formation of clearly separated hygroscopicity modes. However, they are the main processes that can transform a non- $\mathrm{CCN}$ into $\mathrm{CCN}$ through the mixing between hydrophobic and soluble material, heterogeneous reactions onto aerosol surfaces being an alternative of not yet quantified importance. Neglecting such reactions, the timescales for mixing by condensation of soluble species (sulphate, nitrate, MSA) and coagulation of insoluble with soluble particles (sea-salt, aged sulphate-rich accumulation mode particles) are the ones that will determine the residence time of hydrophobic carbonaceous particles in the atmosphere.

\subsection{Removal of insoluble aerosol by coagulation}

Where fresh hydrophobic carbonaceous particles are formed co-incident with high concentrations of gaseous precursors and photochemical conversion, "Condensation" is likely to be efficient, although in sufficiently high concentrations of gaseous precursors the ageing of hydrophobic particles may also occur through secondary particle formation and coagulation. The presence of a high concentration of pre-existing accumulation mode particles however, scavenges an important fraction of the condensable material and delays the growth of the hydrophobic particles. Hence, there is competition between coagulation, condensation and heterogeneous reactions on aerosol surfaces as ageing processes, depending on the magnitude of the accumulation mode, the availability of condensable species, the chemical properties of the particle surface and the oxidant levels. These different regimes can be investigated by field and model studies.

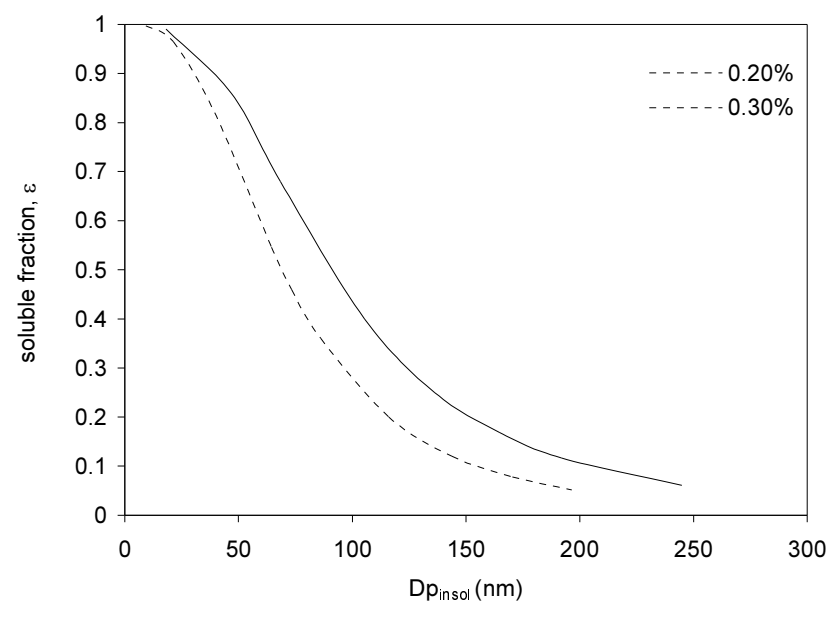

Fig. 4. Soluble fraction to be acquired by initially insoluble particles in order to become $\mathrm{CCN}$ at $0.2 \%$ and $0.3 \%$ supersaturation respectively, as a function of the insoluble particle diameter (applying the Köhler equations).

In the absence of high concentrations of gaseous precursors, coagulation is the more important conversion process. Where large concentrations of more-hygroscopic accumulation mode particles are present, freshly formed carbonaceous particles will be scavenged by these, without significant changes in the hygroscopicity of the pre-existing, particles. Where the pre-existing particles are smaller Nucleation or Aitken mode particles then, the hygroscopicity of the coagulated particles may indeed change.

Modelling studies have focussed on coagulation as a major process leading to mixed, more hygroscopic particles (Ström et al., 1992; Fassi-Fihri et al., 1997). Riemer et al. (2003) modelled explicitly the mixing between soot and soluble salts by coagulation and condensation in a 3-D case study over Germany and obtained a 2 hour turn-over time for soot during day-time (dominated by condensation) and a $20 \mathrm{~h}$ turn-over time during the night (dominated by coagulation). Wehner et al. (2002) applied a simple model with condensation, coagulation and entrainment with background and freshly emitted urban aerosol to successfully explain the transition of a street canyon aerosol size distribution to urban background on a time scale of less than $1 \mathrm{~h}$.

The time scales for mixing between fresh hydrophobic particles and hygroscopic material by condensation and coagulation can be investigated relatively simply for various conditions. Here we examine the coagulation between preexisting accumulation mode particles and fresh carbonaceous particles in order to provide an upper limit to the turn over time, and compare that with condensation as a lower. The case of coagulation with smaller freshly formed soluble particles, will fall between these two. According to the Köhler equation, the critical diameter for an ammonium sulphate particle at $0.2 \%$ supersaturation (SS) is equal to $80 \mathrm{~nm}$, coag- 


$$
\mathrm{SO}_{2}=200 \mathrm{ppt}
$$

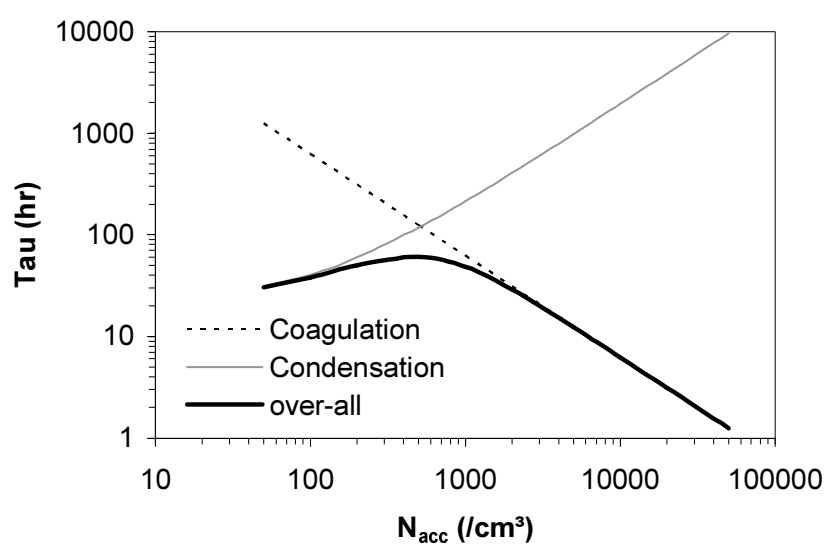

Fig. 5. Turn-over time to convert hydrophobic particles with initial concentration of $1000 \mathrm{~cm}^{-3}$ and diameter $50 \mathrm{~nm} \mathrm{CCN}(0.3 \%)$ by coagulation (dashed line) and condensation (full gray line), as a function of accumulation mode concentration $\left(D_{a c c}=150 \mathrm{~nm}\right)$. Condensation is assumed to be controlled by the formation rate of $\mathrm{H}_{2} \mathrm{SO}_{4}$ with $\mathrm{SO}_{2}=200 \mathrm{ppt}$ and $\mathrm{OH}=2 \times 10^{6}$ molecules $\mathrm{cm}^{-3}$. The combined turn-over time is indicated in the full black line. (Applying Eqs. 12-17.)

ulation between a hydrophobic particle of any diameter $\left(\mathrm{D}_{p}\right)$ with soluble accumulation mode particles with $\mathrm{D}_{p}>80 \mathrm{~nm}$ will result in a $\mathrm{CCN}$ at $0.2 \% \mathrm{SS}$. The turn-over time for internal mixing by coagulation is given by:

$\tau_{C O A}=\frac{1}{k_{12} N_{a c c}}$

with $k_{12}$ the effective coagulation coefficient between hydrophobic and hygroscopic accumulation mode particles, and $N_{a c c}$ the number concentration in the accumulation mode. $\tau_{C O A}$ is the time needed to coagulate $63 \%$ of the hydrophobic particles. We assume here that the mixing process reduces the number of hydrophobic particles without changing the number of hydrophilic ones. It does not convert hydrophobic to hydrophilic with regard to the aerosol number concentration.

The characteristic time for internal mixing by condensation depends on the source rate of the condensing species (e.g. $\mathrm{H}_{2} \mathrm{SO}_{4}$ ), on the scavenging rate by the background (accumulation mode) aerosol, and on the size of the initial hydrophobic particles. Assuming that the partitioning of the condensing soluble species happens proportionally to the particle surface area, the total mass required by condensation $\left(M_{\text {tot }}\right)$ is given by:

$M_{t o t}=M_{h f}\left(1-\frac{N_{a c c} D_{a c c}^{2}}{N_{h f} D_{h f}^{2}+N_{a c c} D_{a c c}^{2}}\right)^{-1}$

and $M_{h f}$ the mass of insoluble particles is given by:

$M_{h f}=\rho \frac{\varepsilon}{1-\varepsilon} \frac{\pi}{6} N_{h f} D_{h f}^{3}$ (b)

$$
\mathrm{N}_{\mathrm{hf}}=1000 \mathrm{~cm}^{-3}, \mathrm{D}_{\mathrm{hf}}=50 \mathrm{~nm}, \varepsilon=0.68
$$

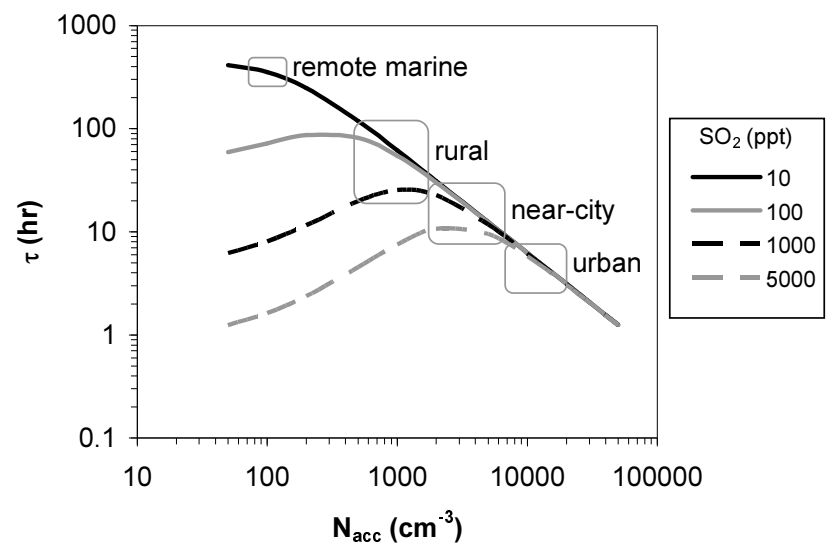

Fig. 6. Turn-over time to convert hydrophobic particles to $\mathrm{CCN}$ in clean and polluted conditions for different initial conditions of the hygrophobic mode. $\varepsilon$ is the required soluble fraction for the particles in order to activate at $0.3 \% \mathrm{SS}$. Condensation is assumed to be controlled by the formation rate of $\mathrm{H}_{2} \mathrm{SO}_{4}$ with $\mathrm{SO}_{2}=200 \mathrm{ppt}$ and $\mathrm{OH}=2 \times 10^{6}$ molecules $\mathrm{cm}^{-3}$.

hence

$M_{t o t}=\rho \frac{\varepsilon}{1-\varepsilon} \frac{\pi}{6} N_{h f} D_{h f}^{3}\left(1-\frac{N_{a c c} D_{a c c}^{2}}{N_{h f} D_{h f}^{2}+N_{a c c} D_{a c c}^{2}}\right)^{-1}$

with

$\rho=$ the density of the condensing species

$\varepsilon=$ the required soluble fraction to convert an initially insoluble particle of diameter $D_{h f}$ into a $\mathrm{CCN}$ at a given supersaturation (given by the Köhler equation)

$N_{h f}=$ the number concentration of insoluble (hydrophobic) particles

$N_{a c c}=$ the number concentration of soluble particles in the accumulation mode of diameter $D_{a c c}$

The (e-folding) time for condensation of $63 \%$ of the required mass is then given by:

$\tau_{C O N}=\frac{0.63 M_{t o t}}{F}$

with $F$ the mass source rate for $\mathrm{H}_{2} \mathrm{SO}_{4}$ formation.

The over-all turn-over time $\tau$ for bringing insoluble aerosol in the soluble mode both by coagulation and condensation is then given by

$\tau=\left(\frac{1}{\tau_{C O A}}+\frac{1}{\tau_{C O N}}\right)^{-1}$

The competition between condensation and coagulation is clearly demonstrated in Fig. 5: At the given $\mathrm{SO}_{2}$ and $\mathrm{OH}$ levels ( $200 \mathrm{ppt}$ and $2 \times 10^{6}$ molecules $\mathrm{cm}^{-3}$, respectively) the maximum turn-over time $\tau$ to convert a $50 \mathrm{~nm}$ insoluble particle into a $\mathrm{CCN}$ at $0.2 \% \mathrm{SS}$ is $60 \mathrm{~h}$, when $\mathrm{N}_{a c c}=500 \mathrm{~cm}^{-3}$. For higher and lower values of $\mathrm{N}_{a c c}, \tau$ becomes lower. 
A proper evaluation of $\tau$ requires a consistent application of values for $\mathrm{SO}_{2}$ and $\mathrm{N}_{a c c}$, which obviously depend strongly on the type of location. Figure 5 shows $\tau$ as a function of $\mathrm{N}_{a c c}$ (hygroscopic accumulation mode) for various $\mathrm{SO}_{2}$ concentrations and initial properties of hydrophobic particles with initial diameter $\mathrm{D}_{h f}=50 \mathrm{~nm}$ and $\mathrm{N}_{h f}=1000 \mathrm{~cm}^{-3}$. Typical $\left[\mathrm{SO}_{2}, \mathrm{~N}_{a c c}\right]$ ranges for marine to urban conditions are indicated on the graphs. It appears that, in urban and nearcity conditions, $\tau$ is completely controlled by coagulation, whatever the $\mathrm{SO}_{2}$ concentration, with turn-over times from minutes to some hours. Smaller particles have a shorter lifetime for otherwise identical conditions.

In the coagulation-controlled regime, $\tau$ is independent of $\mathrm{N}_{h f}$. This is the case for all situations in Fig. 6 that shows that this turn-over time could be strongly reduced (condensation - controlled) if higher $\mathrm{SO}_{2}$ concentrations (or other soluble, condensable material) prevailed. The turn-over time for marine conditions is of the order of several days to weeks. This would, e.g. apply to particles from ship emissions, which can survive for long time.

The turn-over times for rural and near-city conditions correspond to the ageing rates applied in the models cited above. However, most of the traffic and industrial related emissions are confined to the urban environment where a fast initial ageing phase takes place. Hence, some hours after emission when the urban plume starts to disperse on regional scale, most of the conversion has already happened.

\subsection{Chemical ageing of aerosols}

As above mentioned, conversion of hydrophobic to hygroscopic particles can also occur via chemical ageing i.e. heterogeneous chemical reactions on the surface of the particles. These reactions can alter the chemical composition of the particles forming for instance more polar, hygroscopic products than the precursor particulate material. The understanding and the documentation of these processes is actually in its infancy.

Rudich (2003) has published a comprehensive review of some of the laboratory studies that have been conducted the last years to characterize the chemical processing of organic aerosol. Since then more thorough studies have been performed particularly on the reactions of ozone and $\mathrm{OH}$ with organic surfaces and aerosols, most notably on oleic acid aerosol particles and multicomponent particles. These studies used well-defined laboratory models to identify the kinetics, reaction mechanisms and implications for the $\mathrm{CCN}$ activity of organic aerosols (Moise and Rudich, 2002; Smith et al., 2002; 2003; Katrib et al., 2004; Vieceli et al., 2004; Molina et al., 2004).

Römpp et al. $\left(2005^{1}\right)$ suggested that oxidation of linear dicarboxylic acids $\left(\mathrm{C}_{9}-\mathrm{C}_{11}\right)$ by $\mathrm{OH}$-radicals yields various iso-

\footnotetext{
${ }^{1}$ Römpp, A., Winterhalter, R., Berresheim, H., and Moortgat, G. K.: Oxodicarboxylic acids in atmospheric aerosol, Atmos. Environ., submitted, 2005.
}

mers of oxodicarboxylic acids. The oxidation occurs in the particle phase. The formed acids are more polar and hygroscopic than the parent dicarboxylic acids. The ratio of oxodicarboxylic acids to the parent dicarboxylic acid measured in aerosol field samples at two locations in Europe showed good correlation with $\mathrm{OH}$-radical concentrations.

Ozone reactions with organic particulate mater in the form of soot or organic acid films or organic aerosols have been shown to alter the chemical properties of the aerosol surfaces. Chughtai et al. (1999) found that surface oxidation of soot by reaction with $\mathrm{O}_{3}$ increases the hydration of the particles. Studies of diesel particles coated by benzo $(a)$ pyrene $(\mathrm{BaP})$ have demonstrated that during exposure to $\mathrm{O}_{3}$ the particles become more hydrophilic (Weingartner et al., 1997; Kotzick and Niessner, 1999) with a rate (r) that depends on the $\mathrm{O}_{3}$ levels. The presence of $\mathrm{H}_{2} \mathrm{O}$ serves as an inhibitor by competitive adsorption on the soot active sites. Pöschl et al. (2001) based on laboratory experiments have proposed a pseudo-first-order decay rate coefficient (r) for BaP reaction with $\mathrm{O}_{3}$ that depends on ozone concentrations, the adsorption rate coefficient of $\mathrm{O}_{3}$ that serves as the oxidation medium and the adsorption rate coefficient of $\mathrm{H}_{2} \mathrm{O}$ that serves as an inhibitor by competitive adsorption.

Based on that parameterisation, Tsigaridis and Kanakidou (2003) tentatively calculated a chemical turn-over time for the conversion of hydrophobic soot coated by BaP to hydrophilic that varies spatially due to the $\mathrm{O}_{3}$ and water vapour variability from a few hours to about 10 days with a mean tropospheric value of about a day. This has to be viewed with caution since not all soot is coated by $\mathrm{BaP}$ and other heterogeneous reactions might take place on soot and be responsible for chemical conversion of hydrophobic to hydrophilic aerosol in the atmosphere.

Moise and Rudich (2002) detected aldehydes as the major volatile product of reactions of $\mathrm{O}_{3}$ with aerosols with a fatty acid component. Eliason et al. (2003) found that ozonolysis of long chain unsaturated carboxylic (fatty) acids leads to smaller molecules of higher hygroscopicity (mainly aldehydes and carboxylic acids) that can stay in the aerosol phase or escape to the atmosphere (Eliason et al., 2003, 2004). Molina et al. (2004) investigated the $\mathrm{OH}$-initiated oxidation of solid organics in the presence of $\mathrm{O}_{2}, \mathrm{NO}_{\mathrm{x}}$ and $\mathrm{H}_{2} \mathrm{O}$ and detected small gas phase products including $\mathrm{CO}, \mathrm{CO}_{2}$, $\mathrm{CH}_{2} \mathrm{O}, \mathrm{CH}_{3} \mathrm{CHO}, \mathrm{CH}_{3} \mathrm{OH}$, and $\mathrm{HCOOH}$ that escape from the aerosol phase by volatilisation. However, acid-catalysed heterogeneous reactions of aldehydes on diesel soot might increase the aerosol mass by making them less volatile but the overall modification of the hygroscopic properties of the resulting organic material will depend on the oxidation mechanism. Hydration, hemiacetal and acetal formation, polymerization and aldol condensation have been proposed as potential mechanisms to explain the observed acid-catalysed heterogeneous reactions of organic mater (Jang et al., 2003; Iinuma et al., 2004). 
Katrib et al. (2004) suggest new reaction pathways for the formation of large molecular weight products in the ozonolysis reactions of oleic acid. This new reaction pathway involves reactions of Criegee intermediates in the condensed phase with aldehydes, ketones and alkenes and it does not involve acidity. Kawamura et al. (1995, 1996, 2005) and Narukawa et al. (2003) provide experimental evidence that $\mathrm{Br}$ chemistry in the Arctic transforms unsaturated diacids to smaller saturated acids. Ozonolysis of oleic and linoleic acid is shown to contribute to activation of particles to cloud droplets (Broekhuizen et al., 2005). Reactions of $\mathrm{OH}, \mathrm{NO}_{3}$, $\mathrm{Cl}$ and $\mathrm{Br}$ radicals with organic layers have been found to change the hygroscopicity of the surfaces as measured by contact angle and microbalance methods (Demou et al., 2003; Eliason et al., 2003; Rudich et al., 2000; Moise and Rudich, 2001).

- These heterogeneous reactions modify the aerosol mass and its hygroscopic properties and affect the gas phase chemistry in the atmosphere.

- The consideration of such reactions in global climate models is crucial for the better representation of the ageing of aerosols and of their ability to act as $\mathrm{CCN}$ but requires a better than the actual understanding of the mechanisms involved.

In addition to these mechanisms, chemical ageing of aerosols occurs during cloud processing of particles, relevant knowledge is summarized in the next section. Recently, Maria et al. (2004) on the basis of observational growth rates of atmospheric particles, evaluated that consideration of such surface- and volume- limited chemical reactions should increase the carbonaceous particle burdens in climate models by $70 \%$.

\section{Chemical interactions with clouds - cloud processing}

More than $60 \%$ of the total sulphate on a global scale is estimated to be produced in clouds (Langner and Rodhe, 1991; Liao et al., 2003). It has been shown in several studies that the production of sulphate in cloud drops can contribute significantly to the aerosol mass (e.g., Chameides and Stelson, 1992; Hegg et al., 1996; Zhang et al., 1999) and may lead either to an enhancement or to a suppression of the cloud drop number concentration (Feingold and Kreidenweis, 2000). The dissolution into cloud drops leads to a separation of soluble and insoluble species, respectively, and possibly to different reaction pathways. Dissolved species will be released to the gas phase after evaporation of the cloud. However, they may undergo chemical conversions in the aqueous phase changing their physical properties (e.g., vapour pressure) and/or chemical properties (e.g., ability to form low volatility adducts). The importance of chemical conversions in the tropospheric aqueous phase (i.e., clouds and fogs) leading to inorganic secondary aerosol mass production (in particular sulphate) is recognized. On the contrary, the significance of such mechanism for SOA production is not yet well established and therefore is not included in large scale models.

The water soluble fraction of organic carbon can consist on average of 35\% of mono- and dicarboxylic acids (Decesari et al., 2000). In urban environments dicarboxylic acids contribute $1 \%$ of the aerosol mass; in less polluted regions the contributions can be higher, with average values of $\sim 7-20 \%$ and even up to 30-50\% (Satsumbayashi et al., 1989, 1990). Major components in this group are small dicarboxylic acids $\left(\mathrm{C}_{2}-\mathrm{C}_{6}\right)$ with oxalic acid being the major compound with fractions of about $50 \%-75 \%$ of the total dicarboxylic acid mass found in rainwater (Sempéré and Kawamura, 1996) as well as aerosol samples in the marine boundary layer (Kawamura and Sakaguchi, 1999). Observations by Baboukas et al. (2000) in the marine boundary layer have revealed that at relative humidities around $80 \%$ about $30 \%$ of oxalic and $46 \%$ of pyruvic acid are present in the gas phase.

In general, enhanced oxidant concentrations have been detected in the interstitial parts of clouds which facilitate the efficient oxidation of organic trace gases there which leads to small aldehydes, alcohols, monocarboxylic acids, and acetone (Blando and Turpin, 2000). Yao et al. (2002) found a clear correlation between the sulphate mass size distribution and those for oxalate, malonate and succinate. Both sulphate and dicarboxylic acids accumulate in the drop mode, i.e. particles which acted as cloud condensation nuclei and, thus, were processed by clouds. Similar observations were made by Mochida et al. (2003a) showing bimodal mass distributions for both $\mathrm{C}_{2}-\mathrm{C}_{4}$ dicarboxylic acids and sulphate, respectively. The modification of the larger size aerosol mode was ascribed to mass addition in clouds. Based on correlations of concentrations in both the gas and particle phase, Mochida et al. (2003b) conclude that the precursors for these dicarboxylic acids might have anthropogenic origin. Another indicator for cloud processing is the presence of hydroxymethanesulfonate $\left(\mathrm{HMS}^{-}\right.$) in mixed dicarboxylic acid/sulphate particles (Lee et al., 2002, 2003). Since HMS ${ }^{-}$ is exclusively formed within the aqueous phase it is likely that other constituents of these particles also originate from cloud processing. All these observations suggest that chemical processing within atmospheric aqueous aerosols might contribute to secondary organic aerosol formation.

Kawamura and Sakaguchi (1999) using principal component analysis of individual diacid, coupled with information on photochemical reactions, suggest that $\mathrm{C}_{2}$ and $\mathrm{C}_{3}$ diacids present in aerosols are likely produced by the oxidation of $\mathrm{C}_{4}$ and longer-chain diacids, whereas longer-chain $\left(\mathrm{C}_{5}-\mathrm{C}_{10}\right)$ diacids are produced through the oxidation of semivolatile fatty acids which are also oxidation products of unsaturated fatty acids. Oxygenated organics have Henry's law Constants of $\mathrm{K}_{H} \approx 100 \mathrm{M} \mathrm{atm}^{-1}$ (alcohols) up to $\mathrm{K}_{H} \approx 10^{9} \mathrm{M} \mathrm{atm}^{-1}$ (di-, and ketocarboxylic acids) (Sander, 1999). Thus, the 
aqueous phase might represent a significant sink for the few highly water soluble organic species that exist in the atmosphere. Aumont et al. (2000) have calculated that difunctional organic compounds, which are formed either in the gas or aqueous phase, are preferable in the gas phase. Only organics with three or more functional groups (e.g., hydroxy and/or carbonyl compounds) have a vapour pressure sufficiently low to enable significant partitioning into the aqueous phase. However, the chemical pathways in their model cannot predict the high amounts of dicarboxylic acids found in aerosol samples.

Graedel and Weschler (1981) give a detailed overview of chemical conversions of organics in aqueous atmospheric aerosols. They show that aldehydes in the gas phase might act as precursors for organic acid formation in the aqueous phase which is reflected in similar concentration patterns for both species groups. These oxidation processes are faster and more efficient in the aqueous phase due to hydration effects, while in the gas phase photooxidation of aldehydes usually leads to the loss of the carbonyl function. Chebbi and Carlier (1996) suggest that high concentrations of glyoxal and methylglyoxal in clouds might act as precursors for oxalic and pyruvic acid formation, respectively. Warneck (2003) suggested that in marine environments ethylene and acetylene may act as gas phase precursors of oxalic acid in the aqueous phase via the formation of glyoxal that is dissolved and reacts in the aqueous phase. Glyoxal can be also produced from the oxidation of aromatics. Thus the proposed mechanism of oxalic acid formation is also valid under polluted conditions. It seems likely that oxalic and pyruvic acids may be formed in clouds and are released upon evaporation. Up to now there is no comprehensive mechanism available predicting their formation in the gas phase.

Recently detailed chemical multiphase mechanisms have been suggested in order to elucidate oxalate formation in clouds. Herrmann et al. (2000) and Ervens et al. (2003) developed the Chemical Aqueous Phase Radical Mechanism (CAPRAM) for modelling tropospheric multiphase chemistry that contains a detailed treatment of the oxidation of organic compounds with one and two carbon atoms. Possible pathways for the formation of small dicarboxylic acids are included in the chemical mechanism by Ervens et al. (2004) where toluene, ethylene, isoprene and cyclohexene are assumed as gas phase precursors. The kinetics of aqueous phase reactions relevant for atmospheric chemistry have been recently reviewed by Herrmann (2003) including spectroscopic data of a significant number of peroxy-radicals in aqueous solution and kinetic data for $\mathrm{OH}$ and $\mathrm{NO}_{3}$ radical reactions in aqueous solution, for various organic molecules like carbonylic and carboxylic compounds, phenols and amines. However, the current state of chemical mechanism development for aqueous phase chemistry is quite limited due to the lack of appropriate rate constants and, to a greater extent, results of product studies (Herrmann, 2003).
Beside the formation of low volatility organics in clouds, and, thus, modification of the mass and hygroscopic properties of aerosols, the absorption properties of aerosols might also be changed by cloud processing. Keto- and dicarboxylates likely form complexes with transition metals, in particular, with iron and copper (Zuo and Hoigné, 1992, 1994). In contrast to the 'free' dicarboxylates, these complexes absorb light in the visible range leading to photo-oxidation of the organics. In addition, it has been shown by Gelencsér et al. (2003) that hydroxyl substituted aromatic compounds can be oxidized to humic-like substances in aqueous solution which are light-absorbing in the visible range as well. However, these effects are not yet included in complex cloud radiation models so that the overall effect of this phenomenon cannot be quantified.

In summary,

- At the current state of model development the role that cloud chemistry plays with respect to organic mass production, compared to other processes, cannot yet be determined.

- The chemical mass production processes seem to be restricted to dicarboxylic acids. Other fractions of the water soluble organic carbon consisting of neutral and polyacidic compounds (Decesari et al., 2000) probably have other sources.

- Processing of organic species in cloud droplets might influence both the direct and indirect effect of aerosols by modifying the mass (i.e. size) and the composition and thus the physical characteristics (like hygroscopic and radiative properties) of the aerosol. This latter might be the most important effect of cloud organic chemistry.

- Despite the potential importance of the tropospheric aqueous phase with respect to organics, this process is not included in global models.

\section{Organic aerosol and water interactions}

The water uptake by the organic aerosol components and their interactions with the inorganic salts dissolved in the same aqueous solution changes the aerosol water concentration and the resulting aerosol properties. At the same time, the extent of the partitioning for any individual organic compound between the gas and particulate phases depends not only on the amounts and properties of the compound, but also on the amount of water present in the atmosphere. Understanding the effects of aerosol water on SOA formation and vice versa is, therefore, central to understanding the SOA formation and role in the atmosphere.

The aerosol hygroscopicity is commonly expressed by the growth factor (GF) that is the ratio between the humidified 
and dry particle diameter at a reference relative humidity (RH). Most (but not all) recent studies have been obtained at or converted to a reference humidity of $90 \%$. For pure substances, the hygroscopic diameter or mass growth of aerosol particles can be calculated if the concentration of the solute material as function of the water vapour pressure ratio (partial pressure of water vapour divided by saturation water vapour pressure) over the particle surface is known. For flat solution surfaces or for large particles, this water vapour pressure ratio is equal to the $\mathrm{RH}$, which can be measured at some distance from the particle. For particles smaller than a few hundred nanometres in diameter, the water vapour pressure ratio that the particles senses - the water activity of the solution - is smaller than the RH away from the particle. The correction factor is given by the Kelvin term, as described by the Köhler equation (Appendix A - Eq. A1).

Data on the relation between solute concentration and water activity (or RH) is therefore crucial for these calculations. If all solutions behaved ideally, this would simply be given by Raoult's law, and would be quite straightforward to estimate from basic chemical solute data. Raoult's law simply states that the water activity (or equilibrium RH) over the solution is given by the ratio of the moles of water molecules to the moles of all molecules in the solution (water molecules plus all dissolved ions and/or molecules other than water). Various formulations of Raoult's law are used in most calculations of aerosol particle activation into cloud droplets, since the solutions are normally sufficiently diluted at the point of activation. However, since most solutions deviate from ideal behaviour empirical data on water activity versus solute concentration are needed. Additional important thermodynamic data needed to describe hygroscopic growth are densities (dry solute and solution), surface tension, and for some substances also solute vapour pressures for aqueous solutions.

Here, we will review the existing data describing the water activity as a function of solute concentration for pure organic compounds, their mixtures and mixtures of organic and inorganic compounds.

The solute concentration is normally given as mole fraction of solute (moles of solute per moles of solute plus water) or molality (moles of solute per kg of water). Water activity data for a wide range of inorganic substances can be found in the literature (for instance: Robinson and Stokes, 1959; Tang et al., 1997 and references therein), and will not be discussed here.

Corresponding data for water soluble organic compounds relevant to atmospheric applications are rather scarce in comparison, partly because organic compounds were previously not considered important for the hygroscopic and cloudforming properties of atmospheric aerosols, and also because organic compounds are more difficult to measure than inorganic compounds, especially the low-molecular weight organics due to their high volatility.
7.1 Water activity data for organic compounds: laboratory work on individual compounds

Instrumentation: Measurements of water activity as function of organic solute concentration can be performed either on bulk solutions or on suspended particles. While bulk measurements, using commercially available and highly accurate water activity meters, can only provide data for saturated solutions or more dilute, the methods based on observations of suspended solution particles are able to quantify the water uptake also for highly supersaturated solutions that would rapidly crystallize in the bulk. Since it is likely that supersaturated solutions are found in atmospheric aerosols, data for supersaturated solutions are highly relevant, but these studies involve the use of non-commercial instrumentation such as an electrodynamic balance (EDB; Peng et al., 2001) or a Hygroscopic Tandem Differential Mobility Analyzer (HTDMA; Mikhailov et al., 2004). The RH to which the suspended particles are subjected can be varied over a wide range in both these instruments ( $\sim 0 \%$ to $\sim 99 \%)$, and can thus be used to study the full $\mathrm{RH}$ hysteresis behaviour of a multitude of relevant compounds and mixtures. The EDB relies on the balancing of gravitational forces and normally requires the suspended particles to be larger than a few $\mu \mathrm{m}$ in diameter, while the HTDMA technique separates particles according to their electrical mobility and is optimal for submicrometer particles. Special-design HTDMA instruments have been used to particle sizes down to $10 \mathrm{~nm}$ or less. Since the Kelvin curvature correction term is substantial for these ultra fine particles, the HTDMA can give some additional insight regarding particle surface tension. The scanning EDB is a recent improvement of the traditional EDB, allowing much faster water activity measurements to be performed over a wide range of RH, and facilitates studies of semi-volatile organic compounds (Choi and Chan, 2002b).

For both the EDB and HTDMA, a reference state of known composition must be chosen. There are two possibilities (1) a dehydrated particle at low $\mathrm{RH}$, and (2) a droplet at high $\mathrm{RH}$ for which water activity data is available or can be measured in bulk solution. The choice of reference state can be problematic for compounds for which bulk water activity data are not available and for which the particles are suspected to retain water even at very low RH.

The HTDMA instrument is a flow-through system, producing data on the distribution of hygroscopic diameter growth for a large number of aerosol particles for each particle dry diameter and RH. This instrument is therefore well suited for field studies of the hygroscopic properties of atmospheric aerosol particles, and numerous such studies using HTDMA instruments have been carried out in a variety of environments. The EDB relies on the capture of a single particle in an electric field, and is only suited for laboratory studies. The HTDMA and EDB instruments are therefore in many ways complementary for studies of particle water uptake. 
Available data: Bulk data for the water activity and other thermodynamic properties are available for a large number of organic compounds. References are given in Saxena and Hildemann (1997), who point to, in particular, the extensive data compilation of the Dortmund Data Bank DECHEMA (Gmehling et al., 1994). These data will not be discussed further here, but nevertheless constitute a valuable resource for water activity data for organic compounds at solute concentrations below saturation. The water activity data obtained with EDB and HTDMA instruments are summarized in Table 7 .

Table 7 is structured per organic compound studied and includes humic-like substances (HULIS): humic and fulvic acids, organic acids, mostly dicarboxylic acids, and some organic compounds that do not dissociate in solution such as sugars, organic salts, and finally pharmaceutical compounds. This data compilation was limited to include only well-defined WSOC or mixtures thereof, also in mixtures with inorganic compounds of atmospheric relevance. It does not include studies of $\mathrm{CCN}$ properties of organic compounds. The studies in Table 8 present, either water activity as a function of solute concentration, or hygroscopic particle growth in some form.

Since this field of research is rather new, most of the work cited was published within the last few years only. The interest in the hygroscopic properties of WSOC started somewhat earlier in the pharmaceutical sciences owing to their importance for lung deposition and drug administration, and was reviewed already in 1993 by Hickey and Martonen (1993). Most of the earlier EDB and HTDMA studies focussed on inorganic compounds such as sulphates and nitrates, and are not discussed here. Several of the studies present only qualitative results (Brooks et al., 2002; Brooks et al., 2003; Lightstone et al., 2000; Braban et al., 2003; Marcolli et al., 2004). Hansson et al. (1998) used a TDMA to examine the effect of tetracosane, octanoic acid, and lauric acid on the hygroscopic properties of $\mathrm{NaCl}$ aerosol particles at $\mathrm{RH}$ between 30 and $95 \%$. A slight lowering of the deliquescence relative humidity, DRH and suppression of hygroscopic growth for the $\mathrm{NaCl}$-organic compound mixtures were observed when compared to pure $\mathrm{NaCl}$ particles. Despite the mixing of the organic material with $\mathrm{NaCl}$, hysteresis was observed for decreasing RH histories, suggesting the formation of metastable droplets. Few parameterisations are given showing that this field is still in its infancy. However, parameterisations are needed for implementation in models of water uptake by organic compounds, or can be used to test the quality of the published results in repeat experiments.

- We strongly recommend efforts to derive parameterisations of water activity versus solute concentration (molality or mole fraction of solute) from the available data and in all future studies. HTDMA parameterisations given as hygroscopic diameter growth factor as function of relative humidity should preferably be recalcu- lated and presented as water activity versus solute concentration. Error estimates should be clearly stated in parameterized form that can easily be incorporated into models.

In several of the studies, the applicability of the ZdanovskiiStokes-Robinson (ZSR) mixing rule was tested to examine the water uptake of well-defined mixtures, and to deduce interaction terms to be used in models (Chan and Chan, 2003). The ZSR method assumes that no interaction occurs between the various compounds of the solution, and is equivalent to adding the amount of water taken up by the individual compounds (relative to their mass or molar fractions) in order to calculate the water uptake of the mixture. In most cases, the ZSR mixing rule works fairly in describing the water uptake of both organic-organic and organic-inorganic mixtures and can be used as a first approximation. There are however large deviations in some cases, which are difficult to account for. Deviations from the simple water additivity of the ZSR mixing rule have been studied and are often discussed in terms of the ability of the organic compounds for "salting in" or "salting out", or in other words whether the presence of the organics increases or decreases the water uptake of the solution due to interactions between the organic and the inorganic compounds. Organics were observed to decrease the water uptake by $\mathrm{NaCl}$ but increase that of ammonium sulphate (Prenni et al., 2003; Choi and Chan, 2002a; Cruz and Pandis, 2000). The dissociation behaviour of the organic compounds needs to be taken into account when studying their water activity and $\mathrm{CCN}$ properties.

It can be proven theoretically that the mutual DRH of an aerosol particle consisting of a mixture of compounds is always lower than the DRH of the individual compounds. This was noted by Wexler and Seinfeld (1991) to be valid for inorganic compounds. Marcolli et al. (2004) extended this theory to organic compounds and argued that a mixture of several organics, as is likely to appear in atmospheric aerosol particles, may remain in the liquid phase and retain water even at very low RH. In other words, the DRH of the organic mixtures or organic-inorganic mixtures is depressed. This is in general agreement with field observations. This behaviour is potentially of great importance for atmospheric applications, since it means that a liquid aqueous phase would nearly always be present, affecting the radiative properties of the aerosol and possibly also affect the overall aqueous phase reaction rates. This can also explain the observation that

- Organic compounds contribute to water uptake most significantly at low RH, while at high $\mathrm{RH}$, the inorganics dominate see for instance Dick et al. (2000).

- For mixtures of poorly soluble organics and inorganics, the lowering of DRH is small or negligible (Cruz and Pandis, 2000), while for more soluble organic compounds, the effect is clearly noticeable (Brooks et al., 2002). 
Table 7. Compilation of literature with water activity data of WSOC, pharmaceutical compounds and organic salts.

\begin{tabular}{|c|c|c|c|c|}
\hline WSOC & Reference & Instru-ment & Data & Comment \\
\hline \multirow[t]{3}{*}{ Adipic acid } & $\begin{array}{l}\text { Prenni et al. } \\
\text { (2001) }\end{array}$ & HTDMA & $\begin{array}{l}\text { GF (0.45-0.93) Data in figures only } \\
\text { and } \mathrm{GF} \text { at } \mathrm{RH}=80 \%, 90 \%\end{array}$ & $\begin{array}{l}\text { GF parameterisation presented } \\
\text { in Prenni et al. (2003). }\end{array}$ \\
\hline & $\begin{array}{l}\text { Marcolli et al. } \\
\qquad(2004)\end{array}$ & $\begin{array}{l}\text { Water } \\
\text { activity } \\
\text { meter }\end{array}$ & $\begin{array}{l}\text { aw-molality data only for certain } \\
\text { mixtures at mutual DRH, Some } \\
\text { additional data in figures, no } \\
\text { parameterisation }\end{array}$ & $\begin{array}{l}\text { Bulk measurements. Mixtures } \\
\text { only (organics, organics- } \\
\text { inorganics). In mixtures with } \\
\text { AmmSulf, AmmNitr and } \mathrm{NaCl}\end{array}$ \\
\hline & $\begin{array}{l}\text { Hämeri et al. } \\
\text { (2002) }\end{array}$ & HTDMA & $\begin{array}{l}\text { Data in figures only, no } \\
\text { parameterisation }\end{array}$ & In mixtures with AmmSulf only \\
\hline Alanine & Na et al. (1995) & EDB & $\begin{array}{l}\text { Water activity parameterisation, } 5 \text { th } \\
\text { order polynomials }\end{array}$ & \\
\hline $\begin{array}{l}\text { Bovine serume } \\
\text { albumin proteine }\end{array}$ & $\begin{array}{l}\text { Mikhailov et al. } \\
\qquad(2004)\end{array}$ & HTDMA & $\begin{array}{l}\text { BSA: Data compared with water } \\
\text { activity parameterisation based on } \\
\text { osmotic potentials }\end{array}$ & $\begin{array}{l}\text { Also in mixtures with } \mathrm{NaCl} \text { and } \\
\text { AmmNitr }\end{array}$ \\
\hline \multirow[t]{2}{*}{ Citric acid } & $\begin{array}{l}\text { Choi and Chan } \\
\text { (2002a) }\end{array}$ & EDB & $\begin{array}{l}\text { Raw data, no parameterisation: } \\
\text { http://ihome.ust.hk/ keckchan }\end{array}$ & $\begin{array}{l}\text { In mixtures with AmmSulf and } \\
\mathrm{NaCl} \text { only (ZSR) }\end{array}$ \\
\hline & Peng et al. (2001) & EDB & $\begin{array}{l}\text { Raw data } \\
\text { http://ihome.ust.hk/ keckchan } \\
\text { Gamma-law parameterisation }\end{array}$ & UNIFAC comparison \\
\hline \multirow{2}{*}{$\begin{array}{l}\text { Fulvic Acid Nordic } \\
\text { Aquatic Reference } \\
\text { (IHSS) }\end{array}$} & $\begin{array}{l}\text { Chan and Chan } \\
\qquad(2003)\end{array}$ & EDB & $\begin{array}{l}\text { aw (0.05-0.9) gamma-law (aw vs mass } \\
\text { ratio) }\end{array}$ & $\begin{array}{l}\text { Also mixtures FA with } \\
\text { AmmSulf, } \mathrm{NaCl}\end{array}$ \\
\hline & Gysel et al. (2004) & HTDMA & GF (gamma law GF vs RH) & Particle restructuring discussed \\
\hline \multirow[t]{3}{*}{$\begin{array}{l}\text { Fulvic acid Suwannee } \\
\text { River (IHSS) }\end{array}$} & $\begin{array}{l}\text { Svenningsson et } \\
\text { al. (2005) }\end{array}$ & HTDMA & aw vs molality (5th order polynomial) & $\begin{array}{l}\text { Pure compounds and mixtures } \\
\text { organics-inorganics, ZSR }\end{array}$ \\
\hline & $\begin{array}{l}\text { Brooks et al. } \\
\qquad(2004)\end{array}$ & HTDMA & GF parameterisation & $\begin{array}{l}\text { Also mixtures HA with } \\
\text { AmmSulf, ZSR }\end{array}$ \\
\hline & $\begin{array}{l}\text { Chan and Chan } \\
\text { (2003) }\end{array}$ & & $\begin{array}{l}\text { aw (0.05-0.9) gamma-law (aw vs } \\
\text { mass ratio) }\end{array}$ & $\begin{array}{l}\text { Also mixtures FA with } \\
\text { AmmSulf, } \mathrm{NaCl}\end{array}$ \\
\hline \multirow[t]{5}{*}{ Glutaric acid } & $\begin{array}{l}\text { Prenni et al. } \\
\qquad(2003)\end{array}$ & HTDMA & $\mathrm{GF}(\mathrm{RH})$ 3rd order polynomial & $\begin{array}{l}\text { Data from Prenni et al. (2001). } \\
\text { Mixtures with AmmSulf (ZSR) }\end{array}$ \\
\hline & $\begin{array}{l}\text { Prenni et al. } \\
\qquad(2001)\end{array}$ & HTDMA & $\begin{array}{l}\text { GF (0.45-0.93) Data in figures only } \\
\text { and GF at } \mathrm{RH}=80 \%, 90 \%\end{array}$ & $\begin{array}{l}\text { GF parameterisation presented } \\
\text { in Prenni et al. (2003). }\end{array}$ \\
\hline & $\begin{array}{l}\text { Choi and Chan } \\
\text { (2002a) }\end{array}$ & EDB & $\begin{array}{l}\text { Raw data, no parameterisation: } \\
\text { http://ihome.ust.hk/ keckchan }\end{array}$ & $\begin{array}{l}\text { In mixtures with AmmSulf and } \\
\mathrm{NaCl} \text { only (ZSR) }\end{array}$ \\
\hline & $\begin{array}{l}\text { Choi and Chan } \\
\text { (2002b) }\end{array}$ & SEDB & Data in figures only, no numbers & $\begin{array}{l}\text { New scanning EDB presented. } \\
\text { Also mixtures (ZSR) }\end{array}$ \\
\hline & $\begin{array}{l}\text { Marcolli et al. } \\
\qquad(2004)\end{array}$ & $\begin{array}{l}\text { Water } \\
\text { activity } \\
\text { meter }\end{array}$ & $\begin{array}{l}\text { aw-molality, data only for certain } \\
\text { mixtures at mutual DRH, some } \\
\text { additional data in figures, no } \\
\text { parameterisation }\end{array}$ & $\begin{array}{l}\text { Bulk measurements. Mixtures } \\
\text { only (organics, organics- } \\
\text { inorganics). In mixtures with } \\
\text { AmmSulf, AmmNitr and } \mathrm{NaCl}\end{array}$ \\
\hline
\end{tabular}


Table 7. Continued.

\begin{tabular}{|c|c|c|c|c|}
\hline & Wise et al. (2003) & $\begin{array}{l}\text { Water } \\
\text { activity } \\
\text { meter }\end{array}$ & GF (gamma law GF vs RH) & $\begin{array}{l}\text { Bulk measurements. Also in } \\
\text { mixtures with AmmSulf }\end{array}$ \\
\hline & $\begin{array}{l}\text { Cruz and Pandis } \\
\text { (2000) }\end{array}$ & HTDMA & Data at $\mathrm{RH}=85 \%$ and in figures. & $\begin{array}{l}\text { In mixtures with AmmSulf and } \\
\mathrm{NaCl} \text { only, ZSR }\end{array}$ \\
\hline & Peng et al. (2001) & EDB & $\begin{array}{l}\text { Raw data } \\
\text { http://ihome.ust.hk/ keckchan } \\
\text { Gamma-law parameterisation }\end{array}$ & UNIFAC comparison \\
\hline \multirow[t]{2}{*}{ Glycerol } & $\begin{array}{l}\text { Choi and Chan } \\
\text { (2002a) }\end{array}$ & EDB & $\begin{array}{l}\text { Raw data, no parameterisation: } \\
\text { http://ihome.ust.hk/ keckchan }\end{array}$ & $\begin{array}{l}\text { In mixtures with AmmSulf and } \\
\mathrm{NaCl} \text { only (ZSR) }\end{array}$ \\
\hline & $\begin{array}{l}\text { Choi and Chan } \\
\text { (2002b) }\end{array}$ & SEDB & Data in figures only. & $\begin{array}{l}\text { New scanning EDB presented. } \\
\text { Also mixtures (ZSR) }\end{array}$ \\
\hline Glycine & Na et al. (1995) & EDB & $\begin{array}{l}\text { Water activity parameterisation, } 5 \text { th } \\
\text { order polynomials }\end{array}$ & \\
\hline $\begin{array}{c}\text { Humic acid Nordic } \\
\text { Aquatic Reference } \\
\text { (IHSS) }\end{array}$ & Gysel et al. (2004) & HTDMA & GF (gamma law GF vs RH) & Particle restructuring discussed \\
\hline Humic acid Fluka & $\begin{array}{l}\text { Brooks et al. } \\
\text { (2004) }\end{array}$ & HTDMA & GF parameterisation & $\begin{array}{l}\text { Also mixtures HA with } \\
\text { AmmSulf, ZSR }\end{array}$ \\
\hline $\begin{array}{c}\text { Humic acid } \\
\text { Leonardite Standard }\end{array}$ & $\begin{array}{l}\text { Brooks et al. } \\
\text { (2004) }\end{array}$ & HTDMA & GF parameterisation & $\begin{array}{l}\text { Also mixtures HA with } \\
\text { AmmSulf, ZSR }\end{array}$ \\
\hline Itaconic acid & Na et al. (1995) & EDB & $\begin{array}{l}\text { Water activity parameterisation, } 5 \text { th } \\
\text { order polynomials }\end{array}$ & \\
\hline levoglucosan & $\begin{array}{l}\text { Svenningsson et } \\
\text { al. (2005) }\end{array}$ & HTDMA & aw vs molality (5th order polynomial) & $\begin{array}{l}\text { Pure compounds and mixtures } \\
\text { organics-inorganics, ZSR }\end{array}$ \\
\hline \multirow[t]{4}{*}{ Maleic acid } & $\begin{array}{l}\text { Svenningsson et } \\
\text { al. (2005) }\end{array}$ & HTDMA & aw vs molality (5th order polynomial) & $\begin{array}{l}\text { Pure compounds and mixtures } \\
\text { organics-inorganics, ZSR }\end{array}$ \\
\hline & $\begin{array}{l}\text { Choi and Chan } \\
\text { (2002b) }\end{array}$ & SEDB & Data in figures only, no numbers & $\begin{array}{l}\text { New scanning EDB presented. } \\
\text { Also mixtures (ZSR) }\end{array}$ \\
\hline & $\begin{array}{l}\text { Marcolli et al. } \\
\qquad(2004)\end{array}$ & $\begin{array}{l}\text { Water } \\
\text { activity } \\
\text { meter }\end{array}$ & $\begin{array}{l}\text { aw-molality data only for certain } \\
\text { mixtures at mutual DRH, Some } \\
\text { additional data in figures, no } \\
\text { parameterisation }\end{array}$ & $\begin{array}{l}\text { Bulk measurements. Mixtures } \\
\text { only (organics, organics- } \\
\text { inorganics). In mixtures with } \\
\text { AmmSulf, AmmNitr and } \mathrm{NaCl}\end{array}$ \\
\hline & Wise et al. (2003) & $\begin{array}{l}\text { Water } \\
\text { activity } \\
\text { meter }\end{array}$ & GF (gamma law GF vs RH) & $\begin{array}{l}\text { Bulk measurements. Also in } \\
\text { mixtures with AmmSulf }\end{array}$ \\
\hline \multirow[t]{2}{*}{ Malic acid } & $\begin{array}{l}\text { Choi and Chan } \\
\text { (2002b) }\end{array}$ & SEDB & Data in figures only, no numbers & $\begin{array}{l}\text { New scanning EDB presented. } \\
\text { Also mixtures (ZSR) }\end{array}$ \\
\hline & $\begin{array}{l}\text { Marcolli et al. } \\
\text { (2004) }\end{array}$ & $\begin{array}{l}\text { Water } \\
\text { activity } \\
\text { meter }\end{array}$ & $\begin{array}{l}\text { aw-molality data only for certain } \\
\text { mixtures at mutual DRH, Some } \\
\text { additional data in figures, no } \\
\text { parameterisation }\end{array}$ & $\begin{array}{l}\text { Bulk measurements. Mixtures } \\
\text { only (organics, organics- } \\
\text { inorganics). In mixtures with } \\
\text { AmmSulf, AmmNitr and } \mathrm{NaCl}\end{array}$ \\
\hline
\end{tabular}


Table 7. Continued.

\begin{tabular}{|c|c|c|c|c|}
\hline & Peng et al. (2001) & EDB & $\begin{array}{l}\text { Raw data } \\
\text { http://ihome.ust.hk/ keckchan } \\
\text { Gamma-law parameterisation }\end{array}$ & UNIFAC comparison \\
\hline 1-malic acid & Wise et al. (2003) & $\begin{array}{l}\text { Water } \\
\text { activity } \\
\text { meter }\end{array}$ & GF (gamma law GF vs RH) & $\begin{array}{l}\text { Bulk measurements. Also in } \\
\text { mixtures with AmmSulf }\end{array}$ \\
\hline \multirow[t]{8}{*}{ Malonic acid } & $\begin{array}{l}\text { Hämeri et al. } \\
\text { (2002) }\end{array}$ & HTDMA & $\begin{array}{l}\text { Data in figures only, no } \\
\text { parameterisation }\end{array}$ & In mixtures with AmmSulf only \\
\hline & $\begin{array}{l}\text { Prenni et al. } \\
\text { (2001) }\end{array}$ & HTDMA & $\begin{array}{l}\text { GF (0.45-0.93) Data in figures only } \\
\text { and GF at RH=80\%, } 90 \%\end{array}$ & $\begin{array}{l}\text { GF parameterisation presented } \\
\text { in Prenni et al. (2003). }\end{array}$ \\
\hline & $\begin{array}{l}\text { Prenni et al. } \\
\text { (2003) }\end{array}$ & HTDMA & $\mathrm{GF}(\mathrm{RH}) 3 \mathrm{rd}$ order polynomial & $\begin{array}{l}\text { Data from Prenni et al. (2001) } \\
\text { Mixtures with AmmSulf (ZSR) }\end{array}$ \\
\hline & $\begin{array}{l}\text { Choi and Chan } \\
\text { (2002a) }\end{array}$ & EDB & $\begin{array}{l}\text { Raw data, no parameterisation: } \\
\text { http://ihome.ust.hk/ keckchan }\end{array}$ & $\begin{array}{l}\text { In mixtures with AmmSulf and } \\
\mathrm{NaCl} \text { only (ZSR) }\end{array}$ \\
\hline & $\begin{array}{l}\text { Choi and Chan } \\
\text { (2002b) }\end{array}$ & SEDB & Data in figures only, no numbers & $\begin{array}{l}\text { New scanning EDB presented. } \\
\text { Also mixtures (ZSR) }\end{array}$ \\
\hline & $\begin{array}{l}\text { Marcolli et al. } \\
\qquad(2004)\end{array}$ & $\begin{array}{l}\text { Water } \\
\text { activity } \\
\text { meter }\end{array}$ & $\begin{array}{l}\text { aw-molality data only for certain } \\
\text { mixtures at mutual DRH, Some } \\
\text { additional data in figures, no } \\
\text { parameterisation }\end{array}$ & $\begin{array}{l}\text { Bulk measurements. Mixtures } \\
\text { only (organics, organics- } \\
\text { inorganics). In mixtures with } \\
\text { AmmSulf, AmmNitr and } \mathrm{NaCl}\end{array}$ \\
\hline & Wise et al. (2003) & $\begin{array}{l}\text { Water } \\
\text { activity } \\
\text { meter }\end{array}$ & GF (gamma law GF vs RH) & $\begin{array}{l}\text { Bulk measurements. Also in } \\
\text { mixtures with AmmSulf }\end{array}$ \\
\hline & Peng et al. (2001) & EDB & $\begin{array}{l}\text { Raw data } \\
\text { at:http://ihome.ust.hk/ keckchan } \\
\text { Gamma-law parameterisation }\end{array}$ & UNIFAC comparison \\
\hline Methylsuccinic acid & $\begin{array}{l}\text { Marcolli et al. } \\
\qquad \text { (2004) }\end{array}$ & $\begin{array}{l}\text { Water } \\
\text { activity } \\
\text { meter }\end{array}$ & $\begin{array}{l}\text { aw-molality data only for certain } \\
\text { mixtures at mutual DRH, Some } \\
\text { additional data in figures, no } \\
\text { parameterisation }\end{array}$ & $\begin{array}{l}\text { Bulk measurements. Mixtures } \\
\text { only (organics, organics- } \\
\text { inorganics). In mixtures with } \\
\text { AmmSulf, AmmNitr and } \mathrm{NaCl}\end{array}$ \\
\hline \multirow[t]{4}{*}{ Oxalic acid } & $\begin{array}{l}\text { Prenni et al. } \\
\qquad(2001)\end{array}$ & HTDMA & $\begin{array}{l}\mathrm{GF}(0.45-0.93) \text { Data in figures only } \\
\text { and } \mathrm{GF} \text { at } \mathrm{RH}=80 \%, 90 \%\end{array}$ & $\begin{array}{l}\text { GF parameterisation presented } \\
\text { in Prenni et al. (2003). }\end{array}$ \\
\hline & $\begin{array}{l}\text { Marcolli et al. } \\
\text { (2004) }\end{array}$ & $\begin{array}{l}\text { Water } \\
\text { activity } \\
\text { meter }\end{array}$ & $\begin{array}{l}\text { aw-molality data only for certain } \\
\text { mixtures at mutual DRH, Some } \\
\text { additional data in figures, no } \\
\text { parameterisation }\end{array}$ & $\begin{array}{l}\text { Bulk measurements. Mixtures } \\
\text { only (organics, organics- } \\
\text { inorganics). In mixtures with } \\
\text { AmmSulf, AmmNitr and } \mathrm{NaCl}\end{array}$ \\
\hline & Wise et al. (2003) & $\begin{array}{l}\text { Water } \\
\text { activity } \\
\text { meter }\end{array}$ & GF (gamma law GF vs RH) & $\begin{array}{l}\text { Bulk measurements. Also in } \\
\text { mixtures with AmmSulf }\end{array}$ \\
\hline & $\begin{array}{l}\text { Peng et al. } \\
\text { (2001) }\end{array}$ & EDB & $\begin{array}{l}\text { Raw data } \\
\text { http://ihome.ust.hk/ keckchan } \\
\text { Gamma-law parameterisation }\end{array}$ & UNIFAC comparison \\
\hline
\end{tabular}


Table 7. Continued.

\begin{tabular}{|c|c|c|c|c|}
\hline & $\begin{array}{l}\text { Prenni et al. } \\
\text { (2003) }\end{array}$ & HTDMA & $\mathrm{GF}(\mathrm{RH})$ 3rd order polynomial & $\begin{array}{l}\text { Data from Prenni et al. (2001). } \\
\text { Mixtures with AmmSulf (ZSR) }\end{array}$ \\
\hline Phtalic acid & $\begin{array}{l}\text { Hämeri et al. } \\
\qquad(2002)\end{array}$ & HTDMA & $\begin{array}{l}\text { Data in figures only, no numbers! no } \\
\text { parameterisation! }\end{array}$ & In mixtures with AmmSulf only \\
\hline Pinonic acid & $\begin{array}{l}\text { Cruz and Pandis } \\
\text { (2000) }\end{array}$ & HTDMA & Data at $\mathrm{RH}=85 \%$ and in figures. & $\begin{array}{l}\text { In mixtures with AmmSulf and } \\
\mathrm{NaCl} \text { only, ZSR }\end{array}$ \\
\hline $\begin{array}{l}\text { Polyacrylic acids } \\
\text { Sigma-Aldrich }\end{array}$ & $\begin{array}{l}\text { Brooks et al. } \\
\qquad(2004)\end{array}$ & HTDMA & GF parameterisation & $\begin{array}{l}\text { Also mixtures PAA with } \\
\text { AmmSulf, ZSR }\end{array}$ \\
\hline \multirow[t]{9}{*}{ Succinic acid } & $\begin{array}{l}\text { Prenni et al. } \\
\qquad(2001)\end{array}$ & HTDMA & $\begin{array}{l}\text { GF }(0.45-0.93) \text { Data in figures only } \\
\text { and GF at } \mathrm{RH}=80 \%, 90 \%\end{array}$ & $\begin{array}{l}\text { GF parameterisation presented } \\
\text { in Prenni et al. (2003). }\end{array}$ \\
\hline & $\begin{array}{l}\text { Choi and Chan } \\
\text { (2002a) }\end{array}$ & EDB & $\begin{array}{l}\text { Raw data, no parameterisation: } \\
\text { http://ihome.ust.hk/ keckchan }\end{array}$ & $\begin{array}{l}\text { In mixtures with AmmSulf and } \\
\mathrm{NaCl} \text { only (ZSR) }\end{array}$ \\
\hline & $\begin{array}{l}\text { Marcolli et al. } \\
\qquad(2004)\end{array}$ & $\begin{array}{l}\text { Water } \\
\text { activity } \\
\text { meter }\end{array}$ & $\begin{array}{l}\text { aw-molality data only for certain } \\
\text { mixtures at mutual DRH, Some } \\
\text { additional data in figures, no } \\
\text { parameterisation }\end{array}$ & $\begin{array}{l}\text { Bulk measurements. Mixtures } \\
\text { only (organics, organics- } \\
\text { inorganics). In mixtures with } \\
\text { AmmSulf, AmmNitr and } \mathrm{NaCl}\end{array}$ \\
\hline & Wise et al. (2003) & $\begin{array}{l}\text { Water } \\
\text { activity } \\
\text { meter }\end{array}$ & GF (gamma law GF vs RH) & $\begin{array}{l}\text { Bulk measurements. Also in } \\
\text { mixtures with AmmSulf }\end{array}$ \\
\hline & Peng et al. (2001) & EDB & $\begin{array}{l}\text { Raw data } \\
\text { http://ihome.ust.hk/ keckchan } \\
\text { Gamma-law parameterisation }\end{array}$ & UNIFAC comparison \\
\hline & $\begin{array}{l}\text { Lightstone et al. } \\
\qquad(2000)\end{array}$ & EDB & Water activity for data points only & In mixtures with AmmNitr only \\
\hline & $\mathrm{Na}$ et al. (1995) & EDB & $\begin{array}{l}\text { Water activity parameterisation, } 5 \text { th } \\
\text { order polynomials }\end{array}$ & \\
\hline & $\begin{array}{l}\text { Hämeri et al. } \\
\qquad(2002)\end{array}$ & HTDMA & $\begin{array}{l}\text { Data in figures only, no } \\
\text { parameterisation }\end{array}$ & In mixtures with AmmSulf only \\
\hline & $\begin{array}{l}\text { Svenningsson et } \\
\text { al. (2005) }\end{array}$ & HTDMA & aw vs molality ( 5 th order polynomial) & $\begin{array}{l}\text { Pure compounds and mixtures } \\
\text { organics-inorganics, ZSR }\end{array}$ \\
\hline Tartatic acid & Peng et al. (2001) & EDB & $\begin{array}{l}\text { Raw data } \\
\text { http://ihome.ust.hk/ keckchan } \\
\text { Gamma-law parameterisation }\end{array}$ & UNIFAC comparison \\
\hline \multicolumn{5}{|l|}{ organic salts } \\
\hline $\begin{array}{l}\text { (sodium) : formate, } \\
\text { acetate, succinate, } \\
\text { pyruvate, malonate, } \\
\text { maleate, } \\
\text { methanesulfonate, } \\
\text { oxalate }\end{array}$ & $\begin{array}{l}\text { Peng and Chan } \\
\text { (2001a) }\end{array}$ & EDB & $\begin{array}{l}\text { aw (0.05-0.99 varying with salt) } \\
\text { polynomial (aw vs } \mathrm{mfs})\end{array}$ & Salts only \\
\hline ammonium oxalate & $\begin{array}{l}\text { Peng and Chan } \\
\text { (2001a) }\end{array}$ & EDB & $\begin{array}{l}\text { aw (0.05-0.99 varying with salt) } \\
\text { polynomial (aw vs } \mathrm{mfs})\end{array}$ & Salts only \\
\hline
\end{tabular}


Table 7. Continued.

\begin{tabular}{c|l|l|l|l}
$\begin{array}{c}\text { Humic acid Sodium } \\
\text { salt -Aldrich }\end{array}$ & Gysel et al. (2004) & HTDMA & GF & \\
\hline $\begin{array}{c}\text { pharmaceutical } \\
\text { compounds }\end{array}$ & & EDB & Power law molality vs aw (0-0.97) & $\begin{array}{l}\text { pure and in mixtures with NaCl } \\
\text { (ZSR) }\end{array}$ \\
\hline $\begin{array}{c}\text { Disodium fluorescein } \\
\text { Atropine sulphate } \\
(1997)\end{array}$ & $\begin{array}{l}\text { Peng et al. } \\
(2000)\end{array}$ & EDB & $\begin{array}{l}\text { Data in figures only, No } \\
\text { parameterisation }\end{array}$ & Data at 37 C \\
\hline $\begin{array}{c}\text { iosproterenol } \\
\text { hydrochloride }\end{array}$ & $\begin{array}{l}\text { Peng et al. } \\
(2000)\end{array}$ & EDB & $\begin{array}{l}\text { Data in figures only, No } \\
\text { parameterisation }\end{array}$ & Data at 37 C \\
\hline $\begin{array}{c}\text { iosproterenol } \\
\text { hemisulphate }\end{array}$ & $\begin{array}{l}\text { Peng et al. } \\
(2000)\end{array}$ & EDB & $\begin{array}{l}\text { Data in figures only, No } \\
\text { parameterisation }\end{array}$ & Data at 37 C \\
\hline $\begin{array}{c}\text { Disodium } \\
\text { cromoglycate }\end{array}$ & $\begin{array}{l}\text { Peng et al. } \\
(2000)\end{array}$ & EDB & $\begin{array}{l}\text { Data in figures only, No } \\
\text { parameterisation }\end{array}$ & Data at 37 C \\
\hline
\end{tabular}

\subsection{Modelling of SOA - water interactions}

Most regional (Binkowski and Roselle, 2003) and global (Liousse et al., 1996; Griffin et al., 1999b; Kanakidou et al., 2000; Chung and Seinfeld, 2002; Tsigaridis and Kanakidou, 2003) models neglect the ability of SOA to influence directly (by absorbing water) or indirectly (by changing the activity coefficients of the inorganic components) the aerosol water uptake. There are three major barriers that prevent a detailed description of the interactions among organic, inorganic aerosol compounds and water.

- First, there is a lack of fundamental chemical and thermodynamic information about organic compounds (Clegg et al., 2001), the identity of which is often unknown. Important thermodynamics data would include Henry's law constants, equilibrium vapour pressures, dissociation constants of the acidic organic compounds, as well as solubilities in water (Anttila et al., 2002).

- Second, a suitable theoretical framework is needed that would allow the prediction of the properties of complex mixed (organic and inorganic) particles, based on a sparse set of data.

- Third, the theoretical framework developed must be computationally efficient, so it can be included within a typical global model simulation.

Considerable effort has been expended towards achieving these goals. Saxena and Hildemann (1997) proposed that the UNIquac Functional-group Activity Coefficient UNIFAC method (Fredeslund et al., 1994) could be a useful first approximation for estimating water activities of aqueous or- ganic solutions. They argued that UNIFAC can reproduce in most cases, water activities to within approximately $15 \%$ for a wide variety of compounds (e.g., glycols, dicarboxylic acids, keto acids) and a wide range of solute concentrations. The following paragraphs summarise the first efforts to describe the SOA-water interactions and to estimate how much aerosol water is associated with SOA.

Ansari and Pandis (2000) used the UNIFAC method to predict the water uptake of SOA. Their model assumed that the aerosol consisted of a primarily inorganic and a predominantly organic phase, which did not interact with each other. The inorganic contained inorganic salts and water while the organic phase contained the organic species and small amounts of water and semivolatile inorganics (e.g., ammonium nitrate). The model predictions were qualitatively consistent with the few available measurements suggesting that the hygroscopic growth of SOA is significantly less than their inorganic counterparts. Using lumped SOA species, they reported that SOA accounts for approximately $10 \%$ of total aerosol water and increases aerosol nitrate concentrations by approximately $10 \%$. At high relative humidity (greater than $85 \%$ ), the effect of SOA on nitrate partitioning and water uptake was negligible. At low relative humidity (less than $50 \%$ ), SOA could account for $20 \%$ of aerosol water.

Seinfeld et al. (2001) considered the interaction of individual SOA compounds with water vapour; the free energy was calculated using UNIFAC. Their model did explain how increasing $\mathrm{RH}$ in biogenic hydrocarbon/ozone systems uniformly increases both the amount of condensed organic mass and the amount of liquid water in the aerosol phase. The presence of inorganic compounds was not considered. The 
model gave relatively good agreement with the measurements of Cocker et al. (2001a) for 50\% RH but tended to underpredict the water uptake at $85 \%$ RH (e.g. predicted volumetric growth of $20 \%$ versus observed $30 \%$ ). The study also indicated that it may be a useful first approximation to assume a unity activity coefficient for many compounds making up SOA mixtures.

In a sensitivity study, Bowman and Karamalegos (2002) estimated that the dissolution of SOA compounds in water could increase the SOA concentration by as much as $50 \%$. The SOA species were also increasing the aerosol water concentration by roughly $1 \mu \mathrm{g} \mu \mathrm{g}^{-1}$ of SOA at $80 \% \mathrm{RH}$. The effects were more pronounced during the nighttime high relative humidity periods.

Ming and Russell (2002) proposed a combined PitzerUNIFAC approach for the description of the phase equilibria of mixtures of electrolytes and organic species in aqueous solutions. The activity coefficient of each species in solution was explicitly related to the chemical composition by treating the (inorganic) ion-water, organic-water and ion-organic interactions. The model predicted that the mixing of highly soluble organic compounds (solubility higher than $4 \mathrm{~mol} \mathrm{~L}^{-1}$ ) can decrease the deliquescence $\mathrm{RH}$ of the salt, a phenomenon typically seen in the deliquescence of multicomponent inorganic aerosols. This model was used to simulate the hygroscopic behaviour of sea-salt aerosol using twenty insoluble and four soluble organic species (Ming and Russell, 2001). The hygroscopic diameter growth factor of a particle consisting of purely inorganic sea salt was predicted to be $15 \%$ higher than that of a particle consisting of $70 \%$ inorganic sea salt and 30\% organics for moderate and high RH. The effect increases for higher organic mass fractions.

Water activity predictions from calculations using the UNIFAC model were found to agree with the measured water activity data for oxalic, malonic, succinic, glutaric, and citric acid to within $40 \%$ but deviations were as large as $100 \%$ for malic acid and tartaric acid (Peng et al., 2001). After modification of the functional group interaction parameters of the $\mathrm{COOH}-\mathrm{H}_{2} \mathrm{O}-\mathrm{OH}-\mathrm{H}_{2} \mathrm{O}$, and $\mathrm{OH}-\mathrm{COOH}$ pairs by fitting the UNIFAC model with the measured data the agreement of predictions and measurements improved to within $35 \%$ for all the acids studied.

Clegg et al. (2001) proposed a thermodynamic framework for the description of the aqueous aerosol phase containing both inorganics and organics applicable at medium to high $\mathrm{RH}$ when water is the major component of the solution (solvent). In this approach the ion-water, organic-water, and ionorganic contributions to activity coefficients are calculated independently. Even with this simplification data for aqueous solutions of the organic molecules are required.

Koo et al. (2003a) described the interactions between the SOA species and water by using representative organic species and the UNIFAC method to describe the water absorption by the lumped SOA compounds. Comparison between the predictions of this model and the few available smog chamber studies suggested a serious underprediction (by a factor of 2 to 3 ) of the water concentration predicted by the models. The authors corrected for this bias by using a constant correction factor for each precursor. Application of the tool to Southern California suggested that SOA increases the aerosol water concentration by $2-13 \%$ depending on the conditions. The effect of this additional SOA water on aerosol nitrate was found to be insignificant for all cases.

Pun et al. (2002) classified SOA compounds as either "hydrophobic" or "hydrophilic". The hydrophobic species are assumed dissolved in a predominantly organic phase together with the primary organic aerosol components. Hydrophilic compounds are assumed to dissolve in the aqueous aerosol phase together with inorganic salts; the organic compounds however were not allowed to affect the activity coefficients of the inorganic salts. The activity coefficients of the organic solutes were calculated using UNIFAC and the aerosol water content was estimated using the Zdanovskii-StokesRobinson (ZSR) approach (with the basic assumption that the quantities of water associated with each solute are additive). Three anthropogenic and two biogenic hydrophilic SOA species were used as surrogates in the model to represent the individual SOA compounds. The properties of these surrogate compounds were reasonable estimates based on assumed structures of these molecules.

Most SOA-water modelling studies have relied on arbitrarily chosen model compounds for the representation of the hygroscopic properties of the SOA mixture. Fuzzi et al. (2001) proposed a complimentary conceptual approach based on functional group analysis. The method relies on the construction of model compounds based on experimental information (chromatographic analysis and carbon analysis of each fraction and HNMR analysis).

\subsection{Hygroscopicity of SOA and multicomponent carbona- ceous aerosol: laboratory studies}

The hygroscopic behaviour of freshly formed carbonaceous particles (primary as well as secondary) has been studied in the laboratory for a number of biogenic and anthropogenic model compounds. Table 8 gives some examples of recent studies and results. It shows that freshly formed carbonaceous particles (soot as well as secondary organics) have very low to low growth factors GF: diesel soot can be considered as hydrophobic whereas oxidation products of toluene, a model compound for anthropogenic SOA, are moderately hygroscopic. Also water soluble organic compounds, as humic and fulvic acid, as well as 'isolated organic matter', have very low hygroscopicity, LH (Gysel et al., 2004). On the other hand, the few available laboratory studies on the hygroscopicity of biomass burning aerosol show that, unlike the previous classes of carbonaceous particles, they have a hygroscopic behaviour comparable to inorganic salts.

Virkkula et al. (1999) measured the hygroscopic properties of aerosol formed by oxidation of three monoterpenes, 
Table 8. Overview of hygroscopicity studies in laboratory of carbonaceous particles.

\begin{tabular}{|c|c|c|c|}
\hline Aerosol type & Conditions & GF $(90 \%)$ & Reference \\
\hline $\begin{array}{l}\text { Oxidation products } \alpha \text {-and } \\
\beta \text {-pinene, limonene }\end{array}$ & $\begin{array}{l}\text { Ozonolysis and photo-oxidation, } \\
\text { dry atmosphere }\end{array}$ & $\approx 1.1$ & Virkkula et al. (1999) \\
\hline \multirow[t]{3}{*}{ Oxidation products of toluene } & Dry, $\mathrm{NO}_{\mathrm{X}}$-free & 1.22 & Marelli et al. (2003) \\
\hline & Dry, high $\mathrm{NO}_{\mathrm{x}}$ & 1.15 & (unpublished data) ${ }^{\mathrm{b}}$ \\
\hline & $\mathrm{RH}=50 \%$, high $\mathrm{NO}_{\mathrm{x}}$ & 1.17 & \\
\hline Nordic ref. Fulvic Acid & Commercial acids and salts & 1.13 & Gysel et al. (2004) \\
\hline Nordic ref. Humic Acid & & 1.06 & \\
\hline Humic acid sodium salt & & 1.06 & \\
\hline Isolated organic matter (ISOM) & $\begin{array}{l}\text { Solid-phase extracted organic } \\
\text { matter from water soluble } \\
\text { fraction in atmospheric samples }\end{array}$ & $1.08-1.17$ & Gysel et al. (2004) \\
\hline \multirow[t]{2}{*}{ Diesel soot } & $1 \mathrm{~kW}$ load, no fuel additives & $<1.01$ & Weingartner et al. (1997) \\
\hline & $2 \mathrm{~kW}$ load, sulfur-enhanced fuel & $1.015-1.025$ & \\
\hline Biomass fuel (moist forest residue) & Moving grate boiler & 1.65 & Pagels et al. (2003) \\
\hline $\begin{array}{l}\text { Globular Protein } \\
\text { (Bovine Serum Albumin) }\end{array}$ & Commercial product (nebulised solution) & 1.06 & Mikahilov et al. (2004) \\
\hline
\end{tabular}

${ }^{a}$ for biogenic SOA see also Table 9. ${ }^{b}$ presented at SOA workshop, Belgirate, September 2003

limonene, alpha-pinene, and beta-pinene, using a tandem differential mobility analyzer (TDMA). The experiments included ozonolysis and photooxidation with and without ammonium sulphate seed aerosol. Pure organic particles, formed by oxidation of the terpenes in the absence of the seed aerosol, proved to be slightly hygroscopic. The diameter growth factor was close to 1.1 at RH $85 \%$. In the experiments with ammonium sulphate seed aerosol the growth factor decreased from approximately 1.5 before the start of terpene oxidation to approximately 1.1 as the oxidation products condensed on the particles. Their analysis showed that in the internally mixed particles, ammonium sulphate and the organic products take up water independently of one another.

The majority of laboratory investigations of SOA formation have been carried out in the absence of water. A roughly $10 \%$ increase in the overall aerosol yield of the apinene/ozone system was observed by Cocker et al. (2001a) when the $\mathrm{RH}$ of the experiments was increased from less than $2 \%$ to around $50 \%$. The observed change in the overall aerosol yield during pinene ozonolysis in the presence of water vapour includes the effects of water vapour on gas-phase chemistry, the water uptake of the particles, and the change in the partitioning of the SOA compounds. Further analysis indicated that most of this increase was due to the water uptake by the SOA. The presence of aqueous salt particles in the system was found to reduce the overall (organic material plus associated water) aerosol yield relative to the no seed experiments by 15-35\%. The effect differed according to the salt, with ammonium sulphate causing the greatest reduction in yield. The authors argued that the presence of the electrolytes reduces the fraction of the organic aerosol partitioning from the gas to the aerosol phase.
Table 9. Diameter hygroscopic growth factors of SOA obtained from TDMA measurements.

\begin{tabular}{lccc}
\hline SOA Source & $\mathrm{RH}$ & Growth factor & Reference \\
\hline$\alpha-$ pinene $/ \mathrm{O}_{3}$ & $50 \%$ & 1.04 & Cocker et al. (2001a) \\
$\alpha-$ pinene $/ \mathrm{O}_{3}$ & $85 \%$ & 1.09 & Cocker et al. (2001a) \\
$\alpha-$ pinene $/ \mathrm{O}_{3}$ & $85 \%$ & 1.07 & Virkkula et al. (1999) \\
$\alpha-$ pinene $/ \mathrm{NO}_{\mathrm{x}}$ & $85 \%$ & 1.09 & Virkkula et al. (1999) \\
$\beta-$ pinene $/ \mathrm{NO}_{\mathrm{x}}^{\mathrm{a}}$ & $85 \%$ & 1.10 & Virkkula et al. (1999) \\
limonene $/ \mathrm{O}_{3}$ & $85 \%$ & 1.09 & Virkkula et al. (1999) \\
\hline
\end{tabular}

a This growth factor was estimated from experiments that included ammonium sulphate seed aerosol.

Edney et al. (2000) irradiated toluene/propylene/NOx/air mixtures in the presence of submicron ammonium sulphate aerosol. The generated aerosols contained organic and inorganic constituents with liquid water concentrations ranging from 4 to $65 \mu \mathrm{g} \mathrm{m}^{-3}$. They concluded that the presence of aerosol liquid water did not significantly change the amount of the SOA that formed from the oxidation of toluene. The amount of SOA generated during the photooxidation of $\mathrm{m}$ xylene and 1,3,5-trimethylbenzene in the presence of ammonium sulphate aerosol was also unaffected by the presence of water at RH up to $50 \%$ (Cocker et al., 2001b). The water uptake by SOA produced during the photooxidation of toluene, p-xylene, and 1,3,5-trimethylbenzene in the presence of $\mathrm{NO}_{\mathrm{x}}$ and ammonium sulphate aerosol was negligible compared to the water due to the inorganics (Kleindienst et al., 1999). Cocker et al. (2001b) observed that the hygroscopicity of the 
aerosol formed during the photooxidation of $\mathrm{m}$-xylene and 1,3,5-trimethylbenzene at $85 \% \mathrm{RH}$ increased with the extent of the reaction, indicating that the first-generation oxidation products undergo further oxidation.

Kleindienst et al. (2002) investigated the SOA formation from the irradiation of simulated automobile exhaust. The hygroscopic potential of the aerosol was determined with the use of a liquid water content analyzer, and the analysis indicated that the aerosol uptake of water was minor at relative humidities less than 70\%. Organic analysis of the collected aerosol from this complex system indicated that the identified oxidation products were identical to those found in the toluene oxidation system.

Jang and Kamens (1998) investigated the humidity effects on the gas/particle partitioning of twenty different semivolatile organic compounds (primary and secondary) in the organic layer of wood soot, diesel soot, and SOA. A model based on the UNIFAC approach was used to estimate the activity coefficients. It was concluded that the humidity effect on partitioning of semivolatile compounds is most significant for hydrophobic compounds in polar aerosols.

\subsection{Hygroscopicity of ambient aerosols}

Numerous field studies have been conducted in the past decades to document the hygroscopicity of atmospheric particles under a variety of conditions. In many cases particles with clearly distinct hygroscopic properties have been observed in a single air sample. These hygroscopicity classes are usually classified as "near hydrophobic", "less hygroscopic" (LH) and "more hygroscopic" (MH). However, depending on the environment, the actual GF corresponding to each of these classes (in particular the $\mathrm{LH}$ and $\mathrm{MH}$ ) can show large variation. Table 10 gives an overview of recent studies from which we have extracted frequency of occurrence and number fraction of particles with $\mathrm{GF}<1.2$ and those with $\mathrm{GF}>1.2$. Without claiming to be exhaustive, we have tried to compile studies that give typical results for a range of atmospheric conditions, from the street canyon to the remote marine environment. More data compilations can be found in Cocker et al. (2001) and Baltensperger et al. (2002). The separation of the two classes at GF 1.2 is rather arbitrary, but has been made in the first place to evaluate the trend in the $\mathrm{LH}$ aerosol fraction to the total population when moving away from the source areas (urban background) to remote sites. The column "fraction of occurrence" is the product of the "fraction of time" LH particles occur and "number fraction" when LH particles occur, which allows to rank the importance of these particles.

As can be seen in the studies mentioned in Table 10, the GF of these particles tends to increase with particle size. Hence, the data indicates that mixing of the initially less hygroscopic particles with soluble secondary aerosol, increases the hygroscopicity of the particles.
Biomass burning plumes measured in the Amazonian basin are strongly dominated at all sizes by LH particles, even when they are relatively aged. Also here, inspection of the GF values shows an increase of the GF with particle size (Vestin, 2003). African biomass burning plumes aged over the Atlantic show all particles in the more hygroscopic class, indicating the presence of (secondary) soluble components, possibly originating from marine dimethylsulfide (DMS) oxidation products, or anthropogenic pollutants co-transported with the plume.

Also in conditions where secondary "organic" aerosol is being formed (Boreal, Amazon and Mediterranean forests) the LH fraction remains high, although also here decreasing with particle size. This indicates an internal mixing between soluble salts and the in-situ formed organic components.

The picture emerging from the 'real-world' data is the following:

- Under traffic-dominated conditions (street canyon and urban background), a significant fraction of LH particles is quasi permanently observed. This fraction decreases with increasing particle size for a given urban site.

- The time fraction of occurrence of these less hygroscopic particles decreases progressively when moving from the urban background to continental and to remote marine locations. Simultaneously, a population of more hygroscopic particles is always present.

Analysis of the results of the following studies has led to a series of valuable insights regarding the role of organics in the hygroscopic growth of particles. The study of the hygroscopic behaviour of atmospheric particles collected above the North Atlantic Ocean by Posfai et al. (1998) suggested that organic films on the particles may be responsible for the observed relatively large water uptake at low relative humidities.

Swietlicki et al. (1999) combined measurements of hygroscopic diameter growth factors and aerosol composition in Northern England to investigate the role of organics in the aerosol water uptake. For particles in the $0.17-0.53 \mu \mathrm{m}$ size range they were able to reproduce the observed growth that agreed with the theoretical estimate within experimental error for all cases but one. They proposed that the discrepancy for this air mass for which the aerosol had undergone extensive photochemical processing was due to organics.

Lowenthal et al. (2003) examined the ability of organic aerosols to absorb water as a function of relative humidity (RH) using data collected during the 1999 Big Bend Regional Aerosol and Visibility Observational Study (BRAVO). On average, organics accounted for $22 \%$ of $\mathrm{PM}_{2.5}$ mass. Hourly RH exceeded $80 \%$ only $3.5 \%$ of the time and averaged 44\%. BRAVO aerosol chemical composition and dry particle size distributions were used to estimate $\mathrm{PM}_{2.5}$ light scattering at low and high ambient RH. Liquid water 
Table 10. Overview of recent hygroscopicity measurements in the field.

\begin{tabular}{|c|c|c|c|c|c|c|c|c|c|}
\hline \multirow[b]{2}{*}{ Aerosol type } & \multirow[b]{2}{*}{$\begin{array}{c}\text { Dp } \\
(\mathbf{n m})\end{array}$} & \multirow[b]{2}{*}{ Location } & \multirow[b]{2}{*}{ Season } & & \multicolumn{2}{|c|}{$\begin{array}{l}\text { \% of time } \\
\text { occurring }\end{array}$} & \multirow{2}{*}{$\begin{array}{c}\begin{array}{c}\% \text { of } \\
\text { parti- } \\
\text { cles with } \\
\text { LH }\end{array} \\
\end{array}$} & \multirow{2}{*}{$\begin{array}{l}\text { Frac- } \\
\text { tion of } \\
\text { occur- } \\
\text { rence }\end{array}$} & \multirow[b]{2}{*}{ Reference } \\
\hline & & & & & $\begin{array}{c}\text { LH } \\
(\mathrm{GF}< \\
1.2)\end{array}$ & $\begin{array}{c}\text { MH } \\
\text { (GF> } \\
1.2) \\
\end{array}$ & & & \\
\hline \multirow[t]{2}{*}{ Street Canyon } & 10 & $\begin{array}{l}\text { HelsinkiFin } \\
\text { land }\end{array}$ & Winter & & 81 & 90 & 47 & 0.38 & $\begin{array}{l}\text { Väkevä et al, } \\
2002\end{array}$ \\
\hline & 20 & & & & 99 & 91 & 52 & 0.51 & \\
\hline \multirow{2}{*}{$\begin{array}{c}\text { Urban } \\
\text { background }\end{array}$} & 20 & Milan, Italy & Winter & & 98 & 100 & 39 & 0.38 & Van \\
\hline & 100 & & & & 100 & 100 & 35 & 0.35 & $\begin{array}{l}\text { unpublished } \\
\text { data }\end{array}$ \\
\hline \multirow[t]{4}{*}{$\begin{array}{c}\text { Urban } \\
\text { background }\end{array}$} & 20 & Milan, Italy & Summer & & 100 & 0 & 100 & 1.00 & $\begin{array}{l}\text { Baltensperger } \\
\text { et al, } 2002\end{array}$ \\
\hline & 50 & & & $*$ & 100 & 100 & 51 & 0.51 & \\
\hline & 100 & & & $*$ & 100 & 100 & 38 & 0.38 & \\
\hline & 200 & & & $*$ & 100 & 100 & 28 & 0.28 & \\
\hline \multirow[t]{4}{*}{$\begin{array}{l}\text { Continental } \\
\text { influenced }\end{array}$} & 50 & $\begin{array}{c}\text { Lindenberg, } \\
\text { Germany }\end{array}$ & Summer & & 0 & 100 & 0 & 0.00 & $\begin{array}{c}\text { Busch et al., } \\
1999\end{array}$ \\
\hline & 100 & & & $*$ & 100 & 100 & 5 & 0.05 & \\
\hline & 150 & & & $*$ & 100 & 100 & 2 & 0.02 & \\
\hline & 250 & & & $*$ & 100 & 100 & 5 & 0.05 & \\
\hline \multirow{2}{*}{$\begin{array}{c}\text { Continental, } \\
\text { influenced }\end{array}$} & 20 & Ispra, Italy & Summer & & 50 & 83 & 68 & 0.34 & Van \\
\hline & 100 & & & & 80 & 82 & 36 & 0.29 & $\begin{array}{c}\text { unpublished } \\
\text { data }\end{array}$ \\
\hline \multirow[t]{4}{*}{$\begin{array}{c}\text { Continental, } \\
\text { influenced }\end{array}$} & 35 & $\begin{array}{l}\text { Sagres, } \\
\text { Portugal }\end{array}$ & Summer & & 34.7 & 100 & 34 & 0.12 & $\begin{array}{l}\text { Swietlicki et } \\
\text { al., } 2000\end{array}$ \\
\hline & 50 & & & & 20.4 & 100 & 16 & 0.03 & \\
\hline & 100 & & & & 7.4 & 100 & 14 & 0.01 & \\
\hline & 250 & & & & 63.6 & 100 & 24 & 0.15 & \\
\hline $\begin{array}{l}\text { Continental, } \\
\text { forest, } \\
\text { influenced }\end{array}$ & 100 & $\begin{array}{l}\text { Vinon, } \\
\text { France } \\
\text { (Mediterran } \\
\text { ean) } \\
\end{array}$ & Summer & & 91 & 100 & 25 & 0.23 & $\begin{array}{c}\text { Van } \\
\text { Dingenen, } \\
\text { unpublished } \\
\text { data } \\
\end{array}$ \\
\hline \multirow[t]{4}{*}{$\begin{array}{l}\text { Amazone } \\
\text { forest }\end{array}$} & 35 & Brasil & Spring & \# & 100 & 7 & 92 & 0.92 & $\begin{array}{l}\text { Zhou et al., } \\
2002\end{array}$ \\
\hline & 50 & & & \# & 94 & 9 & 97 & 0.91 & \\
\hline & 109 & & & \# & 13 & 96 & 46 & 0.06 & \\
\hline & 264 & & & \# & 11 & 97 & 24 & 0.03 & \\
\hline \multirow[t]{4}{*}{ Boreal forest } & 20 & $\begin{array}{c}\text { Hyytiälä, } \\
\text { Finland }\end{array}$ & Spring & $\$$ & 50 & 50 & 100 & 0.50 & $\begin{array}{l}\text { Hämeri et al., } \\
2001\end{array}$ \\
\hline & 50 & & & $\$$ & 70 & 70 & 65 & 0.46 & \\
\hline & 109 & & & $\$$ & 83 & 100 & 53 & 0.44 & \\
\hline & 264 & & & $\$$ & 87.3 & 100 & 28 & 0.24 & \\
\hline \multirow{4}{*}{$\begin{array}{l}\text { Biomass } \\
\text { burning plume, } \\
\text { fresh }\end{array}$} & 20 & Amazonia & Tropics & & 100 & 0 & 100 & 1 & Vestin, 2003 \\
\hline & 50 & & & & 100 & 0 & 100 & 1 & \\
\hline & 110 & & & & 100 & 2 & 100 & 1 & \\
\hline & 265 & & & & 100 & 33 & 87 & .87 & \\
\hline \multirow{4}{*}{$\begin{array}{c}\text { Biomass } \\
\text { burning plume, } \\
\text { slightly aged }\end{array}$} & 20 & Amazonia & Tropics & & 95 & 30 & 92 & 0.87 & Vestin, 2003 \\
\hline & 50 & & & & 100 & 0 & 100 & 1 & \\
\hline & 110 & & & & 100 & 0 & 100 & 1 & \\
\hline & 265 & & & & 100 & 27 & 89 & 0.89 & \\
\hline \multirow{4}{*}{$\begin{array}{c}\text { Biomass } \\
\text { burning plume, } \\
\text { aged }\end{array}$} & 20 & Amazonia & Tropics & & 59 & 64 & 86 & 0.5 & Vestin, 2003 \\
\hline & 50 & & & & 100 & 2 & 100 & 1 & \\
\hline & 110 & & & & 100 & 78 & 78 & 0.78 & \\
\hline & 265 & & & & 96 & 94 & 39 & 0.37 & \\
\hline
\end{tabular}


Table 10. Continued.

\begin{tabular}{|c|c|c|c|c|c|c|c|c|}
\hline \multirow[t]{3}{*}{$\begin{array}{c}\text { Biomass } \\
\text { burning plume } \\
\text { very aged }\end{array}$} & 50 & $\begin{array}{c}\text { W-Africa - } \\
\text { Atlantic } \\
\text { Ocean }\end{array}$ & Tropics & 0 & 100 & 0 & 0.000 & \multirow[t]{3}{*}{$\begin{array}{c}\text { Massling et } \\
\text { al., } 2003\end{array}$} \\
\hline & 150 & & & 0 & 100 & 0 & 0.000 & \\
\hline & 250 & & & 0 & 100 & 0 & 0.000 & \\
\hline \multirow{3}{*}{$\begin{array}{c}\text { Marine, } \\
\text { continental } \\
\text { influenced, } \\
\text { aged } 12 \text { to } 36 \\
\text { hours }\end{array}$} & 50 & \multirow[t]{3}{*}{$\begin{array}{l}\text { Indian } \\
\text { Ocean }\end{array}$} & \multirow[t]{3}{*}{ Tropics } & 0 & 100 & 0 & 0.000 & \multirow[t]{3}{*}{$\begin{array}{l}\text { Massling et } \\
\text { al., } 2003\end{array}$} \\
\hline & 150 & & & 0 & 100 & 0 & 0.000 & \\
\hline & 250 & & & 35 & 100 & 0.05 & 0.000 & \\
\hline \multirow[t]{4}{*}{ Marine, clean } & 50 & \multirow[t]{4}{*}{$\begin{array}{l}\text { NE- } \\
\text { Atlantic }\end{array}$} & \multirow[t]{4}{*}{ Summer } & 0 & 100 & 0 & 0.000 & \multirow[t]{4}{*}{$\begin{array}{l}\text { Swietlicki et } \\
\text { al., } 2000\end{array}$} \\
\hline & 100 & & & 1.9 & 100 & 8 & 0.002 & \\
\hline & 150 & & & 0.9 & 100 & 17 & 0.002 & \\
\hline & 250 & & & 0.9 & 100 & 10 & 0.001 & \\
\hline \multirow[t]{4}{*}{ Marine, clean } & 35 & \multirow{4}{*}{$\begin{array}{l}\text { Tenerife, } \\
\text { Canary } \\
\text { Islands }\end{array}$} & \multirow[t]{4}{*}{ Summer } & 3.1 & 100 & 15 & 0.005 & \multirow{4}{*}{$\begin{array}{c}\text { Swietlicki et } \\
\text { al., } 2000\end{array}$} \\
\hline & 50 & & & 2.7 & 100 & 24 & 0.006 & \\
\hline & 109 & & & 2.5 & 100 & 16 & 0.004 & \\
\hline & 264 & & & 0 & 100 & 0 & 0.000 & \\
\hline $\begin{array}{l}\text { Marine, coastal } \\
\text { nucleation }\end{array}$ & 20 & $\begin{array}{l}\text { Mace- } \\
\text { Head, } \\
\text { Ireland }\end{array}$ & Summer & 8 & 92 & 4 & 0.003 & $\begin{array}{l}\text { Väkevä et al, } \\
2002\end{array}$ \\
\hline
\end{tabular}

* set $\%$ of occurrence $=100 \%$ when info missing; \# the discontinuity between Aitken and accumulation mode caused by the artificial separation at GF 1.2 ; Aitken mode particles have the LH GF only slightly $<1.2$, accumulation mode particles have a GF=1.22-1.32; $\$$ Taking into account periods of internal mixing with diurnal cycle of being $<1.2$ for about $50 \%$ of the time

growth associated with inorganic species was sufficient to account for measured light scattering for $\mathrm{RH}$ between 70 and $95 \%$. Analysis of visibility measurements in the Great Smoky Mountain (Eastern US) and Grand Canyon (Western US) suggested that organics were weakly to non hygroscopic (Malm and Day, 2001).

Dick et al. (2000) found that the water content of sub-0.4 micrometer particles measured by TDMA in Great Smoky Mountains was higher than the sulphate-associated water modelled using laboratory data for binary aqueous solutions and the method of Zdanovskii-Stokes-Robinson (ZSR) for multi-component solutions over a wide range of humidities $(\mathrm{RH}=5-85 \%)$. Furthermore, excess water was observed to increase in proportion to the organic fraction of mass. Organic-associated water content was considerably less than that of sulphate compounds, on a volume basis, for high RH, but comparable or greater for low RH.

Speer et al. (2003) used a beta gauge to measure the change in $\mathrm{PM}_{2.5}$ mass on a filter as a function of relative humidity in a humidity-controlled environmental chamber. For six of the eight samples collected in North Carolina, the measured liquid water concentrations exceeded those predicted from the presence of the inorganic constituents. A relationship between the excess liquid water and the measured organic carbon mass was found, although the standard deviations associated with the measurements were large. Through modelling studies it was determined that, on average, about
$20 \%$ of the aerosol water could be associated with organic compounds. These results were relatively consistent with the measurements and analysis of Khlystov et al. (2005) in the Northeastern US. The authors concluded that as much as $30 \%$ of the aerosol water during the summer could be due to the organics.

The study of the hygroscopic behaviour of atmospheric particles collected above the North Atlantic Ocean by Posfai et al. (1998) suggested that organic films on the particles may be responsible for the observed relatively large uptake at low relative humidities. On the other hand, it has been hypothesized that the presence of organic films on the surface of aerosols can strongly inhibit condensational growth. Chuang (2003a) measured the timescale for condensational growth of ambient particles with diameters of 50 and $100 \mathrm{~nm}$ in Mexico City. He showed that almost all the particles (more than 98\%) during both wet and dry conditions exhibit timescales of less than $3 \mathrm{~s}$.

\section{Organic aerosol-cloud interactions}

It was originally assumed that cloud condensation nuclei $(\mathrm{CCN})$ concentration at a given supersaturation is mainly a function of aerosol number concentration and the ability of an aerosol particle to become cloud droplet is mainly controlled by the aerosol particle radius (e.g., Feingold, 2003). 
Recently, studies which use new data on aerosol chemical composition (e.g., Shulman et al., 1996; Facchini et al., 1999b; Mircea et al., 2002; Nenes et al., 2002b) show that chemical composition of the aerosol can also influence the CCN number concentrations.

- Understanding of the processes by which the particles containing organic compounds are transformed into drops is a necessary requirement for improving the certainty of climate change predictions (Charlson et al., 2001).

- This need for understanding organic aerosol will become even more important in the future, where carbonaceous aerosol emissions from developing economies are expected to dramatically increase (IPCC, 2001).

Cloud droplet activation is a key process for the indirect effect, since it is the direct microphysical aerosol-cloud link. Although the basic theory of aerosol activation is well established, inclusion of numerical activation models (e.g., Jensen and Charlson, 1984; Flossmann et al., 1985; Pruppacher and Klett, 1980; Seinfeld and Pandis, 1998; Nenes et al., 2001) is in itself computationally challenging, so activation needs to be parameterized. Numerous such parameterisations have appeared over the years (e.g., Twomey, 1959; Squires and Twomey, 1960; Feingold and Heymsfield, 1992; Cohard et al., 1998, 2000; Ghan et al., 1993, 1995; Abdul-Razzak et al., 1998; Abdul-Razzak and Ghan, 2000; Chuang and Penner, 1995; Rissman et al., 2004; Nenes and Seinfeld, 2003). Very few of these relationships can explicitly account for the effect of organic aerosol. This is because

- the properties of potentially $\mathrm{CCN}$ active organics in aerosols are not sufficiently known and thus

- the resulting modified Köhler equation for CCN containing organics cannot be solved explicitly for their critical supersaturation, $S_{c}$, a requirement for most extant parameterisations.

8.1 Organic species and their effect on cloud droplet formation.

Organic species, accounting from 10 to $70 \%$ of the total ambient aerosol mass (Saxena and Hildemann, 1996; Zappoli et al., 1999; Turpin et al., 2000) are an important class of compounds and are at present poorly characterized (Jacobson et al., 2000). Novakov and Penner (1993), Novakov and Corrigan (1996), Facchini et al. (1999b) (and others) have proved that the more water soluble organic compounds in particular influence the ability of an aerosol particle to act as CCN. However, the interactions of organic species with water vapour are largely unknown. Köhler theory has been shown to apply for CCN composed of simple organic molecules (Cruz and Pandis, 1997), but fails to describe more complex organic species (e.g., Raymond and Pandis, 2003). Organic compounds can introduce competing effects on the activation behaviour of $\mathrm{CCN}$ by:

Alteration of surface tension: The presence of organic surface active species, i.e., reductions in solution surface tension relative to pure water, promotes $\mathrm{CCN}$ activation by decreasing the critical supersaturation (Shulman et al., 1996; Facchini et al., 1999a). Inorganic salts do not appreciably increase surface tension in CCN (Pruppacher and Klett, 1980). Facchini et al. (2000) have shown that humic-like compounds have a more pronounced surface-active behaviour, when compared to other class of compounds like mono- and di-carboxylic acids. Another important factor determining surface tension reduction is related to the amount of dissolved organic among the CCN size distribution and hence is connected to the concentration and solubility properties of surfactants in deliquescent particles (Rissman et al., 2004; Decesari et al., 2003).

Contribution of solute: Organic compounds can contribute soluble material to the growing particle and affect its growth. Those with limited solubility can lead to a gradual dissolution of solute; this increases the amount of dissolved material in the particle phase. The added soluble material will eventually facilitate the formation of a cloud droplet (e.g., Shulman et al., 1996; Laaksonen et al., 1998). This results in equilibrium curves with multiple maxima if the solubility limits of the slightly soluble aerosol constituents are gradually exceeded, which can lead to large but stable drops that are typically assumed to be activated (Laaksonen et al., 1998). Hori et al. (2003) pointed out that the critical supersaturations for slightly water-soluble compounds could depend significantly on the initial particle phase (solid or liquid) that appears a key factor to be determined in order to evaluate the actual CCN ability for these compounds. In addition, the interaction between inorganic and organic compounds is not well understood. Current approaches predict either profound (Clegg et al., 2001) or negligible effects (Ming and Russell, 2001) on the water activity within the aerosol. At present, thermodynamic data for more realistic aerosol chemical composition are sparse. It should be noted however that the presence of some highly soluble material in the aerosol (such as sulphate) can dominate the water uptake enough to diminish the aforementioned complexities; nevertheless the contribution of slightly soluble salts to the activation properties of the aerosol needs to be considered (Raymond and Pandis, 2003).

Affecting wettability: Recent work (Raymond and Pandis, 2002) shows that a pure organic compound, even with solubility less than $0.01 \mathrm{~g} \mathrm{~cm}^{-3}$, could be an efficient $\mathrm{CCN}$ if its contact angle with water is close to zero. It may be that liquid water, because of the small contact angle, does not effectively come into contact with the soluble material to dissolve it; therefore the material never gets incorporated into a droplet that may form on its surface and affect subsequent water uptake. The effect of wettability may not be an issue for ambient multi-component aerosol, which almost always 
contains wettable material, and thus can always form a film of liquid water that would dissolve substances of any contact angle.

Affecting growth kinetics: It is known that film monolayer of certain compounds (called "film-forming compoundsFFC" by Feingold and Chuang, 2002) can inhibit the rate of condensation and evaporation (Barnes, 1986; Rubel and Gentry, 1984; Chuang, 2003). This inhibition is expressed through the water accommodation coefficient (Eq. A3). The accepted value of the condensation coefficient for water vapour onto cloud droplets is $\sim 0.045$, although the values range considerably between studies (Pruppacher and Klett, 1980; Mozurkewich, 1986). The degree to which this inhibition occurs in ambient aerosol is highly uncertain, although there is evidence for the existence of FFC compounds in ambient aerosol with a water accommodation coefficient as low as $10^{-5}$ (Chuang, 2003).

Slow growth kinetics can also arise from the presence of compounds of limited solubility (Shulman et al., 1996; Shantz et al., 2003). The existence of slowly-growing CCN, depending on how the material is distributed among the particle size distribution, can either decrease (Feingold and Chuang, 2002) or increase droplet number (Nenes et al., 2002b). There is increasing evidence that such hydrophobic films (e.g., fatty acids) can have both biogenic and anthropogenic sources. In addition to these water-insoluble, hydrophobic films, there are indications, using dynamic surface tension measurements that also water-soluble organics accumulate at the air-water-interface (Decesari et al., 2003).

Quite often, an organic compound may exhibit many of the aforementioned properties, leading to complex $\mathrm{CCN}$ behaviour. This complexity most likely explains the diversity of conclusions with regard to the role of organics found in the published literature (e.g., Mircea et al., 2002; Feingold 2003; Nenes et al., 2002b; Ervens et al., 2004b; Rissman et al., 2004). Understanding the effect of organics on $\mathrm{CCN}$ properties is important to assess their effect on cloud droplet number. Nevertheless, the relative influence of organic species on cloud droplet formation strongly depends on the mass size distribution of the organic aerosol, on the number size distribution and the dynamical conditions of cloud formation (Nenes et al., 2002a, b; Rissman et al., 2004).

\subsection{Representation of the water soluble organic compounds} (WSOC) in models

In the absence of chemical composition information, aerosol WSOC is often assumed to be composed of compounds which are not representative of ambient particulate matter. This can clearly bias modelling studies that utilize an incomplete description of organic aerosol. For example, observations of surface tension depression in ambient cloud water samples (Facchini et al., 1999a) show completely different behaviour from aqueous solutions of monocarboxylic (Seidl, 2000) and dicarboxylic acids (Shulman et al., 1996) which are typically used to represent ambient WSOC. Even if a complete chemical characterization of aerosol was available, the complexity and large number of compounds typically found in aerosols would render it an almost intractable modelling problem. Hence, there is the need for an appropriate simplification of the WSOC by assuming a mixture of a few compounds that could capture most of the physicochemical properties of the real organic mixture.

Several authors have speculated on the nature and origin of the WSOC (e.g., Saxena and Hildemann, 1996; Pun et al., 2000; Ervens et al., 2004a), but observations on speciation of WSOC in ambient aerosol are sparse (Likens et al., 1983; Kiss et al., 2001; Mayol-Bracero et al., 2002; Zappoli et al., 1999; Facchini et al., 1999b). Historically, the speciation of organic carbon is done by identification of individual compounds. However, this approach is labour-intensive and can account for only a small fraction of the total aerosol mass. Most importantly, such methods do not identify most of the polar oxygenated organic fraction, which are the more watersoluble species and thus, possibly CCN active (e.g., Rogge et al., 1993).

An alternative approach to characterization of WSOC is based on functional group analysis (Decesari et al., 2000; Russell et al., 2002), which aims to characterize the relative abundance of functional groups that are responsible for the WSOC chemical properties. Recently a procedure based on functional group analysis (Decesari et al., 2000) to derive a simplified model of WSOC fraction has been proposed (Fuzzi et al., 2001). Quantitative measurements of organic carbon concentration and proton concentration of the main functional groups contained in the aerosol WSOC mixture are used to formulate a set of a few model compounds (acidic, basic, neutrals), which can be used to simulate the chemical and physical properties of water soluble organic aerosol. The same conceptual method to derive model compounds applied to Po Valley aerosol (Fuzzi et al. 2002) can be used for other aerosol populations. The ultimate aim of these studies is to represent the hygroscopicity, the chemical reactivity and the physical and optical properties of OA with the same model compounds and mixtures.

\section{Optical properties of organics}

To quantify the direct aerosol influence on the atmospheric radiative balance the fundamental parameters to investigate are the optical depth, $\tau$, and the single scattering albedo (SSA), $\omega$ (Hansen et al., 1997). The optical depth is the extinction resulting from absorption and scattering of radiation by the aerosols in a column and is directly dependent on the aerosol amount. The spectral characteristics of $\tau$ are required to model the radiative effects of aerosols, to retrieve aerosol parameters from satellite remote sensing, and to correct for aerosol effects in remote sensing of the earth's surface. In a more detailed understanding of the influence of 
different aerosol types on the radiative balance, the key parameter to be explored is the single scattering albedo (Hansen et al., 1997). The single scattering albedo of a single particle is defined as:

$\varpi=\frac{Q_{s c a t}}{Q_{s c a t}+Q_{a b s}}$

where $Q_{\text {scat }}$ and $Q_{a b s}$ are the scattering and absorption efficiencies of the aerosol, commonly calculated by Mie theory assuming spherical aerosols and adopting the aerosol complex index of refraction and a size distribution. The single scattering albedo of aerosols is thus determined by the aerosol size and its composition, that is by its complex index of refraction, $\tilde{N}(\lambda)=\mathrm{n}(\lambda)+\mathrm{ik}(\lambda) ; k(\lambda)$ is the wavelength dependent absorption index and $n(\lambda)$ is the corresponding refractive index. The interpretation of the single scattering albedo is that for $\omega=1$ the aerosol investigated is totally scattering and lower the global mean surface temperature; low values of $\omega$ indicate that the aerosols will increase the global mean surface temperature. Several climate and radiative model studies have investigated the turnover value and critical values in the range from $0.85-0.91$ are reported (Hansen et al., 1997; Haywood and Shine, 1995).

9.1 The optical properties of organic compounds present in tropospheric aerosols

The single scattering albedo is strongly dependent on the refractive and particularly the absorption index in the UV and visible region. Until now, only soot (with high black carbon content) aerosols are known to have a positive direct aerosol forcing, increasing the surface temperature. Only a single study exists on the complex index of refraction of various organic aerosol components and mixtures representative of atmospheric conditions (Myhre and Nielsen, 2004). Consequently, the effect of the individual organic compounds in the aerosols on the incoming solar radiation is characterized by a large uncertainty.

Whereas data on the complex index of refraction of mixtures of organic components relevant to atmospheric aerosols is sparse, there are several studies of pure organic liquids and their absorption index and/or refractive index in the short wavelength region at a single selected wavelength or in a wider region (Bertie and Lan, 1995; El-Kashef, 1998; Jacobson, 1999; Li et al., 1994; Marsh, 1987; Räty et al., 1999). Figures 7a, b summarize the absorption and refractive indices, respectively, of organic components relevant to the troposphere. These figures include the optical constants of some pure organic liquid components (Bertie and Lan, 1995; El-Kashef, 1998; Jacobson, 1999; Li et al., 1994; Marsh, 1987; Räty et al., 1999), the absorption and refractive index of lignin dissolved in water (Räty et al., 1999), and selected optical constants of aqueous organic acids present in tropospheric aerosols, and fog samples (Myhre and Nielsen, 2003; Myhre and Nielsen, 2004). Finally, a typical literature value
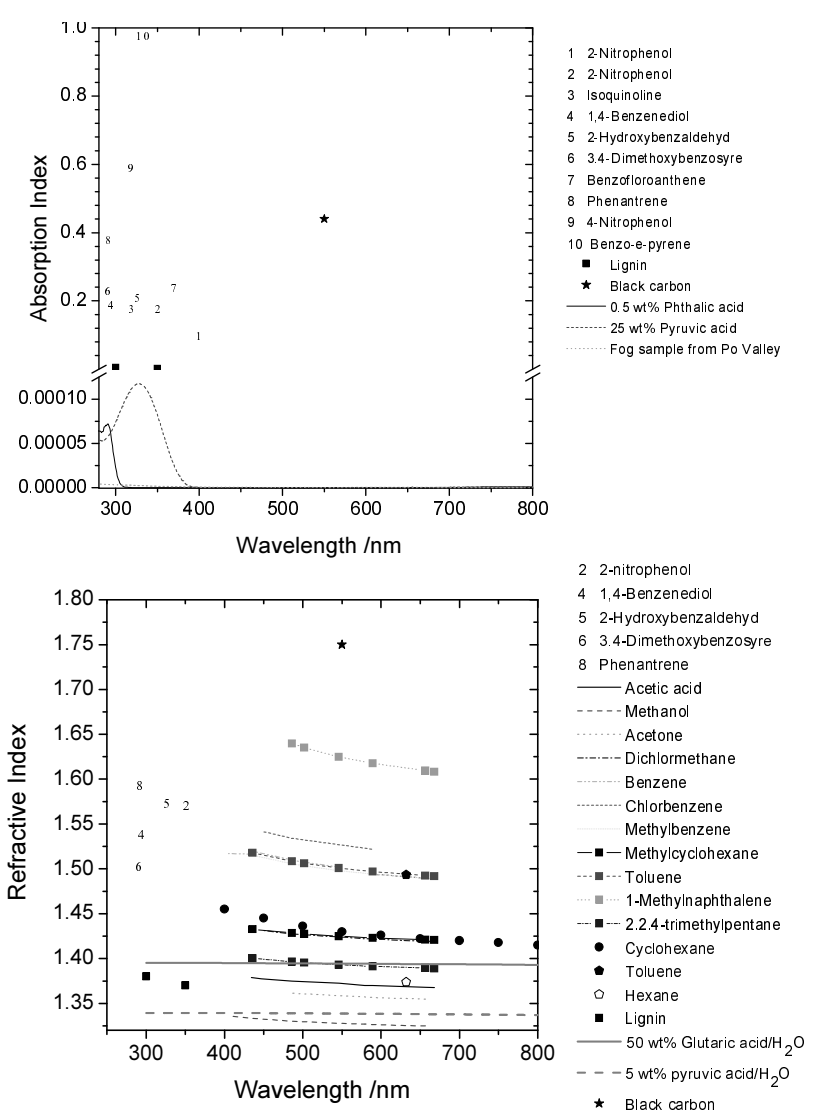

Fig. 7. Optical constants of pure organic liquids relevant to tropospheric aerosols, organic acids identified in the aerosol WSOC fraction and polluted fog samples. (a) Upper panel: Absorption indices, $\mathrm{k}(\lambda)$ (b) Lower panel: Refractive index, $\mathrm{n}(\lambda)$.

of soot (Liu et al., 2002) is indicated by solid star in this figure to show the optical constants of an aerosol component, which is known to strongly absorp in the atmosphere.

Jacobson (1999) investigated the influence of nitrated and aromatic aerosols and gases on the extinction processes responsible for the reductions in the downward solar irradiance in the Los Angeles region. The absorption index of the aerosol components was derived at the wavelength of strongest absorption from molar absorption spectra and reported along with corresponding available refractive index data. Table 11 contains a selection of the optical constants reported by Jacobson (1999). All the components listed are observed in the atmospheric particulate matter (Jacobson, 1999 and references therein), in particular in polluted regions. The components with the highest absorption index in each class of the organic compounds listed in Table 11 are included in Fig. 7. As mentioned, Jacobson (1999) reported only the absorption index at one wavelength - the one with the maximum absorption index. Several of the components will certainly have absorption tails in the $400-500 \mathrm{~nm}$ range; such as nitrobenzene and nitro phenols (Jacobson, 1999), and 
Table 11. A selection of the optical constants reported by Jacobson (1999). All the components listed are observed in the tropospheric particulate matter.

\begin{tabular}{|c|c|c|c|c|}
\hline Chemical name & $\lambda_{\text {peak }} / \mathrm{nm}$ & $\mathrm{k}(\lambda)$ & $\mathrm{n}(\lambda)$ & Solubility in water \\
\hline \multicolumn{5}{|l|}{ Nitrated aromatics } \\
\hline 2-nitrophenol & 351 & 0.18 & 1.5724 & slightly soluble \\
\hline 2.6-Dinitrophenol & 350 & 0.3 & & insoluble \\
\hline 1.2-Dimethoxy-4-nitrobenzene & 323 & 0.31 & & insoluble \\
\hline 2-Methyl-4-nitrophenol & 319 & 0.54 & & slightly soluble \\
\hline 4-Nitrophenol & 317 & 0.59 & & slightly soluble \\
\hline 2.4-Dinitrophenol & 292 & 0.49 & & slightly soluble \\
\hline 4-Methyl-2-nitrophenol & & & 1.5744 & \\
\hline \multicolumn{5}{|l|}{ Benzaldehydes } \\
\hline 2-Hydroxybenzaldehyde & 326 & 0.21 & 1.5740 & slightly soluble \\
\hline 3-Methoxybenzaldehyde & 310 & 0.12 & 1.5530 & insoluble \\
\hline 3-Methylbenzaldehyde & 255 & 0.85 & 1.5454 & slightly soluble \\
\hline \multicolumn{5}{|l|}{ Aldehydes } \\
\hline Formaldehyde & 330 & 0.0007 & & soluble \\
\hline \multicolumn{5}{|l|}{ Benzoic acids } \\
\hline 3.4-Dimethoxybenzoic acid & 290 & 0.23 & & insoluble \\
\hline 4-Methylbenzoic acid & 280 & 0.025 & & insoluble \\
\hline Benzoic acid & 279 & 0.039 & 1.5040 & slightly soluble \\
\hline \multicolumn{5}{|l|}{ Aromatic polycarboxcylic acids } \\
\hline Phathlic acid & 281 & 0.09 & & slightly soluble \\
\hline \multicolumn{5}{|l|}{ Phenols } \\
\hline 1,4-Benzenediol & 294 & 0.19 & & soluble \\
\hline 4-Methylphenol (p-cresol) & 286 & 0.1 & 1.5312 & slightly soluble \\
\hline Phenol & 275 & 0.068 & 1.5408 & soluble \\
\hline 2-Methylphenol (o-Cresol) & 273 & 0.096 & 1.5361 & soluble \\
\hline \multicolumn{5}{|l|}{ Aromatic hydrocarbons } \\
\hline Anthracene & 376 & 0.14 & & insoluble \\
\hline Benzofloroanthene & 369 & 0.24 & & insoluble \\
\hline Fluoranthene & 357 & 0.34 & & insoluble \\
\hline Acenenaphtalene & 339 & 0.17 & & insoluble \\
\hline Pyrene & 334 & $1.13 ?$ & & \\
\hline Benzoic[a]pyrene & 333 & 0.94 & & \\
\hline Benzoic[e]pyrene & 332 & 0.98 & & \\
\hline Acenenaphtalene & 320 & 0.06 & 1.6048 & insoluble \\
\hline Chrysene & 319 & 0.4 & & insoluble \\
\hline 2-Methylnaphtalene & 318 & 0.021 & 1.6015 & insoluble \\
\hline Naphthalene & 311 & 0.011 & 1.5898 & insoluble \\
\hline Fluorene & 300 & 0.4 & & insoluble \\
\hline Phenantrene & 291 & 0.38 & 1.5943 & insoluble \\
\hline \multicolumn{5}{|l|}{ Organic bases } \\
\hline 1-Methyl isoquinoline & 320 & 0.13 & 1.6095 & slightly soluble \\
\hline Isoquinoline & 318 & 0.18 & 1.6148 & insoluble \\
\hline 2.4-Dimethylquinoline & 315 & & 1.6075 & slightly soluble \\
\hline Quinoline & 308 & 0.18 & 1.6268 & insoluble \\
\hline Indole & 287 & 0.23 & & soluble \\
\hline
\end{tabular}

the very strong absorbers like Benzo[e]pyrene, observed by Rogge et al. (1993) in Los Angeles. Pure liquid nitro phenol has an absorption index close to 0.1 at $400 \mathrm{~nm}$ (Jacobson, 1999); this value is also included in Fig. 7a. The work of Jacobson (1999) clearly demonstrates that more labora- tory data is needed as many of the components observed in the tropospheric aerosols have high absorption indices in the UV-region and with absorption tails in the visible region.

Räty et al. (1999) investigated the complex index of refraction of 2 solutions, red food colour and lignin, in the range 
from $250-450 \mathrm{~nm}$. Their study of lignin has relevance to atmospheric aerosols, and the results at selected wavelengths are included in Fig. 7. Räty et al. (1999) presents the data of lignin exclusively in graphical form showing maximum absorption at $\sim 290 \mathrm{~nm}$. The samples were prepared by diluting $40 \mathrm{~g}$ lignin $\mathrm{L}^{-1}$ water and further concentrated by evaporating the initial volume to the half. They report an absorption index at $300 \mathrm{~nm}$ estimated to 0.005 decreasing to 0.002 at $350 \mathrm{~nm}$. The corresponding values of $n(\lambda)$ are 1.38 and 1.37, respectively; the values are included in Fig. 7 by solid squares.

A series of studies report only the refractive index, $n(\lambda)$, of pure organic liquids. Marsh (1987) measured the refractive index at $293 \mathrm{~K}$ of 1-Methylnaphthalene, toluene, and 2.2.4trimethylpentane at 7 selected wavelengths in the UV and visible range. All the values are included in Fig. 7b as different symbols connected with lines. Li et al. (1994) have measured the refractive index of liquid $n$-hexane and toluene at $632.8 \mathrm{~nm}$ at 7 temperatures ranging from $15-45^{\circ} \mathrm{C}$. Their results for toluene are in excellent agreement with those of Marsh (1987) and their value for $n$-hexane is shown in the figure by an open start. Bertie and Lan (1995) calculated the refractive index of pure acetic acid, methanol, acetone, dichloromethane, benzene, chlorobenzene and methylbenzene in the UV-Visible region by extending the KramersKronig transformation of absorption indices obtained in the infrared region. The results are presented in Fig. 7 as solid and dotted lines. Unfortunately, they did not present absorption indices in the UV-region, only in the infrared region. ElKashef (1998) measured the refractive index of cyclohexane in the range from $400-800 \mathrm{~nm}$ at $293 \mathrm{~K}$; the results are only presented in graphical form and selected values are included in Fig. 7 by solid circles. The temperature dependence of the refractive index in this wavelength range is reported to be in the order of $\mathrm{dn} / \mathrm{dT}=-5 \times 10^{-4} \mathrm{~K}$ for all the investigated pure organic components (Bertie and Lan, 1995; El-Kashef, 1998; Li et al., 1994). Various other studies of the refractive index, $n(\lambda)$, of organic liquids report values at one single wavelength, $590 \mathrm{~nm}$, and some of them are relevant to atmospheric conditions (Aminabhavi et al., 1996; Cases et al., 2001; De Lorenzi et al., 1997; Gomez-Diaz et al., 2001; Ritzoulis and Fidantsi, 2000; Segade et al., 2003). The results from these studies are consistent with the values presented in Fig. 7b. Several of these studies investigate the refractive index of binary organic liquids (Aminabhavi et al., 1996; Cases et al., 2001; Gomez-Diaz et al., 2001; Segade et al., 2003). Cases et al. (2001) investigated mixtures of formamid and 3 carboxylic acids and Segade at al. (2003) investigated the properties of octane mixed with 7 alkanols. The studies show that the deviation from a linear mixing rule is less than $5 \times 10^{-3}$ and that the largest deviations are observed in the region around 0.5 mole fraction.

Recently Myhre and Nielsen (2004) reported the complex index of refraction of several aqueous organic acids. They investigated the absorption and refractive indices of aliphatic dicarboxylic acids and aromatic acids. The concentrations of the investigated samples ranged from highly diluted samples up to saturation concentrations. The organic acids investigated were the low molecular weight dicarboxylic acids: oxalic, malonic, succinic, glutaric, hydroxymalonic acid, in addition they investigated benzoic, phthalic and pinonic acid. The results show that all the aliphatic acids have their absorption bands in the UV-region below $300 \mathrm{~nm}$, except for pyruvic acid. Of the aromatic acids, phthalic acid is the one with the highest absorption index. Pyruvic acid has an absorption band at $328 \mathrm{~nm}$ and the absorption index for a 25 weight percent (wt\%) solution in water is reported as $1.2 \times 10^{-4}$. In the visible and near infrared region the absorption indices of all the acids are nearly identical to that of ammonium sulphate and essentially determined by the water band at $980 \mathrm{~nm}$. The results of 0.5 weight percent (wt \%) phthalic acid and $25 \mathrm{wt} \%$ pyruvic acid are included in Fig. 7a. Regarding the refractive index of the aqueous organic acids it is essentially determined by the amount acid present, and not by any molecular characteristics of the components. The refractive index changes linearly with the total acid weight percent in the investigated concentration range; $0-60 \mathrm{wt} \%$ and the results of $50 \mathrm{wt} \%$ glutaric acid and $5 \mathrm{wt} \%$ pyruvic acid are shown in Fig. $7 \mathrm{~b}$ as fat solid and dotted grey lines.

\subsection{The optical properties of mixtures of organic com- pounds}

In addition, Myhre and Nielsen (2004) calculated the single scattering albedo, SSA, of some binary mixtures as well as one complex mixture adopting the same size distribution as normally used in modelling studies of sulphate aerosols. The conclusion from these calculations was that all the investigated organic acids have a pure scattering effect. They scatter solar radiation similar to sulphate aerosols and they have similar cooling effect on the climate. Nevertheless, in the interpretation of the results it is important to remember that at tropospheric conditions the saturation concentrations may well be much higher than in the binary water/acid solutions due to the other components present in the aerosol. This will affect the absorption indices and in turn the SSA.

The content of organic components in fog water exhibits a clear similarity to that observed for the water-soluble fraction of the fine mode aerosols collected in polluted areas as the Po Valley, Italy (Fuzzi et al., 2002). Fog samples may thus be considered as diluted aerosols samples. Myhre and Nielsen (2003) have investigated the absorption index of fog samples collected in the Po Valley and the results of the most polluted sample is included in Fig. 7a. The results show that the absorption index has a very broad tail into the visible region. However, the observed difference between the absorption index of water and the fog samples from the Po Valley has negligible effect in the reduction of the single scattering albedo of clouds and fog droplets. Consequently, the scattering and absorption properties of fog and clouds can be treated 
as pure water in radiation calculations, even in polluted regions. This is in line with the conclusion of Liu et al. (2002), who investigated the presence of black carbon, $\mathrm{BC}$, in cloud droplets. They concluded that the observed BC mass concentrations are usually too low to reduce the cloud albedo in any significant way and their conclusion is in agreement with the results of Twohy et al. (1989).

Schnaiter et al. (2003) investigated the impact of coating of soot with organic material formed during ozonolysis of a-pinene. They found strong increases of both the SSA and the absorption cross section of the soot particles due to the coating by SOA and concluded that global forcing by black carbon aerosols should be revised to include the absorption enhancement effect as suggested by Jacobson (2001).

\section{Direct climatic impact of organic aerosol}

The most simplified way to evaluate the radiative forcing of the atmosphere resulting from OA in global models has been the use of a constant extinction coefficient for OA and the assumption that $\mathrm{OA}$ and the other aerosol components are externally mixed. This is the approach that has been followed in the first global study by Liousse et al. (1996), who assumed a constant extinction coefficient of OA within each one of 3 considered wavelength bands and allowed modification of the optical properties of OA by the presence of aerosol associated water similar to that for sulphate aerosols.

Since then a lot of progress has been made (IPCC, 2001 and references therein). A relatively limited number of studies has investigated the direct radiative forcing resulting from organic aerosol (IPCC, 2001 and references therein, Myhre et al., 2001; Takemura et al., 2001; Chung and Seinfeld, 2002) and among them only one (Chung and Seinfeld, 2002) has explicitly treated the occurrence of SOA in the troposphere.

In these studies of radiative forcing, the required optical properties of the aerosols i.e. extinction coefficient, single scattering albedo (SSA) and asymmetry factors are determined by Mie theory calculations that require wavelength and size dependent refractive indices of aerosols. For these calculations the refractive indices of the individual aerosol components are needed as well as the assumed dry mass density and size distribution of aerosols. The wavelength bands used for the radiative calculations vary, in number and size, from one model to the other. Kinne et al. (2003) present a very comprehensive evaluation of 7 global models considering at least 5 aerosol components including OA, by comparison with satellite and AERONET ground-based data. The reader is referred to Kinne et al. (2003) for an overview of the major differences that can exist between models with regard to the above mentioned parameters that determine the overall aerosol optical properties on which replies the calculated climatic impact of aerosols. The ongoing AEROCOM intercomparison exercise (http://nansen.ipsl.jussieu.fr/ AEROCOM) is expected to go a step further and quantify the contribution of the various factors to the overall uncertainty in the latest radiative forcing calculations.

Hereafter we aim to provide a summary of how different models are treating the OA for direct forcing calculations. When comparing the extinction coefficients at a specific wavelength used for OA in global models (when this information is available), one can notice a factor of 3-4 difference in the adopted values. For instance, Liousse et al. (1996) assumed a specific extinction coefficient of $4 \mathrm{~m}^{2} \mathrm{~g}^{-1}$ (at $550 \mu \mathrm{m}$ ) for dry OA that was considered to be purely scattering, whereas Cooke et al. (1999) adopted a slightly lower value of $3.6 \mathrm{~m}^{2} \mathrm{~g}^{-1}$ (at $500 \mu \mathrm{m}$ ), SSA of 0.98 (slightly absorbing OA from fossil fuel) and effective radius of $0.02 \mu \mathrm{m}$. Koch et al. (2001) used a specific extinction coefficient for OA of $8 \mathrm{~m}^{2} \mathrm{~g}^{-1}$ (at $550 \mu \mathrm{m}$ ) to account for neglecting the water uptake by organics, SSA of 0.96 and effective radius of $0.5 \mu \mathrm{m}$. Chung and Seinfeld (2002) used an extinction coefficient of $2.53 \mathrm{~m}^{2} \mathrm{~g}^{-1}$ for dry OA, SSA of 0.94 and effective radius of $0.5 \mu \mathrm{m}$. These assumptions affect the calculated direct radiative global forcing of OA since they apply to the OA distributions computed on the basis of emissions, chemistry, transport and deposition processes as discussed in the previous sections.

Another important source of differences in the radiative forcing calculations for $\mathrm{OA}$ is the consideration or not of the water associated to that aerosol. Although, there is not always sufficient information on whether and how the water uptake by OA has been taken into account in the models. Chung and Seinfeld (2002) calculated an increase by $-0.09 \mathrm{Wm}^{-2}$ in the radiative forcing at the top of the atmosphere since preindustrial time produced by wet OA compared with that calculated for the dry OA $\left(-0.09 \mathrm{Wm}^{-2}\right)$. This difference seems to apply also when mixtures (external or internal) of aerosols are considered and points to the importance of understanding the interactions between OA and water in the atmosphere as described above. Note that there is important spatial and temporal variability in this forcing. In addition, the consideration of internally mixed aerosol (ammonium sulphate, and carbonaceous) is lowering the calculated cooling direct climate effect of aerosols compared with the externally mixed aerosol case (from -0.78 to $-0.48 \mathrm{~W} \mathrm{~m}^{-2}$ ).

Indeed, the consideration of internal mixing of aerosols has been recently shown critical for forcing estimates (Jacobson, 2001a; Lesins et al., 2002). Recent observational data show the drastic enhancement of BC absorption when it is coated by soluble material (Schaiter et al., 2003). Lesins et al. (2002) estimated that for specific internal mixing assumptions nearly all of the cooling effect predicted for the external mixture is counterbalanced by the $\mathrm{BC}$ absorption enhancement.

This points to the importance of consideration of the mixing state of the aerosol. However, significant gaps exist in the knowledge of the optical and the hygroscopic behaviour 
of internally mixed aerosols, especially the involvement of organic aerosol compounds.

Future model investigations, forcing estimates and atmospheric chemistry simulations need to consider the physical mixing of its individual components and the interactions between them.

\section{Indirect climatic impact of organic aerosol}

Indirect effects of aerosols on climate refer to the various mechanisms by which aerosols can perturb the albedo of the Earth's clouds. In this section we first give a general description of the indirect effect and then focus on the role of OA. Twomey $(1959,1977)$ identified what is generally referred to as the first indirect effect, in which increased cloud condensation nucleus $(\mathrm{CCN})$ concentrations result in increased cloud drop concentrations, smaller drop radii, and more reflective clouds. Albrecht (1989) noted that a decrease in cloud drop effective radius may lead to lower coalescence rates, hence reduced precipitation and a longer cloud lifetime and greater spatial extent, a phenomenon that is sometimes referred to as the second indirect effect. Boers and Mitchell (1994) and Pincus and Baker (1994) noted that changes in cloud microphysics and precipitation alter the radiative cooling and latent heating within a cloud. Hansen et al. (1997) identified a so-called "semi-direct" effect, in which changes in the thermal structure of the atmosphere resulting from aerosol solar absorption (principally by black carbon) suppress cloud formation. Black carbon heating can also affect cloud albedo through an alteration of the cloud condensation nucleus (CCN) spectrum during cloud formation (Conant et al., 2002; Nenes et al., 2002b). Changes in cold ice-cloud microphysical and radiative properties in response to changing atmospheric aerosol concentrations have also been postulated (Jensen and Toon, 1992; DeMott et al., 1994, 1997), although in this case ice nucleating (IN) particles, rather than $\mathrm{CCN}$, are the relevant aerosol particles. In situ measurements revealed that organic-containing aerosols are less abundant than sulphate aerosols in ice cloud particles, suggesting that organics do not freeze preferentially (Cziczo et al., 2004). A model study explained this finding by the disparate water uptake of organic aerosols, and suggests that organics are unlikely to significantly modify cirrus formation unless they are present in very high concentrations (compared to sulphate-rich particles) at low temperatures and hamper water condensation (Kaercher and Koop, 2005). Relative to present-day understanding of aerosol$\mathrm{CCN}$-cloud linkages, much less is known about the nature of IN, their sources, and their indirect effects on cold clouds (IPCC, 2001).

The number of $\mathrm{CCN}$ is a critical link between aerosols, clouds, and precipitation. Since clouds are effective reflectors of incoming solar radiation, even small perturbations in their properties can significantly impact the amount of solar radiation absorbed by the planet, and thus affect climate. It is currently thought that aerosol-cloud interactions have a net cooling effect; quantitative estimates are highly uncertain, of the order of the greenhouse warming effect itself (IPCC, 2001).

There are two reasons for the large uncertainty associated with the indirect effect.

- The first originates from the wide range of length scales involved in cloud-aerosol interactions: from hundreds of kilometres (that of the largest cloud systems) down to tens of meters (that of individual updrafts responsible for production of new drops).

- The other reason is our poor understanding of the distribution of global CCN.

General Circulation Models (GCMs) are far from being able to resolve the scales involved in cloud formation. Much of the properties of warm clouds can be estimated if the relationship between aerosol and cloud droplet number is known. The first global climate modelling studies used an empirical approach, with cloud droplet number concentration being linked to a property available in a global aerosol model, such as total aerosol sulphate mass (e.g., Boucher and Lohmann, 1995), or total aerosol number (e.g., Gultepe and Isaac, 1996). Relating one bulk aerosol characteristic to cloud droplet number is subject to significant uncertainty. For example, in the RACE subset of the Gultepe and Isaac (1996) observations, the cloud droplet number concentration may range from 50 to $400 \mathrm{~cm}^{-3}$, for an aerosol number concentration of $800 \mathrm{~cm}^{-3}$. This variability in cloud droplet concentration leads to a significant uncertainty in the prediction of cloud radiative properties. This is illustrated by the Kiehl et al. (2000) study of the first indirect aerosol effect, in which several different empirical relationships yield estimates of the global annual average indirect forcing ranging between -0.40 and $-1.78 \mathrm{~W} \mathrm{~m}^{-2}$. The scatter in empirical aerosol-cloud droplet number correlations indicates that cloud droplet number can be strongly influenced by factors other than e.g., aerosol number or sulphate mass. One factor contributing to this scatter can be the presence of organics as discussed in Sect. 7.

Recently, first-principles approaches to predicting cloud droplet number have emerged (e.g., Ghan et al., 1997; Lohmann et al., 1999; Jacobson, 2003, 2004), in which a cloud droplet number balance in each GCM grid cell is established. Lohmann et al. (2000) have used this approach in a GCM. They evaluated the 1st and 2nd indirect effect due to sulphate and carbonaceous aerosols between $-1.1 \mathrm{~W} \mathrm{~m}^{-2}$ for an internally-mixed aerosol and $-1.5 \mathrm{Wm}^{-2}$ for an externally-mixed aerosol. They attributed this difference mainly to the increased climatic impact of carbonaceous aerosol when externally mixed aerosol is considered, due to higher atmospheric loadings and smaller particle sizes. The impact of the semi-direct effect was discussed by 


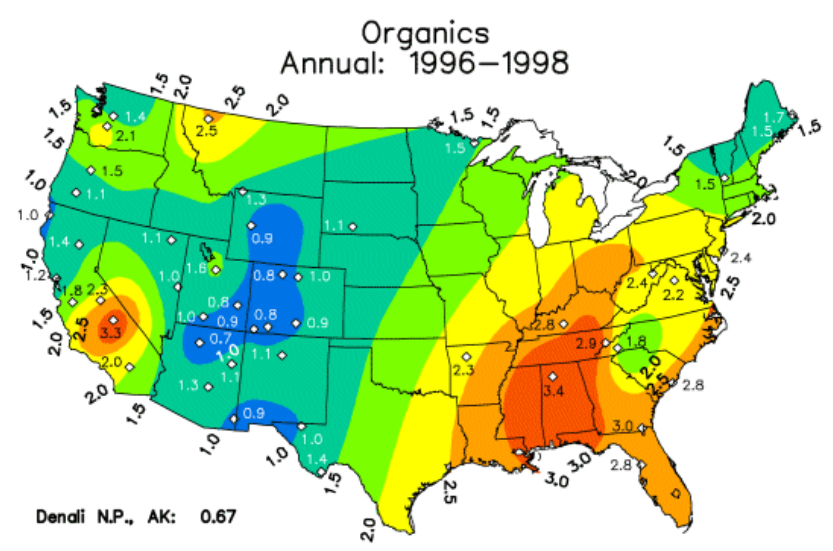

Fig. 8. Estimated spatial patterns of OC (in $\mu \mathrm{m} / \mathrm{m}^{3}$ based on OM to OC ratio of 1.4) and the locations of PM monitoring sites. The map was produced using data from only the background sites so it does not include the major industrial areas (from Malm et al., 2000).

several authors (Lohmann and Feichter, 2001; Penner et al., 2003) who found it only of minor importance at the top-ofthe-atmosphere and of uncertain sign. Penner et al. (2003) and Johnson et al. (2004a) pointed out that the semi-direct effect can result in a cooling depending on the location of $\mathrm{BC}$ in the vertical with respect to the cloud.

Chuang et al. (2002) estimated the impact of BC absorption in clouds to globally change the first indirect effect by less than $0.07 \mathrm{~W} \mathrm{~m}^{-2}$, whereas locally it could decrease the forcing by as much as $0.7 \mathrm{~W} \mathrm{~m}^{-2}$ in regions where BC emissions are pronounced. However, this estimate does not include the recently discovered enhancement of $\mathrm{BC}$ absorption due to coating by organics (Schnaiter et al., 2003). Chuang et al. (2002) estimated the total first indirect forcing to be $-1.85 \mathrm{~W} \mathrm{~m}^{-2}$, with $-0.30 \mathrm{~W} \mathrm{~m}^{-2}$ associated with anthropogenic sulfate, $-1.16 \mathrm{~W} \mathrm{~m}^{-2}$ associated with carbonaceous aerosols from biomass burning, and $0.52 \mathrm{~W} \mathrm{~m}^{-2}$ associated with carbonaceous aerosols from fossil fuel combustion. They also found that the first indirect forcing of aerosols was also sensitive to the loading of natural SOA. They found that the first indirect forcings for suphate and for carbonaceous are reduced from -0.31 to $-0.26 \mathrm{~W} \mathrm{~m}^{-2}$ and from -1.67 to $-1.27 \mathrm{~W} \mathrm{~m}^{-2}$, respectively, when the SOA source is increased by a factor of 5 from 8.4 to $42 \mathrm{Tg}^{-1}$. This study assumed that all SOA is formed in the boundary layer, although as discussed in the introduction, significant part of SOA is formed in the free troposphere. Therefore, this assumption introduces additional uncertainties since Penner et al. (2003) have shown that climate forcing depends significantly on the altitude of the injections of the aerosols since higher injections increase the aerosol lifetimes and subsequently their burden. They found that higher-altitude injections of biomass burning carbonaceous aerosols tend to enhance the negative longwave forcing and $\mathrm{BC}$ aerosols injected at high altitudes can increase cloudiness at lower altitudes, where tempera- ture may decrease. Moreover, Chuang et al. (2002) showed that indirect forcing is overestimated when some of natural or anthropogenic aerosols are omitted.

- Few global climate modelling studies evaluated the indirect climatic impact of carbonaceous aerosols.

- It has been found that when neglecting the other types of aerosols, the climatic impact of carbonaceous aerosols is overestimated.

- The calculated first indirect forcing is sensitive to the SOA global chemical production as well as to the other natural aerosol components.

- The evaluation of the impact of SOA on the indirect effect calculations relies on our understanding of the involvement of organic aerosol compounds in the hygroscopic behaviour of internally mixed aerosols and requires improvement (see Sect. 8).

- The effect of enhanced absorption by BC on cloud properties when $\mathrm{BC}$ is coated by organics has to be considered in the indirect forcing calculations as well as the involvement of SOA on CCN formation and growth and thus on cloud occurrence and properties.

The different approaches to estimate the global indirect climatic aerosol effects are discussed by Lohmann and Feichter (2005).

\section{Datasets of particulate organic carbon for evaluation of global models}

The following discusses the 'traditional' ground based observations that can provide information on specific aerosol component. As stated and well documented in the review paper by Jacobson et al. (2000), the sampling, extraction, and analysis techniques in use influence what we know about atmospheric organic aerosols., since what we find in the organic fraction is to a large extent determined by how we look. The reader is directed to this earlier review for an extensive discussion on these topics. The present work focuses the discussion mainly on the major sources of uncertainties that influence global modeling results and their evaluation.

\subsection{Ground based observations of OC}

About 10 years ago, the world wide distribution of organic aerosols was poorly known because of the lack of long term datasets. One of the first particulate organic carbon (OC) data compilation by Liousse et al. (1996) relied on OC measurements from a quite large number of sampling sites (21) but most of them (13) covered only a period of 1-2 months. This was nevertheless enough to show that organic matter is a ubiquitous and significant constituent of 
Table 12. Normalized OC concentrations determined with different techniques in samples collected at various sampling sites.

\begin{tabular}{llll}
\hline OC determination method types & $\begin{array}{l}\text { Los Angeles Basin } \\
\text { Countess et al. (1990) }\end{array}$ & $\begin{array}{l}\text { Berlin city centre (D) } \\
\text { Schmid et al. (2000) }\end{array}$ & $\begin{array}{l}\text { Melpitz rural site (D) } \\
\text { Ten Brink et al. (2004) }\end{array}$ \\
\hline 1- TOR $\mathrm{T}<500-650^{\circ} \mathrm{C}$ in $\mathrm{He}$ & $1.00(0.99-1.01)$ & 1.00 & \\
2- TOT T $<600-900^{\circ} \mathrm{C}$ in $\mathrm{He}$ & 1.19 & $1.11(0.99-1.31)$ & 1.31 \\
3- $\mathrm{T}<525-620^{\circ} \mathrm{C}$ in $\mathrm{He}$ & $1.18(1.11-1.21)$ & $0.76(0.66-0.93)$ & 0.56 \\
$4-\mathrm{T}<400^{\circ} \mathrm{C}$ in $\mathrm{O}_{2}$ (gradient) & $1.04(1.00-1.08)$ & 0.62 & 0.72 \\
$5-\mathrm{T}<340^{\circ} \mathrm{C}$ in $\mathrm{O}_{2}$ (flash heating) & & 0.79 & 1.03 \\
6- $\mathrm{T}<650^{\circ} \mathrm{C}$ in $\mathrm{He}$ + charred OC & & &
\end{tabular}

1- Thermo-optical reflectance. OC evolved at up to $500-600^{\circ} \mathrm{C}$ in $\mathrm{He}$, EC at up to $700-800^{\circ} \mathrm{C}$ in $\mathrm{He}+\mathrm{O}_{2}$. Charring corrected by sample reflectance measurement.; 2- Thermo-optical transmission. OC evolved at up to $600-900^{\circ} \mathrm{C}$ in $\mathrm{He}$, EC at up to $600-900^{\circ} \mathrm{C}$ in $\mathrm{He}+\mathrm{O}_{2}$. Charring corrected by sample transmission measurement.; 3- Thermo-oxidation methods. OC evolved at up to 525-620 ${ }^{\circ} \mathrm{C}$ in $\mathrm{He}$, EC at up to $600-750^{\circ} \mathrm{C}$ in $\mathrm{He}+\mathrm{O}_{2}$. No charring assessment.; 4- Thermal method. Sample heated at $20^{\circ} \mathrm{C}$ min ${ }^{-1}$ in $\mathrm{O}_{2}$. No charring expected. OC/EC split difficult to define.; 5- Thermal. OC evolved at up to $340^{\circ} \mathrm{C}$ in $\mathrm{He}+\mathrm{O}_{2}$, EC at up to $650^{\circ} \mathrm{C}$ in $\mathrm{O}_{2}$. No charring assessment.; 6 Thermo-oxidation method similar to (3). Charring assessed by measuring EC in a sample aliquot immersed in an oxidant career gas at $340^{\circ}$ for $2 \mathrm{~h}$.

the aerosol. During the last decade, organic (and elemental) carbon started to be more commonly measured over longer time periods. In a recent compilation of long term aerosol chemistry data sets produced in Europe (Putaud et al., 2003, 2004) OC measurements were included in 10 of the 16 compiled data sets. Recently, OC measurements have been added to the EMEP monitoring program, for a limited amount of the EMEP super-sites only though (http: //www.nilu.no/projects/ccc/). In the USA a number of measuring networks provide OC data. Organic carbon and chemical speciation measurements have been included in the measurements program of the EPA super sites. One of the oldest continuous ones is the IMPROVE (Interagency Monitoring at Protected Visual Environments) data set with measurements in background sites (http://vista.cira.colostate.edu/improve). The network has currently 150 sites and collects information about aerosol composition and optical properties. Some of the sites have collected more than 15 years of data. Figure 8 shows the estimated spatial patterns of OC and the locations of PM monitoring sites (Malm, 2000). The map was produced using data from only the background sites so it does not include the major industrial areas. Concentrations of OC and elemental carbon (EC or as used in this document black carbon: $\mathrm{BC}$, see discussion below) in mainly urban and sub-urban areas in the US are measured by the Speciation and Trends Network (STN). The measurements started in 2001 and include around 200 stations around the country. PMEL Atmospheric Chemistry Data Server contains OC (and BC) data for most cruises in the Atlantic, Pacific, Antarctic and Indian Ocean since 1997. To our knowledge, long term OC (and EC/BC) measurements have also been performed in South America (de Almeida Azevedo et al., 2002; Tsapakis et al., 2002) and South East Asia (Kim et al., 2000; Sau and Khalil, 1993). The WMO-WDCA (http://rea.ei.jrc.it/netshare/wilson/WDCA) is currently aim- ing at compiling all these long term aerosol data sets in a common format to make them available to the community. This should increase the number of available extensive OC data sets in the next future.

\subsection{Definition problem}

A possible source of systematic error in particulate OC determination arises from the difficulty of separating $\mathrm{OC}$ and EC/BC. Actually, the border between these two "species" is only instrumentally defined. For Chow et al. (1993), OC evolves at up to $520^{\circ} \mathrm{C}$ in inert career gas, and $\mathrm{EC} / \mathrm{BC}$ from 520 to $650^{\circ} \mathrm{C}$ in an oxidant career gas. The two major protocols for OC and BC split (in US) are the NIOSH and IMPROVE protocols (see references in Chow et al., 1993). There are also variations of these protocols using different temperature profiles. Charring, the transformation of $\mathrm{OC}$ to $\mathrm{BC}$ during the thermal analysis which is dependent on analytical condition and sampling substrate nature, can also strongly affect the reported OC/BC partitioning. Several intercomparisons showed that differences in $\mathrm{OC} / \mathrm{BC}$ split definition and in charring amplitude and/or correction lead to large interlaboratory variability in $\mathrm{EC} / \mathrm{BC}$ determination of up to a factor of 3 (Turpin et al., 1990; Schmid et al., 2001). As a consequence, the difference in OC determination from two different techniques can be as high as a factor of 2 . The OC averages determined with various methods and normalized to the thermo-optical reflectance method are shown in Table 12. Differences in averages can reach $>50 \%$. It is surprising that methods accounting for charring could lead to lower OC values than other methods in the intercomparison described by Countess (1990), contrary to what was observed in a previous intercomparison (Groblicki et al., 1983). The intercomparisons based on sample collected in Europe (Schmid et al., 2000; ten Brink et al., 2004) showed in con- 
Table 13. Normalized concentrations of OC found with different sampling techniques at various sampling sites.

\begin{tabular}{lllll}
\hline Sampling method & $\begin{array}{l}\text { Face velocity } \\
\mathrm{cm} / \mathrm{s}\end{array}$ & $\begin{array}{l}\text { Los Angeles Basin (USA) } \\
\text { Hering et al. (1990) }\end{array}$ & $\begin{array}{l}\text { Eastern Asia } \\
\text { Mader et al. (2003) }\end{array}$ & $\begin{array}{l}\text { Melpitz (D) } \\
\text { Ten Brink et al. (2004) }\end{array}$ \\
\hline Quartz fiber filter (Hi Vol) & $>37$ & 1.00 & 1.00 & 1.00 \\
Quartz fiber filter (Low Vol) & $22-25$ & 1.04 & & 1.01 \\
Denuded quartz fiber filter & 20 & 1.35 & 0.65 & \\
Quartz fiber filter corrected for positive artifact & $>37$ & 0.74 & $1.00-1.25$ & \\
Quartz fiber filter corrected for negative artifact & $>37$ & & & 0.71 \\
Impactors & - & 0.49 & & 0.66 \\
ACPM 5400* & - & & & \\
\hline
\end{tabular}

* Ambient Carbon Particulate Monitor RP 5400 (Ruprecht and Pataschnick)

trast that methods correcting for charring all lead to higher OC values.

- The definition (if possible) of an international standard for ambient particulate BC might allow adjustment and homogenisation of observations that should also be applied to the emission factors that are adopted for the construction of emission inventories.

\subsection{Analytical problems}

OC measurements may be seriously affected by various artifacts at the sampling and analysis stages (Turpin et al., 2000). Sampling artifacts have been extensively studied in the USA. Several sampling methods (filtration, adsorption- corrected filtration, impaction) compared in Hering et al. (1990) showed up to $70 \%$ differences in single samples. Also Eatough et al. (1993) showed that sampling in Utah (USA) with heated quartz fiber filters may lead to $20-80 \%$ negative artifacts and up to $50 \%$ positive artifacts in single samples. The OC averages (over 18 samples) obtained by Hering et al. (1990) with various sampling methods and normalized to the results obtained from sampling with a plain undenuded quartz fiber filter at a face velocity of ca. $38 \mathrm{~cm} / \mathrm{s}$ are compared in Table 12. Normalized concentrations ranged from 0.49 to 1.34 in the Los Angeles Basin. These results may not be valid for other locations, since sampling artifacts are expected to depend on the aerosol (gaseous and particulate) carbonaceous species mixture and on meteorological conditions. Indeed, Mader et al. (2003) and ten Brink et al. (2004) found different results for positive artifact corrected quartz filter data in Easten Asia and impactors in Europe, respectively (Table 13).

The artifact-free wet annular denuder-steam jet aerosol collector combination (WAD-SJAC) with on-line analysis of total OC is a promising method for OC measurement. Such an instrument was tested during the Intercomp2000 experiment in Germany (ten Brink et al., 2004) and led to results, which tend to indicate that positive $\mathrm{OC}$ sampling artifacts on filters were predominant at this site. However, such a kind of artifact free combination is not very suited for long term monitoring programs, and does not permit to collect enough organic material for speciation. Various filter-based devices have nevertheless been proposed to limit and/or assess positive and negative sampling artifacts when using quartz fiber filters. Positive artifacts were addressed through the back-toback filter technique (Fitz, 1990; Novakov et al., 1997), the Teflon + quartz/quartz simultaneous sampling method (Mc Dow and Huntzicker, 1990; Chow et al., 1996), or the use of diffusion denuders, in which sorbents were quartz (Fitz, 1990) or carbon impregnated paper strips (Eatough et al., 1989, 1993, 1996; Tang et al., 1994), activated $\mathrm{Al}_{2} \mathrm{O}_{3}$ (Appel et al., 1989), or XAD-4 (Mader et al., 2001, 2003; Fan et al., 2003). The use of a denuder shifts the gas/particle equilibrium of semi-volatile organic compounds, and renders the assessment of negative artifacts essential. Negative artifacts were determined by trapping the organic molecules volatilized from the particles upstream quartz fiber filter in sorbent like carbon impregnated glass fiber filters (Eatough et al., 1993, 1996, 2001; Tang et al., 1994), XAD-4 impregnated quartz fiber filters (Fan et al., 2003), or poly-urethane foams (Kavouras et al., 1999). However, these combinations do not always solve completely the problem. First of all, the denuder efficiency is sometimes not $100 \%$, and may vary with time and meteorological conditions. Their efficiency should therefore be continuously monitored, though parallel monitoring of particle-free ambient air, which makes this approach quite labor intensive. Second, none of these sorbents can withstand temperatures higher than $450^{\circ} \mathrm{C}$ for a few tens of seconds.

Although, volatile or semi-volatile species trapped in the sorbents are expected to have a relatively low boiling point $\left(<300^{\circ} \mathrm{C}\right)$, this temperature limitation might prevent the evolution of the whole trapped OC. Indeed, analysis of quartz back up filter with the EGA method $\left(20^{\circ} \mathrm{C} \mathrm{min}^{-1}\right.$ ramp from 50 to $650^{\circ} \mathrm{C}$ in oxygen career gas) shows that a large fraction of non particulate $\mathrm{OC}$ is evolved in the $300-500^{\circ} \mathrm{C}$ temperature range (Kirchstetter et al., 2001). Another approach to tackle OC sampling artifacts consists in using particle con- 
Table 14. OC to OM conversion ratios determined from OM specification in samples collected at various sites.

\begin{tabular}{lllll}
\hline & USA & Caribbean (airborne) & $\begin{array}{l}\text { Eastern Asia (airborne) } \\
\text { Russel (2003) }\end{array}$ & $\begin{array}{l}\text { Eastern Asia (surface) } \\
\text { Russel (2003) }\end{array}$ \\
\hline $\begin{array}{l}\text { Non-urbin and Lim (2001) } \\
\text { Russel (2003) }\end{array}$ & $2.1 \pm 0.2$ & $1.34 \pm 0.1$ & $1.38 \pm 0.1$ & $1.36 \pm 0.2$ \\
Urban & $1.63 \pm 0.2$ & & & \\
\hline
\end{tabular}

centrators like a simple virtual impactor with a low 50\% cut-off or a more complex device based on the same aerodynamic particle segregation principle (Sioutas et al., 1999). Without eliminating sampling artifacts, particle concentration can considerably lower them, by discarding $>70 \%$ of the air stream while keeping most particles in the sample flow. Particle concentrators have been used in combination with diffusion denuders and sorbents to increase their efficiency (e.g., Tang et al., 1994).

Unfortunately, despite the demonstrated occurrence of significant sampling artifacts and the description of remedies in the literature, numerous $\mathrm{OC}$ measurements published up to now have been performed without accounting for possible artifacts. This is perhaps due to the fact that artifact free sampling systems are complicated, not commercially available, and above all not always well characterized in various environments (Turpin et al., 2000). Such devices are not widely available and have to be used as reference techniques. However, as sampling artifacts are expected to depend on the OC mixture, filter type, temperature and relative humidity, it seems difficult to correct older non-artifact free OC data.

\subsection{Mass-to-Carbon ratio}

Mass closure experiment can increase our confidence on the overall accuracy in organic aerosol concentrations. On the top of providing an opportunity of determining the sources and amplitude of random uncertainties, mass closure experiments can indeed constrain OC measurements when (1) overall random uncertainties in aerosol mass and component concentrations are small enough and (2) aerosol mass and component concentrations are determined independently. However, assessing the aerosol mass concentration from the sum of its components necessitates accounting for the non-carbon atoms contained in the particulate organic matter. This is usually done by using an OC-OM conversion factor, expected to represent the mean molecular mass -to- carbon mass ratio of the particulate organic matter. Values ranging from 1.2 to 1.7 have been used in the past. Turpin and Lim (2001) concluded that ratios of $1.6 \pm 0.2$ for urban aerosol and $2.1 \pm 0.2$ for non-urban aerosol appear more accurate, but Russell (2003) found a mean ratio of $1.4 \pm 0.2$ for samples collected in Asia and the Caribbean (Table 14). Actually, to really constrain OC measurements, each mass closure experiment should include a precise and independent determination of the aerosol mass concentration, of all the aerosol components' concentration, and of the OC-OM conversion ratio to be applied. Such a work is quite demanding, but necessary to demonstrate experimental OC data quality.

A laborious task in atmospheric aerosol modeling is to evaluate the accuracy of the models and identify and quantify their uncertainties. A first step in evaluation of the model results can be achieved by comparison with data of total organic particulate mass.

In addition:

- Chemical speciation may provide valuable information on the major sources contributing to the observed aerosol (by using appropriate tracer compounds) and therefore can indicate model deficiencies and improve parameterisations.

- Chemical characterisation of organics based on functional group analysis (Sect. 8.2) and allowing the description of the total organic aerosol based on a set of few compounds (acid, basic, neutral) is a promising measuring approach that can allow the evaluation of models, especially with regard to cloud formation properties, when appropriately designed.

Size resolved aerosol mass, number and chemical composition information will allow evaluation of the calculated aerosol distributions. Additional information on absorption and scattering of the radiation is required to evaluate the optical properties of the aerosol mixtures computed by the models. The last years a lot of effort concentrated on comparison of model results with satellite observations that provide a 'global' view of the atmosphere. However, although critical for understanding atmospheric chemistry, satellite data cannot be used to evaluate the accuracy of the model simulations of one aerosol component like the organic aerosol since they provide aerosol optical thickness data that integrate all aerosol constituents in the tropospheric column.

- It is the synergistic use of ground based, aircraft and remote sensing observations that will allow optimal evaluation of global model capabilities in simulating global organic aerosol distributions (see example by Kinne et al., 2003). 


\subsection{Estimation of SOA from field observations}

Estimating the SOA concentration from field observations remains a challenging task. Unfortunately there is no direct method for measuring SOA. Field measurements of OC provide just an upper bound that is the maximum possible concentration of SOA in the corresponding area.

Since primary OC and EC are mostly emitted from the same sources, EC can be used as a tracer for primary combustion-generated OC (Gray et al., 1986; Turpin and Huntzicker, 1995; Strader et al., 1999). The formation of SOA increases the ambient concentration of OC and the ambient OC/EC ratio. OC/EC ratios exceeding the expected primary emission ratio are an indication of SOA formation. Primary ratios of OC and EC vary from source to source and show temporal and diurnal patterns, but since EC is only emitted from combustion sources, gaseous tracers of combustion $\left(\mathrm{CO}, \mathrm{NO}, \mathrm{NO}_{\mathrm{x}}\right)$ can be used to determine periods dominated by primary aerosol emissions (Cabada et al., 2004). Ozone is an indicator of photochemical activity, and it also can be used as a tracer for periods where secondary organic aerosol production is expected. In this case, increases in the OC/EC ratio correlated to ozone episodes are indicative of SOA production. The major weakness of the method is its reliance on the assumption of a constant primary OC/EC during the analysis period. Variations of sources strengths, meteorology, etc. are expected to change the primary OC/EC. This assumption can be relaxed if there are high temporal resolution data by grouping the data by period of day, month, etc. In any case, this variability introduces significant uncertainties in the estimated SOA concentration. Even if such an almost constant ratio exists, its determination is non-trivial. The primary OC/EC ratio is primarily determined either from measurements during periods where the primary sources dominate the ambient OC or from emission inventories (Gray, 1986; Cabada et al., 2002). Once more the existence of measurements every $2-4 \mathrm{hr}$ reduces significantly the uncertainty of the estimated SOA concentration (Cabada et al., 2004). An upper limit of the SOA concentration can also be estimated based on the unexplained OC during the use of the CMB approach and organic speciation measurements (Zheng et al., 2002).

Measurements of the SOA product concentrations could be helpful in estimating the SOA concentrations using observations. However, one needs to be careful because a lot of these species continue reacting in the atmosphere and therefore are not conserved as SOA tracers.

Constraining the global SOA production remains quite challenging. Most current estimates are based on measurements of the OC concentrations, the fraction of the OC that is primary and the lifetime of OC in the atmosphere. All these (as described in various sections of the paper) are quite uncertain. There are relatively few $\mathrm{OC}$ measurements with significant uncertainties due to sampling and analytical issues. In addition, the fraction of the organic aerosol that is secondary is quite uncertain especially in the more polluted continental regions. Finally the lifetime of the OC is a lot more uncertain compared to that of the inorganic salts (see Sect. 4.3). The result is that estimates of the global SOA production based on observations are as uncertain as these of the models. This demonstrates the large uncertainties and difficulties in evaluating the SOA modeling.

\section{Conclusions}

Our understanding of the organic aerosols in the atmosphere has been significantly improved during the last decade although significant gaps remain. The present paper did not aim to refer to all the experimental and modelling studies on organic aerosol (OA) but to i) summarize the recent understanding of the occurrence and behaviour of OA in the atmosphere with focus on the secondary organic aerosol (SOA), ii) point out the uncertainties related to the relevant extra simplified parameterisations used in the global chemistry transport and climate models and iii) identify areas where further research is needed.

What do we know?

- The major SOA precursors are biogenic VOC. The anthropogenic contribution to the SOA formation is small on a global scale, although it can be important in polluted regions.

- At the global scale chemical formation of SOA could be at least $50 \%$ of the primary OA emissions.

- The known chemical mechanisms that form SOA are

- Gas phase $\mathrm{OH}, \mathrm{NO}_{3}, \mathrm{O}_{3}$ reactions. There is ample evidence that the ozonolysis reactions are major contributors to SOA formation.

- Heterogeneous reactions that result in the decrease of the volatility of the semi- volatile compounds that are portioned between aerosol and gas phase.

- Aqueous phase reactions can be a significant source of dicarboxylic acids.

- The major aerosol compounds resulting from a-pinene and b-pinene gas phase oxidation have been identified and there is knowledge on the chemical mechanisms leading to non-volatile products.

- Few global climate modelling studies evaluated the indirect climatic impact of carbonaceous aerosols comparable to sulphate that has been extensively studied.

- It has been found that when neglecting the other types of aerosols, the climatic impact of carbonaceous aerosols is overestimated.

Of what do we have only a qualitative, not sufficient understanding? 
- The nature and the role of products less volatile than pinic acid ("the nucleating species") remains unclear although they are expected not to be among the major aerosol constituents.

- The emissions of sesquiterpenes that have very high aerosol potential and the chemical composition of aerosol particles produced from them, remains poorly known.

- Large uncertainties exist in the emission inventories of primary carbonaceous aerosols. These uncertainties are mostly due to temporal-regional-sectorial attribution of emission factors to activities, but also due to differences in measurement techiniques used to determine these emission factors.

- The emission inventories of the gaseous organics that have been identified as precursors of SOA, are also subject to serious uncertainties dominated by those in the emission rates and the missing pieces of information on chemical speciation of the emissions (e.g. the fast reacting sesquiterpenes).

- Although the thermodynamics involved in the partitioning between the gas and particulate phase are understood, there is a need for experimental data on the enthalphy of evaporisation of the semi-volatile organics that partition on the aerosol phase.

- The removal of carbonaceous aerosols from the atmosphere depends largely on the conversion of the hydrophobic to hydrophilic aerosols that is not satisfactorily known and parameterised in the models. Like for all other aerosol components it is expected that the wet deposition parameterisation used in models is a major source for uncertainty in the amount of SOA residing in the atmosphere.

- Actual estimates of global SOA formation range from 12 to $70 \mathrm{Tg} \mathrm{SOA} \mathrm{y}^{-1}$. The reduction of this uncertainty requires improved and chemically speciated emission inventories, better understanding of the chemical processes forming SOA and description of the size distribution of the aerosols in the global models.

- Some knowledge on the hygroscopicity and optical properties of individual organics exists and requires further measurements. Additional data are needed on the optical properties of internally mixed aerosols and their hygroscopic behaviour, especially of organic aerosol compounds.

- At low relative humidities (below about 50\%) SOA could account for $20 \%$ of the aerosol water. Data on the interactions between inorganic and organic compounds and their impact on water activity within the aerosol are missing.
- The role of organic aerosol in micro-physical cloud and rain processes is qualitatively understood but requires further understanding. The thermodynamic properties of potentially $\mathrm{CCN}$ active organics in aerosols are not sufficiently documented.

- The calculated climatic forcing seems to be sensitive to the SOA global chemical production as well as to the other natural aerosol components.

What are the emerging topics?

- Recent developments both on aerosol sampling and chemical analysis resulted in new findings that show the formation of low volatility oligomers and polymers. These findings may lead to significant changes in the current SOA modelling approaches. The separation between the primary and secondary organic aerosol components becomes more difficult after the recent detection of oligomers in SOA since compounds that have been considered of primary origin might be chemically produced.

- Compounds that were previously not considered as aerosol precursors have been suggested to contribute significantly to the SOA mass in the atmosphere (e.g. isoprene). More examples will probably be identified in the near future.

- Aqueous phase chemistry -cloud processing of aerosols identified as a possibly important source of SOA, the strength of which requires evaluation.

- The coating of BC by SOA results in a strong increase of both the Single Scattering Albedo and the absorption cross section of the soot particles that has to be considered in climate forcing studies.

- Recent results (O'Dowd et al., 2004) have indicated a new POA source connected to biological activity in the ocean which produces submicrometre particles. Its importance and influence on marine $\mathrm{CCN}$ require further work.

What is the consequence for (future) climate modelling?

- It has been found that the neglect of the other types of aerosols leads to an overestimate in the impact of carbonaceous aerosols. The consideration of internal mixing of aerosols has been recently shown critical for forcing estimates, in general smaller effects are calculated when the internally mixed aerosol is considered since internal mixing affects both aerosol lifetime and properties.

- The evaluation of the climatic impact of OA (both primary and secondary) relies on our understanding of the involvement of organic aerosol compounds in 
the hygroscopic behaviour of internally mixed aerosols that has to be improved. It requires consideration of OA interactions with the other aerosol constituents and aerosol associated water. Such interactions are altering the absorptive and scattering properties of the aerosol, their hygroscopicity and their ability to form $\mathrm{CCN}$

- Appropriate parameterisations need to be developed to allow incorporation of information about the direct (optical properties) and indirect effect (CCN activity) of $\mathrm{OA}$ in the global models that are actually treating $\mathrm{OA}$ in a very simplified way.

- The development of SOA precursor gas emissions under future climate regimes and land-use is probably important, but up-to-date only a few speculative studies are available.

What are the key priorities for research?

- There is an open question whether the laboratory studies of SOA with relatively high concentrations of precursor molecules and oxidants are also valid under real atmospheric conditions or not. Recent laboratory studies have pointed out the influence of $\mathrm{OH}$-scavenger and Criegee-intermediate scavenger (e.g. water) on aerosol yieds during ozonolysis experiments. These observations have to be considered to carefully translate chamber experiment results to atmospheric conditions. In this perspective, the impact of $\mathrm{NO}_{\mathrm{x}}$ levels on the aerosol yields and the final products of the photooxidation reactions has to be investigated.

- Most modeling studies rely on arbitrary chosen model compounds to represent the hygroscopicity or optical properties of the (S)OA-inorganic aerosol mixture. The use of model compounds constructed based on experimental information could provide more realistic representation of the properties of the OA mixture.

- The involvement of organics in the new particle formation deserves further studies to determine its importance on regional and global scales. The nature of products less volatile than pinic acid ("the nucleating species") remains an open question although they are expected not to be among the major aerosol constituents.

- More studies on sesquiterpenes-temperature dependence of aerosol yields and product identification are needed since these compounds seem to have a large SOA froming potential.

- Appropriately designed chamber experiments have to be performed to develop and validate chemical reference schemes for aerosol for subsequent simplification based on understanding of chemical processes.
- The importance of multiphase chemistry in SOA formation has to be determined.

- Better measuring techniques are needed for carbonaceous aerosols especially with regard to the understanding of the chemical composition and the ageing processes of OA. Particular attention is needed to avoid artifacts in sampling and analysis of OA compounds. Since the distinction between black and organic carbon is not clear, observations have to be accompanied by the definition of the measured quantity. Effort has to be put into avoiding inconsistencies between measurements of carbonaceous aerosols.

- Homogeneisation of observations of carbonaceous aerosols is needed that should also be applied to the emission factors that are adopted for the construction of chemical speciated emission inventories. This will allow a better comparison of model results with measurements.

- The synergistic use of ground based, aircraft and remote sensing observations will allow optimal evaluation of global model capabilities in simulating global organic aerosol distributions.

- The effect of enhanced absorption by BC on cloud properties when $\mathrm{BC}$ is coated by organics has to be considered both in the direct and in the semi-direct forcing calculations.

- Feedback-climate mechanisms involving organics have to be investigated since SOA from biogenic volatile organics is estimated to be the major contributor to the SOA mass. Thus significant biosphere-climate feedbacks are expected to be involved with SOA existence in the atmosphere.

\section{Appendix A: Theory of hygroscopic growth of particles and of cloud formation}

The interaction of inorganic species with supersaturated water vapour is appropriately described by traditional Köhler theory (Köhler, 1936), in which thermodynamic arguments provide the water vapour supersaturation needed to form a droplet, as a function of its dry radius and chemical composition. The equilibrium condition is equality of the chemical potential of water between the aqueous phase and the vapour phase adjacent to the droplet surface. This relation is typically expressed in terms of the equilibrium ambient water saturation ratio $S_{e q}$ (water vapour pressure over equilibrium vapour pressure) and the droplet diameter, $\mathrm{D}_{p}$ :

$S_{e q}=\exp \left[\frac{4 \sigma M_{w}}{\rho_{w} R T D_{p}}-\frac{M_{w} \nu \Phi m}{1000}\right]$ 
where $\sigma$ is the droplet solution surface tension, $\rho_{w}$ is the density of water, $R$ is the universal gas constant, $T$ is temperature, $M_{w}$ is the molecular weight of water, $v$ is the total number of ions produced by dissociation of one molecule of solute, $\Phi$ is the practical osmotic coefficient of the solution, and $m$ is the solution molality. The product $\nu \Phi$ is also known as the "effective van't Hoff factor". An approximation frequently made is that the solution is dilute $(\Phi=1)$, although this assumption does introduce some error (Brechtel and Kreidenweis, 2000). This error primarily affects the larger nuclei, since their molalities are higher at activation than smaller nuclei, but often does not significantly affect the number of $\mathrm{CCN}$.

The droplet curvature (first term in Eq. A1) tends to increase the water vapour pressure, while the presence of solute (second term in Eq. A1) acts to lower it. Expressing $S_{e q}$ as a function of droplet diameter for a given initial particle, one obtains an equilibrium (or "Köhler") curve that increases steeply when $S_{e q}<1$ and goes through a maximum at some $S_{e q}$ above unity, the critical supersaturation, $S_{c}$. If the ambient $S$ exceeds $S_{c}$, there is always a gradient of water vapour causing water to diffuse to and condense on the droplet, resulting in unconstrained growth. When this happens, the droplet is said to be "activated"; atmospheric cloud formation takes place when $S$ starts crossing the critical supersaturation of particles in the air.

Inside a cloud, the driving force for the increase of $S$ is cooling caused usually by expansion of rising air, mixing or radiation. Condensational depletion of water vapour and release of latent heat of condensation slow down the increase of $S$, and at some point, $S$ reaches a maximum. In principle, all droplets with critical supersaturations below the maximum value of $S$ achieved can activate to cloud droplets, although the diffusional growth of droplets may be sufficiently slow that all droplets with critical supersaturations below the maximum $S$ will not have time to activate (Nenes et al., 2001). The maximum value of $S$ achieved in rising air, as well as the number of activated droplets results from a competition between the ambient cooling rate and condensational depletion of water vapour from the growing CCN. Thus, anything that can affect the growth rate of droplets would potentially affect cloud droplet number. Droplet growth can be expressed as (Seinfeld and Pandis, 1998):

$$
\begin{aligned}
& \frac{d D_{p_{i}}}{d t}=\left[\frac{\rho_{w} R T}{4 p^{\circ} D_{v}^{\prime} M_{w}}+\frac{\Delta H_{v} \rho_{w}}{4 k_{a}^{\prime} T}\left(\frac{\Delta H_{v} \rho_{w}}{T R}-1\right)\right]^{-1} \\
& \frac{1}{D_{p_{i}}}\left(S-S_{e q}\right)
\end{aligned}
$$

where $p^{o}$ is the saturation vapour pressure of water, $\Delta \mathrm{H}_{v}$ is the heat of vaporization of water, $D_{v}^{\prime}$ is the mass transfer coefficient of water vapour to the droplet, and, $k_{a}^{\prime}$ is the heat conductivity of air, modified for non-continuum effects (Seinfeld and Pandis, 1998).
Based on Eq. (A2), the maximum value of $S$ is affected by the number concentration, size distribution, and composition of the aerosol particles present. Compositional effects are not only expressed in $S_{e q}$ (Eq. A1); they can also affect $D_{v}^{\prime}$. This is because the size of $\mathrm{CCN}$ is comparable to the mean free path of air molecules; thus, the probability, $\alpha$, of a water vapour molecule "sticking" upon the growing droplet will influence $D_{v}^{\prime}$, (Seinfeld and Pandis, 1998):

$$
D_{v}^{\prime}=\frac{D_{v}}{1+\frac{2 D_{v}}{\alpha \mathrm{D}_{\mathrm{p}}} \sqrt{\frac{2 \pi M_{w}}{R T}}}
$$

where $D_{v}$ is the diffusivity of water vapour in air. $\alpha$, also known as "mass accommodation coefficient", is affected by the chemical nature of the droplet-gas interface. The presence of surfactants may lower the value of $\alpha$ from the commonly accepted value of $\sim 0.045$ (Pruppacher and Klett, 1980 ) and affect the microphysical evolution of clouds (e.g., Feingold and Chuang, 2002; Nenes et al., 2002a). 


\section{Appendix B: List of abbreviations}

AEROCOM
BC
BRAVO
CCN
DMS
DRH
EC
EDB
EMEP

EPA

FFC

GCM

GF

$\mathrm{HMS}^{-}$

HNMR

HTDMA

IMPROVE

IN

IUPAC

LH

$\mathrm{MCM}$

$\mathrm{MH}$

NMVOC

OA

OM

ORVOC

OSOA

OVOC

POA

$\mathrm{RH}$

SAPRC

SOA

SSA

TDMA

UNIFAC

UV

VOC

WMO-WDCA

WSOC

ZSR
Global Aerosol Model Intercomparison

Black carbon

Big Bend Regional Aerosol and

Visibility Observational Study

Cloud Condensation Nuclei

Dimethyl Sulfide

Deliquescence Relative Humidity

Elemental Carbon

Electrodynamic balance

Co-operative Programme for

Monitoring and Evaluation of the Long-

Range Transmission of Air Pollutants

in Europe

Environmental Protection Agency

film-forming compounds

General Circulation Model

Growth Factor

Hydroxymethanesulfonate

Proton Nuclear Magnetic Resonance

Spectroscopy

Hygroscopic Tandem Differential

Mobility Analyzer

Interagency Monitoring at

Protected Visual Environments

Ice Nuclei

International Union of Pure

and Applied Chemistry

Low Hygroscopicity

Master Chemical Mechanism

Medium Hygroscopicity

Non Methane Volatile Organic

Compounds

Organic Aerosol

Organic Particulate Mater

Other reactive volatile organic

compounds

Origin and Formation of Secondary

Organic Aerosol

Other volatile organic compounds

Primary Organic Aerosol

Relative Humidity

Statewide Air Pollution Research

Center chemical mechanism

Secondary Organic Aerosol

Single Scatering Albedo

Tandem Differential Mobility Analyzer

UNIquac Functional-group Activity

Coefficient method

Ultra Violet

Volatile Organic Compounds

World Meteorological Organization -

World Data Centre for Aerosol

Water Soluble Organic Compounds

Zdanovskii-Stokes-Robinson approach
Acknowledgements. This work has been supported by the EU project PHOENICS: EVK2-CT2001-00098. We thank all participants of the PHOENICS workshop on Organic Aerosol in Belgirate in September 2003 for communication of their results and fruitful discussions. B. Ervens acknowledges support by the NOAA Office of Global programs. The authors thank the reviewers, all those who commented on the web as well as J. van Aardenne and L. Barrie for their constructive comments.

Edited by: S. Martin

\section{References}

Abdul-Razzak, H., Ghan, S., and Rivera-Carpio, C.: A parameterisation of aerosol activation. Part I: Single aerosol type, J. Geophys. Res., 103, 6123-6132, 1998.

Abdul-Razzak, H. and Ghan, S.: A parameterisation of aerosol activation 2. Multiple aerosol types, J. Geophys. Res., 105, 68376844, 2000.

Abdul-Razzak, H. and Ghan, S.: A parameterisation of aerosol activation 3. Sectional representation, J. Geophys. Res., 107(D3), doi:10.1029/2001JD000483, 2002.

Abbot, D. S., Palmer, P. I., Martin, R. V., Chance, K. V., Jacob, D. J., and Guenther, A.: Seasonal and interannual variability of isoprene emissions as determined by formaldehyde column measurements from space, Geophys. Res. Lett., 30(16), 1886, doi:10.1029/2003GL017336, 2003.

Albrecht, B. A.: Aerosols, cloud microphysics, and fractional cloudiness, Science, 245, 1227-1230, 1989.

Alvarado, A., Arey, J., and Atkinson, R.: Kinetics of the gas phase reactions of $\mathrm{OH}$ and $\mathrm{NO}_{3}$ radicals and $\mathrm{O}_{3}$ with the monoterpene reaction products pinonaldehyde, caronaldehyde and sabinaketone, J. Atmos. Chem., 31, 281-297, 1998.

Alvarado, A., Tuazon, E. C., Aschmann, S. M., Atkinson, R., and Arey, J.: Products of the gas phase reactions of $\mathrm{O}(3 \mathrm{P})$ atoms and $\mathrm{O}_{3}$ with a-pinene and 1,2-dimethyl-1-cyclohexene, J. Geophys. Res., 103(D19), 25 541-25 552, doi:10.1029/98JD00524, 1998 b.

Aminabhavi, T. M., Patil, V. B., Aralaguppi, M. I., and Phayde, H. T. S.: Density, Viscosity, and Refractive Index of the Binary Mixtures of Cyclohexane with Hexane, Heptane, Octane, Nonane, and Decane at $(298.15,303.15$, and 308.15) K, J. Chem. Eng. Data, 41(3), 521-525, 1996.

Andersson-Skold, Y. and Simpson, D.: Secondary organic aerosol formation in northern Europe: A model study, J. Geophys. Res., 106(D7), 7357-7374, 2001.

Andreae, M. O. and Crutzen, P. J.: Atmospheric aerosols: biogeochemical sources and role in atmospheric chemistry, Science, 276, 1052-1058, 1997.

Ansari, A. S. and Pandis, S. N.: Water absorption by secondary organic aerosol and its effect on inorganic aerosol behavior, Environ. Sci. Technol., 34, 71-77, 2000.

Anttila, T., Kerminen, V. M., and Kulmala, M., A tool for estimating the contribution of water-soluble organic compounds to the particle mass and condensational growth in the atmosphere, Atmos. Environ., 36, 5897-5908, 2002.

Anttila, T. and Kerminen, V. M.: Condensational growth of atmospheric nuclei by organic vapours, J. Aerosol Sci., 34, 41-61, 2003. 
Appel, B. R., Cheng, W., and Salaymeh, F.: Sampling of carbonaceous particles in the atmosphere-II, Atmos. Environ., 23, 2167$2175,1989$.

Arey, J., Atkinson, R., and Aschmann, S. M.: Product study of the gas phase reactions of monoterpenes with the $\mathrm{OH}$ radical in the presence of NOx, J. Geophys. Res., 95, 18 539-18 546, 1990.

Aschmann, S. M., Reissel, A., Atkinson, R., and Arey, J.: Products of the gas phase reaction of the $\mathrm{OH}$ radical with alpha- and betapinene in the presence of NOx, J. Geophys. Res., 103, $25553-$ 25 561, 1998.

Atkinson, R.: Gas-phase Tropospheric chemistry of organic compounds, 1, Alkanes and alkenes, J. Phys. Chem. Ref. Data Monogr., 2, 1-216, 1997.

Atkinson, R. and Arey, J.: Atmospheric chemistry of biogenic organic compounds, Acc. Chem. Res., 31, 574-583, 1998.

Atkinson, R.: Atmospheric Chemistry of VOCs and NOx, Atmos. Environ., 34, 2063-2101, 2000.

Aumont, B., Madronich, S., Bey, I., and Tyndall, G. S.: Contribution of Secondary VOC to the Composition of Aqueous Atmospheric Particles: A Modelling Approach, J. Atmos. Chem., 35, 59-75, 2000.

Baboukas, E. D., Kanakidou, M., and Mihalopoulos, N.: Carboxylic acids in gas and particulate phase above the Atlantic Ocean, J. Geophys. Res., 105(D11), 14 459-14 471, 2000.

Balkanski, Y., Jacob, D., Gardner, G., Graustein, W., and Turekian, K. K.: Tropospheric Residence Times of Continental Aerosols derived from a Three Dimensional Simulation of 210-Pb, J. Geophys. Res., 98, 20 573-20 586, 1993.

Balkanski, Y.: Atmospheric residence time of continental aerosols, $\mathrm{PhD}$ thesis, Harvard University, 1991.

Baltensperger, U., Streit, N., Weingartner, E., Nyeki, S., Prévôt, A. S. H., Van Dingenen, R., Virkkula, A., Putaud, J. P., Even, A., ten Brink, H., Blatter, A., Neftel, A., and Gäggeler, H. W.: Urban and rural aerosol characterisation of summer smog events during the PIPAPO field campaign in Milan, Italy, J. Geophys. Res., 107, 8193, doi:10.1029/2001JD001292, 2002.

Barnes, G. T.: The effects of monolayers on the evaporation of liquids, Adv. Colloid Interface Sci., 25, 89-200, 1986.

Barnes, I. (Ed): The European Photoreactor EUPHORE, 4th Report 2001; http://www.physchem.uni-wuppertal.de/PC-WWW_Site/ Publications/Publications.html, 2004.

Bauer, H., Kasper-Giebl, A., Löflund, M., Giebl, H., Hitzenberger, R., Zibuschka, F., and Puxbaum, H.: The contribution of bacteria and fungal spores to the organic carbon content of cloud water, precipitation and aerosols, Atmos. Res., 64, 109-119, 2002.

Berndt, T. and Boge, O.: Products and mechanism of the gas-phase reaction of $\mathrm{NO}_{3}$ radicals with $\alpha$-pinene, J. Chem. Soc., Faraday Transactions, 93, 3021-3027, 1997.

Bertie, J. E. and Lan, Z.: The refractive index of colorless liquids in the visible and infrared: Contributions from the absorption of infrared and ultraviolet radiation and the electronic molar polarizability below $20500 \mathrm{~cm}^{-1}$, J. Chem. Phys., 103(23), 1015210161, 1995.

Bilde, M. and Pandis, S. N.: Evaporation rates and vapor pressures of individual aerosol species formed in the atmospheric oxidation of alpha- and beta-pinene, Environ. Sci. Technol., 35(16), 33443349, 2001.

Bilde, M., Svenningsson, B., Monster, J., and Rosenorn, T.: Evenodd alternation of evaporation rates and vapor pressures of $\mathrm{C} 3-$
C9 dicarboxylic acid aerosols, Environ. Sci. Technol., 37(7), 1371-1378, 2003.

Binkowski, F. S. and Roselle, S. J.: Models-3 community multiscale air quality (CMAQ) model aerosol component 1. Model description, J. Geophys. Res., 108(D6), 4183, doi:10.1029/2001JD001409, 2003.

BIOVOC: Final report on the EU project on Degradation Mechanisms of Biogenic VOC \& BIOVOC', Contract reference: ENVCT95-0059, Co-ordinator Dr. J. Hjorth, JRC Ispra, 1998.

Blando, J. D. and Turpin, B. J.: Secondary organic aerosol formation in cloud and fog droplets: a literature evaluation of plausibility, Atmos. Environ., 34, 1623-1632, 2000.

Boers, R. and Mitchell, R. M.: Absorption feedback in stratocumulus clouds, Influence on cloud top albedo, Tellus-A, 46, 229-241, 1994.

Bond, T. C., Streets, D. G., Yarber, K. F., Nelson, S. M., Woo, J. H., and Klimont, Z.: A technology-based global inventory of Black and Organic Carbon emissions from Combustion, J. Geophys. Res., 109, D14203, doi:10.1029/2003JD003697, 2004.

Bonn, B., Schuster, G., and Moortgat, G. K.: Influence of water vapor on the process of new particle formation during monoterpene ozonolysis, J. Phys. Chem. A, 106, 2869-2881, 2002.

Bonn, B. and Moortgat, G. K.: New particle formation during alpha- and beta-pinene oxidation by $\mathrm{O}_{3}, \mathrm{OH}$ and $\mathrm{NO}_{3}$, and the influence of water vapour: particle size distribution studies, Atmos. Chem. Phys., 2, 183-196, 2002,

SRef-ID: 1680-7324/acp/2002-2-183

Bonn, B. and Moortgat, G. K.: Sesquiterpene ozonolysis: Origin of atmospheric new particle formation from biogenic hydrocarbons, Geophys. Res. Lett., 30, 1585-1588, 2003.

Bonn, B., von Kuhlmann, R., and Lawrence, M. G.: High contribution of biogenic hydroperoxides to secondary organic aerosol formation, Geophys. Res. Lett., 31, L10108, doi:10.1029/2003GL019172, 2004.

Boucher, O. and Lohmann, U.: The sulfate-CCN-cloud albedo effect - A sensitivity study with 2 general-circulation models, Tellus B, 47, 281-300, 1995.

Bowman, F. M. and Karamalegos, A. M.: Estimated effects of composition on secondary organic aerosol mass concentrations, Environ. Sci. Technol., 36, 2701-2707, 2002.

Boy, M., Rannik, U., Lehtinen, K. E. J., Tarvainen, V., Hakola, H., and Kulmala, M.: Nucleation events in the continental boundary layer: Long-term statistical analyses of aerosol relevant characteristics, J. Geophys. Res., 108, 4667-4680, 2003.

Braban, C. F., Carroll, M. F., Styler, S. A., and Abbatt, J. P. D.: Phase Transitions of Malonic and Oxalic Acid Aerosols, J. Phys. Chem. A, 107, 6594-6602, 2003.

Brechtel, F. J. and Kreidenweis, S. M.: Predicting particle critical supersaturation from hygroscopic growth measurements in the humidified TDMA, Part I: Theory and sensitivity studies, J. Atmos. Sci., 57, 1854-1871, 2000.

Broekhuizen, K. E., Thornberry, T., Kumar, P. P, and Abbatt J. P. D.: Formation of Cloud Condensation Nuclei by Oxidative Processing: Unsaturated Fatty Acids, J. Geophys. Res., 109, D24206, doi:10.1029/2004JD005298, 2004.

Brooks, S. D., Wise, M. E., Cushing, M., and Tolbert, M. A.: Deliquescence Behavior of Organic/Ammonium Sulfate Aerosol, Geophys. Res. Lett., 29, 23-1-23-4, 2002. 
Brooks, S. D., Garland, R. M., Wise, M. E., Prenni, A. J., Cushing, M., Hewitt, E., and Tolbert, M. A.: Phase changes in internally mixed maleic acid/ammonium sulfate aerosols, J. Geophys. Res., 108, 4487-4497, 2003.

Brooks, S. D., DeMott, P. J., and Kreidenweis, S. M.: Water Uptake by Particles Containing Humic Materials and Mixtures of Humic Materials with Ammonium Sulfate, Atmos. Environ., 38, 18591868, 2004.

Busch, B., Kandler, K., Schütz, L., and Neusüß, C.: Hygroscopic properties and water-soluble volume fraction of atmospheric particles in the diameter range from $50 \mathrm{~nm}$ to $3.8 \mu \mathrm{m}$ during LACE 98, J. Geophys. Res., 107, doi:10.1029/2000JD000228, 2002.

Cabada J. C., Pandis, S. N., and Robinson, A. L.: Sources of atmospheric particulate matter in Pittsburgh, Pennsylvania, J. Air Waste. Man. Assoc., 52, 732-741, 2002.

Cabada, J. C., Pandis, S. N., Subramanian, R., Robinson, A. L., Polidori, A., and Turpin, B.: Estimating the Secondary Organic Aerosol Contribution to PM2.5 Using the EC Tracer Method, Special Issue of Aerosol Science and Technology on Findings from the Fine Particulate Matter Supersites Program, 140-155, 2004.

Cachier, H., Bremond, M. P., and Buat-Menard, P.: determination of atmospheric soot carbon with a simpler thermal method, Tellus, 41B, 379-380, 1989.

Cadle, S. H. and Mulawa, P. A.: Atmospheric carbonaceous species measurement methods comparison study: GM results, Aerosol Sci. Technol., 12, 128-141, 1990.

Calogirou, A., Larsen, B. R., and Kotzias, D.: Gas-phase terpene oxidation products: a review, Atmos. Environ., 33, 1423-1439, 1999.

Calvert, J. G., Atkinson, R., Kerr, J. A., Madronich, S., Moortgat, G. K., Wallington, T. J., and Yarwood, G.: The mechanisms of atmospheric oxidation of the alkenes, Oxford University Press, London, 2000.

Carter, W. P. L.: SAPRC-99, available via ftp: http://helium.ucr.edu/ carter/), 1997.

Carter, W. P. L.: SAPRC-99, available via ftp: http://helium.ucr. edu/ $\sim$ carter/), 1999.

Cases, A. M., Marigliano, A. C. G., Bonatti, C. M., and Solimo, H. N.: Density, Viscosity, and Refractive Index of Formamide, Three Carboxylic Acids, and Formamide + Carboxylic Acid Binary Mixtures, J. Chem. Eng. Data, 46(3), 712-715, 2001.

Chameides, W. L., Lindsay, R. W., Richardson, J., and Kiang, C. S: The Role of Biogenic Hydrocarbons in Urban Photochemical Smog: Atlanta as a Case Study, Science, 241, 1473-1475, 1998.

Chameides, W. L. and Stelson, A. W.: Aqueous Phase Chemical Processes in Deliquescent Sea-Salt Aerosols: A Mechanism That Couples the Atmospheric Cycles of S and Sea-Salt, J. Geophys. Res., 97, 20 565-20 580, 1992.

Chan, C. K., Kwok, C. S., and Chow, A. H. L.: Study of hygroscopic properties of aqueous mixtures of disodium fluorescein and sodium chloride using an electrodynamic balance, Pharm. Res., 14, 1171-1175, 1997.

Chan, M. N. and Chan, C. K.: Hygroscopic properties of two model humic-like substances and their mixtures with inorganics of atmospheric importance, Environ. Sci. Technol., 37, 5109-5115, 2003.

Charlson, R., Seinfeld, J. H., Nenes, A., Kulmala, M., Laaksonen, A., and Facchini, M. C.: Reshaping the theory of cloud forma- tion, Science, 292, 2025-2026, 2001.

Chebbi, A. and Carlier, P.: Carboxylic Acids in the Troposphere, Occurrence, Sources, and Sinks: A Review, Atmos. Environ., 30, 24, 4233-4249, 1996.

Christoffersen, T. S., Hjorth, J., Horie, O., Jensen, N. R., Kotzias, D., Molander, L. L., Neeb, P., Ruppert, L., Winterhalter, R., Virkkula, A., Wirtz, K., and Larsen, B. R.: cis-Pinic Acid, a Possible Precursor for Organic Aerosol Formation from Ozonolysis of a-Pinene, Atmos. Environ., 32, 1657-1661, 1998.

Choi, M. and Chan, C. K.: The effects of organic species on the hygroscopic behaviors of inorganic aerosols, Environ. Sci. Technol., 36, 2422-2428, 2002a.

Choi, M. Y. and Chan, C. K.: Continuous Measurements of the Water Activities of Aqueous Droplets of Water-Soluble Organic Compounds, J. Phys. Chem. A, 106, 4566-4572, 2002b.

Chow, J. C., Watson, J. G., Pritchett, L. C., Person, W. R., Frazier, C. A., and Purcell, R. G.: The DRI thermal/optical reflectance carbon analysis system: description, evaluation and application in the US air quality studies, Atmos. Environ., 27A, 1185-1201, 1993.

Chow, J. C., Watson, J. G., Lu, Z., Lowenthal, D. H., Frazier, C. A., Solomon, P. A., Thuillier, R. H., and Magliano, K.: Descriptive analysis of PM2.5 and PM10 at regionally representative locations during SJVAQS/AUSPEX, Atmos. Environ., 30, 20792112, 1996.

Chuang, C. C. and Penner, J. E.: Effects of anthropogenic sulfate on cloud drop nucleation and optical properties, Tellus B, 47, 566-577, 1995.

Chuang, P. Y.: Measurement of the Timescale of Hygroscopic Growth for Atmospheric Aerosols, J. Geophys. Res., 108(D9), 4282, doi:10.1029/2002JD002757, 2003.

Chughtai, A. R., Williams, G. R., Atteya, M. M. O., Miller, N. J., and Smith, D. M.: Carbonaceous particle hydration, Atmos. Environ., 33, 2679-2687, 1999.

Chung, S. H. and Seinfeld, J. H.: Global distribution and climate forcing of carbonaceous aerosols, J. Geophys. Res., 107(D19), 4407, doi:10.1029/2001JD001397, 2002.

Claeys, M., Graham, B., Vas, G., Wang, W., Vermeylen, R., Pashynska, V., Cafmeyer, J., Guyon, P., Andreae, M. O., Artaxo, P., and Maenhaut, W.: Formation of Secondary OrganicAerosols Through Photooxidation of Isoprene, Science, 303, 1173-1176, 2004a.

Claeys, M., Wang, W., Ion, A. C., Kourtchev, I., Gelencser, A., and Maenhaut, W.: Formation of secondary organic aerosols from isoprene and its gas-phase oxidation products through reaction with hydrogen peroxide, Atmos. Environ., 38, 4093-4098, 2004b.

Clegg, S. L., Seinfeld, J. H., and Brimblecombe, P.: Thermodynamic modelling of aqueous aerosols containing electrolytes and dissolved organic compound, J. Aerosol Sci., 32, 713-738, 2001.

Cocker, D. R., Clegg, S. L., Flagan, R. C., and Seinfeld, J. H.: The effect of water on gas-particle partitioning of secondary organic aerosol, I: alpha-pinene/ozone system, Atmos. Environ., 35, 6049-6072, 2001a.

Cocker, D. R., Mader, B. T., Kalberer, M., Flagan, R. C., and Seinfeld, J. H.: The effect of water on gas-particle partitioning of secondary organic aerosol, II. m-xylene and 1,3,5trimethylbenzene photooxidation systems, Atmos. Environ., 35, 6073-6085, 2001b. 
Cocker III, D. R., Withlock, N. E., Flagan, R. C., and Seinfeld, J. H.: Hygroscopic properties of Pasadena, California aerosol, Aerosol Sci. Technol., 35, 637-647, 2001.

Cohard, J., Pinty, J., and Bedos, C.: Extending Twomey's analytical estimate of nucleated cloud droplet concentrations from CCN spectra, J. Atmos. Sci., 55, 3348-3357, 1998.

Cohard, J., Pinty, J., and Suhre, K.: On the parameterisation of activation spectra from cloud condensation nuclei microphysical properties, J. Geophys. Res., 105, 11 753-11 766, 2000.

Conant, W. C., Nenes, A., and Seinfeld, J. H.: Black carbon radiative heating effects on cloud microphysics and implications for aerosol indirect forcing, 1, Extended Köhler theory, J. Geophys. Res., 107(D21), 4604, doi:10.1029/2002JD002094, 2002.

Cooke, W. F. and Wilson, J. J. N.: A global black carbon aerosol model, J. Geophys. Res., 101, 19395-19409, 1996.

Cooke, W. F., Liousse, C., Cachier, H., and Feichter, J.: Construction of a $1^{\circ} \times 1^{\circ}$ fossil fuel emission data set for carbonaceous aerosol and implementation and radiative impact in the ECHAM4 model, J. Geophys. Res., 104, 22 137-22 162, 1999.

Countess, R. J.: Interlaboratory analyses of carbonaceous aerosol samples, Aerosol Sci. Technol., 12, 114-121, 1990.

Cruz, C. N. and Pandis, S. N.: A study of the ability of pure secondary organic aerosol to act as cloud condensation nuclei, Atmos. Environ., 31(14), 2205-2214, 1997.

Cruz, C. N. and Pandis, S. N.: Deliquescence and hygroscopic growth of mixed inorganic-organic atmospheric aerosol, Environ. Sci. Technol., 34, 4313-4319, 2000.

Cziczo, D. J., DeMott, P. J., Brooks, S. D., Prenni, A. J., Thomson, D. S., Baumgardner, D., Wilson, J. C., Kreidenweis, S. M., and Murphy D. M.: Observations of organic species and atmospheric ice formation, Geophys. Res. Lett., 31, L12116, doi:10.1029/2004GL019822, 2004.

de Almeida Azevedo, D., Yara Moreira dos Santos, C., and Radler de Aquino Neto, F.: Identification and seasonal variation of atmospheric organic pollutants in Campos dos Goytacazes, Brazil, Atmos. Environ., 36, 14, 2383-2395, 2002.

Decesari, S., Facchini, M. C., Fuzzi, S., and Tagliavini, E.: Characterization of water-soluble organic compounds in atmospheric aerosol: A new approach, J. Geophys. Res., 105, 1481-1489, 2000.

Decesari, S., Facchini, M. C., Matta, E., Lettini, F., Mircea, M., Fuzzi, S., Tagliavini, E., and Putaud, J. P.: Chemical features and seasonal trend of water soluble organic compounds in the Po valley fine aerosol, Atmos. Environ., 35, 3691-3699, 2001.

Decesari, S., Facchini, M. C., Mircea, M., Cavalli, F., and Fuzzi, S.: Solubility properties of surfactants in atmospheric aerosol and cloud /fog water samples, J. Geophys. Res., 108(D21) 4685, doi:10.1029/2003JD003566, 2003.

De Lorenzi, L., Fermeglia, M., and Torriano, G.: Density, Refractive Index, and Kinematic Viscosity of Diesters and Triesters, J. Chem. Eng. Data, 42(5), 919-923, 1997.

DeMott, P. J., Meyers, M. P., and Cotton, W. R.: Parameterisation and impact of ice initiation processes relevant to numerical model simulations of cirrus clouds, J. Atmos. Sci., 51, 77-90, 1994.

DeMott, P. J., Rogers, D. C., and Kreidenweis, S. M.: The susceptibility of ice formation in upper tropospheric clouds to insoluble aerosol components, J. Geophys. Res., 102, 19575-19584, 1997.
Derwent, R. G., Collins, W. J., Jenkin, M. E., Johnson, C. E., and Stevenson, D. S.: The global distribution of secondary particulate matter in a 3-D Lagrangian chemistry transport model, J. Atmos. Chem., 44, 57-95, 2003.

Demou, E., Visram, H., Donaldson, D. J., and Makar, P. A.: Uptake of water by organic films: the dependence on the film oxidation state, Atmos. Environ., 37(25), 3529-3537, 2003.

Dick, W. D., Saxena, P., and McMurry, P. H.: Estimation of water uptake by organic compounds in submicron aerosols measured during the Southeastern Aerosol and Visibility Study, J. Geophys. Res., 105, 1471-1479, 2000.

Diehl, K. and Wurzler, S.: Heterogeneous Drop Freezing in the Immersion Mode: Model calculations considering soluble and insoluble particles in the drops, J. Atmos. Sci., 61, 16, 2063-2072, 2004.

Docherty, K. S. and Ziemann, P. J.: Effects of Stabilized Criegee Intermediate and $\mathrm{OH}$ Radical Scavengers on Aerosol Formation from Reactions of $\beta$-Pinene with $\mathrm{O}_{3}$, Aerosol. Sci. Technol., 37, 877-891, 2003.

Eatough, D. J., Sedar, B., Lewis, L., Hansen, L. D., Lewis, E. A. and Farber, R. J.: Determination of semivolatile organic compounds in particles in the Grand Canyon area, Aerosol Sci. Technol., 10, 438-449, 1989.

Eatough, D. J., Wadworth, A., Eatough, D. A., Crawford, J. W., Hansen, L. D., and Lewis, A. D.: A multi-system, multichannel diffusion denuder sampler for the determination of fineparticulate organic material in the atmosphere, Atmos. Environ., 27A, 1213-1219, 1993.

Eatough, D. J., Eatough, D. A., Lewis, L., and Lewis, A. D.: Fine particulate chemical composition and light extinction at Canyonlands National Park, J. Geophys. Res., 101, 19 515-19531, 1996.

Eatough, D. J., Eatough, N. L., Obeidi, F., Pang, Y., Modey, W., and Long, R.: Continuous determination of PM2.5 mass, including semi-volatile species, Aerosol Sci. Technol., 34, 1-8, 2001.

Edney, E. O., Driscoll, D. J., Speer, R. E., Weathers, W. S., Kleindienst, T. E., Li, W., and Smith, D. F.: Impact of aerosol liquid water on secondary organic aerosol yields of irraddiated toluene/propylene/NOx/ $\left(\mathrm{NH}_{4}\right)_{2} \mathrm{SO}_{4}$ /air mixtures, Atmos. Environ., 34, 3907-3919, 2000.

Edney, E. O., Kleindienst, T. E., Conver, T. S., McIver, C. D., Corse, E. W., and Weathers, W. S.: Polar organic oxygenates in PM2.5 at a southeastern site in the United States, Atmos. Environ., 37, 3947-3965, 2003.

Eliason, T. L., Aloisio, S., Donaldson, D. J., Cziczo, D. J., and Vaida, V.: Processing of unsaturated organic acid films and aerosols by ozone, Atmos. Environ., 37, 2207-2219, 2003.

Eliason, T. L., Gilman, J. B., and Vaida, V.: Oxidation of organic films relevant to atmospheric aerosols, Atmos. Environ., 38, 1367-1378, 2004.

El-Kashef, H.: Measurement of the physical properties of cyclohexane using a laser interferometric technique. II, Optical Materials (Amsterdam), 10(4), 305-312, 1998.

EMEP: Review and Revision, Emission Data reported to CLTRAP, edited by: V. Vestreng, EMEP/MSC-W Note 1/2003, 2003.

Ervens, B., George, C., Williams, J. E., Buxton, G. V., Salmon, G. A., Bydder, M., Wilkinson, F., Dentener, F., Mirabel, P., Wolke, R., and Herrmann, H.: CAPRAM2.4 (MODAC mechanism): An extended and condensed tropospheric aqueous phase mechanism and its application, J. Geophys. Res., 108(D14), 4426, 
doi:10.1029/2002JD002202, 2003.

Ervens, B., Feingold, G., Frost, G. J., and Kreidenweis, S. M.: A modelling study of aqueous production of dicarboxylic acids, Part 1: Chemical pathways and organic mass production, J. Geophys. Res., 109, D15205, doi:10.1029/2003JD004387, 2004a.

Ervens, B., Feingold, G., Clegg, S. L., and Kreidenweis, S. M.: A modelling study of aqueous production of dicarboxylic acids, Part 2: Impact on cloud microphysics, J. Geophys. Res., 109, D15206, doi:10.1029/2003JD004575, 2004b.

Facchini, M. C., Fuzzi, S., Zappoli, S., Andracchio, A., Gelencsér, A., Kiss, G., Krivácsy, Z., Mészáros, E., Hansson, H. C., Alsberg, T., and Zebühr, Y.: Partitioning of the organic aerosol component between fog droplets and interstitial aerosol, J. Geophys. Res., 104, 26 821-26 832, 1999a.

Facchini, M. C., Mircea, M., Fuzzi, S., and Charlson, R. J.: Cloud albedo enhancement by surface-active organic solutes in growing droplets, Nature, 401, 257-259, 1999 b.

Facchini, M. C., Decesari, S., Mircea, M., Fuzzi, S., and Loglio, G.: Surface tension of atmospheric wet aerosol and cloud/fog droplets in relation to their organic carbon content and chemical composition, Atmos. Environ., 33, 4853-4857, 2000.

Fan, X., Brook, J. R., and Mabury, S. A.: Sampling atmospheric carbonaceous aerosols using an integrated gas and particle sampler, Environ. Sci. Technol., 37, 3145-3151, 2003.

Fassi-Fihri, A., Suhre, K., and Rosset, R.: Internal and external mixing in atmospheric aerosols by coagulation: impact on the optical and hygroscopic properties of the sulphate-soot system, Atmos. Environ., 10, 1393-1402, 1997.

Feingold, G. and Heymsfield, A.: Parameterisations of condensational growth of droplets for use in general circulation models, J. Atmos. Sci., 49, 2325-2342, 1992.

Feingold, G. and Kreidenweis, S. M.: Does cloud processing of aerosol enhance droplet concentrations?, J. Geophys. Res., 105(D19), 24 351-24361, 2000.

Feingold, G. and Chuang, P. Y.: Analysis of the infuence of filmforming compounds on droplet growth: Implications for cloud microphysical processes and climate, J. Atmos. Sci., 59, 20062018, 2002.

Feingold, G.: Modelling of the first indirect effect: Analysis of measurement requirements, Geophys. Res. Lett., 30(19), doi:10.1029/2003GL017967, 2003.

Fitz, D. R: Reduction of positive organic artifact on quartz filters, Aerosol Sci. Technol., 12, 142-148, 1990.

Flossmann, A., Hall, W., and Pruppacher. H.: A theoretical study of the wet removal of atmospheric pollutants: Part I: The redistribution of aerosol particles capture through nucleation and impaction scavenging by growing cloud drops, J. Atmos. Sci., 42, 583-606, 1985.

Forstner, H. J. L., Seinfeld, J. H., and Flagan, R. C.: Molecular speciation of secondary organic aerosol from the higher alkenes: 1-Octene and 1-decene, Atmos. Environ., 31, 1953-1964, $1997 \mathrm{~b}$.

Forstner, H. J. L., Seinfeld, J. H., and Flagan, R. C.: Secondary organic aerosol formation from the photooxidation of aromatic hydrocarbons. Molecular composition, Environ. Sci. Technol., 31, 1345-1358, 1997a.

Fredeslund, A. and Sorensen, J. M.: Model for Thermodynamic and Phase Equilibrium Calculations, edited by: Sandler, S. I., Marcel Dekker, N.Y., 4, 287-361, 1994.

Fuchs, N. A.: The Mechanics of Aerosols, Pergamon Press, Oxford,
1964.

Fuzzi, S., Decesari, S., Facchini, M. C., Matta, E., Mircea, M., and Tagliavini, E.: A simplified model of the water soluble organic component of atmospheric aerosols, Geophys. Res. Lett., 28, 4079-4082, 2001.

Fuzzi, S., Facchini, M. C., Decesari, S., Matta, E., and Mircea, M.: Soluble organic compounds in fog and cloud droplets: what have we learned over the past few years?, Atmos. Res., 64(1-4), 8998, 2002.

Gaman, A. I., Kulmala, M., Vehkamaki, H., Napari, I., Mircea, M., Facchini, M. C., and Laaksonen, A.: Binary homogeneous nucleation in water-succinic acid and water-glutaric acid systems, J. Chem. Phys., 120, 282-291, 2004.

Gao, S., Hegg, D. A., Frick, G., Caffrey, P. F., Pasternack, L., Cantrell, C., Sullivan, W., Ambrusko, J., Albrechcinski, T., and Kirchstetter, T. W.: Experimental and modelling studies of secondary organic aerosol formation and some applications to the marine boundary layer, J. Geophys. Res., 106, 27 619-27 634, 2001.

Gao, S., Ng, N. L., Keywood, M., Varutbangkul, V., Bahreini, R., Chung, S. H., Nenes, A., He, J., Yoo, K. Y., Beauchamp, J. L., Hodyss, R. P., Flagan, R. C., and Seinfeld, J. H.: particle Phase Acidity and Oligomer Formation in Secondary Organic Aerosol, Environ. Sci. Technol., 38, 6582-6589, doi:10.1021/es049125k, 2004.

Gaydos, T., Stanier, C .O., and Pandis, S. N.: Modelling of in situ ultrafine atmospheric particle formation in the eastern United States, J. Geophys. Res., 110, D07S12, doi:10.1029/2004JD004683, 2005.

Gelbard, F. and Seinfeld, J. H.: Simulation of multicomponent aerosol dynamics, J. Colloid Interf. Sci., 78, 485-501, 1980.

Gelencsér, A., Hoffer, A., Kiss, G., Tombasz, E., Kurdi, R., and Bencze, L.: In-situ formation of Light-Absorbing Organic Matter in Cloud Water, J. Atmos. Chem., 45, 25-33, 2003.

Geron, C., Rasmussen, R., Arnts, R. R., and Guenther, A.: A review and synthesis of monoterpene speciation from forests in the United States, Atmos. Environ., 34, 1761-1781, 2000.

Ghan, S., Chuang, C., and Penner, J.: A parameterisation of cloud droplet nucleation, Part I: Single aerosol species, Atmos. Res., 30, 197-222, 1993.

Ghan, S., Chuang, C., Easter, R., and Penner, J.: A parameterisation of cloud droplet nucleation, 2. Multiple aerosol types, Atmos. Res., 36, 39-54, 1995.

Ghan, S., Leung, L., Easter, R., and Abdul-Razzak, H.: Prediction of cloud droplet number in a general circulation model, J. Geophys. Res., 102, $21777-21$ 794, 1997.

Glasius, M., Calogirou, A., Jensen, N. R., Hjorth, J., and Nielsen, C. J.: Kinetic study of gas-phase reactions of pinonaldehyde and structurally related compounds, Int. J. Chem. Kinet., 29, 523533, 1997.

Glasius, M., Lahaniati, M., Calogirou, A., Di Bella, D., Jensen, N. R., Hjorth, J., Kotzias, D., and Larsen, B. R.: Carboxylic acids in secondary aerosols from the oxidation of cyclic monoterpenes by ozone, Environ. Sci. Technol., 34, 1001-1010, 2000.

Gmehling, J., Onken, U., Arlt, W., Gronzheuser, P., Weldlich, U., Kolbe, B., and Rarey, J.: DECHEMA Chemistry Data Series, Volume 1. Vapor-liquid Equilibrium Data Collection; DECHEMA (Deutsche Gesellschaft fur Chemisches Apparatewesen, Chemische Technik und Biotechnologie e.V.), Frank- 
furt, Germany, 1994.

Goldstein, A. H., McKay, M., Kurpius, M. R., Schade, G. W., Lee, A., Holzinger R., and Rasmussen, R. A.: Forest thinning experiment confirms ozone deposition to forest canopy is domintaed by reaciton with biogenic VOCs, Geophys. Res. Lett., 31, L22106, doi:10.1029/2004GL021259, 2004.

Gomez-Diaz, D., Mejuto, J. C., and Navaza, J. M.: Physicochemical Properties of Liquid Mixtures, 1. Viscosity, Density, Surface Tension and Refractive Index of Cyclohexane + 2,2,4Trimethylpentane Binary Liquid Systems from 25 DegC to 50 DegC, J. Chem. Eng. Data, 46(3), 720-724, 2001.

Graedel, T. E. and Weschler, C. J.: Chemistry within Aqueous Atmospheric Aerosols and Raindrops, Rev. Geophys. Space Phys., 19, 505-539, 1981.

Gray, H. A.: Control of atmospheric fine primary carbon particle concentrations, EQL Report No. 23, Environmental Quality Laboratory, California Institute of Technology, CA, 1986.

Gray, H. A., Cass, G. R., Huntzicker, J. J., Heyerdahl, E. K., and Rau J. A.: Characteristics of atmospheric organic and elemental carbon concentrations in Los Angeles, Environ. Sci. Technol., 20, 580-589, 1986.

Griffin, R. J., Cocker III, D. R., and Seinfeld, J. H.: Incremental Aerosol Reactivity: Application to Aromatic and Biogenic Hydrocarbons, Environ. Sci. Technol., 33, 2403-2408, 1999a.

Griffin, R. J., Dabdub, D., and Seinfeld, J. H.: Estimate of global atmospheric organic aerosol from oxidation of biogenic hydrocarbons, Geophys. Res. Lett., 26, 2721-2724, 1999b.

Griffin, R. J., Dabdub, D., and Seinfeld, J. H.: Secondary organic aerosol: I. Atmospheric chemical mechanism for production of molecular constituents, J. Geophys. Res., 107(D17), 4332, doi:10.1029/2001JD000541, 2002a.

Griffin, R. J., Dabdub, D., Kleeman, M. J., Fraser, M. P., Cass, G. R., and Seinfeld, J. H.: Secondary organic aerosol: III. Urban/Regional scale model of size- and composition-resolved aerosols, J. Geophys. Res., 107(D17), 4334, doi:10.1029/2001JD000544, 2002b.

Griffin, R. J., Nguyen, K., Dabdub, D., and Seinfeld, J. H.: A coupled hydrophobic-hydrophilic model for predicting secondary organic aerosol formation, J. Atmos. Chem., 44, 171-190, 2003.

Gross, A. and Stockwell, W. R.: Comparison of the EMEP, RADM2 and RACM mechanisms, J. Atmos. Chem., 44, 151-170, 2003.

Groblicki, P. J., Cadle, S. H., Hang, C. C., and Mulawa, P. A.: Interlaboratory comparison of methods for the analysis of organic and elemental carbon in atmospheric particulate matter, General Motors Research 4054, General Motors Research Laboratories, Warren, MI, 1983.

Guenther, A., Zimmerman, P., and Wildermuth, M.: Natural volatile organic compound emission rate estimates for US woodland landscapes, Atmos. Environ., 28, 1197-1210, 1994.

Guenther, A., Hewitt, C. N., Erickson, D., Fall, R., Geron, C., Graedel, T., Harley, P., Klinger, L., Lerdau, M., McKay, W. A., Pierce, T., Scholes, B., Steinbrecher, R., Tallamraju, R., Taylor, J., and Zimmerman, P.: A Global Model of Natural Volatile Organic Compound Emissions, J. Geophys. Res., 100, 8873-8892, 1995.

Guenther, A., Archer, S., Greenberg, J., Harley, P., Helmig, D., Klinger, L., Vierling, L., Wildermuth, M., Zimmerman, P., and Zitzer, S.: Biogenic hydrocarbon emissions and landcover/climate change in a subtropical savannah, J. Phys. Chem.
Earth, 24, 659-667, 1999.

Guenther, A.: Modelling biogenic volatile organic compounds emissions to the atmosphere, in: Reactive hydrocarbons in the Atmosphere, edited by: Hewitt, C. N., Academic Press, San Diego, CA, 97-118, 1999.

Guenther, A., Geron, C., Pierce, T., Lamb, B., Harley, P., and Fall, R.: Natural emissions of non-methane volatile organic compounds, carbon monoxide, and oxides of nitrogen from North America, Atmos. Environ., 34, 2205-2230, 2000.

Gultepe, I. and Isaac, G.: The relationship between cloud droplet and aerosol number concentrations for climate models, Int. J. Climatol., 16, 941-946, 1996.

Gysel, M., Weingartner, E., Nyeki, S., Paulsen, D., Baltensperger, U., Galambos, I., and Kiss, G.: Hygroscopic properties of water-soluble matter and humic-like organics in atmospheric fine aerosol, Atmos. Chem. Phys., 4, 35-50, 2004,

SRef-ID: 1680-7324/acp/2004-4-35.

Hakola, H., Arey, J., Aschmann, S. M., and Atkinson, R.: Product formation from the gas phase reactions of $\mathrm{OH}$ radicals and $\mathrm{O}_{3}$ with a series of monoterpenes, J. Atmos. Chem., 18, 75-102, 1994.

Hallberg, A., Ogren, J. A., Noon, K. J., and Heintzenberg, J.: Phase partioning for different aerosol species in fog, Tellus, 44B, 545$555,1992$.

Hallberg, A., Ogren, J. A., Noon, K. J., Okada, K., Heintzenberg, J., and Svenningsson, I. B.: The influence of aerosol particle composition on cloud droplet formation, J. Atmos. Chem., 19(1-2) 153-171, 1994a.

Hallberg, A., Noon, K. J., Ogren, J. A., Svenningsson, I. B., Flossmann, A., Wiedensohler, A., Hannson, H.-C., Heintzenberg, J., Anderson, T. L., Ardens, B. G., and Maser, R.: J. Atmos. Chem., 19(1-2), 107-127, 1994b.

Hallquist, M., Wängberg, I., and Ljungström, E.: Atmospheric fate of carbonyl oxidation products originating from a-pinene and $\mathrm{d} 3$ carene: Determination of rate of reaction with $\mathrm{OH}$ and $\mathrm{NO}_{3}$ radicals, UV adsorption cross section and vapor pressures, Environ. Sci. Technol., 31, 3166-3172, 1997.

Hämeri, K., Väkevä, M., Aalto, P. P., Kulmala, M., Swietlivki, E., Zhou, J., Seidl, W., Becker, E., and O'Dowd, C. D.: Hygroscopic and $\mathrm{CCN}$ properties of aerosol particles in boreal forest, Tellus, 53B, 359-379, 2001.

Hämeri, K., Charlson, R., and Hansson, H.-C.: Hygroscopic properties of mixed ammonium sulfate and carboxylic acids particles, American Institute of Chemical Engineers Journal, 48, 13091316, 2002.

Hansen, J., Sato, M., and Ruedy, R.: Radiative forcing and climate response, J. Geophys. Res., 102, 6831-6864, 1997.

Hansen, J., Sato, M., Lacis, A., Ruedy, R., Tegen, I., and Matthews, E.: Climate forcings in the Industrial Era. Proc. Natl. Acad. Sci., 95, 12 753-12 758, 1998.

Hansson, H. C., Rood, M. J., Koloutsou-Vakakis, S., Hameri, K., Orsini, D., and Wiedensohler, A.: $\mathrm{NaCl}$ aerosol particle hygroscopicity dependence on mixing with organic compounds, J. Atmos. Chem., 31, 321-346, 1998.

Hatakeyama, S., Katsuyuki, I., Fukuyama, T., and Akimoto, H.: Reactions of ozone with a-pinene and b-pinene in air: Yields of gaseous and particulate products, J. Geophys. Res., 94, 13013 $13024,1989$.

Haywood, J. M. and Shine, K. P.: The effect of anthropogenic sul- 
fate and soot aerosol on the clear sky planetary radiation budget, Geophys. Res. Lett., 22(5), 603-606, 1995.

Hegg, D. A., Rutledge, S. A., Hobbs, P. V., Barth, M. C., and Hertzman, O.: The chemistry of a mesoscale rainband, Q. J. R. Meteorol. Soc., 115, 867-886, 1989.

Hegg, D. A., Majeed, R., Yuen, P. F., Baker, M. B., and Larson, T. V.: The impact of $\mathrm{SO}_{2}$ oxidation in cloud droplets and in haze particles on aerosol light scattering and CCN activity, Geophys. Res. Lett., 23, 2613-2626, 1996.

Hegg, D. A.: The impact of clouds on aerosol populations, IGAC Newsletter, 23, 2001.

Hering, S., Appel, D. R., Cheng., W., Salaymeh, F., Cadle, S. H., Mulawa, A., Cahill, T. A., Eldred, R. A., Surovik, M., Fitz, D., Howes, J. E., Knapp, K. T., Stockburger, L., Turpin, B. J., Huntzicker, J. J., Zhang, X. Q., and McMurry, P. H.: Comparison of sampling methods for carbonaceous aerosol in ambient air, Aerosol Sci. Technol., 12, 200-213, 1990.

Herrmann, H., Ervens, B., Jacobi, H.-W., Wolke, R., Nowacki, P., and Zellner, R.: CAPRAM2.3: A Chemical Aqueous Phase Radical Mechanism for Tropospheric Chemistry, J. Atmos. Chem., 36, 231-284, 2000.

Herrmann, H.: Kinetics of Aqueous Phase Reactions Relevant for Atmospheric Chemistry, Chem. Rev., 103, 12, 4691-4716, 2003.

Hickey, A. J. and Martonen, T. B.: Behavior of hygroscopic pharmaceutical aerosols and the influence of hydrophobic additivities, Pharm. Res., 10, 1-7, 1993.

Hoffmann, T., Odum, J. R., Bowman, F., Collins, D., Klockow, D., Flagan, R. C., and Seinfeld, J. H.: Formation of Organic Aerosols from the Oxidation of Biogenic Hydrocarbons, J. Atmos. Chem., 26, 189-222, 1997.

Hoffmann, T., Bandur, R., Marggraf, U., and Linscheid, M.: Molecular composition of organic aerosols formed in the a-pinene/O3 reaction: implications for new particle formation processes, J. Geophys. Res., 103, 25 569-25 578, 1998.

Hoffmann, T. (Ed.): Final Report of the 5th Framework Programme of the EU project OSOA (Origin and Formation of Secondary Organic Aerosol), contract EVK2-CT-1999-00016; available via the ftp: http://www.isas-dortmund.de/2002/e/staff/ hoffmann/osoa/index.html), 2001.

Hoppel, W., Fitzgerald, J., Frick, G., Caffrey, P., Pasternack, L., Hegg, D., Leaitch, R., Shantz, N., Cantrell, C., Albrechcinski, T., Ambrusko, J., and Sullivan, W.: Particle formation and growth from ozonolysis of $\alpha$-pinene, J. Geophys. Res., 106, 27603 $27618,2001$.

Hori, M., Ohta, S., Murao, N., and Yamagata, S.: Activation capability of water soluble organic substances as CCN, J. Aerosol. Sci., 34(4), 419-448, 2003.

Huebert, B., Bertram, T., Kline, J., Howell, S., Eatough, D., and Blomquist, B.: Measurements of organic and elemental carbon in Asian outflow during ACE-Asia from the NSF/NCAR C-130, J. Geophys. Res., 109, D19S11, doi:10.1029/2004JD004700, 2004.

Intergovernmental Panel on Climate Change (IPCC): Climate Change: The Scientific Basis, Cambridge University Press, UK, 2001.

Iinuma, Y., Böge, O., Gnauk, T., and Hermann, H.: Aerosolchamber study of the a-pinene/O3 reaction: influence of particle acidityon aerosol yields and products, Atmos. Environ, 38, 761-773, 2004.
Jacob, D. and Wofsy, S.: Photochemistry of biogenic emissions over the Amazon forest, J. Geophys. Res., 93, 1477-1486, 1988.

Jacobson, M. Z.: Isolating nitrated and aromatic aerosols and nitrated aromatic gases as sources of ultraviolet light absorption, J. Geophys. Res., 104, 3527-3542, 1999.

Jacobson, M. C., Hansson, H. C., Noone, K. J., and Charlson, R. J.: Organic atmospheric aerosols: Review and state of the science, Rev. Geophys., 38, 267-294, 2000.

Jacobson, M. Z.: Strong radiative heating due to the mixing state of black carbon in atmospheric aerosols, Nature, 409, 695-697, $2001 \mathrm{a}$.

Jacobson, M. Z.: Global direct radiative forcing due to multicomponent anthropogenic and natural aerosols, J. Geophys. Res., 106, 1551-1568, 2001b.

Jacobson, M. Z.: Development of mixed-phase clouds from multiple aerosol size distributions and the effect of the clouds on aerosol removal, J. Geophys. Res., 108, 4245, doi:10.1029/2002JD002691, 2003.

Jacobson, M. Z.: Climate response of fossil fuel and biofuel soot, accounting for soot's feedback to snow and sea ice albedo and emissivity, J. Geophys. Res., 109, D21201, doi:10.1029/2004JD004945, 2004.

Jang, M. and Kamens, R. M.: A thermodynamic approach for modelling partitioning of semivolatile organic compounds on atmospheric particulate matter: Humidity effects, Environ. Sci. Technol., 32, 1237-1243, 1998.

Jang, M. and Kamens, R. M.: Newly characterized products and composition of secondary aerosols from reaction of a-pinene with ozone, Atmos. Environ., 33, 459-474, 1999.

Jang, M. and Kamens, R. M.: Atmospheric secondary aerosol formation by heterogeneous reactions of aldehydes in the presence of a sulfuric acid aerosol catalyst, Environ. Sci. Technol., 35 , 4758-4766, 2001.

Jang, M., Czoschke, N. M., Lee, S., and Kamens, R. M.: Heterogeneous atmospheric aerosol production by acid-catalyzed particlephase reactions, Science, 298, 814-817, 2002.

Jang, M., Carroll, B., Chandramouli, B., and Kamens, R. M.: Particle growth by acid-catalyzed heterogeneous reactions of organic carbonyls on preexisting aerosols, Environ. Sci. Technol., 37, 3828-3837, 2003.

Janson, R., Rosman, K., Karlsson, A., and Hansson, H. C.: Biogenic emissions and gaseous precursors to forest aerosols, Tellus B, 53, 423-440, 2001.

Jaoui, M. and Kamens, R. M.: Mass balance of gaseous and particulate products analysis from a-pinene/NOx/air in the presence of natural sunlight, J. Geophys. Res.-A, 106, 12 541-12 558, 2001.

Jaoui, M. and Kamens, R. M.: Photolysis study of gas phase pinonaldehyde in the presence of natural sunlight, Atmos. Environ., 37, 1835-1851, 2003a.

Jaoui, M. and Kamens, R. M.: Mass balance of gaseous and particulate products from b-pinene/ $\mathrm{O}_{3} /$ air in the absence of light and b-pinene/NOx/air in the presence of natural sunlight, J. Atmos. Chem., 43, 101-141, 2003 b.

Jaoui, M. and Kamens, R. M.: Gaseous and Particulate Oxidation Products Analysis of a Mixture of $\alpha$-pinene $+\beta$-pinene $/ \mathrm{O}_{3} /$ Air in the Absence of Light and $\alpha$-pinene $+\beta$-pinene/NOx/Air in the Presence of Natural Sunlight, J. Atmos. Chem., 44, 259-297, $2003 c$.

Jenkin, M. E., Saunders, S. M., and Pilling, M. J.: The tropospheric 
degradation of volatile organic compounds: a protocol for mechanism development, Atmos. Environ., 31, 81-104, 1997.

Jenkin, M. E., Shallcross, D. E., and Harvey, J. N.: Development and application of a possible mechanism for the generation of cis-pinic acid from the ozonolysis of a- and b-pinene, Atmos. Environ., 34, 2837-2837, 2000.

Jenkin, M. E.: Modelling the formation and composition of secondary organic aerosol from $\alpha$ - and $\beta$-pinene ozonolysis using MCM v3, Atmos. Chem. Phys., 4, 1741-1757, 2004,

SRef-ID: 1680-7324/acp/2004-4-1741.

Jensen, J. and Charlson, R.: On the efficiency of nucleation scavenging, Tellus B, 36, 367-375, 1984.

Jensen, E. J. and Toon, O. B.: The potential effects of volcanic aerosols on cirrus cloud microphysics, Geophys. Res. Lett., 19, 1759-1762, 1992.

Johnson, B. T., Shine, K. P., Forster, P. M.: The semi-direct aerosol effect: The impact of absorbing aerosols on marine stratocumulus, Quarterly Journal of the Royal Meteorological Society, 130, 599, 1407-1422, 2004a.

Johnson, D., Jenkin, M. E., Wirtz, K., and Martin-Reviejo, M.: Simulating the Formation of Secondary Organic Aerosol from the Photooxidation of Toluene, Environ. Chem., 1, 150-165, doi:10.1071/EN04069, 2004b.

Kaercher, B. and Koop, T.: The role of organic aerosols in homogeneous ice formation, Atmos. Chem. Phys., 5, 703-714, 2005,

\section{SRef-ID: 1680-7324/acp/2005-5-703.}

Kalberer, M., Yu, J., Cocker, D. R., Flagan, R. C., and Seinfeld, J. H.: Aerosol formation in the cyclohexene-ozone system, Environ. Sci. Technol., 34, 4894-4901, 2000.

Kalberer, M., Paulsen, D., Sax, M. Steinbacher, M., Dommen, J., Prevot, A. S. H., Fisseha, R., Weingartner, E., Frankevich, V., Zenobi, R., and Baltensperger, U.: Identification of Polymers as Major Components of Atmospheric Organic Aerosols, Science, 303, 1659-1662, 2004.

Kamens, R. M., Jang, M., Chien, C. J., and Leach, K.: Aerosol formation from the reaction of $\alpha$-pinene and ozone using a gasphase kinetics-aerosol partitioning model, Environ. Sci. Technol., 33, 1430-1438, 1999.

Kamens, R. M. and Jaoui, M.: Modelling aerosol formation from a-pinene + NOx in the presence of natural sunlight using gasphase kinetics and gas-particle partitioning theory, Environ. Sci. Technol., 35, 1394-1405, 2001.

Kanakidou, M., Tsigaridis, K., Dentener, F. J., and Crutzen, P. J.: Human-activity-enhanced formation of organic aerosols by biogenic hydrocarbon oxidation, J. Geophys. Res., 105, 9243-9254, 2000.

Katrib, Y., Martin, S. T., Hung, H. M., Rudich, Y., Zhang, H. Z., Slowik, J. G., Davidovits, P., Jayne, J. T., and Worsnop, D. R.: Products and mechanisms of ozone reactions with oleic acid for aerosol particles having core-shell morphologies, J. Phys. Chem. A, 108(32), 6686-6695, 2004.

Kavouras, I. G. and Stephanou, E. G.: Direct evidence of atmospheric secondary organic formation in forest atmosphere through heteromolecular nucleation, Environ. Sci. Technol., 36, 5083-5091, 2002.

Kavouras, I. G., Mihalopoulos, N., and Stephanou, E. G.: Formation of atmospheric particles from organic acids produced by forests, Nature, 395, 683-686, 1998.

Kavouras, I. G., Mihalopoulos, N., and Stephanou, E. G.: Sec- ondary organic aerosol formation vs primary organic aerosol emission: In situ evidence for the chemical coupling between monoterpene acidic photooxidation products and new particle formation over forests, Environ. Sci. Technol., 33, 1028-1037, 1999.

Kavouras, I. G., Lawrence, J., Koutrakis, P., Stephanou, E. G., and Oyola, P.: Measurement of particulate aliphatic and polynuclear aromatic hydrocarbons in Santiago de Chile: source reconciliation and evaluation of sampling artifacts, Atmos. Environ., 33, 4977-4986, 1999.

Kawamura, K., Kasukabe, H., Yasui, O., and Barrie, L. A.: Production of dicarboxylic acids in the arctic atmosphere, Geophys. Res. Lett., 22, 1253-1256, 1995.

Kawamura, K., Kasukabe, H., and Barrie, L. A.: Source and reaction pathways of dicarboxylic acids, ketoacids and dicarbonyls in arctic aerosols: one year of observations, Atmos. Environ., 30, 1709-1722, 1996.

Kawamura, K., Imail, Y., and Barrie, L. A.: Photochemical production and loss of organic acids in high Arctic aerosols during long range transport and polar sunrise ozone depletion events, Atmos. Environ., in press, 2005.

Kawamura, K. and Sakaguchi, F.: Molecular distributions of water soluble dicarboxylic acids in marine aerosols over the Pacific Ocean including tropics, J. Geophys. Res., 104(D3), 3501-3509, 1999.

Kerminen, V. M.: The effect of particle chemical character and atmospheric processes on particle hygroscopic properties, J. Aerosol Sci., 28, 121-132, 1997.

Khlystov, A., Stanier, C. O., Takahama, S., and Pandis, S. N.,: Water content of ambient aerosol during the Pittsburgh Air Quality Study, J. Geophys. Res., 110, D07S10, doi:10.1029/2004JD004651, 2005.

Kiehl, J. T., Schneider, T. L., Rasch, P. J., Barth, M. C., and Wong, J.: Radiative forcing due to sulfate aerosols from simulations with the National Center for Atmospheric Research Community Climate Model, Version 3, J. Geophys. Res., 105, 1441-1457, 2000.

Kim, Y. P., Moon, K.-C, and Lee, J. H.: Organic and elemental carbon in fine particles at Kosan, Korea, Atmos. Environ., 34, 3309-3317, 2000.

Kinne, S., Lohmann, U., Feichter, J., Schulz, M., Timmreck, C., Ghan, S., Easter, R., Chin, M., Ginoux, P., Takemura, T., Tegen, I., Koch, D., Herzog, M., Penner, J., Pitari, G., Holben, B., Eck, T., Smirnov, A., Dubovik, O., Slutsker, I., Tanre, D., Torres, O., Mishchenko, M., Geogdzhayev, I., Chu, A., and Kaufman, Y.: Monthly averages of aerosol properties: A global comparison among models, satellite data and AERONET ground data, J. Geophys. Res., 108(D20), 4634, doi:10.1029/2001JD001253, 2003.

Kirchstetter, T. W., Corrigan, C. E., and Novakov, T.: Laboratory and field investigation of the adsorption of gaseous organic compounds onto quartz filters, Atmos. Environ., 35, 1663-1671, 2001.

Kiss, G., Varga, B., Gelencser, A., Krivanscy, Z., Molnar, A., Alsberg, T., Persson, I., Hansson, H.-C., and Facchini, M. C.: Characterization of polar organic compounds in fog water, Atmos. Environ., 35, 2193-2200, 2001.

Kleindienst, T. E., Smith, D. F., Li, W., Edney, E. O., Driscoll, D. J., Speer, R. E., and Weathers, W. S.: Secondary organic aerosol 
formation from the oxidation of aromatic hydrocarbons in the presence of dry submicron ammonium sulfate aerosol, Atmos. Environ., 33, 3669-3681, 1999.

Kleindienst, T. E., Corse, E. W., Li, W., McIver, C. D., Conver, T. S., Edney, E. O., Driscoll, D. J., Speer, R. E., Weathers, W. S., and Tejada, S. B.: Secondary organic aerosol formation from the irradiation of simulated automobile exhaust, JAWMA, 52, 259272, 2002.

Koch, S., Winterhalter, R., Kolloff, A., Neeb, P., and Moortgat, G. K.: Organic aerosol formation processes in the photooxidation of VOCs, Contribution to the EUROTRAC-2, Chemical Mechanism Development (CMD) Subproject Annual Report, 1998, Published by EUROTRAC-2 International Scientific Secretariat, GSF-Forschungszentrum fuer Umwelt und Gesundheit $\mathrm{GmbH}$, Muenchen, Germany, 189-192, Sept. 1999.

Koch, S., Winterhalter, R., Uherek, E., Kolloff, A., Neeb, P., and Moortgat, G. K.: Formation of new particles in the gas-phase ozonolysis of monoterpenes, Atmos. Environ., 34, 4031-4042, 2000.

Koch, D.: The transport and direct radiative forcing of carbonaceous and sulfate aerosols in the GISS GCM, J. Geophys. Res., 106, 20311-20332, 2001.

Köhler, H.: The nucleus in the growth of hygroscopic droplets, Trans. Faraday Soc., 32, 1152-1161, 1936.

Koo, B. Y., Ansari, A. S., and Pandis, S. N.: Integrated approaches to modelling the organic and inorganic atmospheric aerosol components, Atmos. Environ., 37, 4757-4768, $2003 \mathrm{a}$.

Koo, B., Gaydos, T. M., and Pandis, S. N.: Evaluation of the equilibrium, dynamic, and hybrid aerosol modelling approaches, Aerosol Sci. Technol., 37, 53-64, 2003b.

Kotzick, R. and Niessner, R.: The effects of aging processes on critical supersaturation ratios of ultrafine carbon aerosols, Atmos. Environ., 33, 2669-2677, 1999.

Kubátová, A., Vermeylen, R., Claeys, M., Cafmeyer, J., Maenhaut, W., Roberts, G., and Artaxo, P.: Carbonaceous aerosol characterization in the Amazon basin, Brazil: novel dicarboxylic acids and related compounds, Atmos. Environ., 34, 5037-5051, 2000.

Kulmala, M.: How Particles Nucleate and Grow, Science, 302, 1000-1001, 2003.

Kulmala, M., Hameri, K., Aalto, P. P., Makela, J. M., Pirjola, L., Nilsson, E. D., Buzorius, G., Rannik, U., Dal Maso, M., Seidl, W., Hoffman, T., Janson, R., Hansson, H. C., Viisanen, Y., Laaksonen, A., and O'Dowd, C. D.: Overview of the international project on biogenic aerosol formation in the boreal forest (BIOFOR), Tellus B, 53, 324-343, 2001.

Kulmala, M., Vehkamaki, H., Petaja, T., Dal Maso, M., Lauria, A., Kerminen, V.-M., Birmili, W., and McMurry, P. H.: Formation and growth rates of ultrafine atmospheric particles: a review of observations, J. Aerosol. Sci., 35, 143-176, 2004.

Kulmala, M., Kerminen, V.-M., Anttila, T., Laaksonen, A., and O'Dowd, C. D.: Organic aerosol formation via sulphate cluster activation, J. Geophys. Res., 109, D04205, doi:10.1029/2003JD003961, 2004.

Laaksonen, A., Korhonen, P., Kulmala, M., and Charlson, R.: Modification of the Köhler equation to include soluble trace gases and slightly soluble substances, J. Aerosol Sci., 155, 853-862, 1998.

Lack, D. A., Tie, X. X., Bofinger, N. D., Wiegand, A. N., and Madronich, S.: Seasonal variability of secondary organic aerosol: A global modelling study, J. Geophys. Res., 109,
D03203 doi:10.1029/2003JD003418, 2004.

Larsen, B. R., Di Bella, D., Glasius, M., Winterhalter, R., Jensen, N. R., and Hjorth, J.: Gas-phase $\mathrm{OH}$ oxidation of monoterpenes: Gaseous and particulate products, J. Atmos. Chem., 38, 231-276, 2001.

Lee, S., Murphy, D. M., Thomson, D. S., and Middlebrook, A. M.: Chemical components of single particles measured with Particle Analysis by Laser Mass Spectrometry (PALMS) during the Atlanta Super Site Project: Focus on organic/sulfate, lead, soot, and mineral particles, J. Geophys. Res., 107(D1), doi:10.1029/2000JD000011, 2002.

Lee, S., Murphy, D. M., Thomson, D. S., and Middlebrook, A. M.: Nitrate and oxidized organic ions in single particle mass spectra during the 1999 Atlanta Supersite Project, J. Geophys. Res., 108(D7), 8417, doi:10.1029/2001JD001455, 2003.

Lenz, R.: Final report to the Institute for Environment and Sustainability, JRC Ispra, 2001.

Lesins, G., Chylek, P., and Lohmann, U.: A study of internal and external mixing scenarios and its effect on aerosol optical properties and direct radiative forcing, J. Geophys. Res.-A, 107(D10), 4094-4106, 2002.

Li, W. B., Segre, P. N., Gammon, R. W., Sengers, J. V., and Lamvik, M.: Determination of the temperature and concentration dependence of the refractive index of a liquid mixture, J. Chem. Phys., 101(6), 5058-5069, 1994.

Liao, H., Adams, P. J., Seinfeld, J. H., Mickley, L. J., and Jacob, D. J.: Interactions between tropospheric chemistry and aerosols in a unified GCM simulation, J. Geophys. Res., 108(D1), 4001, doi:10.1029/2001JD001260, 2003.

Lightstone, J. M., Onasch, T. B., Imre, D., and Oatis, S.: Deliquescence, efflorescence, and water activity in ammonium nitrate and mixed ammonium nitrate/succinic acid microparticles, J. Phys. Chem., 104, 9337-9346, 2000.

Likens, G. E., Edgerton, E. S., and Galloway, G. N.: The composition and deposition of organic carbon in precipitation, Tellus, 35B, 16-24, 1983.

Limbeck, A., Kulmala, M., and Puxbaum, H.: Secondary organic aerosol formation in the atmosphere via heterogeneous reaction of gaseous isoprene on acidic particles, Geophys. Res. Lett., 30(19), 1996, doi:10.1029/2003GL017738, 2003.

Limbeck, A. and Puxbaum, H.: Dependence of in-cloud scavenging of polar organic aerosol compounds on the water solubility, J. Geophys. Res., 105, 19857-19867, 2000.

Liousse, C., Penner, J. E., Chuang, C., Walton, J. J., Eddleman, H., and Cachier, H.: A global three-dimensional model study of carbonaceous aerosols, J. Geophys. Res., 101, 19411-19432, 1996.

Liu, L., Mishchenko, M. I., Menon, S., Macke, A., and Lacis, A.: The effect of black carbon on scattering and absorption of solar radiation by cloud droplets, J. Quant. Spec. Rad. Trans., 74(2), 195-204, 2002.

Lohmann, U., Feichter, J., Chuang, C., and Pennner, J. E.: Predicting the number of cloud droplets in the ECHAM GCM, J. Geophys. Res., 104, 9169-9198, 1999.

Lohmann, U., Feichter, J., Penner, J. E., and Leaitch, W. R.: Indirect effect of sulfate and carbonacesous aerols: A mechanistic treatment, J. Geophys. Res., 105, 12 193-12 206, 2000.

Lohmann, U. and Feichter, J.: Can the direct and semi-direct aerosol effect compete with the indirect effect on a aglobal scale?, Geo- 
phys. Res. Lett., 28, 159-161, 2001.

Lohmann, U. and Feichter, J.: Global Indirect aerosol effect: a review, Atmos. Chem. Phys., 5, 715-737, 2005, SRef-ID: 1680-7324/acp/2005-5-715.

Lowenthal, D. H., Kumar, N., Hand, J., Day, D., Kreidenweis, S., Collett, J., Lee, T., and Ashbaugh, L.: Hygroscopic organic aerosols during BRAVO, JAWMA, 53, 1273-1279, 2003.

Mader, B. T., Flagan, R. C., and Seinfeld, J. H.: Sampling atmospheric carbonaceous aerosol using a particle trap/denuder sampler, Environ. Sci. Technol., 35, 4857-4867, 2001.

Mader, B. T, Schauer, J. J., Seinfeld, J. H., Flagan, R. C., Yu, J. Z., Yang, H., Lim, H. J., Turpin, B. J., Deminter, J. T., Heidemann, G., Bae, M. S., Quinn, P., Bates, T., Eatough, D. J., Huebert, B. J., Berttram, T., and Howell, S.: Sampling methods used for the collection of particle-phase organic and elemental carbon during ACE-Asia, Atmos. Environ., 37, 1435-1449, 2003.

Malm, W. C.: Spatial and seasonal patterns and temporal variability of haze and its constituents in the United States, Report III, CIRES, Colorado State University, Fort Collins, Colorado, 2000.

Malm, W. C. and Day, D. E.: Estimates of aerosol species scattering characteristics as a function of relative humidity, Atmos. Environ., 35, 2845-2860, 2001.

Maria, S. F., Russell, L. M., Turpin, B. J., and Porcja, R. J.: FTIR measurements of functional groups and organic mass in aerosol samples over Caribbean, Atmos. Environ., 36, 5185-5196, 2002.

Maria, S. F., Russell, L. M., Gilles, M. K., and Myneni, S. C. B.: Organic aerosol growth mechanims and their climate-forcing implications, Science, 306, 1921-1924, 2004.

Marcolli, C., Luo, B., and Peter, T.: Mixing of the organic aerosol fractions: liquids as the thermodynamically stable phases, J. Phys. Chem. A, 108, 2216-2224, 2004.

Marsh, K. N.: International Union of Pure and Applied Chemistry: Recommended Reference Materials for the Realization of Physicochemical Properties, in: Section Optical Refraction, Blackwell Scientific Publications, Oxford, UK, 500, 1987.

Marti, J. J., Weber, R. J., McMurry, P. H., Eisele, F., Tanner, D., and Jefferson, A.: New particle formation at a remote continental site: Assessing the contributions of $\mathrm{SO}_{2}$ and organic precursors, J. Geophys. Res., 102, 6331-6339, 1997.

Massling, A., Wiedensohler, A., Busch, B., Neusüß, C., Quinn, P., Bates, T., and Covert, D.: Hygroscopic properties of different aerosol types over the Atlantic and Indian Oceans, Atmos. Chem. Phys., 3, 1377-1397, 2003,

SRef-ID: 1680-7324/acp/2003-3-1377.

Mayol-Bracero, O. L., Guyon, P., Graham, B., Roberts, G. C., Andreae, M. O., Decesari, S., Facchini, M. C., Fuzzi, S., and Artaxo, P.: Water-soluble organic compounds in biomass burning aerosols over Amazonia: 2. Apportionment of the chemical composition and importance of the polyacidic fraction, J. Geophys. Res., 107(D20), 8091, doi:10.1029/2001JD000522, 2002.

Matsunaga, S., Mochida, M., and Kawamura, K.: Growth of organic aerosols by biogenic semi-volatile carbonyls in the forestal atmosphere, Atmos. Environ., 37, 2045-2050, 2003.

Mc Dow, S. R. and Huntzicker, J. J.: Vapor adsorption artifact in the sampling of organic aersol: face velocity effects, Atmos. Environ., 24, 2563-2571, 1990.

Meng, Z. and Seinfeld, J. H.: Time scales to achieve atmospheric gas-aerosol equilibrium for volatile species, Atmos. Environ., 30, 2889-2900, 1996.
Mikhailov, E., Vlasenko, S., Niessner, R., and Pöschl, U.: Interaction of aerosol particles composed of protein and salts with water vapor: hygroscopic growth and microstructural rearrangement, Atmos. Chem. Phys., 4, 323-350, 2004,

SRef-ID: 1680-7324/acp/2004-4-323.

Ming, Y. and Russell, L. M.: Predicted hygroscopic growth of sea salt aerosol, J. Geophys. Res., 106, 28 259-28 274, 2001.

Ming, Y. and Russell, L. M.: Thermodynamic equilibrium of organic-electrolyte mixtures in aerosol particles, AIChE J., 48, 1331-1348, 2002.

Mircea, M., Facchini, M. C., Decesari, S., Fuzzi, S., and Charlson, R. J.: The influence of the organic aerosol component on CCN supersaturation spectra for different aerosol types, Tellus B, 54, 74-81, 2002.

Mochida, M., Umemoto, N., Kawamura, K., and Uematsu, M.: Bimodal size distribution of $\mathrm{C}_{2}-\mathrm{C}_{4}$ dicarboxylic acids in the marine aerosols, Geophys. Res. Lett., 30(13), 1672, doi:10.129/2003GL017451, 2003a.

Mochida, M., Kawabata, A., Kawamura, K., Hatsushika, H., and Yamazaki, K.: Seasonal variation and origins of dicarboxylic acids in the marine atmosphere over the western North Pacific, J. Geophys. Res., 108, 4193, doi:10.1029/2002JD002355, 2003b.

Moise, T. and Rudich, Y.: Reactive uptake of ozone by aerosolassociated unsaturated fatty acids: Kinetics, mechanism, and products, J. Phys. Chem. A, 106(27), 6469-6476, 2002.

Moise, T. and Rudich, Y.: Reactive uptake of $\mathrm{Cl}$ and $\mathrm{Br}$ atoms by organic surfaces - a perspective on the processing of organic aerosols by tropospheric oxidants, Geophys. Res. Lett., 28(21), 4083-4086, 2001.

Molina, M. J., Ivanov, A. V., Trakhtenberg, S., and Molina, L. T.: Atmospheric evolution of organic aerosol, Geophys. Res. Lett., 31, L22104, doi:10.1029/2004GL020910, 2004.

Monks, P., Rickard, A. R., Dentener, F. J., Jonson, J. E., Lindskog, A., Roemer, M., Schupbach, E., Friedli, T. K., and Solberg, S.: Trotrep: tropospheric ozone and precursors, trends, budgets, and policy, Project Report of TROTREP, EVK2-CT-1999-00043, 2003.

Mozurkewich, M.: Aerosol Growth and the Condensation Coefficient for Water: A Review. Aer. Sci. Tech., 5, 223-236, 1986.

Myhre, C. E. L. and Nielsen, C. J.: Optical properties of atmospheric fog and cloud droplets collected in the Po Valley, Italy, Asian Chemistry Letters, 7(2\&3), 113-118, 2003.

Myhre, C. E. and Nielsen, C. J.: Optical properties in the UV and visible spectral region of organic acids relevant to tropospheric aerosols, Atmos. Chem. Phys., 4, 1759-1769, 2004,

SRef-ID: 1680-7324/acp/2004-4-1759.

Myhre, G., Stordal, F., Restad, K., and Isaksen, I. S. A.: Estimation of the direct radiative forcing due to sulfate and soot aerosol, Tellus, 50B, 463-477, 1998

Na, H. S., Arnold, S., and Myerson, A. S.: Water activity in supersaturated aqueous-solutions of organic solutes, J. Cryst. Growth, 149, 229-235, 1995.

Naik, V., Delire, Ch., and Wuebbles, D. J.: Sensititvity of global biogenic isoprenoid emissions to climate variability and atmospheric $\mathrm{CO}_{2}$, J. Geophys. Res., 109, D06301, doi:10.1029/2003JD004326, 2004.

Narukawa, M., Kawamura, K., Anlauf, K. G., and Barrie, L. A.: Fine and coarse modes of dicarboxylic acids in the Arctic aerosols collected during Polar Sunrise Experiment 1997, J. Geo- 
phys. Res., 108(D18), 4575, doi:10.1029/203JD003646, 2003.

Nenes, A., Ghan, S., Abdul-Razzak, H., Chuang, P., and Seinfeld, J. H.: Kinetic limitations on cloud droplet formation and impact on cloud albedo, Tellus B, 53, 133-149, 2001.

Nenes, A., Charlson, R. J., Facchini, M. C., Kulmala, M., Laaksonen, A., and Seinfeld, J. H.: Can chemical effects on cloud droplet number rival the first indirect effect?, Geophys. Res. Lett., 29(17), doi:10.1029/2002GL015295, 2002a.

Nenes, A., Conant, W., and Seinfeld, J. H.: Black carbon radiative heating effects on cloud microphysics and implications for the aerosol indirect effect: 2. Cloud microphysics, J. Geophys. Res., 107(D21), doi:10.1029/2002JD002101, 2002b.

Nenes, A. and Seinfeld, J. H.: Parameterization of cloud droplet formation in global climate models, J. Geophys. Res., 108(D14), 4415, doi:10.1029/2002JD002911, 2003.

Novakov, T. and Penner, J. E.: Large contribution of organic aerosols to cloud-condensation-nuclei concentrations, Nature, 365, 823-826, 1993.

Novakov, T. and Corrigan, C. E.: Cloud condensation nucleus activity of the organic component of biomass smoke particles, Geophys. Res. Lett., 23, 2141-2144, 1996.

Novakov, T., Hegg, D. A., and Hobbs, P. V.: Airborne measurements of carbonaceous aerosols on the East coast of the United States, J. Geophys. Res., 102, 30 023-30 030, 1997.

Novakov, T., Ramanathan, V., Hansen, J. E., Kirchstetter, T. W., Sato, M., Sinton, J. E., and Sathaye, J. A.: Large historical changes of fossil-fuel black carbon aerosols, Geophys. Res. Lett., 30(6), 1324, doi:10.1029/2002GL016345, 2003.

Noziere, B., Barnes, I., and Becker, K. H.: Product study of the reactions of a-pinene and of pinonaldehyde with $\mathrm{OH}$ radicals, J. Geophys. Res., 31(4), 291-301, 1999a.

Noziere, B., Spittler, M., Ruppert, L., Barnes, I., Becker, K. H., Pons, M., and Wirtz, K.: Kinetics of the reactions of pinonaldehyde with $\mathrm{OH}$ radicals and with $\mathrm{Cl}$ atoms, Int. J. Chem. Kinetics, 104(D19), 23 645-23 656, 1999b.

O’Dowd, C. D., Aalto, P., Hameri, K., Kulmala, M., and Hoffmann, T.: Aerosol formation-Atmospheric particles from organic vapours, Nature, 416, 497-498, 2002.

O’Dowd, C. D., Facchini, M. C., Cavalli, F., Ceburnis, D., Mircea, M., Decesari, S., Fuzzi, S., Yoon, Y. J., and Putaud, J.-P.: Biogenically driven organic contribution to marine aerosol, Nature, 431, 676-680, 2004.

Odum, J. R., Hoffmann, T., Bowman, F., Collins, D., Flagan, R. C., and Seinfeld, J. H.: Gas/Particle partitioning and secondary organic aerosol yields, Environ. Sci. Technol., 30, 2580-2585, 1996.

Odum, J. R., Jungkamp, T. P. W., Griffin, R. J., Flagan, R. C., and Seinfeld, J. H.: The atmospheric aerosol-forming potential of whole gasoline vapor, Science, 276, 96-99, 1997.

Ogren, J., Groblicki, A., and Charlson, R. J.: Measurement of the removal rate of elemental carbon from the atmosphere, Sci. Total Environ., 36, 329-338, 1984.

Olivier, J., Bouwman, A. F., Van der Maas, C. W. M., Berdowski, J. J. M., Veldt, C., Bloos, J. P. J., Visschedijk, A. J. H., Zandveld, P. Y. J., and Haverlag, J. L.: Description of EDGAR Version 2.0: a set of emission inventories of greenhouse gases and ozone depleting substances for all anthropogenic and most natural sources on a per country basis and on $1^{\circ} \times 1^{\circ}$ grid, RIVM Report nr. 771060002 and TNO-MEP Report nr. R96/119, 1996.
Olivier, J. G. J., Bouwman, A. F., Berdowski, J. J. M., Veldt, C., Bloos, J. P. J., Visschedijk, A. J. H., van de Maas, C. W. M., and Zandveld, P. Y. J.: Sectoral emission inventories of greenhouse gases for 1990 on a per country basis as well as on $1^{\circ} \times 1^{\circ}$, Environ. Science \& Policy, 2, 241-264, 1999a.

Olivier, J. G. J., Bloos, J. P. J., Berdowski, J. J. M., Visschedijk, A. J. H., and Bouwman, A. F.: A 1990 global emission inventory of anthropogenic sources of carbon monoxide on $1^{\circ} \times 1^{\circ}$ developed in the framework of EDGAR/GEIA, Chemosphere, Global Change Science, 1, 1-3, 1-17, 1999b.

Orlando, J. J., Nozière, B., Tyndall, G. S., Orzechowska, E., Paulson, S. E., and Rudich, Y.: Product studies of the $\mathrm{OH}-$ and ozone-initiated oxidation of some monoterpenes, J. Geophys. Res., 105(D9), 11 561-11 572, 2000.

Owen, S. M. Boissard, C., and Hewitt, C. N.: Volatile organic compounds (VOCs) emitted from 40 Mediterranean plant species: VOC speciation and extrapolation to habitat scale, Atmos. Environ., 35, 5393-5409, 2001.

Pagels, J., Strand, M., Rissler, J., Szpila, A., Gudmundsson, A., Bohgard, M., Lillieblad, L., Sanati, M., and Swietlicki, E.: Characteristics of aerosol particles formed during grate combustion of moist forest residue, J. Aerosol Sci., 34, 1043-1059, 2003.

Palen, E. J., Allen, D. T., Pandis, S. N., Paulson, S. E., Seinfeld, J. H., and Flagan, R. C.: Fourier transform infrared analysis of aerosol formed in the photo-oxidation of isoprene and a-pinene, Atmos. Environ., 26, 1239-1251, 1992.

Palmer, P. I., Jacob, D. J., Fiore, A. M., Martin, R. V., Chance, K., and Kurosu, T.: Mapping isoprene emissions over North America using formaldehyde column observations from space, J. Geophys. Res., 108, 4180, doi:10.1029/2002JD002153, 2003.

Pandis, S. N., Paulson, S. E., Seinfeld, J. H., and Flagan, R. C.: Aerosol formation in the photooxidation of isoprene and bpinene, Atmos. Environ., 25, 997-1008, 1991.

Pandis, S. N., Harley, R. H., Cass, G. R., and Seinfeld, J. H.: Secondary organic aerosol formation and transport, Atmos. Environ., 26, 2269-2282, 1992.

Pankow, J. F.: An absorption model of gas/particle partitioning of organic compounds in the atmosphere, Atmos. Environ., 28, 185-188, 1994.

Pankow, J. F., Seinfeld, J. H., Asher, W. E., and Erdakos, G. B.: Modelling the formation of secondary organic aerosol, 1. Application of theoretical principles to measurements obtained in the $\alpha$-pinene/, $\beta$-pinene/, sabinene/, d3-carene/, and cyclohexane/ozone systems, Environ. Sci. Technol., 35, 1164-1172, 2001.

Peeters, J., Vereecken, L., and Fantechi, G.: The detailed mechanism of the $\mathrm{OH}$-initiated atmospheric oxidation of $\alpha$-pinene: a theoretical study, Phys. Chem. Chem. Phys., 3, 5489-5504, 2001.

Peng, C. and Chan, C. K.:The water cycle of water-soluble organic salts of atmospheric importance, Atmos. Environ., 35, 11831192, 2001.

Peng, C., Chow, A. H. L., and Chan, C. K.: Study of the Hygroscopic Properties of Selected Pharmaceutical Aerosols Using Single Particle Levitation, Pharmaceutical Research, 17, 9, 1104-1109, 2000.

Peng, C., Chan, M. N., and Chan, C. K.: The hygroscopic properties of dicarboxylic and multifunctional acids: measurements and UNIFAC predictions, Environ. Sci. Technol., 35, 4495-4501, 
2001.

Penner, J. E., Chuang, C. C., and Grant, K.: Climate forcing by carbonaceous and sulfate aerosols, Clim. Dyn., 14, 839-851, 1998.

Penner, J. E., Zhang, S. Y., and Chuang, C. C.: Soot and smoke aerosol may not warm climate, J. Geophys. Res., 108(D21), 4657, doi:10.1029/2003JD003409, 2003.

Piccot, S. D., Watson, J. J., and Jones, J. W.: A global inventory of volatile organic compound emissions from anthropogenic sources, J. Geophys. Res., 97, 9897-9912, 1992.

Pilinis, C., Seinfeld, J. H., and Seigneur, C.: Mathematical modelling of the dynamics of multi-component atmospheric aerosols, Atmos. Environ., 21, 943-955, 1987.

Pincus, R. and Baker, M.: Effect of precipitation on the albedo susceptibility of clouds in the marine boundary layer, Nature, 372, 250-252, 1994.

Pitchford, M. L. and McMurry, P. H.: Relationship between measured water vapor growth and chemistry of atmospheric aerosol for Grand Canyon, Arizona, in winter 1990, Atmos. Environ., 28, 827-839, 1994.

Pöschl, U., von Kuhlmann, R., Poisson, N., and Crutzen, P. J.: Development and Intercomparison of Condensed Isoprene Oxidation Mechanisms for Global Atmospheric Modelling, J. Atmos. Chem., 37, 29-52, 2000.

Pöschl, U., Letzel, T., Schauer, C., and Niessner, R.: Interaction of ozone and water vapor with spark discharge soot aerosol particles coated with benzo[a]pyrene: $\mathrm{O}_{3}$ and $\mathrm{H}_{2} \mathrm{O}$ adsorption, benzo $[a]$ pyrene degradation, and atmospheric implications, J. Phys. Chem. A, 105, 4029-4041, 2001.

Posfai, M., Xu, H. F., Anderson, J. R., and Buseck, P. R.: Wet and dry sizes of atmospheric aerosol particles: An AFM-TEM study, Geophys. Res. Lett., 25, 1907-1910, 1998.

Prenni, A. J., DeMott, P. J., Kreidenweis, S. M., Sherman, D. E., Russell, L. M., and Ming, Y.: The effects of low molecular weight dicarboxylic acids on cloud formation, J. Phys. Chem. A, 105, 11 240-11 248, 2001.

Prenni, A. J., DeMott, P. J., and Kreidenweis, S. M.: Water uptake of internally mixed particles containing ammonium sulfate and dicarboxylic acids, Atmos. Environ., 37, 4243-4251, 2003.

Pruppacher, H. R. and Klett, J. D.: Microphysics of Clouds and Precipitation, Kluwer Academic Publishers, Dordrecht, Netherlands, 1980

Pun, B. K., Seigneur, C., Grosjean, D., and Saxena, P.: Gasphase formation of water soluble organic compounds in the atmosphere: a retrosynthetic analysis, J. Atmos. Chem., 35, 199223, 2000

Pun, B. K., Griffin, R. J., Seigneur, C., and Seinfeld, J. H.: Secondary organic aerosol: II. Thermodynamic model for gas/particle partitioning of molecular constituents, J. Geophys. Res., 107(D17), 4333, doi:10.1029/2001JD000542, 2002.

Pun, B. K., Wu, S. Y., Seigneur, C., Seinfeld, J. H., Griffin, R. J., and Pandis, S. N.: Uncertainties in modelling secondary organic aerosols: Three-dimensional modelling studies in Nashville/West Tennessee, Environ. Sci. Technol., 37, 3647 3661, 2003.

Putaud, J. P., Raes, F., Van Dingenen, R., et al.: A European aerosol phenomenology; physical and chemical characteristics of particulate matter at kerbside, urban, rural and background sites in Europe, European Commission, Report \# EUR 20411 EN, (http://ccu.ei.jrc.it/ccu), 2003.
Putaud, J. P., Raes, F., Van Dingenen, R., Brüggemann, E., Facchini, M. C., Decesari, S., Fuzzi, S., Gehrig, R., Hüglin, C., Laj, P., Lorbeer, G., Maenhaut, W., Mihalopoulos, N., Müller, K., Querol, X., Rodriguez, S., Schneider, J., Spindler, G., ten Brink, H., Tørseth, K., and Wiedensohler, A.: A European aerosol phenomenology-2: chemical characteristics of particulate matter at kerbside, urban, rural and background sites in Europe, Atmos. Environ., 38, 2579-2595, 2004.

Puxbaum, H. and Limbeck, A.: Observation of Atmospheric Organic Acids and Implications for Secondary Formation, Proceedings of the workshop "Chemical Behaviour of Aromatic Hydrocarbons in the Troposphere", Valencia, Spain, February 27-29, 2000.

Rasmussen, R. A.: What do the hydrocarbons from trees contribute to air pollution?, J. Air Pollut. Contr. Assoc., 22, 537-543, 1972.

Räty, J. A., Vartiainen, E. M., and Peiponen, K.-E.: Resolving optical constants from reflectance of liquids in the UV-visible range, Applied Spectroscopy, 53(1), 92-96, 1999.

Raymond, T. M. and Pandis, S. N.: Cloud activation of singlecomponent organic aerosol particles, J. Geophys. Res., 107, 4787, doi:10.1029/2002JD002159, 2002.

Raymond, T. M. and Pandis, S. N.: Formation of cloud droplets by multicomponent organic particles, J. Geophys. Res., 108(D15), 4469, doi:10.1029/2003JD003503, 2003.

Riemer, N., Vogel, H., and Vogel, B.: Modelling the ageing processes of soot, J. Aerosol Science, Abstracts of the European Aerosol Conference 31 August-5 September, Madrid, S131S132, 2003.

Rissman, T., Nenes, A., and Seinfeld, J. H.: Chemical amplification (or dampening) of the Twomey effect: Conditions derived from droplet activation theory, J. Atmos. Sci., 61(7), 919-930, 2004.

Ritzoulis, G. and Fidantsi, A.: Relative Permittivities, Refractive Indices, and Densities for the Binary Mixtures N, N'Dimethylacetamide with Methanol, Ethanol, 1-Butanol, and 2Propanol at 298.15 K, J. Chem. Eng. Data, 45(2), 207-209, 2000.

Roberts, G. C., Andreae, M. O., Zhou, J., and Artaxo, P.: Cloud condensation nuclei in the Amazon Basin: "Marine" conditions over a continent?, Geophys. Res. Lett., 28(14), 2807-2810, 2001.

Robinson, R. A. and Stokes, R. H.: Electrolytic Solutions, $2^{\text {nd }}$ Edition, Butterworth, London, 1959.

Roelofs, G.-J., Kasibhatla, P., Barrie, L., Bergmann, D., Bridgeman, C., Chin, M., Christensen, J., Easter, R., Feichter, J., Jeuken, A., Kjellstrom, E., Koch, D., Land, C., Lohmann, U., and Rasch, P.: Analysis of regional budgets of sulfur species modelled for the COSAM exercise, Tellus 53B, 673-694, 2001.

Roemer, M.: Trends of ozone and precursors in Europe, status report TOR2, TNO report R2001/244, 2001.

Rogge, W. F., Mazurek, M. A., Hildemann, L. M., Cass, G. R., and Simoneit, B. R. T.: Quantification of urban organic aerosols at a molecular level: Identification, abundance and seasonal variation, Atmos. Environ., 27A, 1309-1330, 1993.

Roselle, S. J.: Effects of biogenic emission uncertainties on regional photochemical modelling of control strategies, Atmos. Environ., 28, 1757-1772, 1994.

Rubel, G. O. and Gentry, J. W.: Measurement of the kinetics of solution droplets in the presence of adsorbed monolayers - determination of water accommodation coefficients, J. Phys. Chem., 88, 3142-3148, 1984.

Rudich, Y.: Laboratory Perspectives on the Chemical Transforma- 
tions of Organic Matter in Atmospheric Particles, Chem. Rev., 103, 5097-5124, 2003.

Rudich, Y., Benjamin, I., Naaman, R., Thomas, E., Trakhtenberg, S., and Ussyshkin, R.: Wetting of hydrophobic organic surfaces and its implications to organic aerosols in theatmosphere, J. Phys. Chem. A, 104(22), 5238-5245, 2000.

Russell, L. M., Maria, S. F., and Myneni, S. C. B.: Mapping organic coatings on atmospheric particles, Geophys. Res. Lett., 29(15), doi:10.1029/2002GL014874, 2002.

Russell, L. M.: Aerosol organic-mass to organic-carbon ratio measurements, Environ. Sci. Technol., 37, 2982-2987, 2003.

Sander, R.: Compilation of Henry's Law Constants for Inorganic and Organic Species of Potential Importance in Environmental Chemistry, (version 3), http://www.mpch-mainz.mpg.de/ $\sim_{\text {sander/res/henry.html, } 1999 .}$

Sanderson, M. G., Collins, W. J., Johnson, C. E., Derwent, R. G., and Garnier, B.: Effect of vegetation changes on isoprene emissions and surface ozone levels in future climates, poster presented at IGAC 2002 conference, 2002.

Satsumbayashi, H., Kurita, H., Yokouchi, Y., and Ueda, H.: Monoand Dicarboxylic Acids under Long-Range Transport of Air Pollution in Japan, Tellus 41B, 219-229, 1989.

Satsumbayashi, H., Kurita, H., Yokouchi, Y., and Ueda, H.: Photochemical Formation of Particulate Dicarboxylic Acids under Long-Range Transport in Japan, Atmos. Environ., 24A, 14431450, 1993.

Sau, J. A. and Khalil, M. A. K.: Anthropogenic contributions to the carbonaceous content of aerosols over the Pacific Ocean, Atmos. Environ., 27, 8, 1297-1307, 1993.

Saunders, S. M., Jenkin, M. E., Derwent, R. G., and Pilling, M. J.: Protocol for the development of the Master Chemical Mechanism, MCM v3 (Part A): tropospheric degradation of nonaromatic volatile organic compounds, Atmos. Chem. Phys. 3, 161-180, 2003.

MCM is assessable via the ftp (http://www.chem.leeds.ac.uk/ Atmospheric/MCM/mcmproj.html)

Saxena, P. and Hildemann, L. M.: Water-Soluble Organics in Atmospheric Particles: A Critical Review of the Literature and Application of Thermodynamics to Identify Candidate Compounds, J. Atmos. Chem., 24, 57-109, 1996.

Saxena, P. and Hildemann, L. M.: Water absorption by organics: Survey of laboratory evidence and evaluation of UNIFAC for estimating water activity, Environ. Sci. Technol., 31, 3318-3324, 1997.

Saxena, P., Hildemann, L. M., McMurry, P. H., and Seinfeld, J. H.: Organics alter hygroscopic behavior of atmospheric particles, J. Geophys. Res., 100(D9), 18 755-18 770, 1995.

Schaap, M., Denier Van Der Gon, H. A. C., Visschedijk, A. J. H., Van Loon, M., ten Brink, H. M., Dentener, F. J., Putaud, J.-P., Guillaume, B., Liousse, C., and Builtjes, P. J. H.: Anthropogenic Black Carbon and Fine Aerosol Distribution over Europe, J. Geophys. Res., 109, D18207, doi:10.1029/2003JD004330, 2004.

Schell, B., Ackermann, I. J., Hass, H., Binkowski, F. S., and Ebel, A.: Modelling the formation of secondary organic aerosol within a comprehensive air quality model system, J. Geophys. Res., 106(D22), 28 275-28 293, 2001.

Schmid, H., Laskus, L., Abraham, H. J., Baltensperger, U., Lavanchy, V., Bizjak, M., Burba, P., Cachier, H., Crow, D., Chow, J., Gnauk, T., Even, A., ten Brink, H. M., Giesen, K.-P., Hitzen- berger, R., Hueglin, C., Maenhaut, W., Pio, C., Carvalho, A., Putaud, J.-P., Toom-Sauntry, D., and Puxbaum, H.: Results of the "carbon conference" international aerosol carbon round robin test stage 1, Atmos. Environ., 35, 2111-2121, 2001.

Schnaiter, M., Horvath, H., Moehler, O., Naumann, K.-H., Saatho, H., and Schoeck, O. W.: UV-VIS-NIR spectral optical properties of soot and soot-containing aerosols, J. Aerosol Sci., 34, 14211444, 2003.

Segade, L., Jimenez de Llano, J., Dominguez-Perez, M., Cabeza, O., Cabanas, M., and Jimenez, E.: Density, Surface Tension, and Refractive Index of Octane + 1-Alkanol Mixtures at T=298.15 K, J. Chem. Eng. Data, 48(5), 1251-1255, 2003.

Seidl, W.: Model for a surface film of fatty acids on rain water and aerosol particles, Atmos. Environ., 34, 4917-4932, 2000.

Seinfeld, J. H. and Pandis, S. N.: Atmospheric Chemistry and Physics: from Air Pollution to Climate Change, John Wiley, New York, 1998.

Seinfeld, J. H. and Pankow, J. F.: Organic atmospheric particulate material, Annu. Rev. Phys. Chem., 54, 121-140, 2003.

Seinfeld, J. H., Erdakos, G. B., Asher, W. E., and Pankow, J. F.: Modelling the formation of secondary organic aerosol (SOA), 2. The predicted effects of relative humidity on aerosol formation in the alpha-pinene/, beta-pinene/, sabinene/, delta 3-carene/, and cyclohexane/ozone systems, Environ. Sci. Technol., 35, 18061817, 2001.

Sempéré, R. and Kawamura, K.: Low Molecular Weight Dicarboxylic Acids and Related Polar Compounds in the remote marine Rain Samples collected from Western Pacific, Atmos. Environ., 30, 10/11, 1609-1619, 1996.

Shantz, N. C., Leaitch, W. R., and Caffrey, P. F.: Effect of organics of low solubility on the growth rate of cloud droplets, J. Geophys. Res., 108(D5), 4168, doi:10.1029/2002JD002540, 2003.

Shulman, M. L., Jacobson, M. C., Charlson, R. J., Synovec, R. E, and Young, T. E.: Dissolution behaviour and surface tension effects of organic compounds in nucleating cloud droplets, Geophys. Res. Lett., 23, 277-280, 1996.

Simpson, D., Winiwarter, W., Borjesson, G., Cinderby, S., Ferreiro, A., Guenther, A., Hewitt, C., Janson, R., Khalil, M. A., Owen, S., Pierce, T. E., Puxbaum, H., Shearer, M., Skiba, U., Steinbrecher, R., Tarrason, L., and Oquist, M.: Inventorying emissions from nature in Europe, J. Geophys. Res., 104, 8113-8152, 1999.

Slinn, W. G. N.: Precipitation scavening, in Atmospheric Science and Power Production, edited by: Randerson, D., U.S. Dept of Energy, Technical Information Center, Oak Ridge, Tenn., 466532, 1984.

Sioutas, C., Kim, S., and Chang, M.: development and evaluation of an ultrafine particle concentrator, J. Aerosol Sci., 30, 1001-1017, 1999.

Smith, G. D., Woods, E., De Forest, C. L. , Baer, T., and Miller, R. E.: Reactive uptake of ozone by oleic acid aerosol particles: Application of single-particle mass spectrometry to heterogeneous reaction kinetics, J. Phys. Chem. A, 106(35), 8085-8095, 2002.

Smith, G. D., Woods, E., Baer, T., and Miller, R. E.: Aerosol uptake described by numerical solution of the diffusion - Reaction equations in the particle, J. Phys. Chem. A, 107(45), 9582-9587, 2003.

Speer, R. E., Edney, E. O., and Kleindienst, T. E.: Impact of organic compounds on the concentrations of liquid water in ambient $\mathrm{PM}_{2.5}$, J. Aerosol. Sci., 34, 63-77, 2003. 
Squires, P. and Twomey, S.: The relation between cloud droplet spectra and the spectrum of cloud nuclei, in: Physics of Precipitation, Geophys. Monogr. Ser., 1960.

Stern, J. E., Flagan, R. C., Grosjean, D., and Seinfeld, J. H.: Aerosol formation and growth in atmospheric aromatic hydrocarbon photooxidation, Environ. Sci. Technol., 21, 1224-1231, 1987.

Strader, R., Lurmann, F., and Pandis, S. N.: Evaluation of secondary organic aerosol formation in winter, Atmos. Environ., 33, 48494863, 1999.

Ström, J., Okada, K., and Heintzenberg, J.: On the state of mixing of particles due to Brownian coagulation, J. Aerosol Sci., 23, 467-480, 1992

Svenningsson, B., Rissler, J., Swietlicki, E., Mircea, M., Bilde, M., Facchini, M. C., Decesari, S., Fuzzi, S., Zhou, J., Mønster, J., and Rosenørn, T.: Hygroscopic Growth and Critical Supersaturations for Mixed Aerosol Particles of Inorganic and Organic Compounds of Atmospheric Relevance, Atmos. Chem. Phys. Discuss., accepted, 2005.

Swietlicki, E., Zhou, J. C., Berg, O. H., Martinsson, B. G., Frank, G., Cederfelt, S. I., Dusek, U., Berner, A., Birmili, W., Wiedensohler, A., Yuskiewicz, B., and Bower, K. N.: A closure study of sub-micrometer aerosol particle hygroscopic behaviour, Atmos. Res., 50, 205-240, 1999.

Swietlicki, E., Zhou, J., Covert, D. S., Hämeri, K., Busch, B., Väkevä, M., Dusek, U., Berg, O. H., Wiedensohler, A., Aalto, P., Mäkelä, J., Martinsson, B. G., Papaspiropoulos, G., Mentes, B., Frank, G., and Stratmann, F.: Hygroscopic properties of aerosol particles in the north-eastern Atlantic during ACE-2, Tellus, 52B, 201-207, 2000.

Tang, I. N.: Thermodynamic and optical properties of mixedsalt aerosols of atmospheric importance, J. Geophys. Res., 102, 1883-1893, 1997.

Tang, I. N. and Munkelwitz, H. R.: Water activities, densities, and refractive indices of aqueous sulfates and sodium nitrate droplets of atmospheric importance, J. Geophys. Res., 99, 18 801-18 808, 1994.

Tang, I. N., Tridico, A. C., and Fung, K. H.: Thermodynamic and optical properties of sea salt aerosols, J. Geophys. Res., 102, 23 269-23 275, 1997.

Tang, H., Lewis, E. A., Eatough, D. J., Burton, R. M., and Farber, R. J.: Determination of the particle size distribution and chemical composition of semi-volatile organic compound sin atmospheric fine particles with a diffusion denuder sampling system, Atmos. Environ., 28, 939-947, 1994.

Tao, Y. and McMurry, P. M.: Vapor pressures and surface free energies of $\mathrm{C}_{14}-\mathrm{C}_{18}$ monocarboxylic acids and $\mathrm{C}_{5}$ and $\mathrm{C}_{6}$ dicarboxylic acids, Environ. Sci. Technol., 23, 1519-1523, 1989.

ten Brink, H., Maenhaut, W., Gnauk, T., Hitzenberger, R., Spindler, G., Chi, X., Putaud, J. P., Bauer, H., Puxbaum, H., Turstic, J., Berner, A., Even, A., and Mueller, K.: INTERCOMP2000: The comparability of methods in use in Europe for measuring the carbon content of fine particulate matter, Atmos. Environ., 38, 6507-6519, 2004.

Tobias, H. J., Docherty, K. S., Beving, D. E., and Ziemann, P. J.: Effect of Relative Humidity on the Chemical Composition of Secondary Organic Aerosol Formed from Reactions of 1Tetradecene and $\mathrm{O}_{3}$, Environ. Sci. Technol., 34, 2116-2125, 2000.

Tobias, H. J., Beving, D. E., Ziemann, P. J., Sakurai, H., Zuk, M.,
McMurry, P. H., Zarling, D., Waytulonis, R., and Kittelson, D. B.: Chemical analysis of diesel engine nanoparticles using a nano-DMA/thermal desorption particle beam mass spectrometer Environ. Sci. Technol., 35, 2233-2243, 2001.

Tolocka, M. P., Jang, M., Ginter, J., Cox, F., Kamens, R., and Johnston, M.: Formation of Oligomers in Secondary Organic Aerosol, Environ. Sci. Technol., 38, 1428-1434, 2004.

Trainer, M., Williams, E., Parrish, D., Burhr, M., Allwine, E., Westberg, H., Fehsenfeld, F., and Liu, S.: Models and observations of the impact of natural hydrocarbons on rural Ozone, Nature, 705-707, 1987.

Tsapakis, M., Lagoudaki, E., Stephanou, E. G., Kavouras, I. G., Koutrakis, P., Oyola, P., and von Baer, D.: The composition and sources of PM2.5 organic aerosol in two urban areas of Chile, Atmos. Environ., 36, 3851-3863, 2002.

Tsigaridis, K.: 3-d simulations of the impact of organic aerosol on the chemistry and the radiative forcing of the atmosphere, $\mathrm{PhD}$ thesis, University of Crete, Greece, 2003.

Tsigaridis, K. and Kanakidou, M.: Global modelling of secondary organic aerosol in the troposphere: A sensitivity analysis, Atmos. Chem. Phys., 3, 2879-2929, 2003.

Tsigaridis, K., Lathiere, J., Kanakidou, M., and Hauglustaine, D. A.: Naturally driven variability in the global secondary organic aerosol over a decade, Atmos. Chem. Phys. Discuss., 5, 12551283,2005 ,

SRef-ID: 1680-7375/acpd/2005-5-1255.

Turpin, B. J. and Huntzicker, J. J.: Identification of secondary organic aerosol episodes and quantification of primary and secondary organic aerosol concentration during SCAQS, Atmos. Environ., 29, 3527-3544, 1995.

Turpin, B. J. and Lim, H. J.: Species contributing to PM2.5 mass concentrations: revisiting common assumptions for estimating organic mass, Aerosol Sci. Technol., 35, 602-610, 2001.

Turpin, B. J., Saxena, P., and Andrews, E.: Measuring and simulating particulate organics in the atmosphere: problems and prospects, Atmos. Environ., 34, 2983-3013, 2000.

Twohy, C. H., Clarke, A. D., Warren, S. G., Radke, L. F., and Charlson, R. J.: Light-absorbing material extracted from cloud droplets and its effect on cloud albedo, J. Geophys. Res., 94, 8623-8631, 1989.

Twomey, S.: The nuclei of natural cloud formation, II. The supersaturation in natural clouds and the variation of cloud droplet concentration, Geofisica pura e applicata, 43, 243-249, 1959.

Twomey, S.: Pollution and the Planetary Albedo, Atmos. Environ., 8, 1251-1256, 1974.

Twomey, S.: The influence of pollution on the shortwave albedo of clouds, J. Atmos. Sci., 34, 1149-1152, 1977.

Väkevä, M., Kulmala, M., Stratmann, F., and Hämeri, K.: Field measurements of hygroscopic properties and state of mixing of nucleation mode particles, Atmos. Chem. Phys., 2, 55-66, 2002, SRef-ID: 1680-7324/acp/2002-2-55.

Vereecken, L. and Peeters, J.: Theoretical study of the formation of acetone in the $\mathrm{OH}$-initiated atmospheric oxidation of $\alpha$-pinene, J. Phys. Chem. A, 104, 11 140-11 146, 2000.

Vestin, A.: Size distribution and cloud nucleating properties of biomass burning aerosol in the Amazon Basin. Master's Thesis, Dept. of Physics, Lund Inst. of Technology, Lund University, Sweden, 2003.

Vieceli, J., Ma, O. L., and Tobias, D. J.: Uptake and collision dy- 
namics of gas phase ozone at unsaturated organic interfaces, J. Phys. Chem. A, 108(27), 5806-5814, 2004.

Vinckier, C., Compernolle, F., and Saleh, A. M.: Qualitative determination of the non-volatile reaction products of the $\alpha$-pinene reaction with hydroxyl radicals, Bull. Aos. Chim. Belg., 106, 501-513, 1997.

Virkkula, A., Van Dingenen, R., Raes, F., and Hjorth, J.: Hygroscopic properties of aerosol formed by oxidation of limonene, $\alpha$ pinene and $\beta$-pinene, J. Geophys. Res., 104, 3569-3579, 1999.

Vizuete, W., Junquera, V., and Allen, D. T.: Sesquiterpene emissions and secondary organic aerosol fomation potentials for southeast Texas, Aerosol Sci. Technol., 38(S1), 167-181, 2004.

Vogel, B., Fiedler, F., and Vogel, H.: Influence of topography and biogenic volatile compounds emissions in the State of BadenWürttemberg on ozone concentrations during episodes of high air temperatures, J. Geophys. Res., 100, 22 907-22 928, 1995.

Wang, S. C., Paulson, S. E., Grosjean, D., Flagan, R. C., and Seinfeld, J. H.: Aerosol formation and growth in atmospheric organic NOx systems, 1 . Outdoor smog chamber studies of $\mathrm{C}_{7}$ and $\mathrm{C}_{8}$ hydrocarbons, Atmos. Environ., 26, 403-420, 1992.

Wangberg, I., Barnes, I., and Becker, K. H.: Product and mechanistic study of the reaction of $\mathrm{NO}_{3}$ radicals with a-pinene, Environ. Sci. Technol., 31, 2130-2135, 1997.

Warneck, P.: In-cloud chemistry opens pathway to the formation of oxalic acid in the marine atmosphere, Atmos. Environ., 37, 2423-2427, 2003.

Wehner, B., Birmili, W., Gnauk, T., and Wiedensohler, A.: Particle number size distributions in a street canyon and their transformation into the urban-air background: measurements and a simple model study, Atmos. Environ., 36, 2215-2223, 2002.

Weingartner, E., Burtscher, H., and Baltensperger, U.: Hygroscopic properties of carbon and diesel soot particles, Atmos. Environ., 31, 2311-2327, 1997.

Went, F. W.: Blue hazes in the atmosphere, Nature, 187, 641-643, 1960.

Wesely, M. L. and Hicks, B. B.: A review of the current status of knowledge on dry deposition, Atmos. Environ., 34, 2261-2282, 2000 .

Wexler, A. S. and Seinfeld, J. H.: Second-generation inorganic aerosol model, Atmos. Environ., 25A, 2731-2748, 1991.

Wexler, A. S., Lurmann, F. W., and Seinfeld, J. H.: Modelling urban and regional aerosols-I. Model development, Atmos. Environ., 28, 3, 531-546, 1994.

Wiedinmyer, C., Guenther, A., Harley, P., Hewitt, N., Geron, C., Artaxo, P., Steinbrecher, R., and Rasmussen, R.: Global Organic Emissions from Vegetation, in: Emissions of Atmospheric Trace Compounds, edited by: Granier, C., Artaxo, P., and Reeves, C., 544 pp., Kluwer Academic Publishers, Dordrecht, The Netherlands, 115-170, 2004.

Whitby, E. R. and McMurry, P. H.: Modal aerosol dynamics modeling, Aerosol Sci. Technol., 27, 673-688, 1997.

Wilson, J., Cuvelier, C., and Raes, F.: A modelling study of global mixed aerosol fields, J. Geophys. Res., 106, 34 081-34 108, 2001.

Winterhalter, R., Neeb, P., Grossmann, D., Kolloff, A., Horie, O., and Moortgat, G. K.: Products and mechanism of the gas phase reaction of ozone with $b$-pinene, J. Atmos. Chem., 35, 165-197, 2000 .

Winterhalter, R., Van Dingenen, R., Larsen, B. R., Jensen, N. R., and Hjorth, J.: LC-MS analysis of aerosol particles from the oxidation of $\alpha$-pinene by ozone and $\mathrm{OH}$ radicals, Atmos. Chem. Phys. Discuss., 3, 1-39, 2003,

SRef-ID: 1680-7375/acpd/2003-3-1.

Wise, M. E., Surratt, J. D., Curtis, D. B., Shilling, J. E., and Tolbert, M. A.: Hygroscopic growth of ammonium sulfate/dicarboxylic acids, J. Geophys. Res., 108, 4638-4642, 2003.

Wisthaler, A., Jensen, N. R., Winterhalter, R., Lindinger, W., and Hjorth, J.: Measurements of acetone and other gas phase product yields from the $\mathrm{OH}$-initiated oxidation of terpenes by protontransfer-reaction mass spectrometry (PTR-MS), Atmos. Environ., 35, 6181-6191, 2001.

Yu, J. Z., Flagan, R. C., and Seinfeld, J. H.: Identification of products containing $-\mathrm{COOH},-\mathrm{OH}$, and $-\mathrm{C}=\mathrm{O}$ in atmospheric oxidation of hydrocarbons, Environ. Sci. Technol., 32, 2357-2370, 1998.

Yu, J., Cocker III, D. R., Griffin, R. J., Flagan, R. C., and Seinfeld, J. H.: Gas-phase ozone oxidation of monoterpenes: Gaseous and particulate products, J. Atmos. Chem., 34, 207-258, 1999a.

Yu, J., Griffin, R. J., Cocker III, D. R., Flagan, R. C., Seinfeld, J. H., and Blanchard, P.: Observation of gaseous and particulate products of monoterpene oxidation in forest atmospheres, Geophys. Res. Lett., 26, 1145-1148, 1999b.

Yao, X., Fang, M., and Chan, C. K.: Size distributions and formation of dicarboxylic acids in atmospheric particles, Atmos. Environ., 36, 2099-2107, 2002.

Zappoli, S., Andracchio, A., Fuzzi, S., Facchini, M. C. A., Gelencsér, A., Kiss, G., Krivácsy, Z., Molnár, A., Mészáros, E., Hansson, H. C., Rosman, K., and Zebühr, Y.: Inorganic, organic and macromolecular components of fine aerosol in different areas of Europe in relation to their water solubility, Atmos. Environ., 33, 2733-2743, 1999.

Zhang, K. M. and Wexler, A. S.: A hypothesis for growth of fresh nuclei, J. Geophys. Res., 107, 4577, doi:10.1029/2002JD002180, 2002.

Zhang, R., Suh, I., Zhao, J., Zhang, D., Fortner, E. C., Tie, X., Molina, L. T., and Molina, M. J.: Atmospheric New Particle Formation Enhanced by Organic Acids, Science, 304, 1487-1490, 2004.

Zhang, S.-H., Shaw, M., Seinfeld, J. H., and Flagan, R. C.: Photochemical Aerosol Formation from alpha-Pinene and beta-Pinene, J. Geophys. Res., 97, 20 717-20 729, 1992.

Zhang, Y., Kreidenweis, S. M., and Feingold, G.: Stratocumulus processing of gases and cloud condensation nuclei 2 . Chemistry sensitivity analysis, J. Geophys. Res., 104(D13), 16 061-16080, 1999.

Zhang, Y., Pun, B., Vijayaraghavan, K., Wu, S., Seigneur, C., Pandis, S. N., Jacobson, M. Z., Nenes, A., and Seinfeld, J. H.: Development and application of the Model of Aerosol Dynamics, Reaction, Ionization, and Dissolution (MADRID), J. Geophys. Res., 109, D01202, doi:10.1029/2003JD003501, 2004.

Zheng, M., Cass, G. R., Schauer, J. J., and Edgerton, E. S.: Source Apportionment of PM2.5 in the Southeastern United States Using Solvent-Extractable Organic Compounds as Tracers, Environ. Sci. Technol., 36, 2361-2371, 2002.

Zhou, J., Swietlicki, E., Hansson, H. C., and Artaxo, P.: Submicrometer aerosol particle size distribution and hygroscopic growth measured in the Amazon rain forest during the wet season, J. Geophys. Res., 107, 8055-8064, 2002. 
Ziemann, P. J.: Evidence for low-volatility diacyl peroxides as a nucleating agent and major component of aerosol formed from reactions of $\mathrm{O}_{3}$ with cyclohexane and homologous compounds, J. Phys. Chem. A, 106, 4390-4402, 2002.

Ziemann, P. J.: Formation of Alkoxyhydroperoxy Aldehydes and Cyclic Peroxyhemiacetals from Reactions of Cyclic Alkenes with $\mathrm{O}_{3}$ in the Presence of Alcohols, J. Phys. Chem. A, 107, 2048-2060, 2003.
Zuo, Y. and Hoigné, J.: Formation of Hydrogen Peroxide and Depletion of Oxalic Acid in Atmospheric Water by Photolysis of Iron(III)-Oxalato-Complexes, Environ. Sci. Technol., 26, 10141022, 1992.

Zuo, Y. and Hoigné, J.: Photochemical Decomposition of Oxalic, Glyoxalic and Pyruvic Acid Catalysed by Iron in Atmospheric Waters, Atmos. Environ., 28, 7, 1231-1239, 1994. 